\title{
SEISMIC REHABILITATION OF STEEL CONCENTRICALLY BRACED FRAMES VULNERABLE TO SOFT-STORY FAILURES THROUGH IMPLEMENTATION OF ROCKING CORES
}

\author{
A Thesis \\ presented to \\ the Faculty of California Polytechnic State University, \\ San Luis Obispo
}

\author{
In Partial Fulfillment \\ of the Requirements for the Degree \\ Master of Science in Civil and Environmental Engineering
}

by

Francisco Sanchez-Zamora

June 2013 
(C) 2013

Francisco Sanchez-Zamora

\section{ALL RIGHTS RESERVED}




\section{COMMITTEE MEMBERSHIP}

TITLE:

AUTHOR:

DATE SUBMITTED:

COMMITTEE CHAIR:

COMMITTEE MEMBER:

COMMITTEE MEMBER:
Seismic Rehabilitation of Steel Concentrically Braced Frames Vulnerable to Soft-story Failures through Implementation of Stiff Rocking Cores

Francisco Sanchez-Zamora

June 2013
Bing Qu, Ph.D., Assistant Professor, CEEN Department

Charles Chadwell, Ph.D., Associate Professor, CEEN Department

Rakesh Goel, Ph.D., Professor, Associate Dean, CEEN Department 


\section{ABSTRACT \\ Seismic Rehabilitation of Steel Concentrically Braced Frames through Implementation of Stiff Rocking Cores \\ Francisco Sanchez-Zamora}

Recent research reports that steel Concentrically Braced Frames (CBFs) (even the codecompliant ones) may be susceptible to soft-story failures during strong earthquakes. Such a failure mode causes catastrophic outcomes and should be definitely avoided in practice. This thesis focuses on development and validation of a seismic retrofit strategy for lowrise and mid-rise steel CBFs vulnerable to soft-story failures. The considered retrofit strategy consists of a sufficiently stiff rocking core (RC) pinned to foundation and connected to the existing frame. For demonstration purpose, two representative benchmark steel CBF buildings, which are the three-and six-story CBFs designed for Los Angeles in the SAC Steel Project, are considered. Finite element (FE) models of the benchmark buildings are validated using the published results and explicitly take into account gusset plates, member yielding, brace buckling, brace rupture, and P-Delta effect. Eigenvalue analyses are first conducted to investigate the effect of RC on system modal properties. It is found that the added RC generally does not significantly change the fundamental period and therefore does not attract excessive earthquake force to the system. Additionally, nonlinear static pushover analyses are performed to address the beneficial contribution of RC to the system under the performance objectives including immediate occupancy, life safety, and collapse prevention. The Monte-Carlo simulation 
technique is used to take into account uncertainty in lateral force distribution and its effect in system seismic performance. It is found that sufficiently stiff RC creates more uniform inter-story distribution along the vertical direction in all considered scenarios. Furthermore, nonlinear dynamic analyses are conducted using three different ground motion suites. It is shown that the systems with properly selected RC can achieve the Best Safety Objective defined in FEMA 356 and ensure the collapse prevention performance under near-fault earthquakes. 


\section{ACKNOWLEDGMENTS}

I would like to express my sincere gratitude to Professor Bing Qu. His knowledge, guidance and enthusiasm for this material made this experience very joyful and meaningful. Without his help this thesis would have been impossible.

I would also like to thank Dr. Chadwell and Dr. Goel for taking time out of their busy schedule to serve on my thesis defense committee.

I would also like to express my sincere gratitude to the U.S. National Science Foundation under Award Number CMMI-1134953. Without their financial support it would have been very difficult to finish this thesis.

Thanks to Jackie Duerr and Maria Manzano for providing me the opportunity to work in the MEP tutoring center and for the scholarships they awarded me.

I am very grateful for the invaluable moral support my family gave me. My parent's advice is what kept me motivated through hard times that I experienced here at Cal Poly. 


\section{Table of Contents}

I

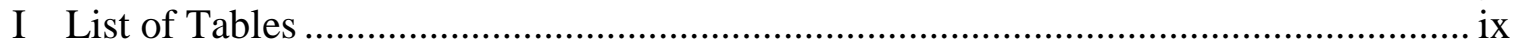

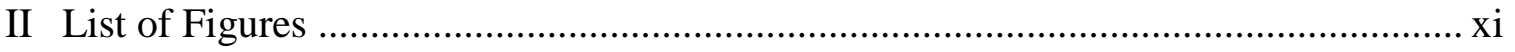

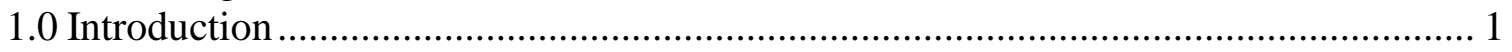

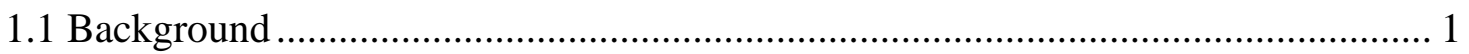

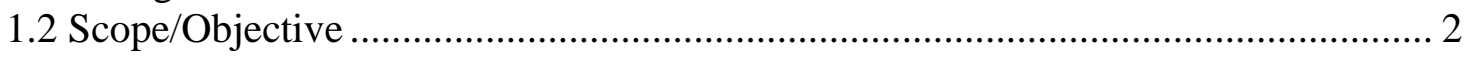

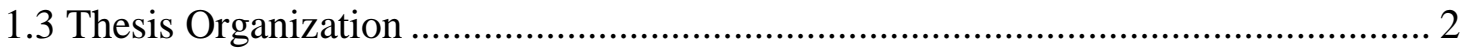

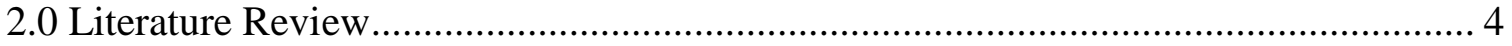

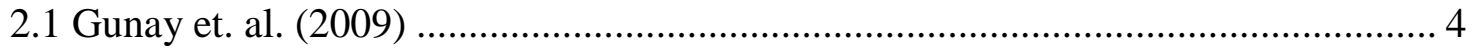

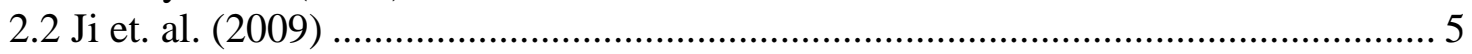

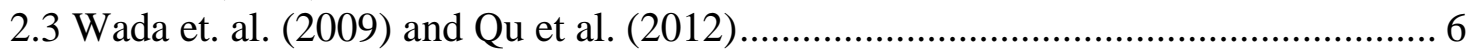

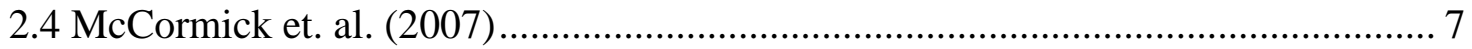

3.0 Description of Retrofit Strategy and Benchmark Building ........................................ 8

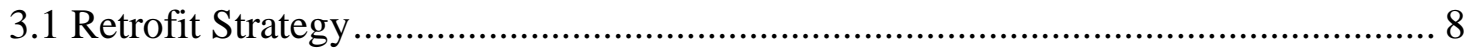

3.2 Selection of Benchmark Building ................................................................... 10

4.0 Finite Element Modeling and Validation................................................................. 16

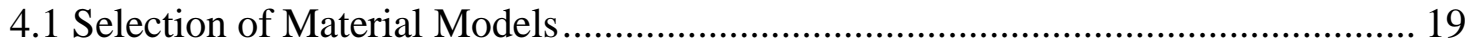

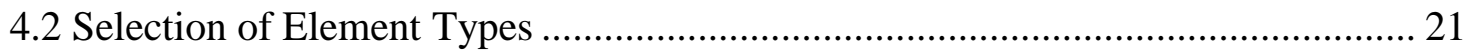

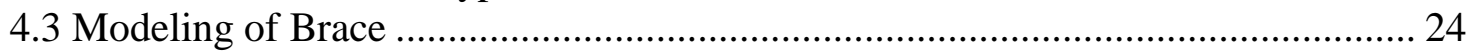

4.3.1 Consideration of Gusset Plate ................................................................... 24

4.3.2 Initial imperfection and global buckling .................................................... 28

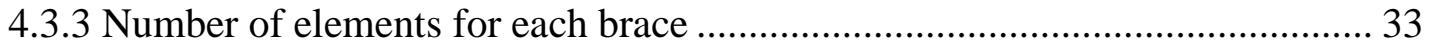

4.3.4 Consideration of Low-Cycle Fatigue Damage ............................................... 38

4.4 Other Techniques to Achieve Numerical convergence ............................................ 41

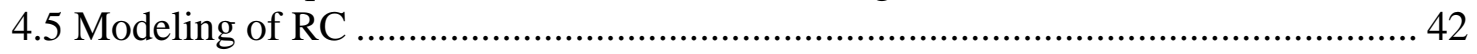

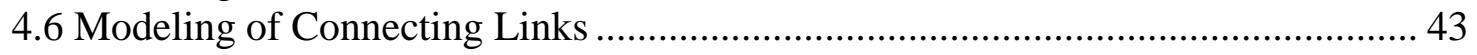

4.7 Modeling of Gravity Column..................................................................... 44

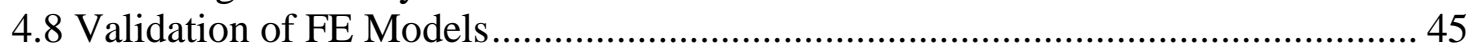

5.0 Seismic Performance Evaluation of Three-Story Building …….............................. 49

5.1 Impact of RC on Modal Properties .................................................................. 49

5.2 Nonlinear Static Pushover Analysis.................................................................... 53

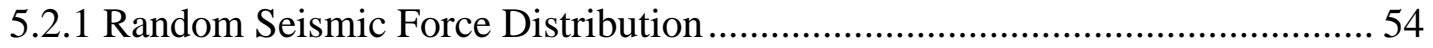

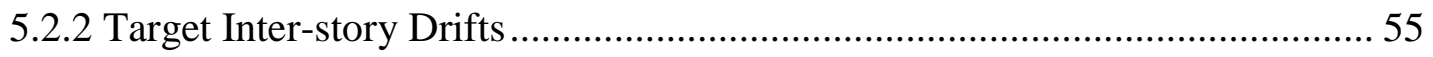

5.2.3 Responses Quantities of Interest.................................................................. 56

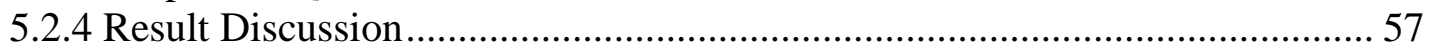

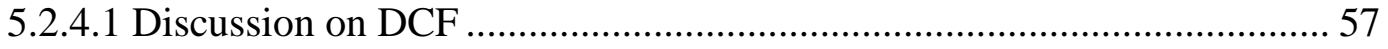

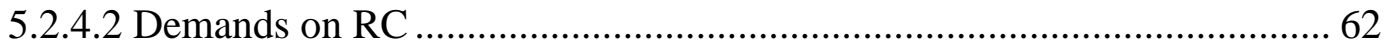

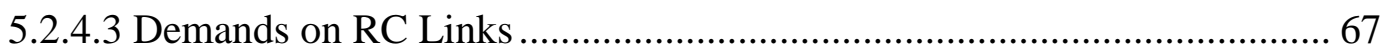

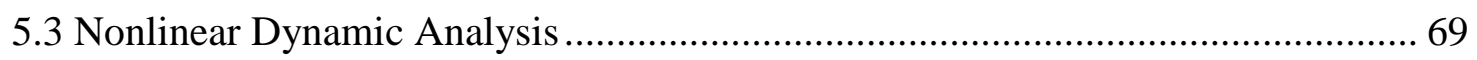

5.3.1 Selection of Ground Motions...................................................................... 70

5.3.2 Response Quantities of Interest .................................................................. 74

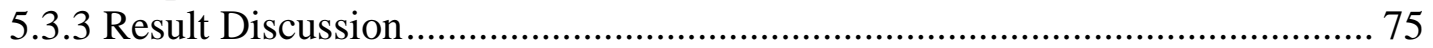


5.3.3.1 Median of the Maximum Inter-story Drifts ............................................ 75

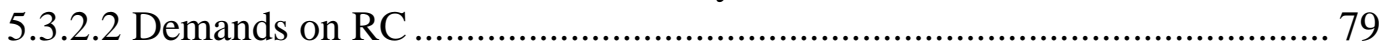

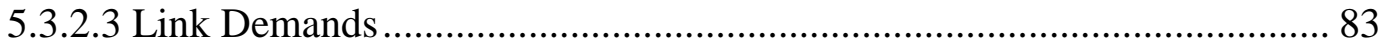

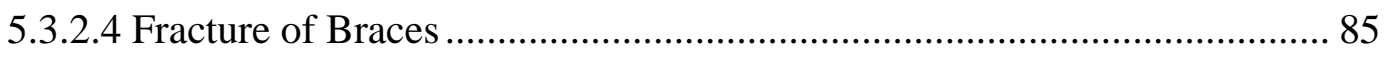

5.3.2.5 Benefits from Links with Energy Dissipation Capacity ........................... 87

5.4 Demonstration Retrofit using Reinforced Concrete RC ........................................ 98

6.0 Seismic Performance Evaluation of Six-Story Building ……................................ 102

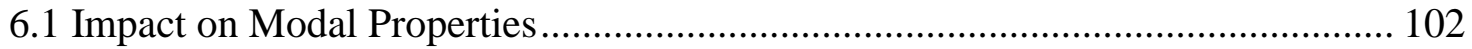

6.2 Nonlinear Static Pushover Analysis.................................................................. 106

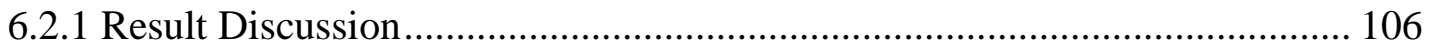

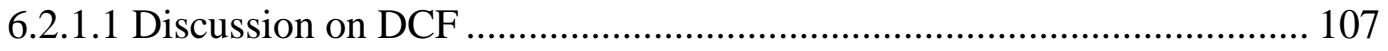

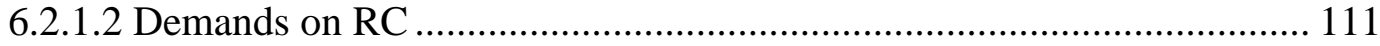

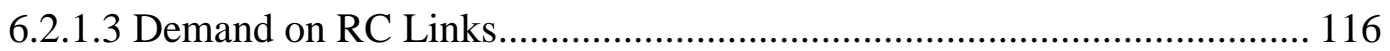

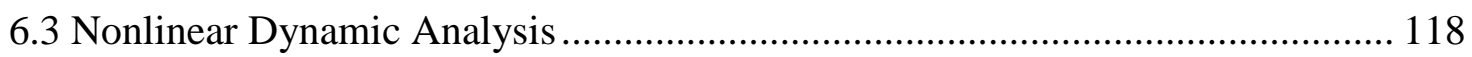

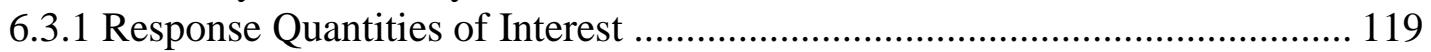

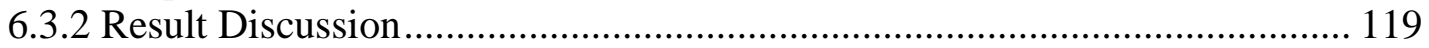

6.3.2.1 Median of the Maximum Inter-Story Drifts.......................................... 119

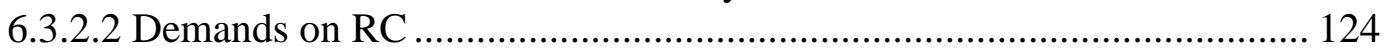

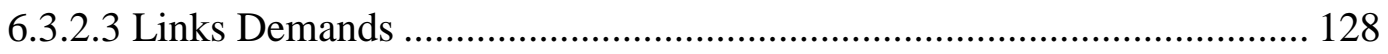

6.3.2.4 Benefits from Links with Energy Dissipation Capacity .......................... 130

6.4 Demonstration Retrofit using Reinforced Concrete RC ……………................... 140

7.0 Summary of Conclusions, and Recommendations for Future Research................... 143

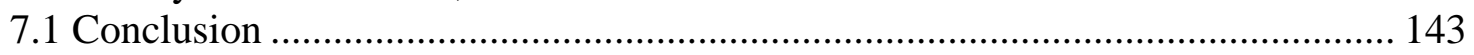

7.2 Recommendations for Future Research .............................................................. 145

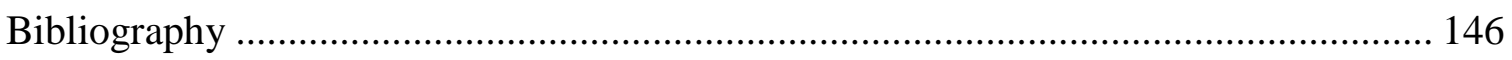

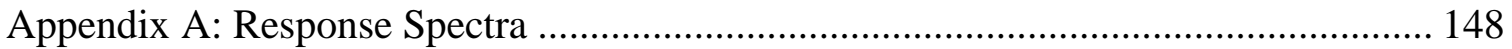

Appendix B: Maximum Inter-Story Drift Results ..................................................... 150 
List of Tables

Page

Table 4-1: Material properties required in the Giuffré-Menegotto-Pinto model............. 20

Table 4-2: Effect of initial imperfection of brace on base shear...................................... 30

Table 4-3: Maximum inter-story drifts with and without P-Delta effect........................ 45

Table 4-4: Fundamental period comparison ............................................................... 46

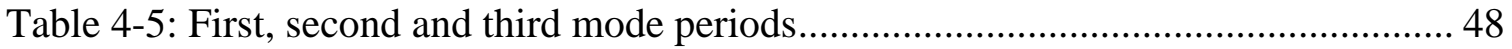

Table 5-1: Comparison of Periods from LA3-A models with different RC stiffness values

Table 5-2: Comparison of Periods from LA3-B models with different RC stiffness

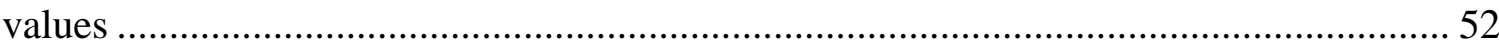

Table 5-3: Ground motions having a probability of exceedence of $2 \%$ in 50 years (adapted from SAC Joint Venture Steel Project Website) ........................................... 72

Table 5-4: Ground motions having a probability of exceedence of $10 \%$ in 50 years (adapted from SAC Joint Venture Steel Project Website) ............................................... 73

Table 5-5: Near-Field Ground Motions (adapted from SAC Joint Venture Steel

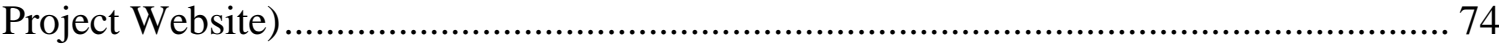

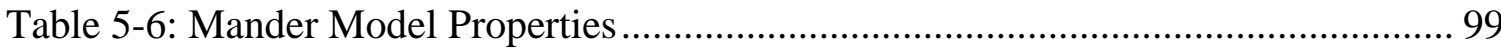

Table 5-7: Todeshini Parabolic Model ............................................................................. 99

Table 5-8: Comparison of elastic RC and reinforced concrete RC under $10 \%$ in 50

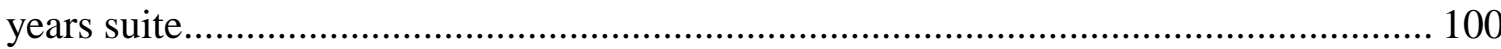

Table 5-9: Comparison of elastic RC and reinforced concrete RC under 2\% in 50 years suite. 100

Table 5-10: Comparison of elastic RC and reinforced concrete RC under near-fault

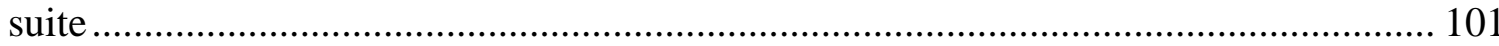

Table 6-1: Comparison of periods from LA6-A with different RC stiffness values ...... 102

Table 6-2: Comparison of periods from LA6-B with different RC stiffness values ...... 104 Table 6-3: Comparison of elastic RC and reinforced concrete RC under $10 \%$ in 50 years suite for LA6-B

Table 6-4: Comparison of elastic RC and reinforced concrete RC under $2 \%$ in 50 years suite for LA6-B

Table 6-5: Comparison of elastic RC and reinforced concrete RC under near-fault suite for LA6-B

Table B-1: Maximum Inter-story Drift in LA3-A under ground motions corresponding to $10 \%$ in 50 years

Table B-2: Maximum Inter-story Drift in LA3-A under ground motions corresponding to $2 \%$ in 50 years

Table B-3: Maximum Inter-story Drift in LA3-A under ground motions corresponding to near-fault earthquakes

Table B-4: Maximum Inter-story Drift in LA3-B under ground motions corresponding to $10 \%$ in 50 
Table B-5: Maximum Inter-story Drift in LA3-B under ground motions corresponding to $2 \%$ in 50

Table B-6: Maximum Inter-story Drift in LA3-B under ground motions corresponding to near-fault earthquakes

Table B-7: Maximum Inter-story Drift in LA6-A under ground motions corresponding to $10 \%$ in 50

Table B-8: Maximum Inter-story Drift in LA6-A under ground motions corresponding to $2 \%$ in 50 years

Table B-9: Maximum Inter-story Drift in LA6-A under ground motions corresponding to near-fault earthquakes

Table B-10: Maximum Inter-story Drift in LA6-B under ground motions corresponding to $10 \%$ in 50 160

Table B-11: Maximum Inter-story Drift in LA6-B under ground motions corresponding to $2 \%$ in 50

Table B-12: Maximum Inter-story Drift in LA6-B under ground motions corresponding to near-fault earthquakes 


\section{List of Figures}

Page

Figure 2.1: Mean inter-story drift profiles for the as-built and retrofitted frames (Gunay et. al., 2009)

Figure 2.2: Comparison of inter-story drifts in existing and retrofitted systems

(Wada et. al., 2009).

Figure 2.3: Effects of implementation of SMA on CBF maximum inter-story drift

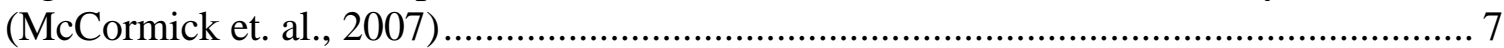

Figure 3.1 A: Original CBF vulnerable to soft-story failure ..............................................

Figure 3.1 B: CBF after retrofit ......................................................................... 9

Figure 3.2: Plan view of three-story and six-story CBF buildings (Sabelli, 2001) .......... 13

Figure 3.3: Configuration of three-story building used for analysis............................... 14

Figure 3.4: Configuration of six-story building used for analysis ................................... 15

Figure 4.1: Schematic of Finite element model for LA3-A and LA3-B .......................... 18

Figure 4.2: Schematic of Finite element model for LA6-A and LA6-B ........................... 19

Figure 4.3: Stress strain curve of Giuffré-Menegotto-Pinto (OpenSees Wiki) ................ 21

Figure 4.4: DBE Vs. FBE (Williamson, 2012) ……………..................................... 22

Figure 4.5: Comparison of results from FBE, DBE and experimental investigation

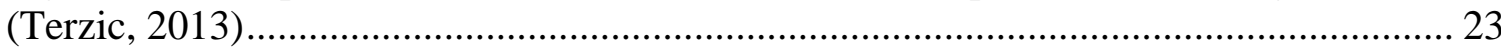

Figure 4.6: Wide flange and HSS fiber distribution ...................................................... 24

Figure 4.7: Comparison of the results from models with different brace end

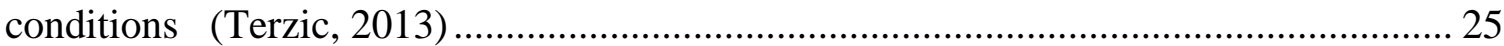

Figure 4.8: Gusset plate connections (Terzic, 2013) ................................................... 26

Figure 4.9: Base shear comparison from CBFs with different gusset plate thickness...... 27

Figure 4.10: Effect of initial imperfection on system performance ................................. 29

Figure 4.11: Effect of initial imperfection on system performance (result from nonlinear dynamic analysis)

Figure 4.12: Comparison of maximum story drifts due to different values of initial imperfection in braces (result from nonlinear dynamic analysis).................................... 32

Figure 4.13: Comparison of maximum floor acceleration due to different values of initial imperfection in braces (result from nonlinear dynamic analysis) .......................... 33 Figure 4.14: Effect of number of elements per brace on system performance (result

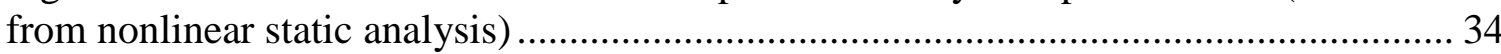

Figure 4.15: Effect of number of elements per brace on system performance (results from nonlinear dynamic analysis)............................................................................ 35

Figure 4.16: Comparison of maximum story drifts due to different numbers of elements in braces 36

Figure 4.17: Comparison of maximum floor accelerations from models with different

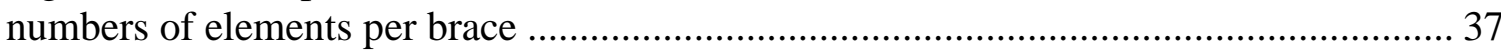

Figure 4.18: Maximum compressive force of bottom-story braces in LA3 and LA6 ...... 38

Figure 4.19: Cyclic Loading Protocol........................................................................ 39 
Figure 4.20: Response of braced frame with and without fatigue in nonlinear static

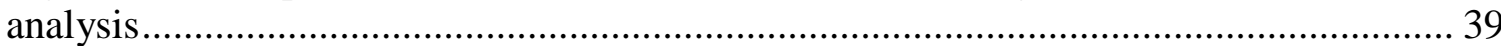

Figure 4.21: Response of left brace with and without fatigue ..................................... 40

Figure 4.22: Response of right brace with and without fatigue .................................. 40

Figure 4.23: Identification of bottom-story stiffness for LA3 and LA6 ........................ 43

Figure 4.24: Comparison of inter-story drift histories of the third story of LA3 with

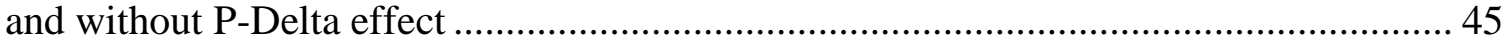

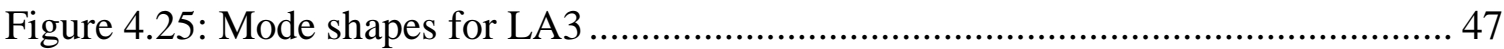

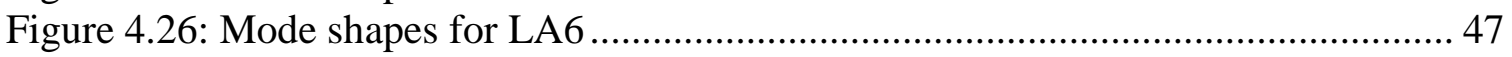

Figure 5.1: Comparison of first mode shape of LA3-A models with different RC

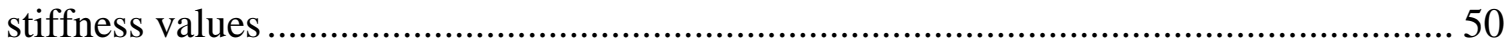

Figure 5.2: Comparison of second mode shape of LA3-A models with different RC

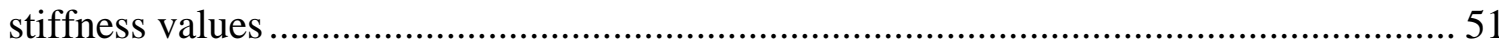

Figure 5.3: Comparison of third mode shape of LA3-A models with different RC

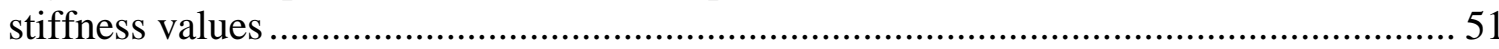

Figure 5.4: Comparison of first mode shape of LA3-B models with different RC

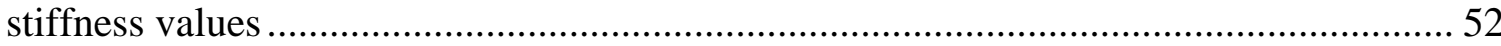

Figure 5.5: Comparison of second mode shape of LA3-B models with different RC stiffness values ........................................................................................... 53

Figure 5.6: Comparison of third mode shape of LA3-B models with different RC

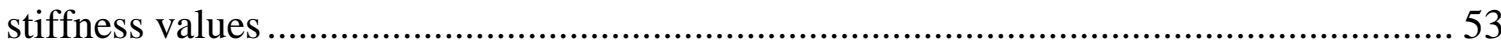

Figure 5.7: DCF for collapse prevention performance objective: LA3-A ..................... 58 Figure 5.8: Maximum DCF for collapse prevention performance objective: LA3-A ...... 59

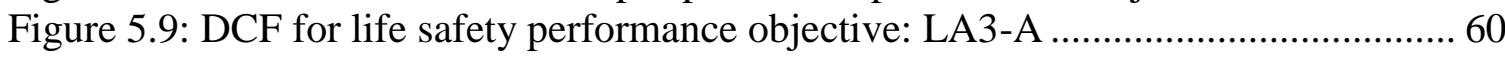
Figure 5.10: Maximum DCF for life safety performance objective: LA3-A .................. 60 Figure 5.11: DCF for immediate occupancy performance objective: LA3-A ................ 61 Figure 5.12: Maximum DCF for immediate occupancy performance objective: LA3-A 62 Figure 5.13: Pushover curve of bottom story of LA3-A............................................ 63

Figure 5.14: Slope of the pushover curve of bottom story of LA3-A............................ 63

Figure 5.15: Maximum RC normalized shear demand considering collapse

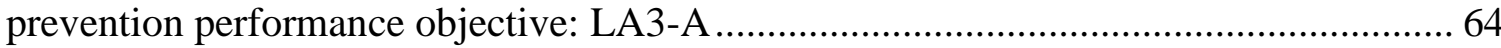
Figure 5.16: Maximum RC normalized shear demand considering life safety

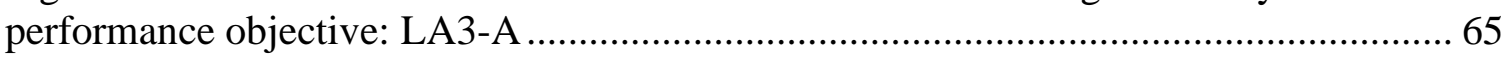

Figure 5.17: Maximum RC normalized shear demand considering immediate

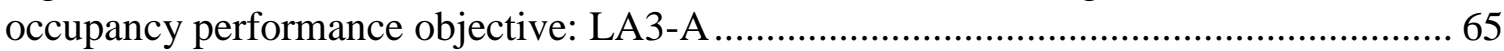

Figure 5.18: Maximum RC normalized moment demand considering collapse

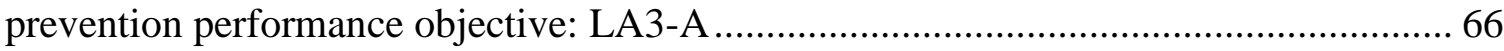

Figure 5.19: Maximum RC normalized moment demand considering life safety

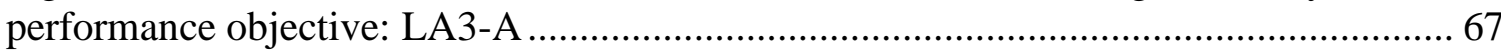

Figure 5.20: Maximum RC normalized moment demand considering immediate occupancy performance objective: LA3-A

Figure 5.21: RC link normalized axial demand considering collapse prevention performance objective: LA3-A 68

Figure 5.22: RC link normalized axial demand considering life safety performance objective: LA3-A 
Figure 5.23: RC link normalized axial demand considering immediate occupancy

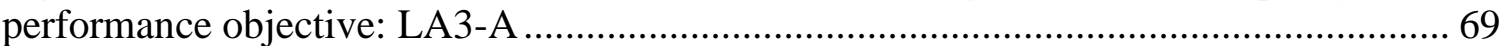

Figure 5.24: Median of the maximum inter-story drifts from all ground motions

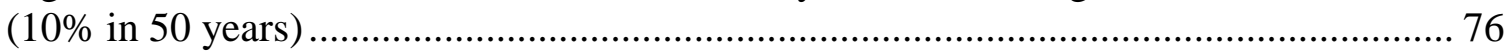

Figure 5.25: Median of the maximum inter-story drifts from critical earthquake

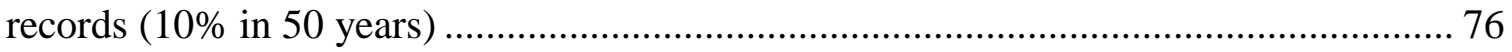

Figure 5.26: Median of the maximum inter-story drifts from all ground motions

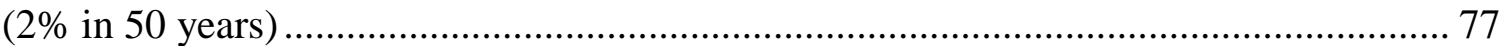

Figure 5.27: Median of the maximum inter-story drifts from critical earthquake

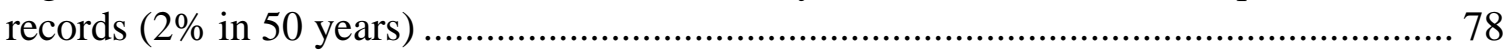

Figure 5.28: Median of the maximum inter-story drifts from all ground motions

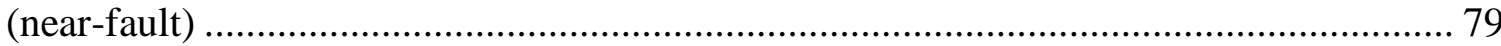

Figure 5.29: Median of the maximum inter-story drifts from critical earthquake records (near-fault) ....................................................................................... 79

Figure 5.30: Normalized median shear demand in RC (Earthquakes corresponding to

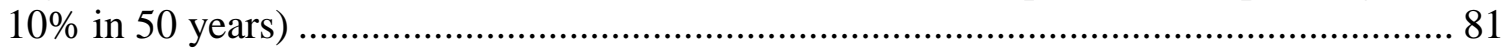

Figure 5.31: Normalized median bending moment demand in RC (Earthquakes corresponding to $10 \%$ in 50 years)

Figure 5.32: Normalized median shear demand in RC (Earthquakes corresponding

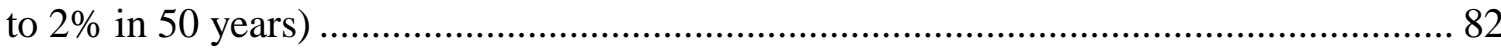

Figure 5.33: Normalized median bending moment demand in RC (Earthquakes

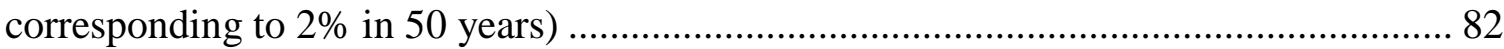

Figure 5.34: Normalized median shear demand in RC (Near-Fault Earthquakes) .......... 83 Figure 5.35: Normalized median bending moment demand in RC (Near-Fault Earthquakes) ........................................................................................... 83

Figure 5.36: Normalized median axial demand in links (Earthquakes corresponding to $10 \%$ in 50 years)

Figure 5.37: Normalized median axial demand in links (Earthquakes corresponding

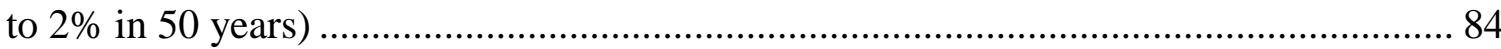

Figure 5.38: Normalized median axial demand in links (Near-Fault Earthquakes) ........ 85

Figure 5.39: Brace axial force history in LA3 under ground motion LA10 ................... 86 Figure 5.40: Brace axial force history in LA3-A under ground motion LA10 ................. 87 Figure 5.41: Comparison of median of maximum inter-story drifts: LA3-A vs LA3-B

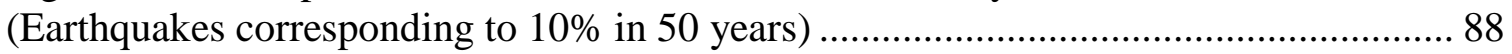
Figure 5.42: Comparison of median of maximum inter-story drifts: LA3-A vs LA3-B

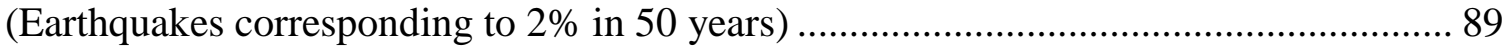
Figure 5.43: Comparison of median of maximum inter-story drifts: LA3-A vs LA3-B (Near-Fault Earthquakes). 89

Figure 5.44: Normalized median shear demand on RC in LA3-B (Earthquakes corresponding to $10 \%$ in 50 years)

Figure 5.45: Normalized median bending moment demand on RC in LA3-B (Earthquakes corresponding to $10 \%$ in 50 years).

Figure 5.46: Normalized median shear demand on RC in LA3-B (Earthquakes corresponding to $2 \%$ in 50 years)

Figure 5.47: Normalized median bending moment demand on RC in LA3-B (Earthquakes corresponding to $2 \%$ in 50 years) 
Figure 5.48: : Normalized median shear demand on RC in LA3-B (Near-Fault

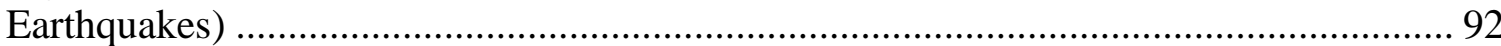

Figure 5.49: Normalized median bending moment demand on RC in LA3-B

(Near-Fault Earthquakes)

Figure 5.50: Normalized median axial demand in Links of LA3-B (Earthquakes

corresponding to $10 \%$ in 50 years)

Figure 5.51: Normalized median shear demand in links of LA3-B (Earthquakes corresponding to $10 \%$ in 50 years )....

Figure 5.52: : Normalized median bending moment demand in links of LA3-B

(Earthquakes corresponding to $10 \%$ in 50 years ) .................................................... 94

Figure 5.53: : Normalized median axial demand in links of LA3-B (Earthquakes corresponding to $2 \%$ in 50 years )

Figure 5.54: Normalized median shear demand in links of LA3-B (Earthquakes corresponding to $2 \%$ in 50 years )

Figure 5.55: Normalized median moment demand in links of LA3-B (Earthquakes

corresponding to $2 \%$ in 50 years )

Figure 5.56: Normalized median axial demand in links of LA3-B (Near-Fault

Earthquakes) 96

Figure 5.57: Normalized median shear demand in links of LA3-B (Near-Fault

Earthquakes) 96

Figure 5.58: Normalized median bending moment demand in links of LA3-B

(Near-Fault Earthquakes)

Figure 5.59: Reinforced concrete RC cross-section for LA3-B

Figure 6.1: Comparison of first mode shape of LA6-A models with different RC

stiffness values

Figure 6.2: Comparison of second mode shape of LA6-A models with different RC stiffness values

Figure 6.3: Comparison of third mode shape of LA6-A models with different RC stiffness values 104

Figure 6.4: Comparison of first mode shape of LA6-B models with different RC stiffness values

Figure 6.5: Comparison of second mode shape of LA6-B models with different RC stiffness values. 105

Figure 6.6: Comparison of third mode shape of LA6-B models with different RC

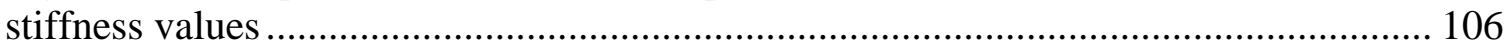

Figure 6.7: DCF for collapse prevention performance objective: LA6-A .................... 108 Figure 6.8: Maximum DCF for collapse prevention performance objective: LA6-A .... 108 Figure 6.9: DCF for life safety performance objective: LA6-A ................................. 109 Figure 6.10: Maximum DCF for life safety performance objective: LA6-A ................ 109 Figure 6.11: DCF for immediate occupancy performance objective: LA6-A ................ 110 Figure 6.12 Maximum DCF for immediate occupancy performance objective: LA6-A 110 Figure 6.13: Nonlinear static pushover curve of bottom story of LA6 ......................... 111 Figure 6.14: Slope of the nonlinear static pushover curve of bottom story of LA6 ...... 112 Figure 6.15: Maximum RC normalized shear demand considering collapse prevention performance objective: LA6-A 
Figure 6.16: Maximum RC normalized shear demand considering life safety performance objective: LA6-A.

Figure 6.17: Maximum RC normalized shear demand considering immediate occupancy performance objective: LA6-A

Figure 6.18: Maximum RC normalized moment demand considering collapse prevention performance objective: LA6-A

Figure 6.19: Maximum RC normalized moment demand considering life safety performance objective: LA6-A

Figure 6.20: Maximum RC normalized moment demand considering immediate occupancy performance objective: LA6-A....

Figure 6.21: RC links normalized maximum axial demand considering collapse prevention performance objective: L6-A.

Figure 6.22: RC links normalized maximum axial demand considering life safety performance objective: L6-A

Figure 6.23: RC links normalized maximum axial demand considering immediate occupancy performance objective: L6-A.

Figure 6.24: Median of the maximum inter-story drifts from all ground motions (10 in 50 years) of LA6-A

Figure 6.25: Median of the maximum inter-story drifts from critical earthquake record (10\% in 50 years) of LA6-A.

Figure 6.26: Median of the maximum inter-story drifts from all ground motions ( $2 \%$ in 50 years) of LA6-A

Figure 6.27: Median of the maximum inter-story drifts from critical earthquake record ( $2 \%$ in 50 years) of LA6-A

Figure 6.28: Median of the maximum inter-story drifts from all ground motions (near-fault) of LA6-A .

Figure 6.29: Median of the maximum inter-story drifts from critical earthquake record (near-fault) of LA6-A

Figure 6.30: Normalized median shear demand in RC for LA6-A (Earthquakes corresponding to $10 \%$ in 50 years)

Figure 6.31: Normalized median bending moment demand in RC for LA6-A (Earthquakes corresponding to $10 \%$ in 50 years)

Figure 6.32: Normalized median shear demand in RC for LA6-A (Earthquakes

corresponding to $2 \%$ in 50 years)

Figure 6.33: Normalized median bending moment demand in RC for LA6-A

(Earthquakes corresponding to $2 \%$ in 50 years)

Figure 6.34: Normalized median shear demand in RC for LA6-A (Earthquakes corresponding to near-fault).....

Figure 6.35: Normalized median bending moment demand in RC for LA6-A

(Earthquakes corresponding to near-fault).

Figure 6.36: Normalized median axial demand in links for LA6-A (Earthquakes corresponding to $10 \%$ in 50 years)

Figure 6.37: Normalized median axial demand in links for LA6-A (Earthquakes corresponding to $2 \%$ in 50 years)

Figure 6.38: Normalized median axial demand in links for LA6-A (Earthquakes corresponding to near-fault). 
Figure 6.39: Comparison of median of maximum inter-story drifts: LA6-A vs

LA6-B (Earthquakes corresponding to $10 \%$ in 50 years)....

Figure 6.40: Comparison of median of maximum inter-story drifts: LA6-A vs

LA6-B (Earthquakes corresponding to $2 \%$ in 50 years). 132

Figure 6.41: Comparison of median of maximum inter-story drifts: LA6-A vs

LA6-B (Near-Fault Earthquakes)

Figure 6.42: Normalized median shear demand on RC in LA6-B (Earthquakes corresponding to $10 \%$ in 50 years)

Figure 6.43: Normalized median bending moment demand on RC in LA6-B

(Earthquakes corresponding to $10 \%$ in 50 years)

Figure 6.44: Normalized median shear demand on RC in LA6-B (Earthquakes corresponding to $2 \%$ in 50 years)

Figure 6.45: Normalized median bending moment demand on RC in LA6-B

(Earthquakes corresponding to $2 \%$ in 50 years)

Figure 6.46: Normalized median shear demand on RC in LA6-B (Near-Fault

Earthquakes)

Figure 6.47: Normalized median bending moment demand on RC in LA6-B

(Near-Fault Earthquakes) 135

Figure 6.48: Normalized median axial demand in Links of LA6-B (Earthquakes

corresponding to $10 \%$ in 50 years) 136

Figure 6.49: Normalized median shear demand in links of LA6-B (Earthquakes corresponding to $10 \%$ in 50 years) 136

Figure 6.50: Normalized median bending moment demand in links of LA6-B

(Earthquakes corresponding to $10 \%$ in 50 years)

Figure 6.51: Normalized median axial demand in links of LA6-B (Earthquakes

corresponding to $2 \%$ in 50 years)

Figure 6.52: Normalized median shear demand in links of LA6-B (Earthquakes

corresponding to $2 \%$ in 50 years) 138

Figure 6.53: Normalized median moment demand in links of LA6-B (Earthquakes

corresponding to $2 \%$ in 50 years) 138

Figure 6.54: Normalized median axial demand in links of LA6-B (Near-Fault Earthquakes) 139

Figure 6.55: Normalized median shear demand in links of LA6-B (Near-Fault

Earthquakes)

Figure 6.56: Normalized median bending moment demand in links of LA6-B

(Near-Fault Earthquakes)

Figure 6.57: Reinforced concrete RC wall cross section for LA6-B

Figure A.1: Response spectra of ground motions corresponding to $10 \%$ in 50 years

suite

Figure A.2: Response spectra of ground motions corresponding to $2 \%$ in 50 years

suite 148

Figure A.3: Response spectra of ground motions corresponding to near-fault suite..... 149

Figure B.1: Number of earthquakes under each performance objective for LA3-A (10\% in 50 years)

Figure B.2: Number of earthquakes under each performance objective for LA3-A ( $2 \%$ in 50 years) 
Figure B.3: Number of earthquakes under each performance objective for LA3-A (near-fault) 164

Figure B.4: Number of earthquakes under each performance objective for LA3-B (10\% in 50 years) 164

Figure B.5: Number of earthquakes under each performance objective for LA3-B ( $2 \%$ in 50 years) 165

Figure B.6: Number of earthquakes under each performance objective for LA3-B (near-fault) 165

Figure B.7: Number of earthquakes under each performance objective for LA6-A (10\% in 50 years) 166

Figure B.8: Number of earthquakes under each performance objective for LA6-A ( $2 \%$ in 50 years) 166

Figure B.9: Number of earthquakes under each performance objective for LA6-A (near-fault)

Figure B.10: Number of earthquakes under each performance objective for LA6-B ( $10 \%$ in 50 years)

Figure B.11: Number of earthquakes under each performance objective for LA6-B ( $2 \%$ in 50 years)

Figure B.12: Number of earthquakes under each performance objective for LA6-B (near-fault) 


\subsection{Introduction}

\subsection{Background}

Typical multi-story steel concentrically braced frames (CBFs) designed according to modern seismic codes are expected to resist lateral seismic forces. The elastic demands are reduced by accounting for structural system ductility which is expected to be reasonably distributed along the building height. The seismic demand is calculated based on some site seismicity in the form of a response spectrum or ground motion histories resulting in some lateral force distribution that the structure will be designed to withstand. The seismic capacity actually implemented along the building height can deviate due to the selection member sizes used to meet the demands resulting in a capacity that exceeds the demand however does so with a different distribution. This difference in capacity vs. demand distributions can result in concentrated ductility demand in multi-story CBFs.

In reality, there exists some uncertainty in the structural properties and mass distribution at the time of the earthquake and even more uncertainty in the magnitude and frequency content of the input motion. This can result in large differences in the assumed demand distribution and resulting designed capacity distribution causing concentrated ductility demands at a certain story. Therefore, even CBF buildings designed according to modern seismic codes may have tendency for concentrated ductility demands. This has been noted by past researchers (MacRae et al., 2004).

The presence of concentrated ductility demands may result in a "soft-story" mechanism in multi-story CBF buildings leading to severe structural damage or collapse in past 
earthquakes. Such deficiencies in building structures can be found in seismic regions throughout the world. In particular, structures near an active fault may be subjected to near-fault ground motion pulses that have tendency to induce very large concentrated ductility demands in the lower stories of buildings (Alavi and Krawinkler, 2004).

Therefore, both CBFs originally designed and constructed with poor seismic practice and new CBFs can have tendencies for concentrated ductility demands which can result in very poor seismic performance or potentially collapse.

\subsection{Scope/Objective}

The objective of this thesis is to evaluate the adequacy of a seismic retrofit strategy for CBF buildings vulnerable to soft-story failures, in which a sufficiently stiff Rocking Core (RC) pinned to ground is introduced to the original deficient CBF building to create more uniform inter-story drift distributions and hence avoid soft-story failures. Two representative steel $\mathrm{CBF}$ frames, including one low-rise and one mid-rise examples that originally exhibit soft-story failures are retrofitted using the considered strategy. Finite Element (FE) models that explicitly take into account brace yielding, buckling and rupture behavior are developed. An analytical research program including nonlinear static pushover analysis and nonlinear dynamic analysis is conducted to address key issues regarding seismic performance evaluation and other aspects (such as design demands) in the retrofitted system.

\subsection{Thesis Organization}

This thesis contains 7 chapters organized in the following manner: 
Chapter 2 presents a brief overview of previous research related to soft-story buildings. In addition, techniques similar to the one considered in this thesis for retrofit of buildings with the potential of soft-story failures are reviewed.

Chapter 3 describes the retrofit strategy proposed in this thesis and selection of the benchmark CBF buildings used in the analyses.

Chapter 4 presents development and validation of the FE element models for benchmark buildings.

Chapter 5 presents the nonlinear static pushover analyses and nonlinear dynamic analyses of the low-rise CBF buildings.

Chapter 6 presents the nonlinear static pushover analyses and nonlinear dynamic analyses of the mid-rise CBF buildings.

Chapter 7 summarizes the results obtained from the analyses and recommendations for future research. 


\subsection{Literature Review}

The proposed retrofit option consists of adding a rocking core to the existing CBF to help redistribute the inter-story drift. This section provides a brief review of previous research conducted on building frame soft-story failures.

\subsection{Gunay et. al. (2009)}

Soft-story failures in recent earthquakes have proved to be very dangerous especially in non-ductile reinforced concrete frames with unreinforced masonry. Recently, Turkey, Taiwan, India, Algeria, Pakistan, China and Italy have experience high magnitude earthquakes that have led to the collapse of many structures killing many individuals. Buildings with the potential to from soft-story failures are most common in developing countries, and are being built at a high rate to accommodate the rapid population growth. Gunay et al. proposed to add rocking infill walls to prevent soft-story mechanisms in non-ductile reinforced concrete moment frames and unreinforced masonry. Based on the nonlinear static and dynamic analyses, the proposed system was able to reduce the formation of a soft-story failure by distributing the drift demand along the height of the building (see Figure 2.1). 

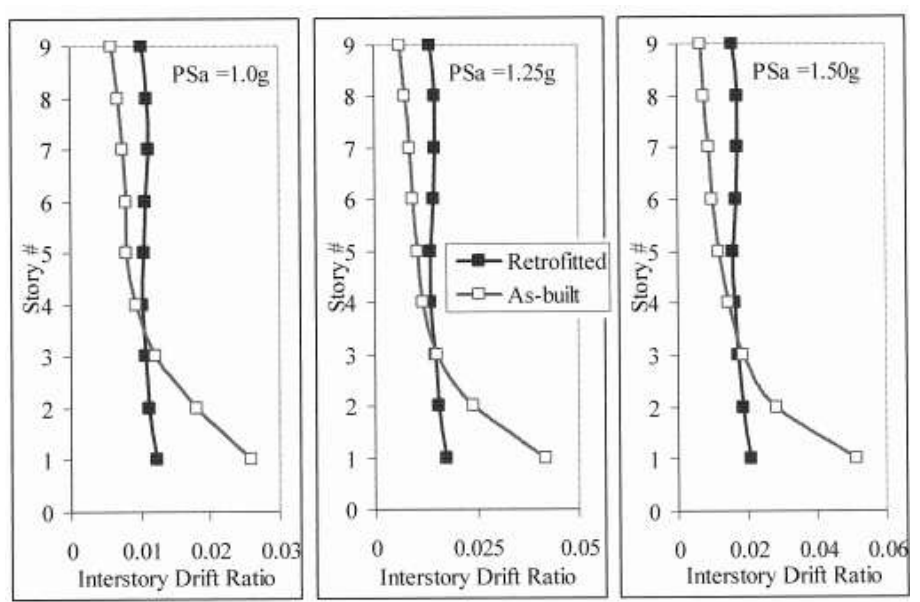

Figure 2.1: Mean inter-story drift profiles for the as-built and retrofitted frames (Gunay et. al., 2009)

\subsection{Ji et. al. (2009)}

CBFs are amongst the most economical type of lateral load resisting system. However, testing shows that braces in CBFs are very vulnerable to buckling, leading to brace fractures due to large deformation concentrating at the center of the braces. Having such a member performance leads to high ductility demand on the story with prematurely buckled and/or fractured braces creating a soft-story failure. Ji et al. (2009) evaluated the performance of adding a continuous gravity columns, assuming, 1) the column is fixed to the foundation, 2) the gravity column is pinned to the foundation. An analytical investigation was done with varying brace slenderness ratio, number of stories and seismic force deduction factor. From nonlinear dynamic analysis it was concluded that the gravity columns are able to redistribute the drift along the height of the building. Having the continuous column fixed at the foundation helped reduced the drift, resulting in less damage of the structure. Furthermore, the retrofitted system is able to achieve the performance of collapse prevention under the BSE-ground motions. However, it was observe that the gravity columns developed significant yielding which is undesirable. 
Also, it is important to mention that Ji et al. did not consider the effects of the gusset plates, instead the brace connections were modeled as pinned which tends to overestimate displacement demands in the system. Additionally, brace fracture due to excessive yielding and low-cycle fatigue was not modeled, thus neglecting dramatic strength and stiffness degradations in the system.

\subsection{Wada et. al. (2009) and Qu et al. (2012)}

Wada et. al (2009) and Qu et al. (2012) evaluated the performance of a reinforced concrete frame vulnerable to soft-story failure with the implementation of a presetressed rocking wall and steel dampers. The building studied is located in Japan and consists of 11 stories. Through extensive nonlinear dynamic analysis, it was concluded that the rocking wall reduces the probability of a soft-story formation. Furthermore, adding the steel dampers further reduces the inter-story drift along the height of the building (Figure 2.2).
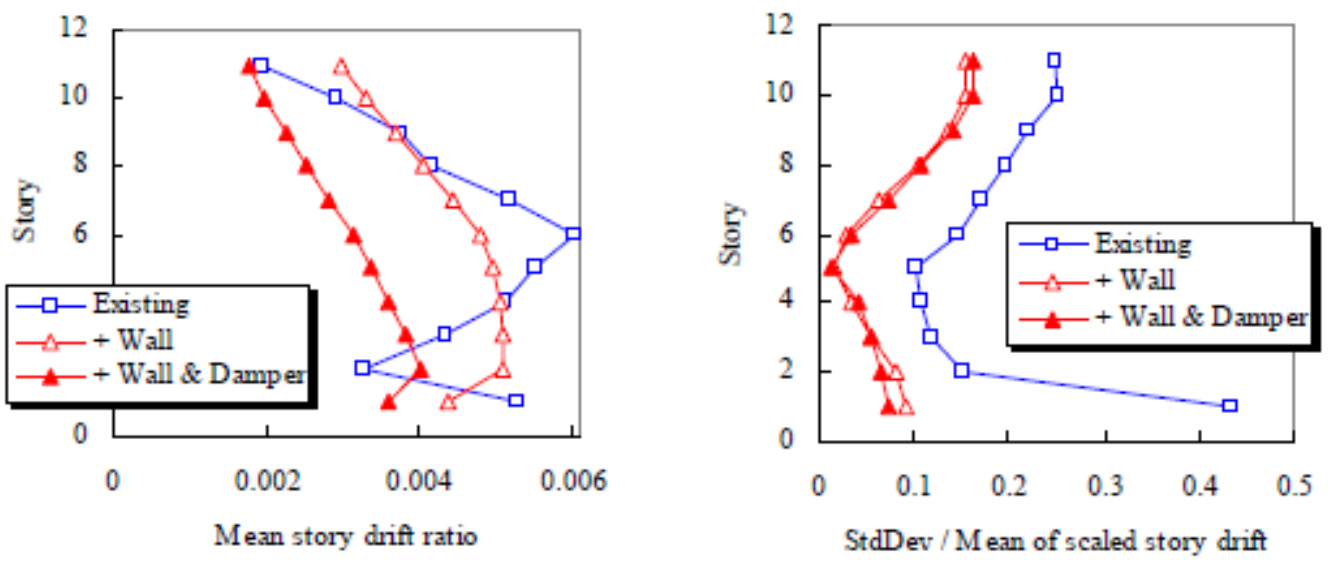

Figure 2.2: Comparison of inter-story drifts in existing and retrofitted systems (Wada et. al., 2009) 


\subsection{McCormick et. al. (2007)}

Past performance of CBFs under large earthquakes have indicated that they have limited ductility and energy dissipation due to the braces buckling and fracturing. McCormick et al. (2007) investigated the performance of three- and six-story CBFs by adding superelastic shape memory (SMAs) alloys at the middle of the braces. SMAs have the ability to undergo very large displacements while reverting back to their original undeformed shape. The buildings were subjected to $2010 \%$ in 50 years ground motions and $202 \%$ in 50 years ground motions. From the results, it was concluded that the SMA braces undergo smaller elongation due to the re-centering force as compared to the original CBF. Also, the maximum inter-story drift for the three- and six-story building decreased with the implementation of the SMA (see Figure 2.3) because the braces were restored to their original length. The roof-drift was also significantly lower with the implementation of the SMA.
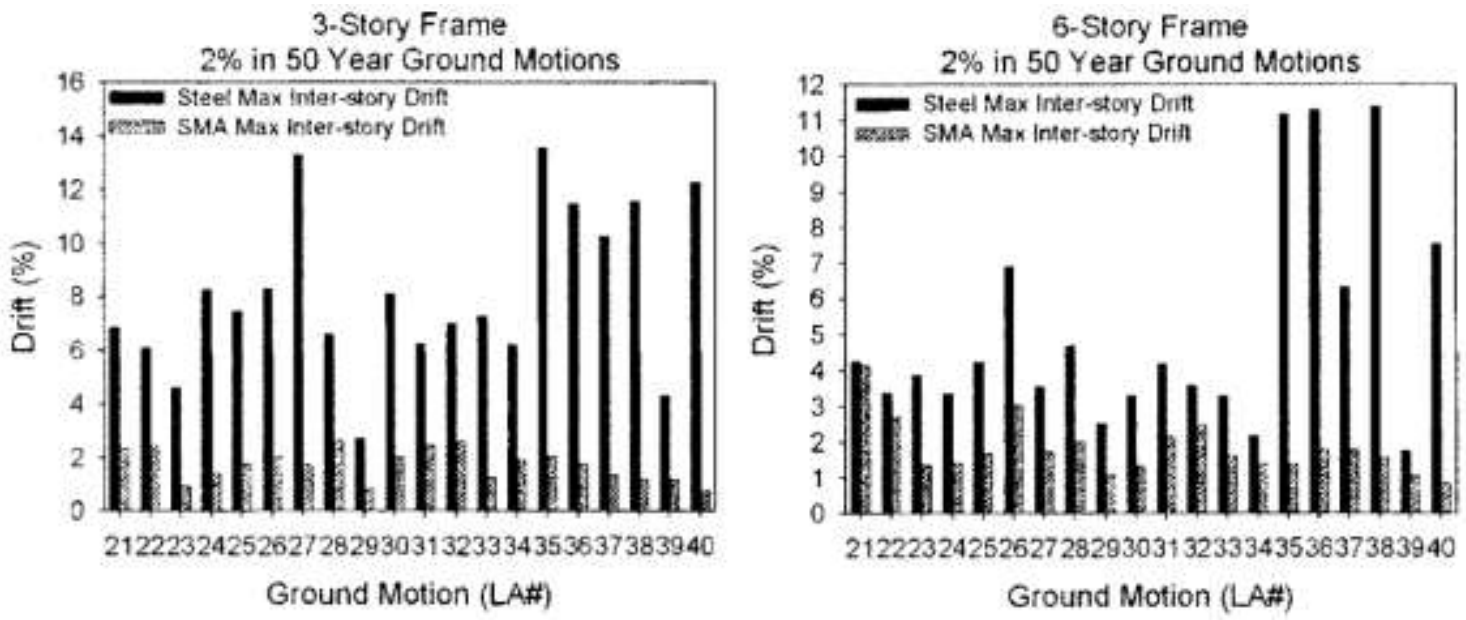

Figure 2.3: Effects of implementation of SMA on CBF maximum inter-story drift (McCormick et. al., 2007) 


\subsection{Description of Retrofit Strategy and Benchmark Building}

As discuss in previous chapters, CBFs may be vulnerable to collapse due to the formation of a soft-story mechanism. When such a mechanism occurs, ductility demand concentrates at the prematurely failed story in which the braces installed are more likely to fracture due to low cycle fatigue damage caused by cyclic load reversals. Once ruptures in the braces occur at a story level, the lateral load from upper portion becomes unable to transfer to lower stories or the foundations. Undoubtedly, such a failure mechanism is detrimental and the structures damaged as such, if not collapse, are not easy to repair; therefore, the soft-story failure should be definitely prevented in seismic design and retrofit. The section describes a retrofit strategy to prevent such a failure mechanism.

\subsection{Retrofit Strategy}

The strategy discussed in this thesis is to install a rocking core (RC) outside of the $\mathrm{CBF}$ buildings vulnerable to soft-story failures. In practice, the stiff rocking core can be implemented as a steel truss or reinforced concrete wall (prestressed if needed) that is pinned to ground. The added RC redistributes the story shears and inter-story drifts along the vertical direction in the CBF building and thus prevents formation of localized softstory mechanism. This thesis focuses on demonstrating the effectiveness of the retrofit strategy and identifying the key parameters affecting the system performance. Hence, the $\mathrm{RC}$ is modeled as a line element as shown in Figure 3.1B for simplicity. While such a simplification may not provide the best estimate for some local responses (such as rotation at the ends of the links connecting the existing structure to RC), it will help understand the contribution of RC in improving the global performance of the retrofitted 
structure. In addition, although demands on RC and preliminary design of RC will be further investigated in Chapter 5 and 6, detailed design of the RC is beyond the scope of this thesis. Figures 3.1 A and B illustrate the behavior of a CBF with a soft first story before and after retrofit, respectively.

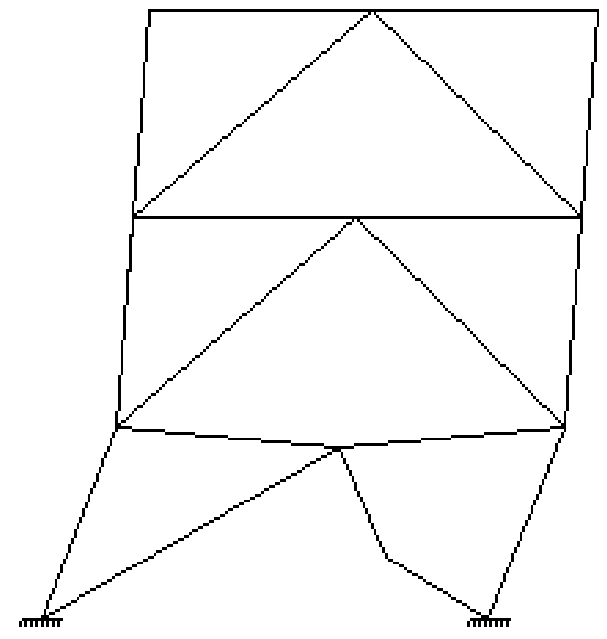

Figure 3.1 A: Original CBF vulnerable to soft-story failure

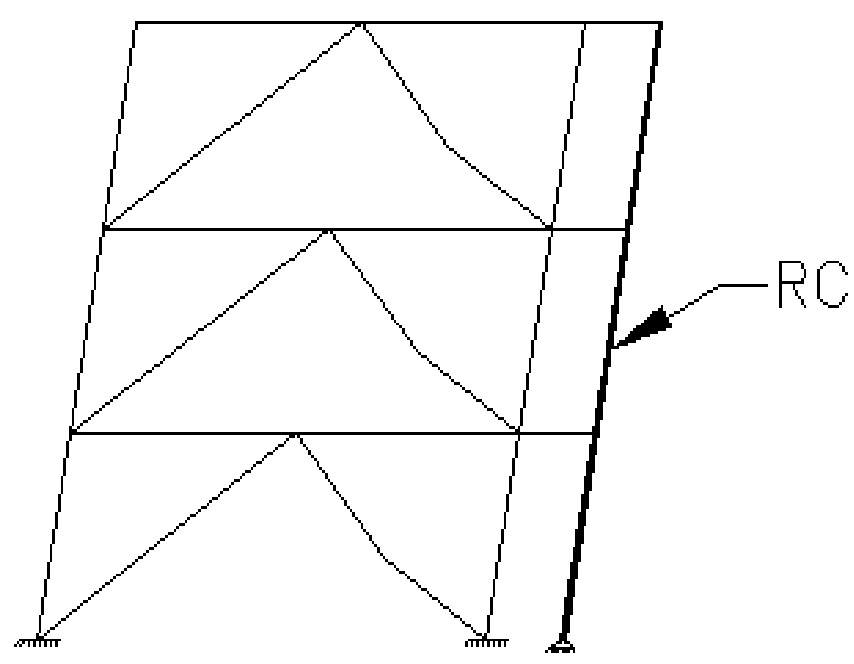

Figure 3.1 B: CBF after retrofit

The RC throughout the analysis was assumed to be elastic and will be designed as such. Moreover, the $\mathrm{RC}$ was assumed to be pinned to the ground since low-rotation stiffness at the RC-to-ground connections combined with the high stiffness of RC does not attract significant seismic forces through the core to the foundation. However, the RC redistributes seismic ductility demands from floors that would otherwise have significant concentrated inter-story drifts to other floors resulting in uniformly distributed system damage.

Steel beam members are used as links connecting the existing structure to RC. Two cases are considered for the connections at the ends of the links, including 1) both ends of the 
links are pinned; and 2) the ends connected to the $\mathrm{RC}$ are fully fixed and the other ends connected to the existing building are pinned. The links from the first case only transfer the interaction axial force between $\mathrm{RC}$ and the existing frame. Beyond transferring the interaction force, the links from the second case also dissipate hysteretic energy through link bending action at the fixed ends. It is recognized that the ends of the links connected to the existing frame are assumed to be pinned in this investigation to avoid adding bending moment demands on the column of the existing frame.

\subsection{Selection of Benchmark Building}

The RC retrofit strategy is intuitively expected to be applicable for low-rise and mid-rise CBFs. To demonstrate the efficiency of the proposed strategy, two representative CBF buildings including one three-story building and one six-story building are selected as low-rise and mid-rise benchmark buildings, respectively. The two CBF buildings were designed by Sabelli (2001) as the CBF examples corresponding to the steel moment frame building examples for the SAC steel project (Gupta and Krawinkler, 1999).

Figure 3.2 provides a plan view of the two CBF buildings. Specifically, these two buildings were designed for Downtown Los Angeles and were assumed to be used for office space. Note in Sabelli (2001) that similar buildings were also designed for Boston and Seattle but these buildings were not considered in this study. Recent research (Uriz and Mahin, 2008) has confirmed that the two selected CBF building frames have the potential to develop the soft-story mechanism under earthquake loading, which best suit the needs of this investigation. 
Both of the selected buildings were designed based on the 1994 Uniform Building Code and 1997 NEHRP Recommended Provisions for Seismic Regulations for New Buildings and Other Structures. The earthquake loads were determined based on the seismic hazards with a $10 \%$ probability of exceedence in 50 years. Both buildings were designed with chevron braced frames along the perimeter of the building to provide lateral load resistance during a seismic event. As shown in Figure 3.2, the three-story building had a total of four braced bays in each direction and the six-story building had a total of six braced bays in each direction. The members of the braced frame were designed consistent with the AISC Load and Resistance Factor Design Code (1994) and Seismic Provisions for Structural Steel Buildings (1997). The columns were designed to be continuous for the three-story frames and were spliced between the fourth and fifth story in the six-story frames. The beams were assumed to be continuous throughout the span. The heights, dimensions and loading information used for design of both buildings are provided below. Further details of the two selected CBF buildings are available in Sabelli (2001).

Floor-to-Floor Height Three-Story Building 13'-0"

$\begin{array}{lll} & \text { Six-Story Building } \\ & \text { Penthouse } & 12^{\prime}-0 " \\ & \text { First Story } & 18^{\prime}-0 " \\ & \text { All Other Stories } & 13^{\prime}-0 " \\ \text { Building Weight: } & \text { Steel Framing } & \text { As Designed } \\ & \text { Floors and Roofs } & \text { 3" Metal Deck with } 2 \text { 1/2” Normal-Weight }\end{array}$

Concrete

Roofing 7 psf


Ceilings/Flooring $\quad 3 \mathrm{psf}$

Mechanical/Electrical 7 psf, 47 psf at Penthouse

Partitions $\quad 20 \mathrm{psf}$ (Gravity Design)

10 psf (Seismic Design and Analysis)

Exterior Wall $25 \mathrm{psf}$

Dimensions: $\quad$ Bay size $\quad 30^{\prime} \times 30^{\prime}$ (2' Perimeter Wall Offset from

Gridline)

Three-Story Building 124'-0" x 184'-0"

Six-Story Building 154'-0" x 154'-0"

Live Loading $\quad$ Both Buildings $50 \mathrm{psf}$

Wind Loading Exposure B per uniform Building Code

Based on the above information the reactive mass of each structure was obtained. The three-story building has a mass of $6.7 \mathrm{kip}-\mathrm{sec}^{2} /$ in per story (i.e., $1.678 \mathrm{kip}-\mathrm{sec}^{2} / \mathrm{in}$ tributary to each braced frame at every story). The six-story building has a mass of 6.9 kip-sec ${ }^{2} /$ in (i.e., $1.16 \mathrm{kip}-\mathrm{sec}^{2} / \mathrm{in}$ tributary to each braced frame at every story). 

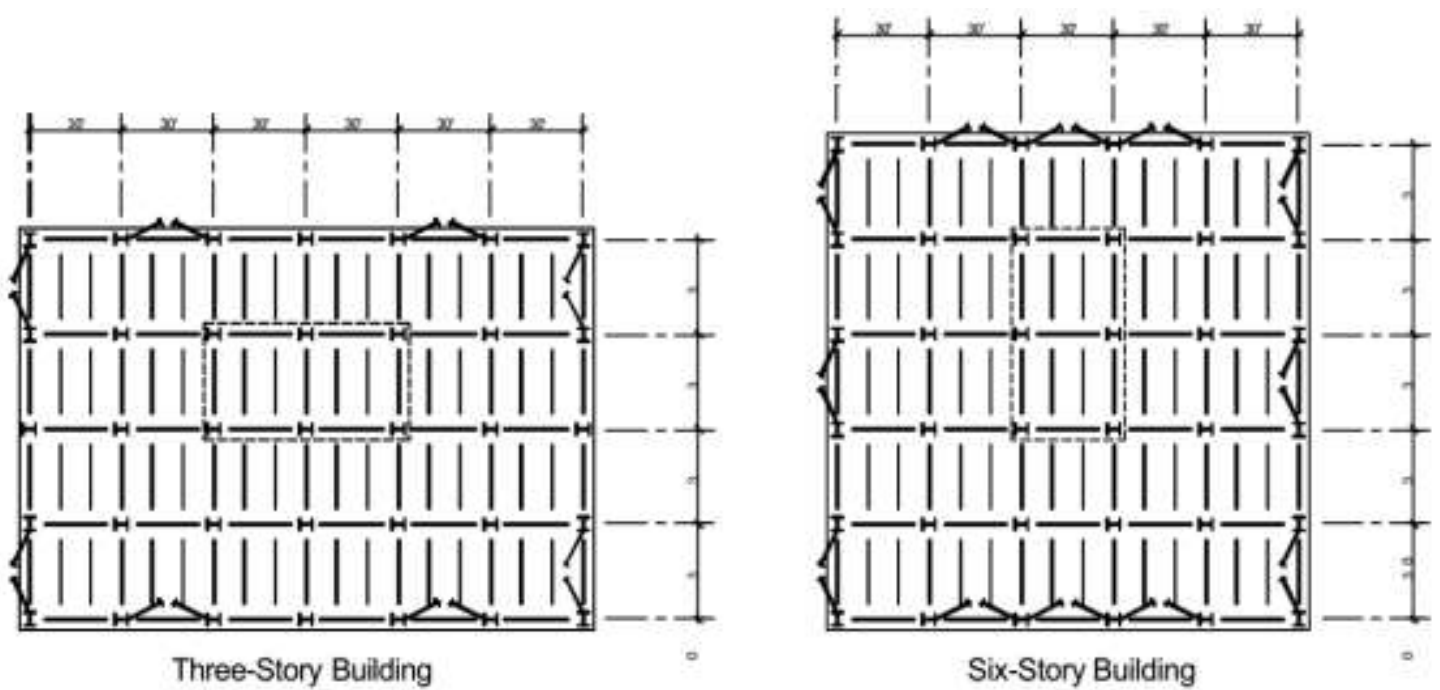

Figure 3.2: Plan view of three-story and six-story CBF buildings (Sabelli, 2001)

For the analysis conducted in this thesis, only one braced frame along each loading direction was modeled for each of the selected building. Therefore, torsional effect and other effects resulting from $3 \mathrm{D}$ to $2 \mathrm{D}$ simplification were neglected. The configurations of the three- and six-story building used for analysis are presented in Figures 3.3 and 3.4, respectively. Other considerations and simplifications for developing numerical models of the two CBFs are provided in detail in Chapter 4. 


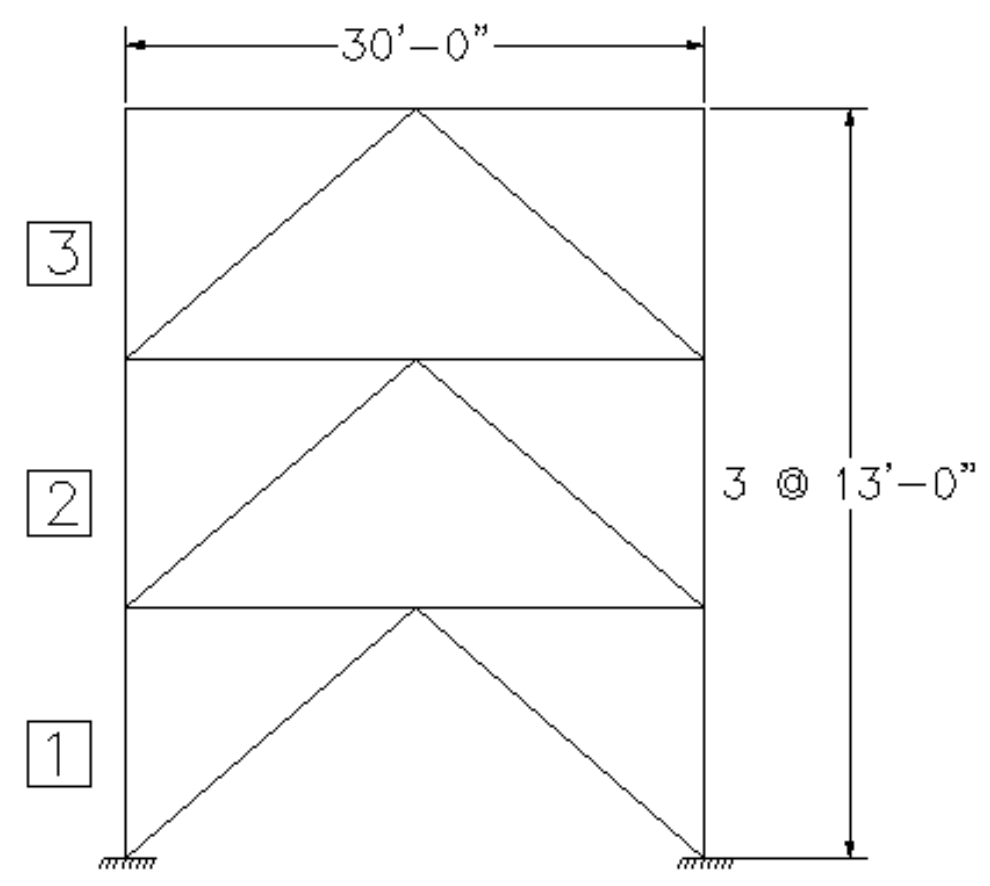

\begin{tabular}{|c|c|c|c|}
\hline Story & $\begin{array}{r}\text { Brace } \\
\text { HSS }\end{array}$ & Column & Beam \\
\hline 3 & $6 \times 6 \times 3 / 8$ & & $w 18 \times 46$ \\
\cline { 1 - 1 } 2 & $8 \times 8 \times 1 / 2$ & \multirow{2}{*}{$w 12 \times 96$} & $w 27 \times 84$ \\
& $8 \times 8 \times 1 / 2$ & & $w 30 \times 90$ \\
\hline
\end{tabular}

Figure 3.3: Configuration of three-story building used for analysis 


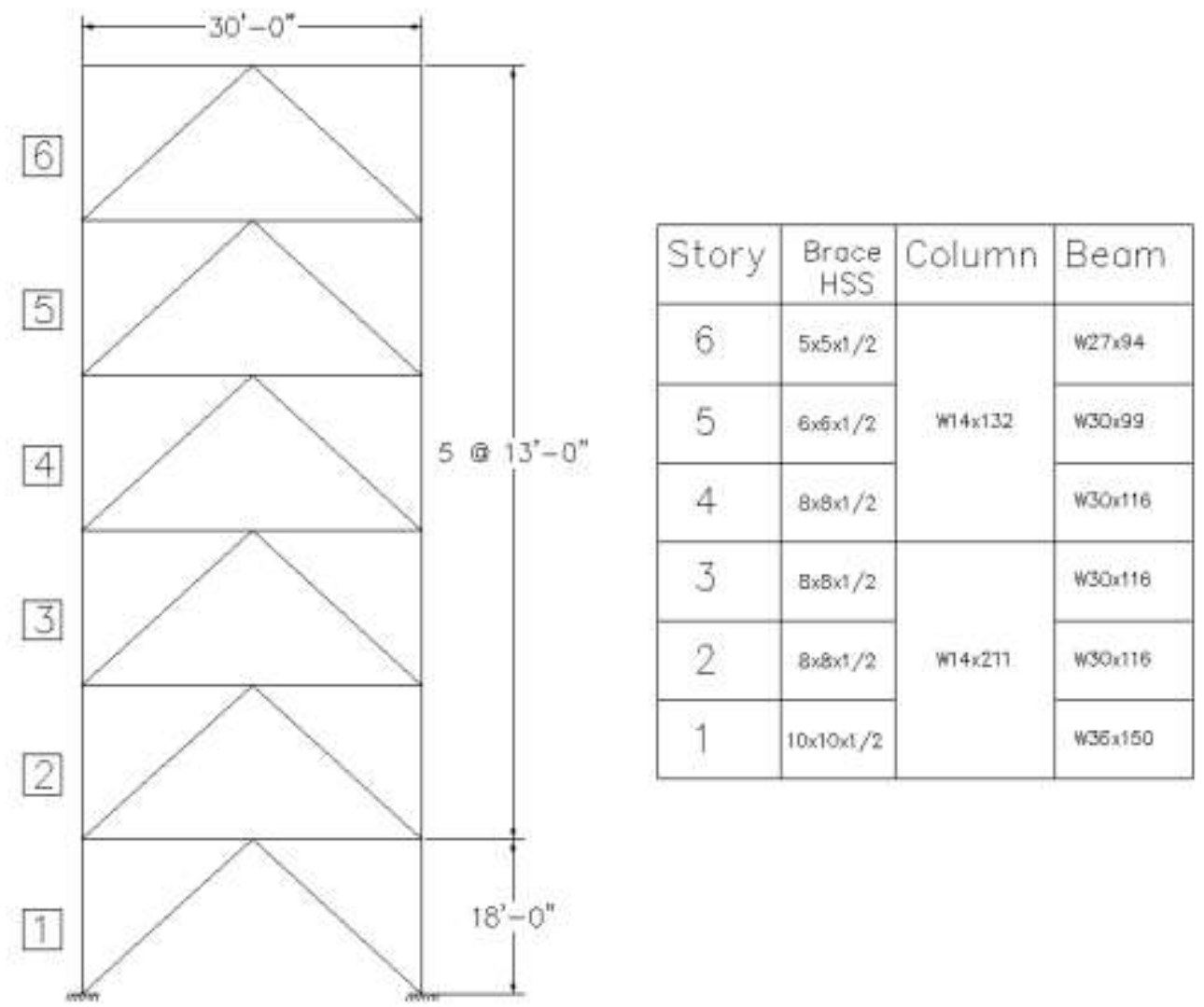

Figure 3.4: Configuration of six-story building used for analysis 


\subsection{Finite Element Modeling and Validation}

Finite element models of the considered CBF buildings with and without the $\mathrm{RC}$ are developed using the Open System for Earthquake Engineering Simulation (OpenSees). This chapter presents 1) description of the FE models, 2) determination of the key parameters required in model development, 3) special effects captured in the models and 4) validation of the developed models.

As discussed in Chapter 3, the buildings used in this study were taken from Sabelli (2001). In the three- and six-story CBF buildings, the lateral load resisting systems consist of four and six chevron braced frames in each direction, respectively. Due to the symmetry of the buildings, only one braced frame was considered for each of the buildings in this thesis. The seismic masses tributary to each CBF was assigned to the FE model described below. Figures 4.1 and 4.2 schematically show the FE models for the three- and six-story CBFs, respectively.

Consistent with the original design, the columns of the original frame in the three-story model were assumed to be continuous from the foundation to the roof level. In the sixstory model the columns were assumed to be spliced between the third and fourth story level and continuous at all other locations. In both cases the columns were fixed at the foundation. The beams were continuous across the span for both the three- and six-story models. The beam-to-column connections were assumed to be pinned.

Initial imperfections were introduced at the middle of each brace to capture global buckling of the members. Local buckling of the braces was not considered in this research. It should be noted that the braces were assumed to be connected to the boundary 
frame with pinned connections in the previous research (i.e., the guessed plates were not explicitly considered) (Sabelli 2001, McCormick et al., 2007). However, recent investigations (Uriz and Mahin 2008;Terzic, 2013) indicate that neglecting the gusset plates may lead to inaccurate prediction of structural performance. As such, this study explicitly models the gusset plate based on the recommendations from Uriz and Mahin (2008). As a result, rigid members were introduced at the connections at the ends of each brace to account for the gusset plate rigidity. A further discussion of flexural resistance due to gusset plates is provided in detail in Section 4.2.

As shown in Figures 4.1 and 4.2, the RCs pinned to the ground are attached to the original frames. The RCs were assumed to remain elastic in all analyses. These links were assumed to be pinned on both ends when they are not expected to absorb any hysteretic energy. They were assumed to be pinned to the original frame and fixed to the $\mathrm{RC}$ when they had energy dissipation capacity. It is noted that the original CBF buildings will be referred to as LA3 and LA6 thereafter, respectively. The models having RC and the links pinned on both sides will be referred to as LA3-A and LA6-A for the three- and six-story models respectively. The models having RC and the links pinned to the frame and fixed to the $\mathrm{RC}$ will be referred to as LA3-B and LA6-B for the three- and six-story models, respectively.

An axially rigid but flexurally weak gravity column was included in each FE model to take into account the P-Delta effect. The gravity column was pinned to foundation. The links used to connect the gravity column to the original frame were assumed to be pinned on each end. 


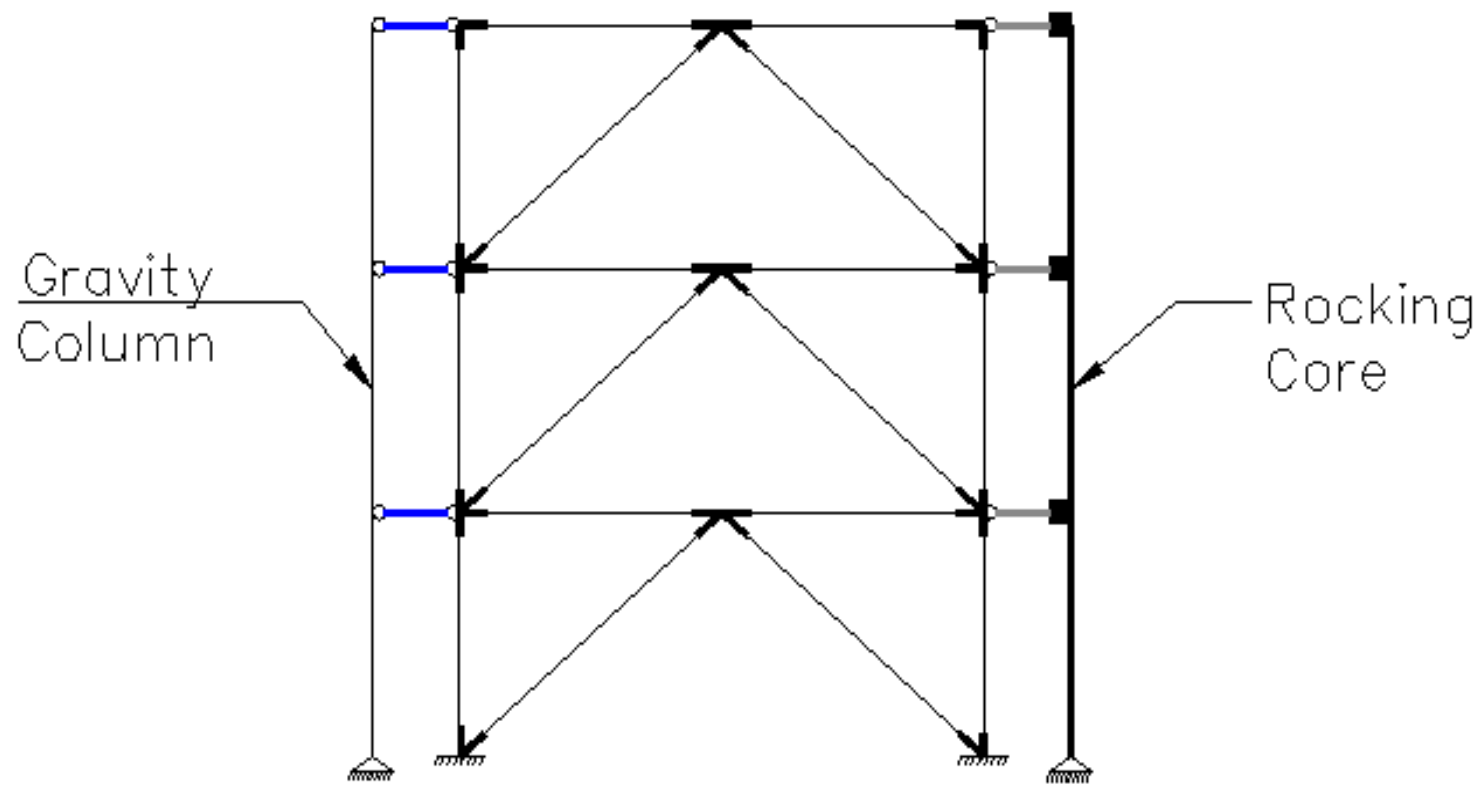

Legends for Braced Frame

- Nonlinear FB Element

- Rigid Elastic Element Truss Element for LA3-A. FB Element for LA3-B.

- Truss Element

- Pinned Connection

Aिm Pinned Connectin

$\pi m$ Fixed Connection

Dinned connection for LA.3-A. Fix Connection for LA3-B

Figure 4.1: Schematic of Finite element model for LA3-A and LA3-B 


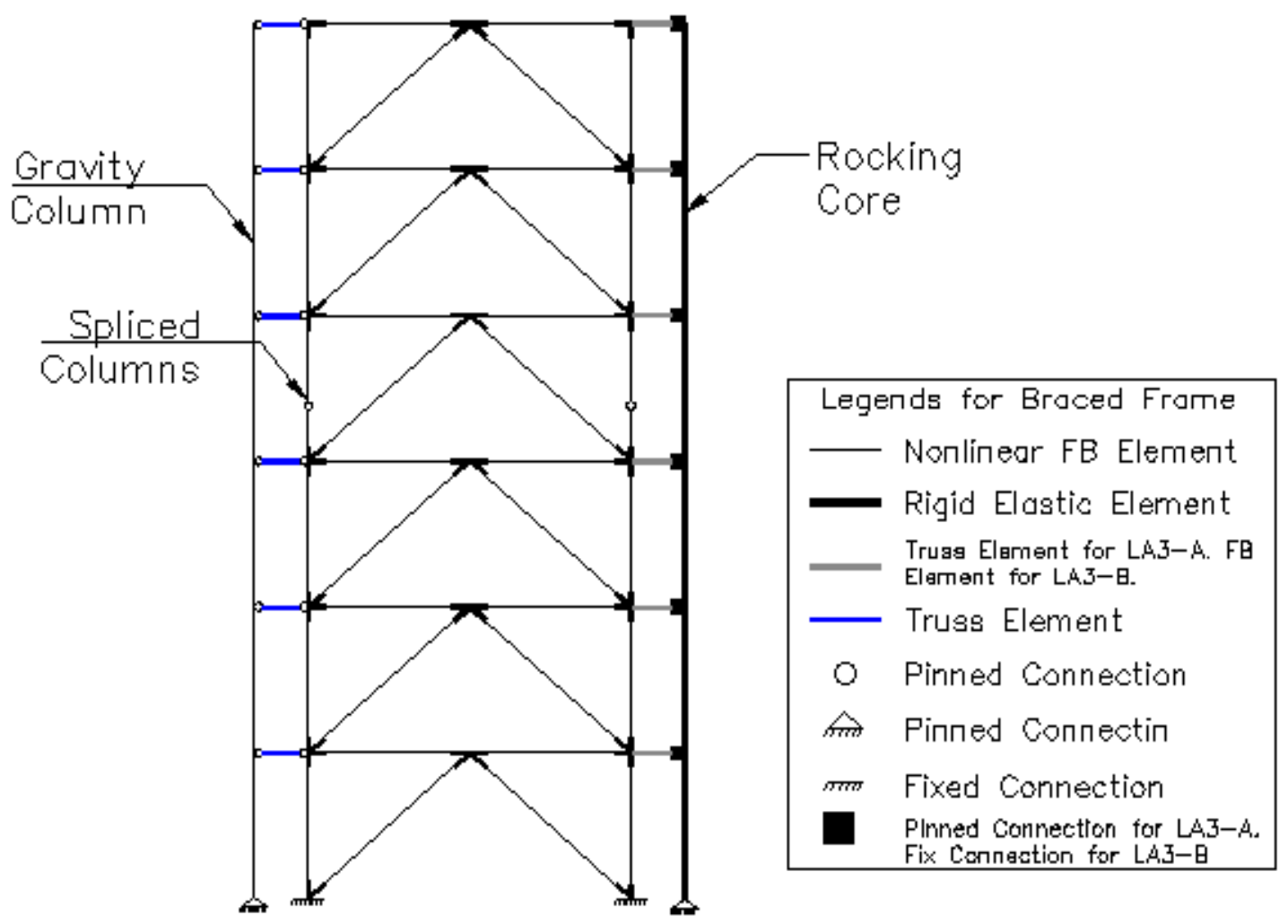

Figure 4.2: Schematic of Finite element model for LA6-A and LA6-B

\subsection{Selection of Material Models}

Many material models have been developed to capture the behavior of steel in the nonlinear region. In this thesis, the material model used for steel was Giuffré-MenegottoPinto with Isotropic Strain Hardening. The OpenSees command Steel02 Material uses the Giuffré-Menegotto-Pinto steel model. This material model was used for the beams, columns, braces and gusset plates.

The initial elastic tangent was assumed to be $29,000 \mathrm{ksi}$. The yield strength of the beams and columns was taken to be $55 \mathrm{ksi}$ as used in Uriz and Mahin (2008). The nominal yield strength of the braces was $46 \mathrm{ksi}$ (ASTM A500 grade B), but experimental testing conducted by Yang and Mahin (2005) showed that the yield strength can be as high as 60 
ksi. Given that material overstrength in braces may trigger soft-story failure (Uriz and Mahin 2008), the strength of $60 \mathrm{ksi}$ was used for brace. The yield strength of the gusset plates was taken to be $55 \mathrm{ksi}$. The strain hardening ratio used for the beams, columns, braces and gusset plates was assumed to be $1.0 \%(0.01)$. The values assumed for parameters that control the transition from elastic to plastic branches and parameters for isotropic hardening, which are presented in Table 4-1, were the same as those recommended by OpenSees. Figure 4.3 shows a typical stress strain curve for the Giuffré-Menegotto-Pinto steel model. In this figure the sensitivity of the parameters that transition from elastic to plastic are shown. The solid line is associated with R0 equal to 20 and the dashed line corresponds to R0 equal to 5 . As shown, a value of 5 has more gradual change than a value of 20 . All the other parameters remain constant. In this study a value of R0 equal to 20 was used as recommended by the OpenSees Wiki.

Table 4-1: Material properties required in the Giuffré-Menegotto-Pinto model

\begin{tabular}{|l|c|c|c|c|c|c|c|c|c|c|}
\hline & $\begin{array}{c}\text { Yield } \\
\begin{array}{c}\text { Strengt } \\
\mathrm{h} \\
(\mathrm{ksi})\end{array}\end{array}$ & $\begin{array}{c}\text { Elastic } \\
\text { Modulus } \\
(\mathrm{ksi})\end{array}$ & $\begin{array}{c}\text { Strain } \\
\text { Hardenin } \\
\text { g Ratio }\end{array}$ & \multicolumn{2}{|c|}{$\begin{array}{c}\text { Transition from } \\
\text { Elastic to Plastic } \\
\text { Parameters }\end{array}$} & \multicolumn{5}{|c|}{$\begin{array}{c}\text { Isotropic Hardening } \\
\text { Parameters }\end{array}$} \\
\hline & $\mathrm{E} 0$ & $\mathrm{Fy}$ & $\mathrm{b}$ & $\mathrm{R} 0$ & $\mathrm{cR} 1$ & $\mathrm{cR} 2$ & $\mathrm{a} 1$ & $\mathrm{a} 2$ & $\mathrm{a} 3$ & $\mathrm{a} 4$ \\
\hline $\begin{array}{l}\text { Columns/ } \\
\text { Beams }\end{array}$ & 29000 & 55 & 0.01 & 20 & 0.925 & 0.15 & 0.0005 & 0.01 & 0.0005 & 0.01 \\
\hline Braces & 29000 & 60 & 0.01 & 20 & 0.925 & 0.15 & 0.0005 & 0.01 & 0.0005 & 0.01 \\
\hline $\begin{array}{l}\text { Gusset } \\
\text { Plates }\end{array}$ & 29000 & 55 & 0.01 & 20 & 0.925 & 0.15 & 0.0005 & 0.01 & 0.0005 & 0.01 \\
\hline
\end{tabular}




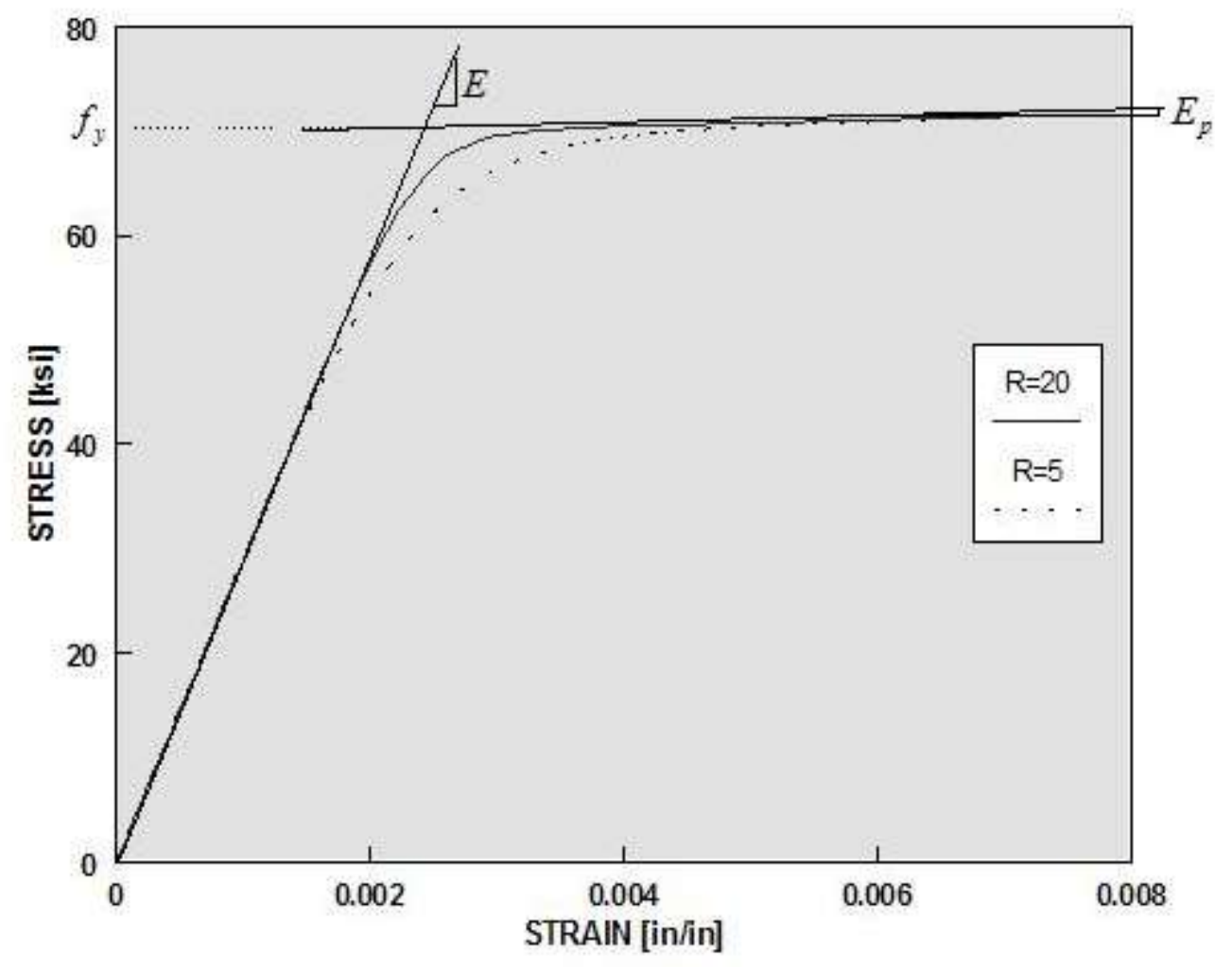

Figure 4.3: Stress strain curve of Giuffré-Menegotto-Pinto (OpenSees Wiki)

\subsection{Selection of Element Types}

A comparison of Force-Based Elements (FBEs) and Displacement-Based Elements (DBEs) was done by Williamson (2012) in modeling steel buildings. In that study, Williamson developed two identical three-story moment frame buildings, one with displacement-base elements, DBE, and the other with force-base elements, FBE. Both frames were excited with the same pair of bidirectional ground motions. It was concluded that there was no significant difference between the two elements. Figure 4.4 shows the first-story drift history for both the FBE and DBE. 


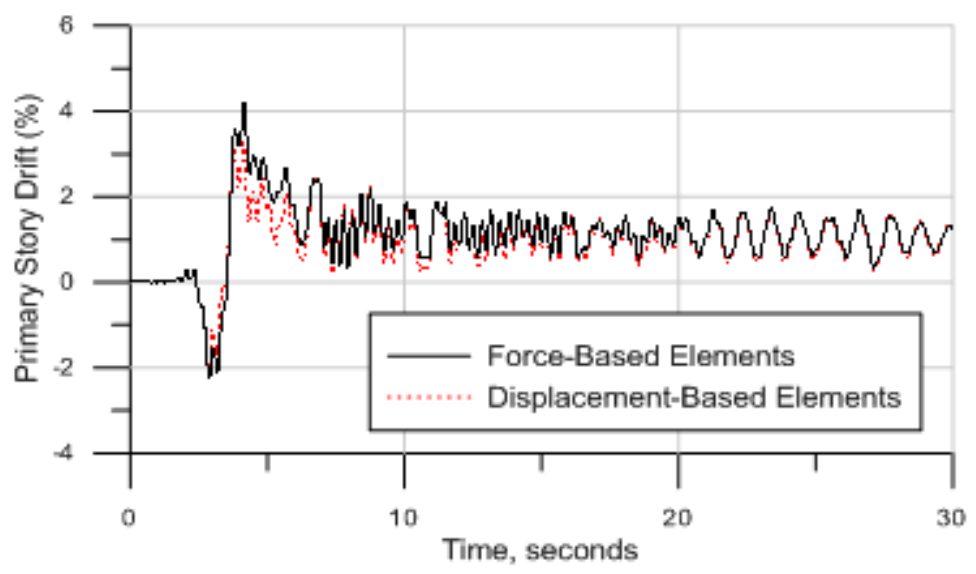

Figure 4.4: DBE Vs. FBE (Williamson, 2012)

It is evident that both elements perform similarly during the elastic phase of the structure. However, during the nonlinear phase the FBE structure exhibited a slightly larger story drift. Williamson (2012) concluded that FBE are more computationally expensive and an increase in integration points along the member help convergence. DBE are computationally inexpensive but require a greater number of elements for convergence and better accuracy.

Also, another study was done to show the difference between FBE and DBE by Terzic (2011). Experimental results were compared with analytical results using FBE and DBE. Figure 4.5 shows the comparison of the results from FBE, DBE, vs. Experimental investigation. It is noted that the column used in the FBE model has one element and 5 integration points. The DBE model consisted of 4 elements with 3 integration points per element. 
FBE vs. Experiment

Column modeled with 1 element

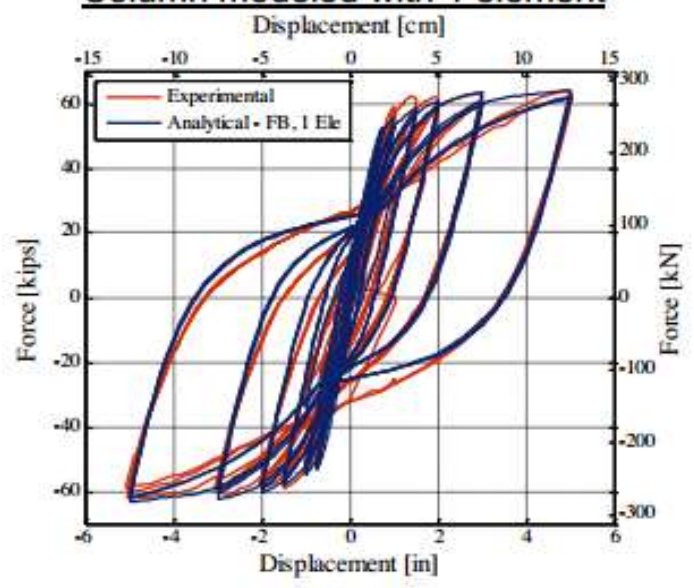

DBE vs. Experiment

Column modeled with 4 elements

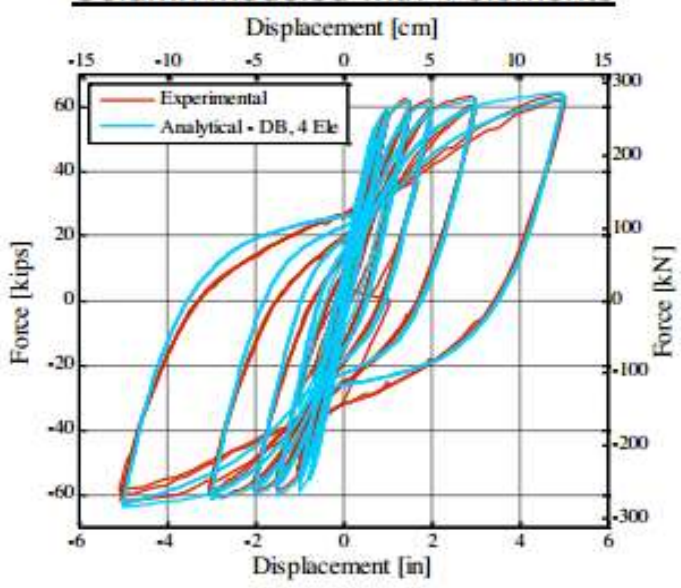

Figure 4.5: Comparison of results from FBE, DBE and experimental investigation (Terzic, 2013)

Terzic (2013) recommends that it is reasonable to use 10 - 20 FBE elements along each brace to capture its buckling behavior and 3 integration points per element. Also, it was recommended to use FBEs and use 4 integration points for the beams and columns of a braced frame. These recommendations were adopted in this thesis.

The number of fibers in an element cross section also has a great impact on the performance of the structure. Having a more refined mesh tends to give more accurate results but the computational time increases significantly. Terzic (2013) recommended for a W-Shape member to use 1 fiber along the width of the flange and thickness of the web, 8 fibers across the thickness of the flange and 4 fibers across the depth of the web. Terzic (2013) also recommended for a HSS member to the fiber distribution as shown in Figure 4.6. 

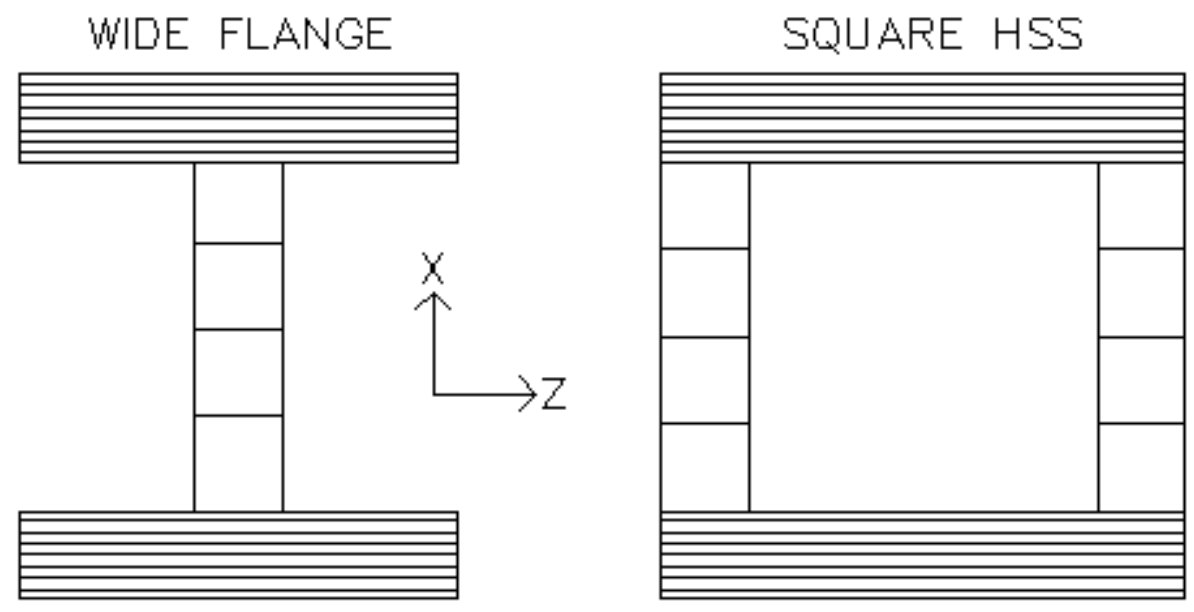

Figure 4.6: Wide flange and HSS fiber distribution

As discuss in Section 4.1, rigid elastic elements were used at beam-to-column connections and brace-to-beam connections. This was done to account for the rigidity that the gusset plates add to the frame members. The elastic modulus was taken to be $29,000 \mathrm{ksi}$ and the moment of inertia was taken to be at least 10 times the moment of inertia of the member adjacent to it. The elastic elements were assumed to be axially rigid with a cross sectional area of $1,000 \mathrm{in}^{2}$.

\subsection{Modeling of Brace}

\subsubsection{Consideration of Gusset Plate}

In this study, the gusset plates at the ends of each brace were explicitly modeled. Sabelli (2001) and McCormick et al., (2007) also investigated seismic performance of LA3 and LA6. In their studies, the ends of each brace were modeled as ideally pinned connections. However, recent studies conducted by Uriz and Mahin (2008) concluded that the results can be very different when gusset plates at the ends of the brace members are considered. 
From their findings, it was recommended that the gusset plate be modeled using a forcebase fiber element or a rotational spring.

Terzic (2013) conducted a case study to compare the response of a one-story CBF with different assumptions in the boundary conditions at the brace ends, which include ideal pinned boundary condition; and explicitly considering the gusset plate at the brace ends using FBEs and springs respectively. The one-story CBF example was subjected to a unidirectional ground motion. Story drift was then compared for all three cases considered. From the results, the spring and the FBE have very similar story drift in both elastic and inelastic regions of the structure. The ideal pinned boundary condition does not match with the FBE and spring results. It is very clear from Figure 4.7 that the ideal pinned end condition provides larger inter-story drift response in the considered structure.

\section{Story drift}
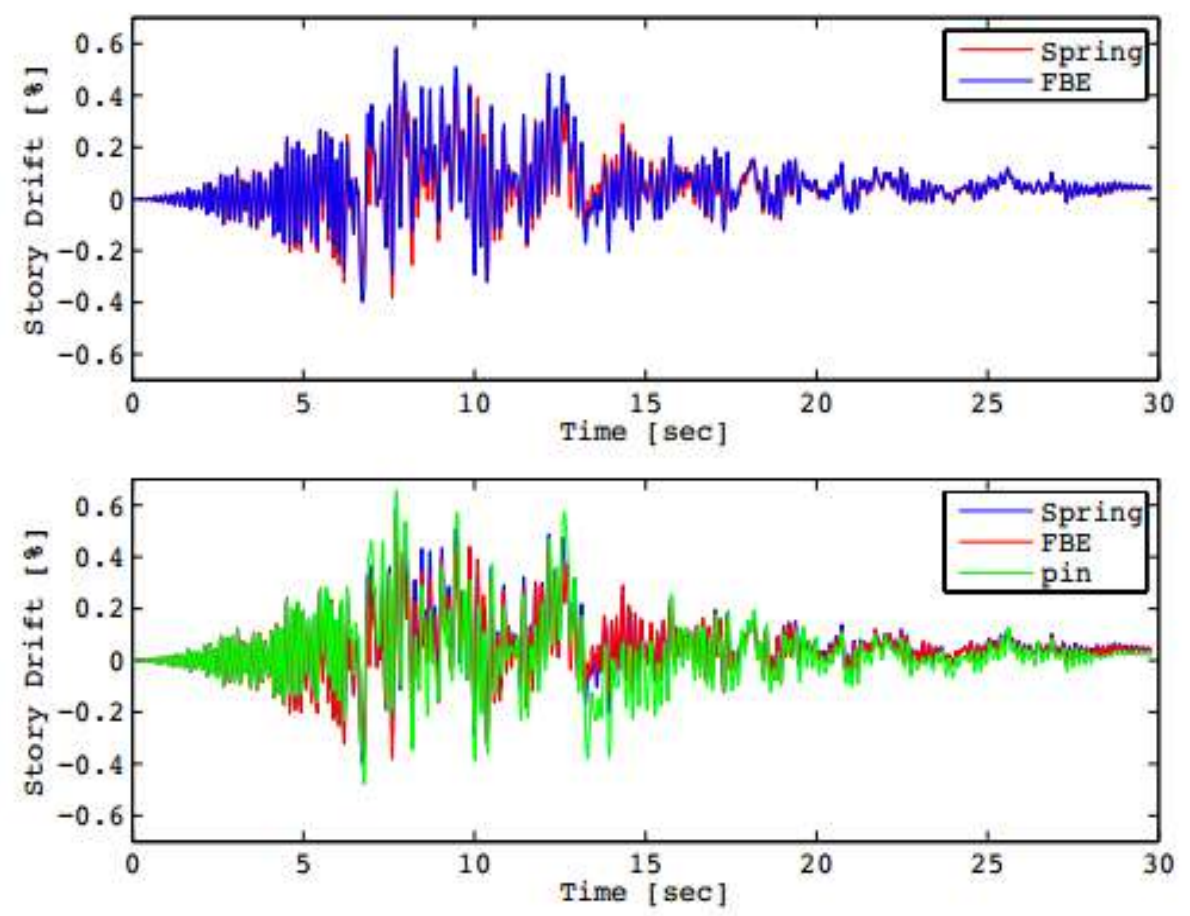

Figure 4.7: Comparison of the results from models with different brace end conditions (Terzic, 2013) 
From figure 4.7 it evident that the residual drift is compromised when an ideal pinnedend condition is used for braces. Terzic also concluded that the floor acceleration and base shear when considering ideal pinned-end condition in braces are not similar to those using springs or FBEs for gusset plates. Further details about the differences in CBF response caused by different assumptions in modeling brace end conditions are available in Terzic (2013).

As shown in Figure 4.8, rigid end zones were introduced in the FE models to account for the additional stiffness due to the presence of gusset plates. Length of the rigid zone was determined according to Terzic (2013). Moreover, FBE was used at the ends of each brace to capture the rotational resistance provided by the gusset plates. Previous experimental results indicate that HSS braces typically exhibits out-of-plane buckling behavior due to the less significant restraining effect of gusset plate along the out of plane direction. In the FE models considered in this investigation, the FBE shown in Figure 4.8 was rotated by 90 degrees along the brace longitudinal direction such that it will be under bending when the brace buckles due to its in-plane initial imperfection. It is noted that such a modification will not change the accuracy of the results but ensures that a $2 \mathrm{D}$ model can capture all the structural performances.

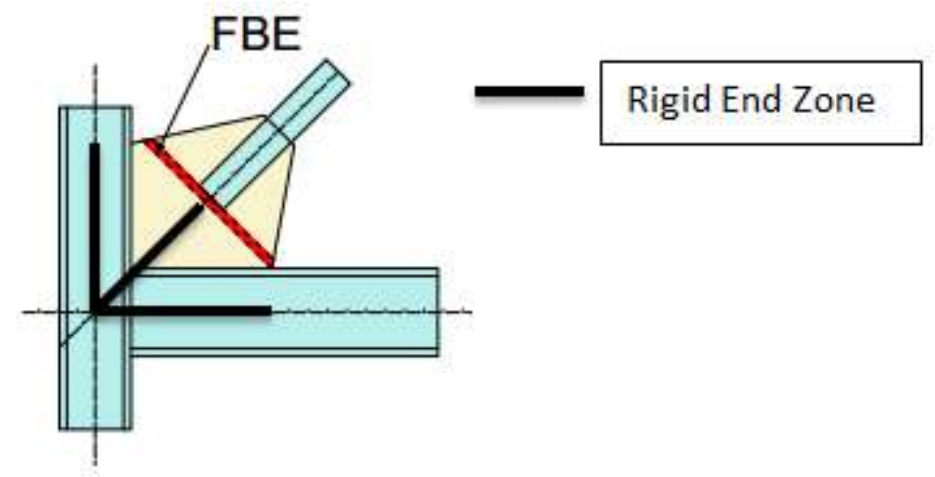

Figure 4.8: Gusset plate connections (Terzic, 2013) 
Nonlinear static analyses were conducted on the bottom story of LA3 to observe the effects the gusset plate thickness on system performance. For comparison purpose, the gusset plate thicknesses were selected to be $0.5,0.75,1.0,1.25$ and 1.5 inches. An initial imperfection of $0.5 \%$ was assumed in the analyses and each brace was considered using 15 FBEs. From the results shown in Figure 4.9, it is evident that the thicker gusset plate thickness tends to lead a larger base shear resistance from the system. This is due to the fact that the rotation restraining effects are more significant in thicker plates, resulting in higher buckling resistance in the brace under compression.

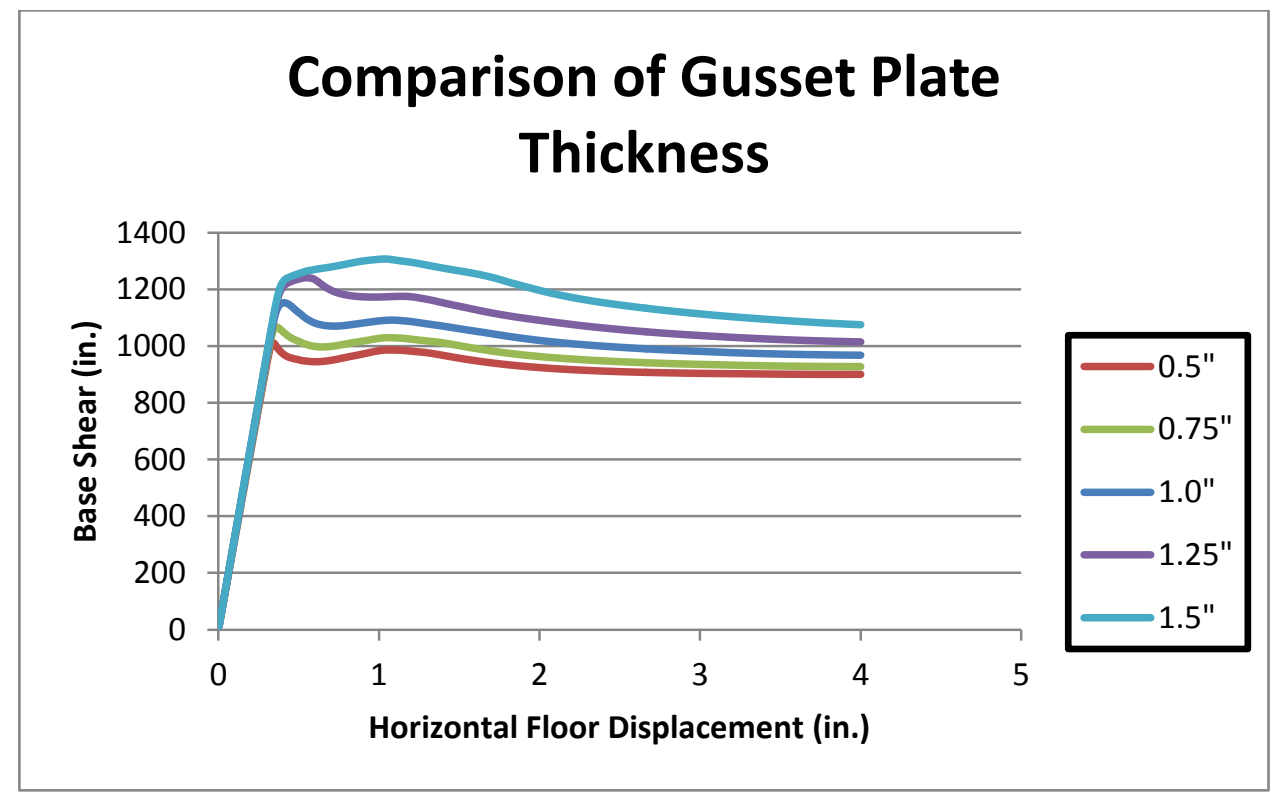

Figure 4.9: Base shear comparison from CBFs with different gusset plate thickness

It is noted that the gusset plate design was not provided in Sabelli (2001). For this research the gusset plate thickness used was determined to be 1.25 and 1.5 inches for LA3 and LA6, respectively. 


\subsubsection{Initial imperfection and global buckling}

In order to simulate global buckling of each brace, an initial imperfection was introduced at the middle of each brace. It is very important to predict the optimal initial imperfection because large values of initial imperfection will cause premature buckling in braces and smaller values will prolong buckling effects. It is important to mention that compression elements have a construction tolerance of 0.1 percent of the effective length as per ASCE-07. However, for this study an initial imperfection of 0.5 percent was used for the ease of convergence.

Nonlinear static and dynamic analyses were done on the first story of the LA3 to compare the results from different initial imperfection values. The initial imperfection values considered for both the pushover and dynamic analysis were $0.1,0.3,0.5$ and 1.0 percent of the effective brace length. Each brace was considered using 15 FBEs.

For the pushover analysis, the model was displaced until the first story displacement reached a maximum story drift of 2.0 percent which corresponds to collapse prevention of a braced frame according to FEMA356 (FEMA 2000). Figure 4.10 shows the base shear of the single story braced frame vs. horizontal story displacement for the initial imperfection values mentioned above. 


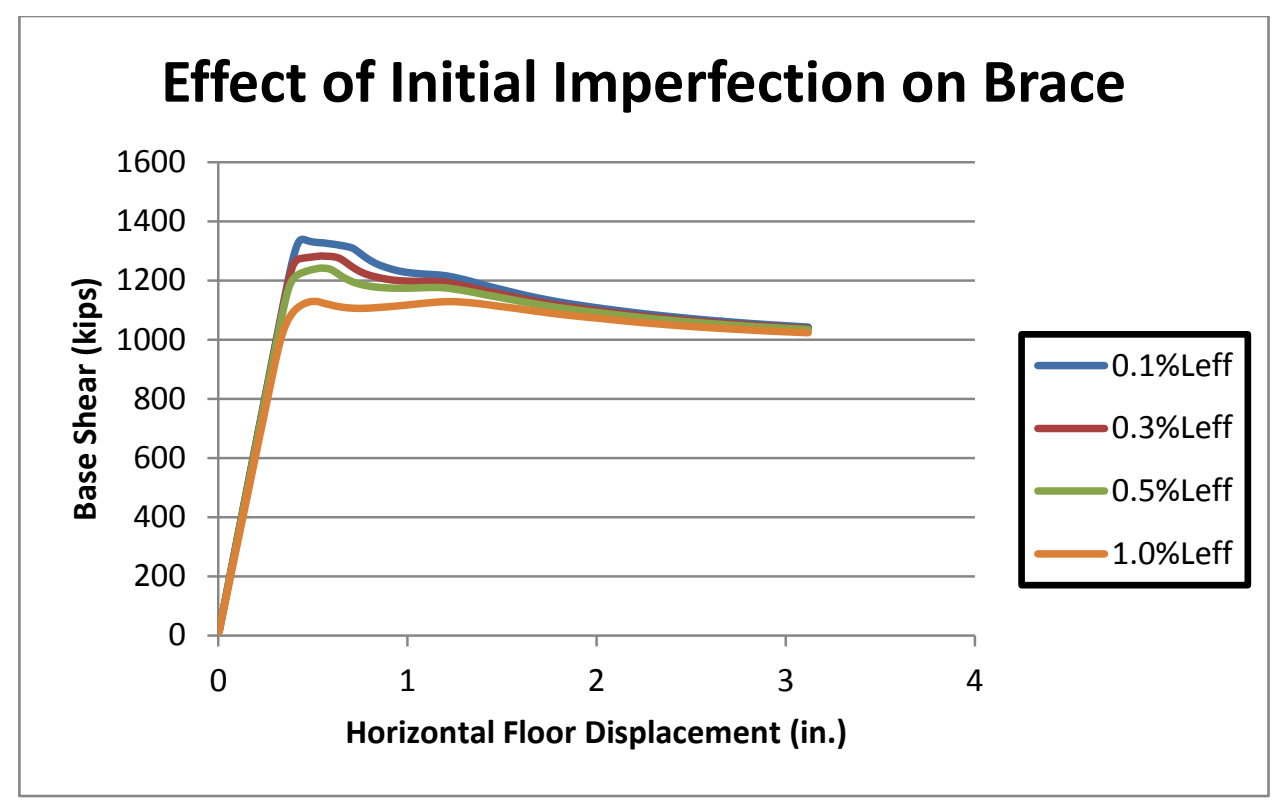

Figure 4.10: Effect of initial imperfection on system performance

From this figure it is evident that at a displacement of 3.12 inches $(2.0 \% \mathrm{drift}$ corresponding to collapse prevention) and a displacement of 2.34 inches ( $1.5 \%$ drift corresponding to life safety) the base shear is very similar in all cases (which is the point of interest in this study). The major difference made by different initial imperfection values is the maximum force it takes for the braces to buckle. Smaller initial imperfection values yield a larger base shear at time of buckling and larger imperfection values yield a lower base shear at the time of buckling. Table 4-2 shows the maximum base shear for each value considered and the base shear at $2.0 \%$ and $1.5 \%$ inter-story drift which correspond to collapse prevention and life safety inter-story drift limits, respectively. 
Table 4-2: Effect of initial imperfection of brace on base shear

\begin{tabular}{|c|c|c|c|}
\hline $\begin{array}{c}\text { Initial } \\
\text { Imperfection } \\
(\% * \text { Leff) }\end{array}$ & $\begin{array}{c}\text { Maximum Base } \\
\text { Shear } \\
\text { (Kips) }\end{array}$ & $\begin{array}{c}\text { Base Shear at 2.0 \% } \\
\text { Drift } \\
\text { (Kips) }\end{array}$ & $\begin{array}{c}\text { Base Shear at } 1.5 \\
\% \text { Drift } \\
\text { (Kips) }\end{array}$ \\
\hline 0.1 & 1339 & 1042 & 1081 \\
\hline 0.3 & 1283 & 1037 & 1073 \\
\hline 0.5 & 1241 & 1033 & 1067 \\
\hline 1.0 & 1130 & 1030 & 1052 \\
\hline
\end{tabular}

The maximum base shear has a significant drop from $0.1 \%$ to $1.0 \%$ initial imperfections while the base shear at $2.0 \%$ and $1.5 \%$ remains very similar. For this thesis, the point of interest is when a story reaches a drift corresponding to life safety and collapse prevention. As shown in Table 4-2, the model predicts the same base shear when the model reach such levels of inter-story drift regardless of the initial imperfection selected.

Nonlinear dynamic analysis was also conducted to investigate the effects of initial imperfections. The same initial imperfection values (0.1-1.0\%, see Table 4-2) were used. All the models were excited with the same uni-directional ground motion in order to compare the results. As shown in Figure 4.10, large difference in brace resistance is expected when the floor displacement ranging from 0.5 in to $1.25 \mathrm{in}$. Therefore, a ground motion which can excite the frame with a maximum floor displacement into that range was selected in the nonlinear dynamic analysis. Figure 4.11 shows the displacement histories of the single story model through the first 10 seconds of a ground motion (i.e., ground motion LA01, see Table 5.4 which will be discussed in detail in Chapter 5). 


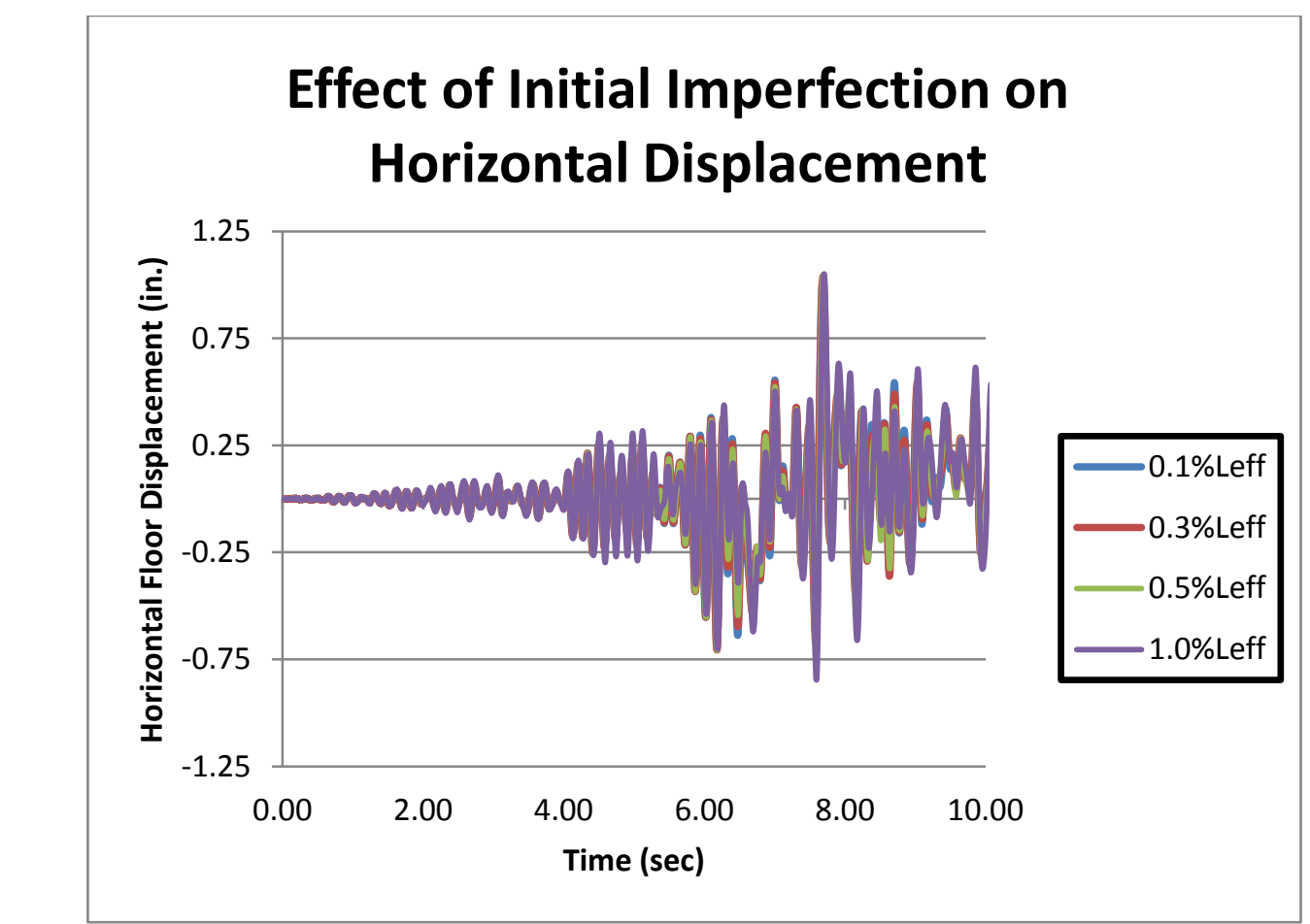

Figure 4.11: Effect of initial imperfection on system performance (result from nonlinear dynamic analysis)

As shown in Figure 4.11, overall the displacement response of the structure is very similar regardless of the initial imperfection. This conclusion can also be proved when considering the maximum inter-story drift. Figure 4.12 shows the maximum inter-story drift for each initial imperfection value considered. 


\section{Effect of Initial Imperfection on Max Story Drift}

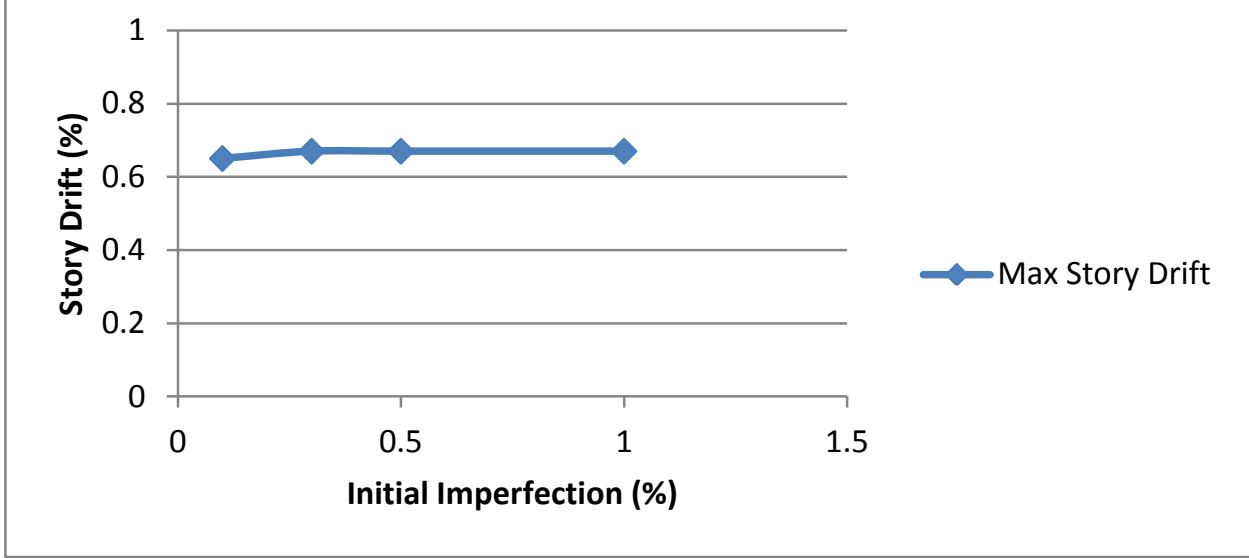

Figure 4.12: Comparison of maximum story drifts due to different values of initial imperfection in braces (result from nonlinear dynamic analysis)

The story drift for an initial imperfection value of $0.1 \%$ was calculated to be $0.65 \%$, while the story drifts for initial imperfection values of $0.3,0.5$ and $1.0 \%$ were all calculated to be $0.67 \%$. Based on these results, the maximum story drift will be very similar regardless of the initial imperfection used.

The floor acceleration was also calculated for each imperfection value considered. The acceleration decreases as the initial imperfection value decreases as shown in Figure 4.13. 


\section{Effect of Initial Imperfection on Floor Acceleration}
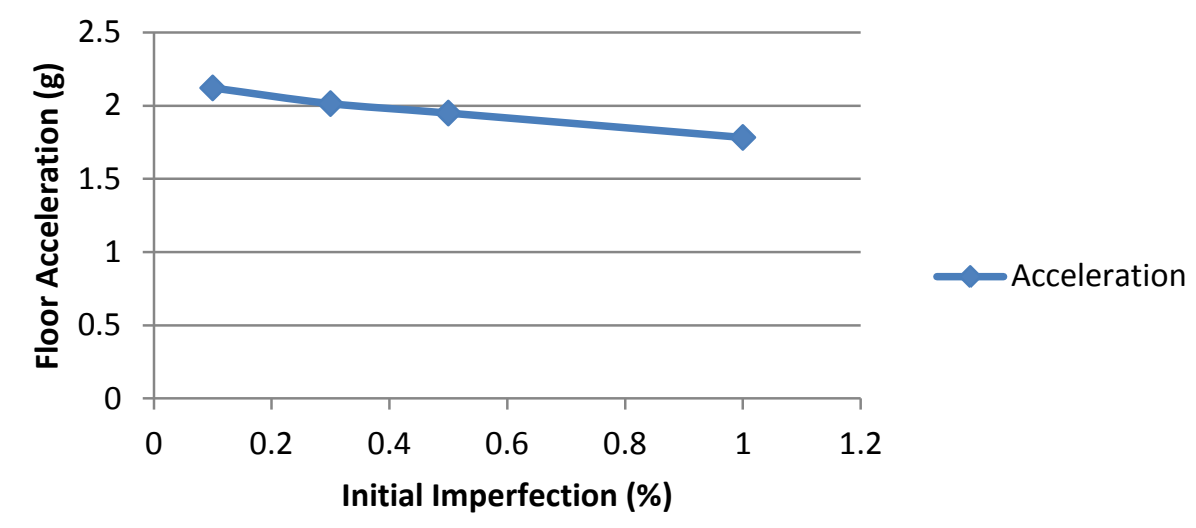

Figure 4.13: Comparison of maximum floor acceleration due to different values of initial imperfection in braces (result from nonlinear dynamic analysis)

The acceleration value decreases from $2.12 \mathrm{~g}$ to $1.78 \mathrm{~g}$ from low to high initial imperfection values. This is a significant change; however, the maximum floor acceleration is not important for the purpose of this study.

From the two studies mentioned above, it was determined that the initial imperfection for this research was $0.5 \%$, which does not significantly affect the result accuracy, but provides the fastest convergence in the nonlinear numerical simulation.

\subsubsection{Number of elements for each brace}

In addition to a proper initial imperfection, it is necessary to subdivide each brace into a sufficient number of elements to successfully capture the buckling behavior of each brace. Terzic (2013) recommends to mesh each brace into 10 to 20 elements in an example structure. A parametric study was done in this thesis to confirm the adequacy of such recommendations. The same model considered in Section 4.3.2 was revisited and 
different numbers of the element and a constant $0.5 \%$ initial imperfection were assigned to the braces.

The first analysis done was nonlinear static analysis to compare the system response. In this analysis the brace was subdivided into 1, 5, 10,15 and 20 elements. An initial imperfection of $0.5 \%$ was assumed in the analyses. As expected, the model with one element per brace did not buckle because no initial imperfection was introduced at the middle of the brace. Both braces reached its yielding limit which means strength reduction due to the buckling of the brace did not occur, hence giving it a larger base shear compared to the other cases. From Figure 4.14 the system base shear responses are identical for the models with 5, 10, 15 and 20 elements per braces.

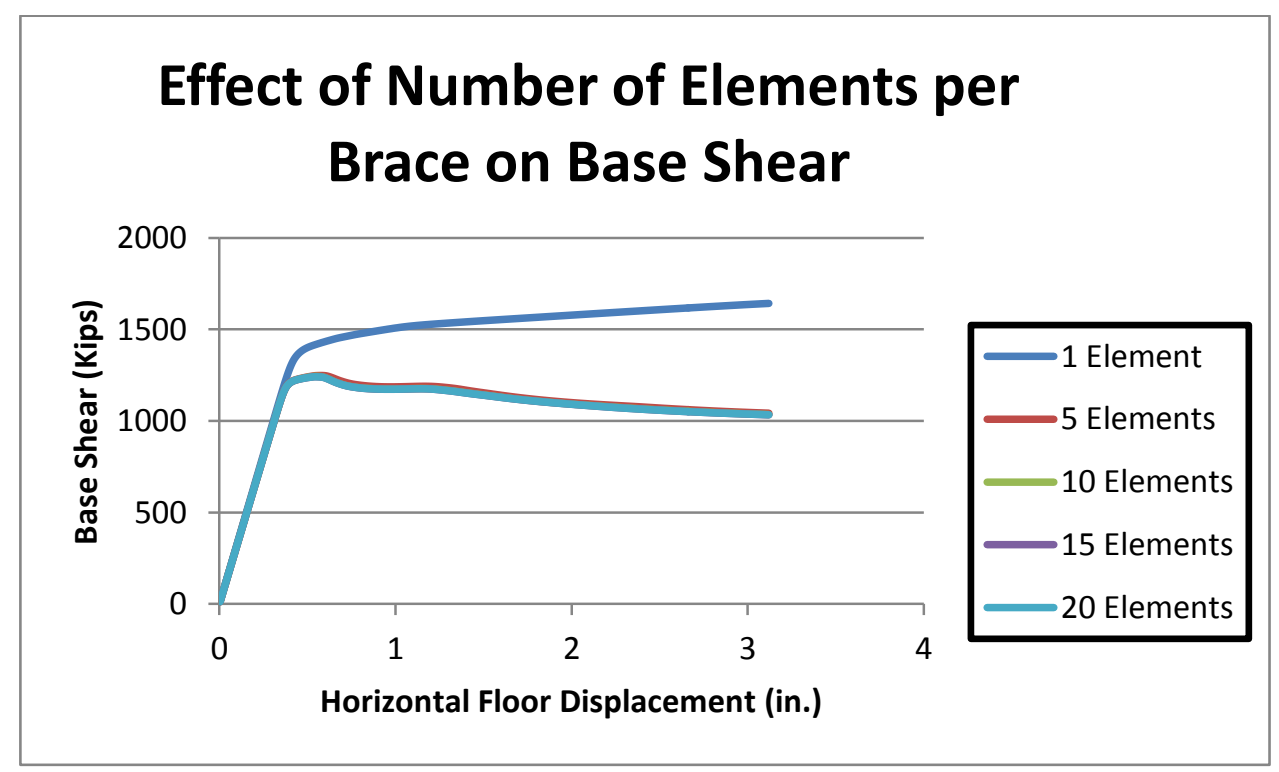

Figure 4.14: Effect of number of elements per brace on system performance (result from nonlinear static analysis)

The second analysis done to investigate the effect of the number of elements per braces was a nonlinear dynamic analysis. The same models were used as the ones used in the brace initial imperfection study but this time the variable was the number of elements per 
brace. Trend of the results were the same as those found in the nonlinear static analysis.

Figure 4.15 shows the displacement response of the systems with different number of elements per brace under the first 10 seconds of the dynamic analysis. As shown, except the case with 1 element used in each brace, the other cases provide very similar results in system displacement response.

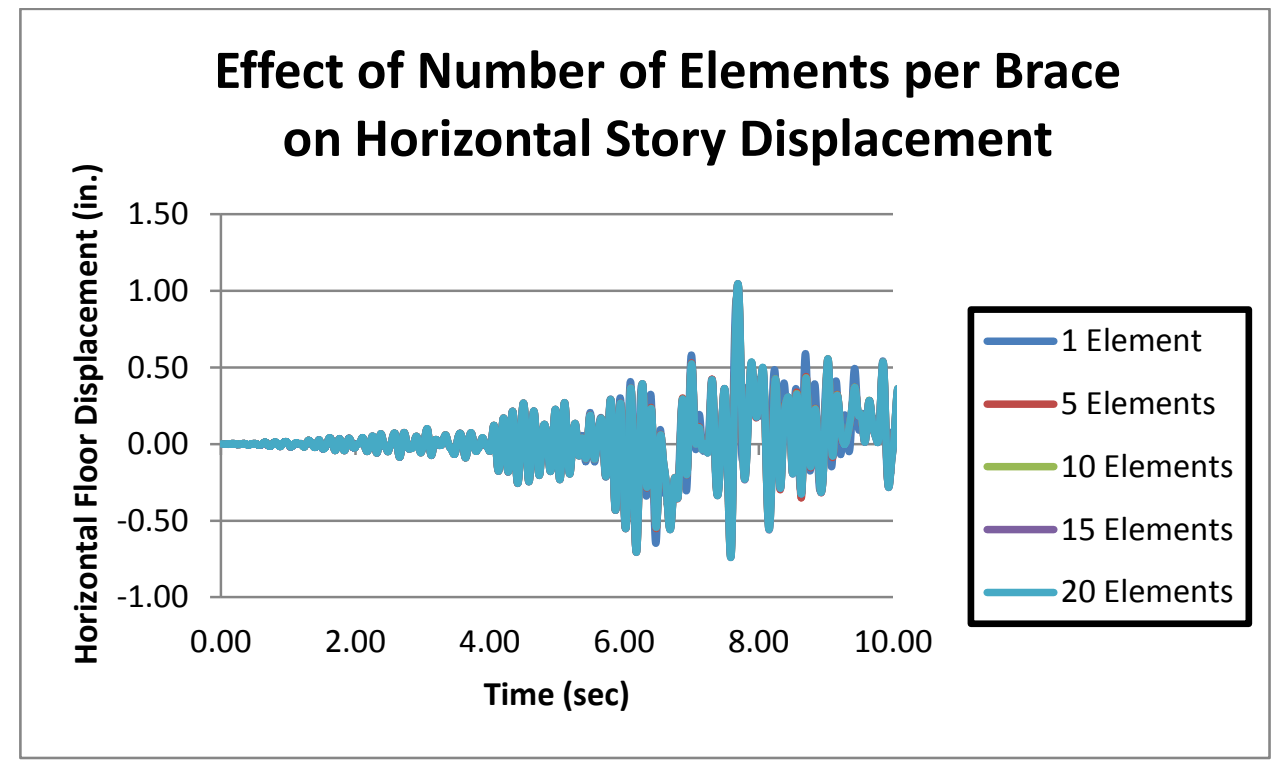

Figure 4.15: Effect of number of elements per brace on system performance (results from nonlinear dynamic analysis)

The maximum story drift was also calculated for each model. From the results, it was concluded that the models with 5,10, 15 and 20 elements per brace had the same maximum story drift with a value of $0.67 \%$ while the model with 1 element per brace had a smaller value of $0.61 \%$. This is due to the fact that the braces did not buckle in the model with 1 element. Figure 4.16 shows the story drift for each case considered. 


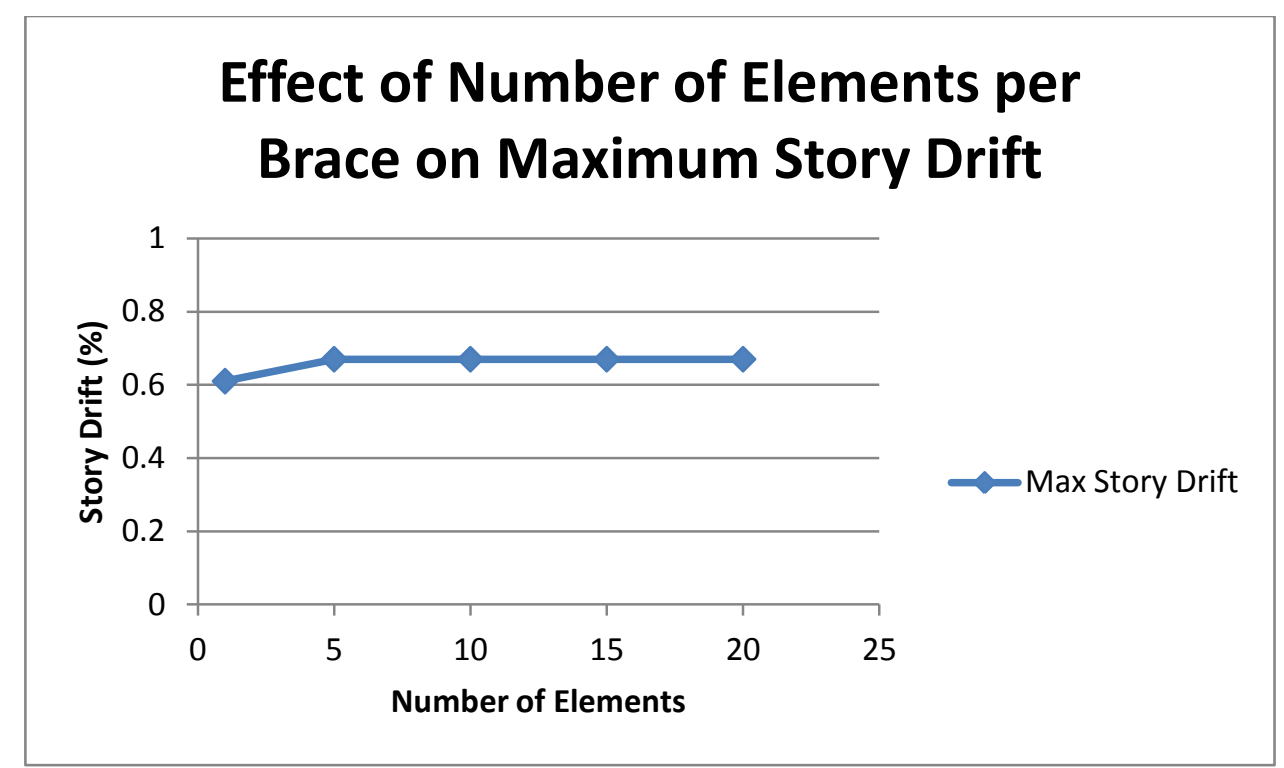

Figure 4.16: Comparison of maximum story drifts due to different numbers of elements in braces

The floor acceleration was also calculated to study the effect of the number of elements per brace. From the results obtained, the floor acceleration for the model with only one element per brace was higher than all the other models. This happened because the brace with only one element did not buckle, making the structure stiffer than the other cases. For all the other models the maximum floor accelerations are very similar. Figure 4.17 shows the change in maximum acceleration as a function of the number of elements per brace. 


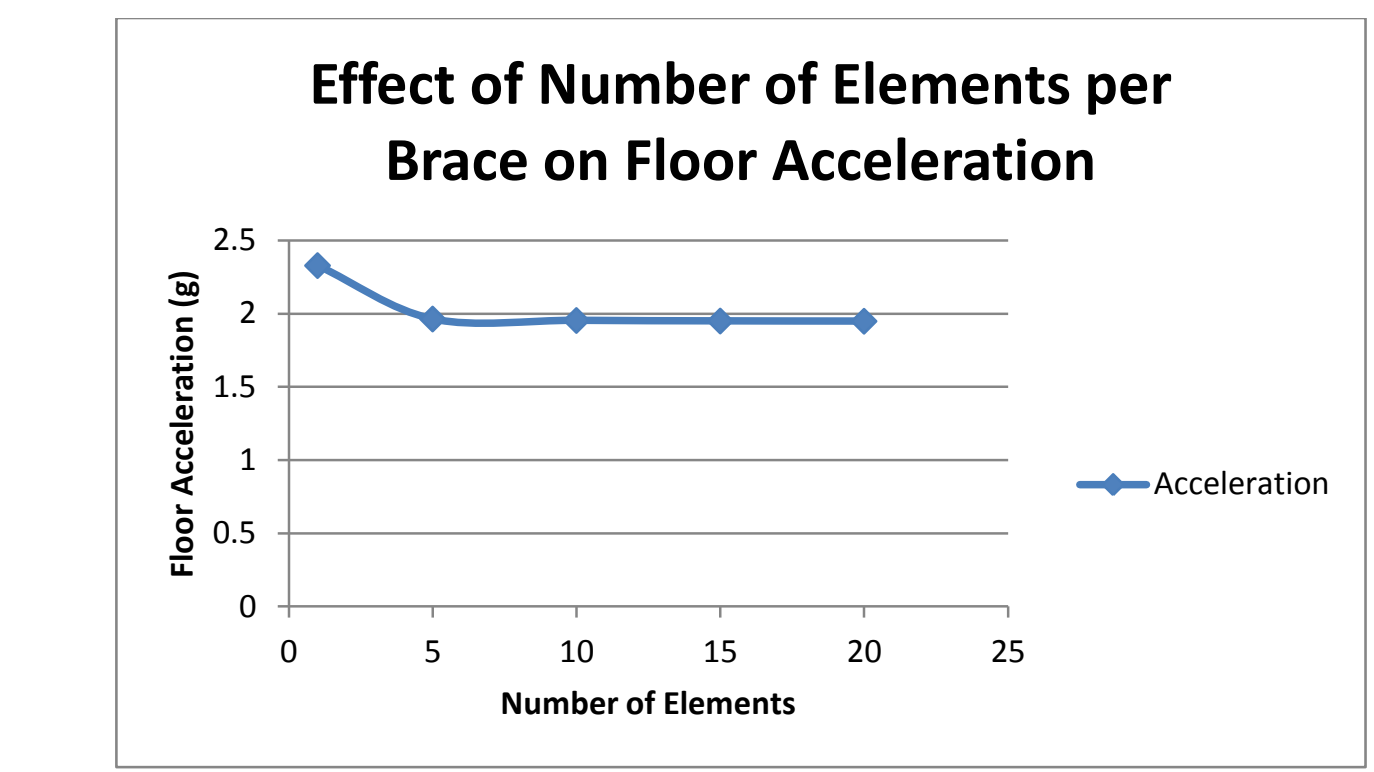

Figure 4.17: Comparison of maximum floor accelerations from models with different numbers of elements per brace

From the two studies mentioned above, it was determine that the adequate number of elements per brace for this research is 15 .

After all the parameters for the braces were determined, the maximum compressional buckling resistance was compared to the theoretical value for the first-story braces in LA3 and LA6, which are HSS 8x8x1/2 and HSS 10x10x1/2 respectively. The maximum compressional axial resistance predicted from OpenSees were 718 kips and 907 kips for HSS $8 \times 8 \times 1 / 2$ and HSS 10x10x1/2, respectively. The maximum compressional axial resistance calculated according to AISC equations (E3-1, E3-2 and E3-4 in AISC 2005) are 768 kips and 975 kips for a HSS 8x8x1/2 and HSS 10x10x1/2, respectively. The AISC predictions were higher than the OpenSees results because the AISC predictions were based on the assumption that the braces boundary conditions were fully fixed at both ends. In the OpenSees models, the braces were connected to the beams and columns through gusset plates which provide less displacement restraining effects compared with 
the ideal fix-fix boundary conditions, thus giving a lower maximum compressional axial resistance for each brace. Figure 4.18 shows the response of the braces in compression during a pushover analysis.

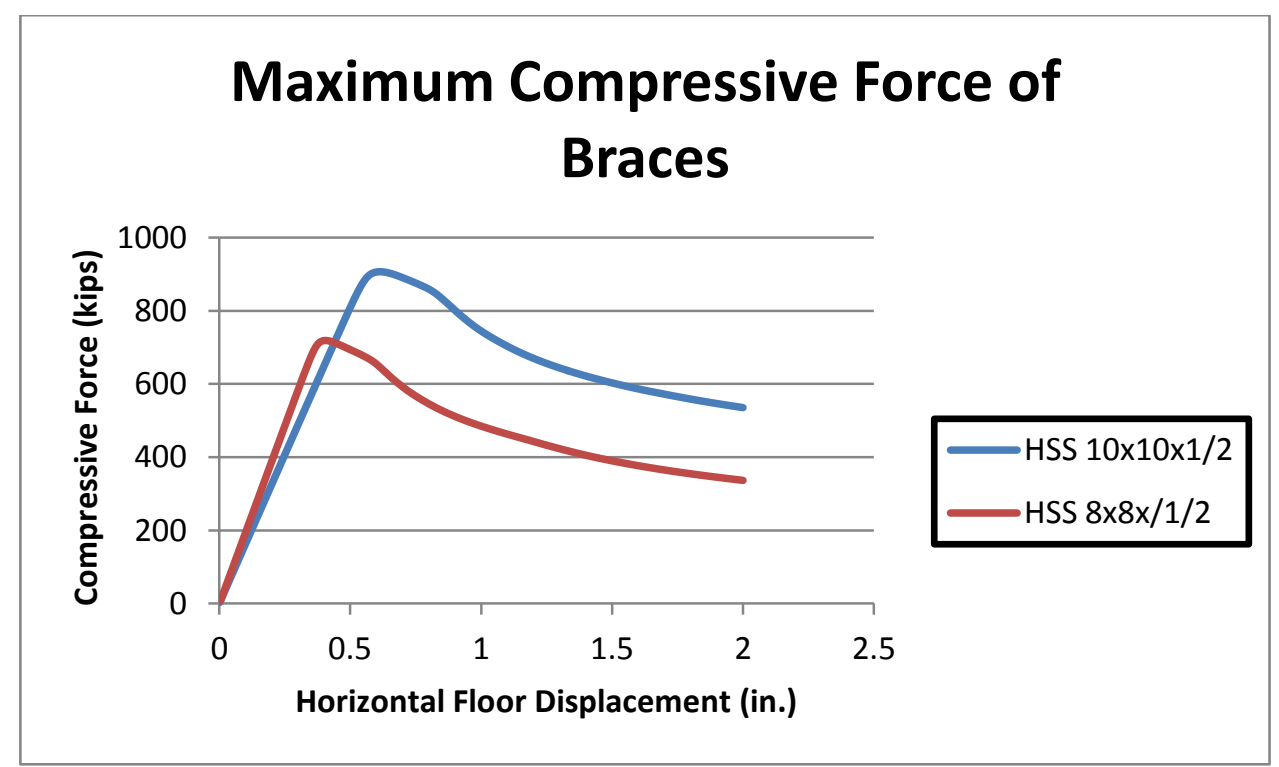

Figure 4.18: Maximum compressive force of bottom-story braces in LA3 and LA6

\subsubsection{Consideration of Low-Cycle Fatigue Damage}

Due to the reversals of large inelastic displacement demand at the middle of each buckled brace during a strong earthquake event, the buckled brace is very susceptible to rupture failure caused by low-cycle fatigue. Uriz and Mahin (2008) recently developed a new material feature in OpenSees that captures the low-cycle fatigue behavior of steel. Parameters required in the material model can be determined from tests and are different for members of different shapes (such as wide-flange and HSS sections). For this study, the parameters for capturing the low-cycle fatigue of HSS braces were selected based on the recommendations by Uriz and Mahin (2008) and Terzic (2013). To observe the effect of low cycle fatigue damage in braces, a case study was done on the bottom-story of LA3 
by subjecting it to a cyclic loading protocol shown in Figure 4.19. Responses of the frame and its each individual brace are compared in Figures 4.20 to 4.22 for models with and without low-cycle fatigue. As shown, when considering low-cycle fatigue, the buckled braces fractured at large deformation levels, resulting in strength and stiffness deteriorations in the system.

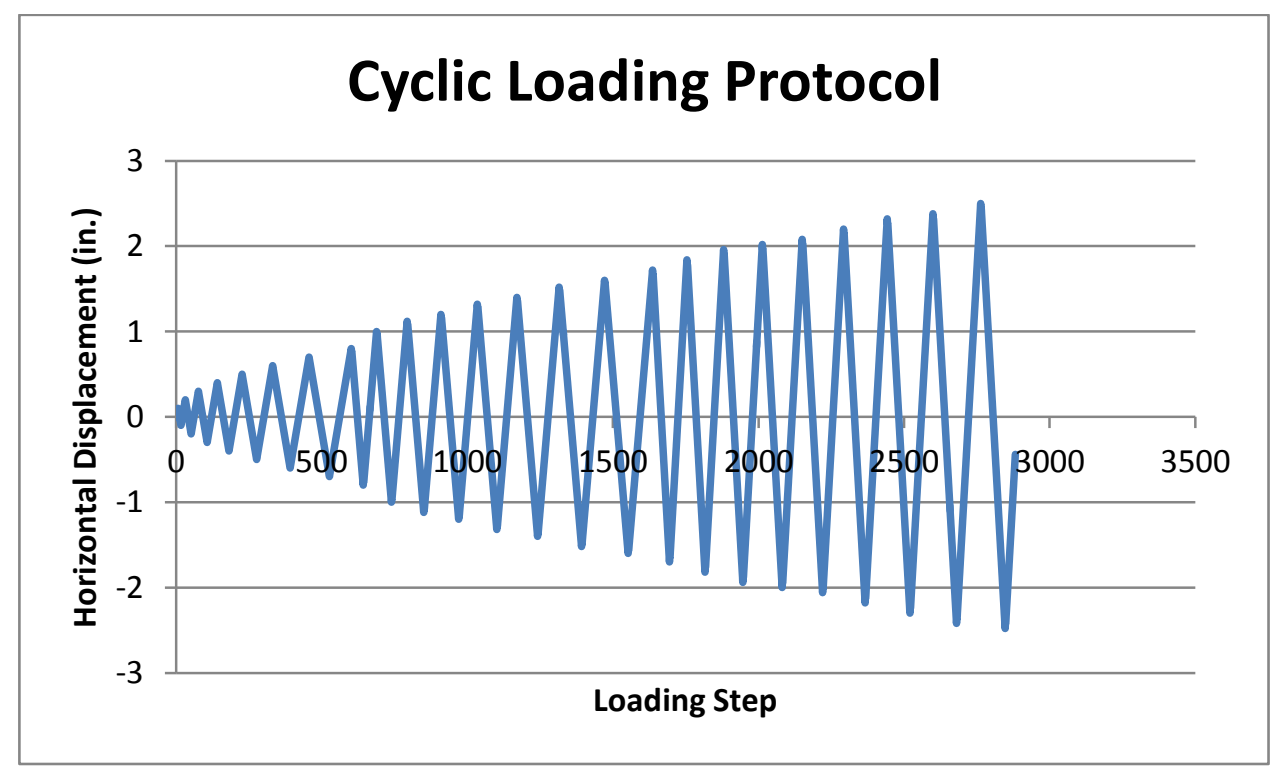

Figure 4.19: Cyclic Loading Protocol

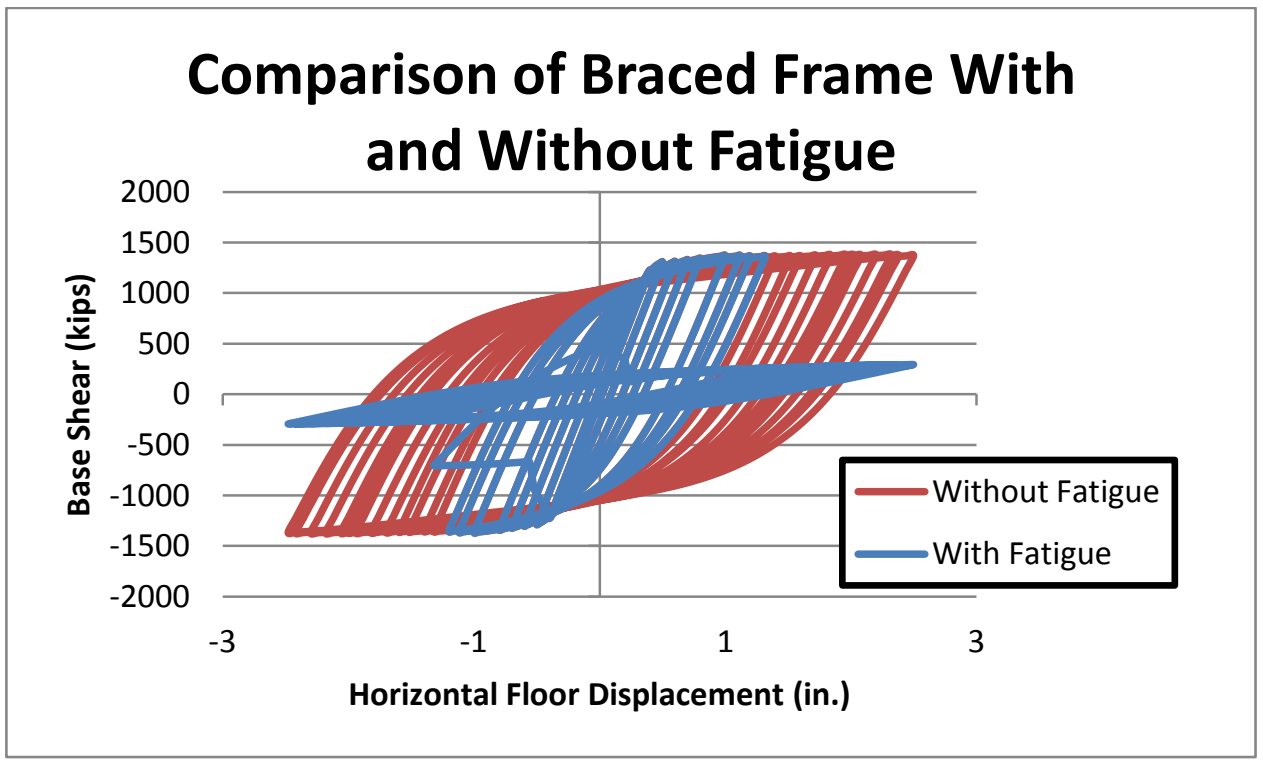

Figure 4.20: Response of braced frame with and without fatigue in nonlinear static analysis 


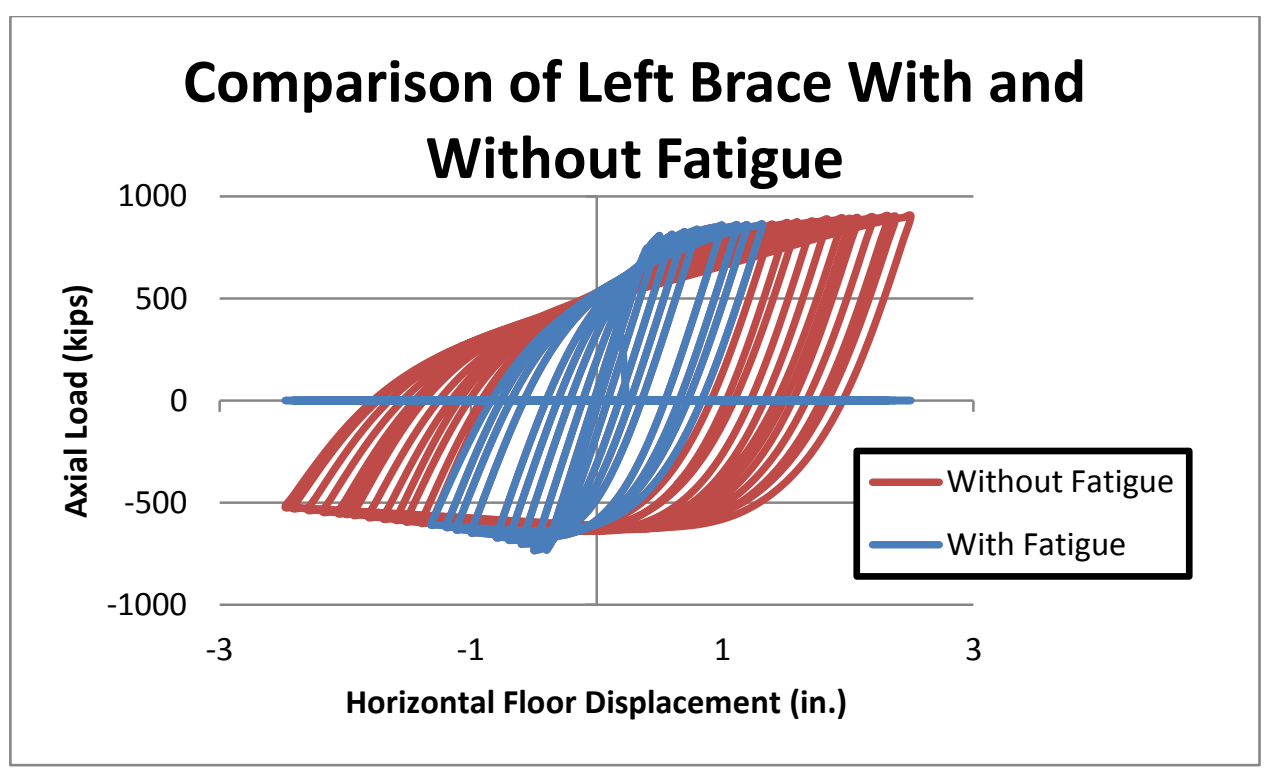

Figure 4.21: Response of left brace with and without fatigue

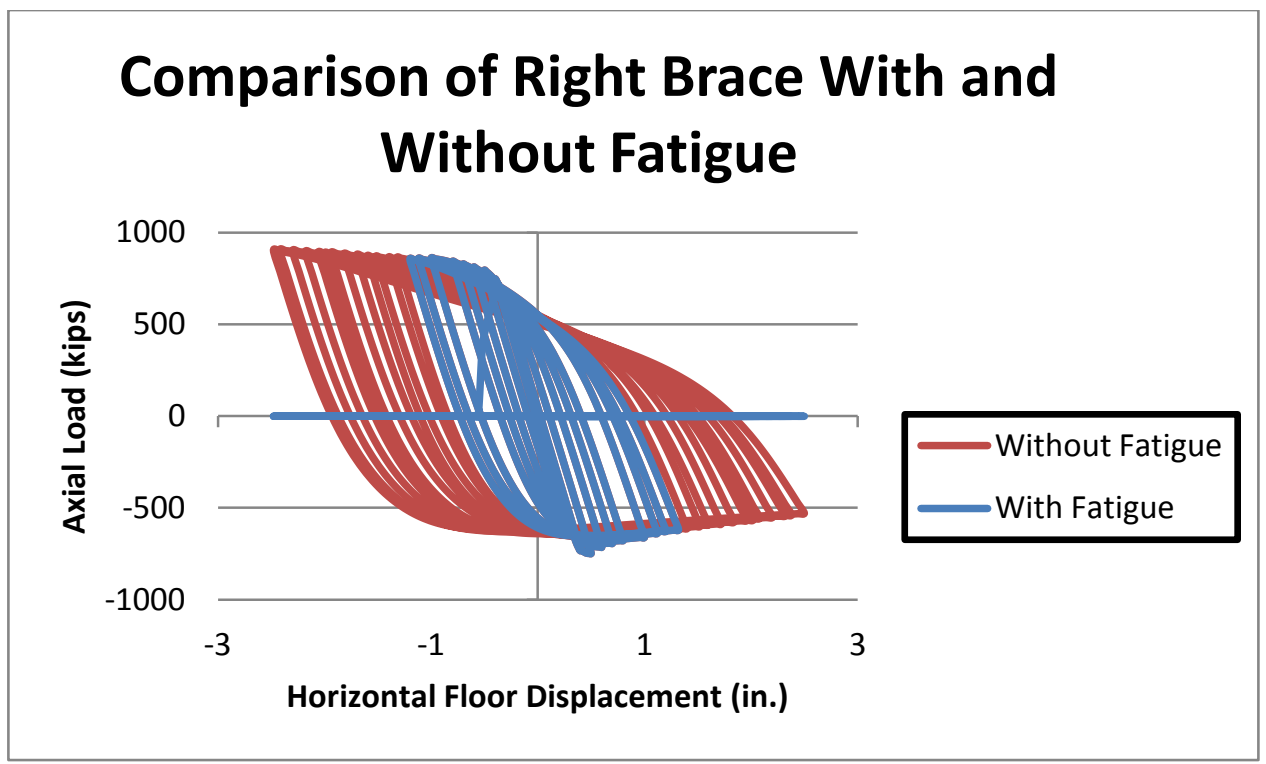

Figure 4.22: Response of right brace with and without fatigue

It is noted that beams and columns in the CBFs investigated in this thesis were also modeled with consideration of low-cycle fatigue. The parameters for capturing low-cycle fatigue of wide-flange beams and columns were also determined based on Uriz and Mahin (2008). However, due to the lower level displacement demands (particularly 
rotation demands) on beams and columns compared with those on buckled brace members, fractures were not observed in the beams and columns in the analysis.

\subsection{Other Techniques to Achieve Numerical convergence}

Ghost members were implemented into the models to achieve better convergence. During the nonlinear response history analysis which will be discussed in detail in Chapters 5 and 6, many braces fracture due to the low-cycle fatigue failure, causing structural discontinuity in the system and thus numerical difficulties in the simulation. For each brace, a ghost member, which consists of a truss element connected to the gusset plates at the ends of the brace, was added. This allows for force transfer through the truss element eliminating convergence problems when brace fracture occurs. The truss element was modeled as an elastic element with an elastic modulus of 29,000 ksi and a small area of $0.5 \mathrm{in}^{2}$. Compared with the actual brace member, the area of the ghost member is very small, avoiding excessive increase in stiffness and strength to the system due to the presence of the ghost member. To observe the effect of adding the ghost elements to the structure a simple study was conducted. The bottom-story of LA3 was subjected to a ground motion (LA01) with and without the ghost elements. The maximum inter-story drift was calculated to be $0.67 \%$ for both cases, which means that the addition of ghost elements does not significantly affect the performance of the structure.

A truss element was also added aligning with each beam to partially consider the effect of concrete slab. The truss elements were assumed to be elastic members with an elastic modulus of 29,000 ksi and a cross-sectional area of 1,000 $\mathrm{in}^{2}$. These members had a very large area due to the fact that the concrete slab is axially rigid. Subjecting the above mentioned one-story structure to the same ground motion, maximum inter-story drift of 
0.67 and $0.64 \%$ was observed from the cases with and without the truss elements, respectively.

\subsection{Modeling of RC}

The RC was assumed to remain elastic during the nonlinear static and dynamic analyses, thus the Opensees elastic beam-column element was used in this thesis. The elastic modulus of the material used for RC was assumed to be $29,000 \mathrm{ksi}$. It was also assumed that the rocking core would remain axially rigid during all analyses and hence a large cross-sectional area of 5,000 in ${ }^{2}$ was used. The moment of inertial of RC was varied to provide different stiffness values in the RC during all analyses. To consider the RC stiffness relative to that of the existing structure, the following stiffness ratio, $a$, is defined.

$$
\alpha=\frac{I_{R C} E}{k_{1} * h_{1}^{3}}
$$

$\mathrm{k}_{1}$ is the stiffness of the bottom-story of a considered structure

$\mathrm{h}_{1}$ is the height of the first story

$\mathrm{E}$ is the elastic modulus of the material used in $\mathrm{RC}$

Rearranging the above equation, the moment of inertia of RC can be calculated below.

$$
I_{R C}=\frac{\alpha * k_{1} * h^{3}}{E}
$$

Different values of $\mathrm{I}_{\mathrm{RC}}$ can be achieved through different values of $a$. Moreover, stiffness of the bottom story, $\mathrm{K}_{1}$, can be obtained from nonlinear static analysis of the considered structures. As a result, $\mathrm{K}_{1}$ was determined to be 3,216 and 2,329 kips/inch for the LA3 
and LA6 models, respectively. Figure 4.23 shows the nonlinear static analysis results at small drift levels in the bottom stories of LA3 and LA6.

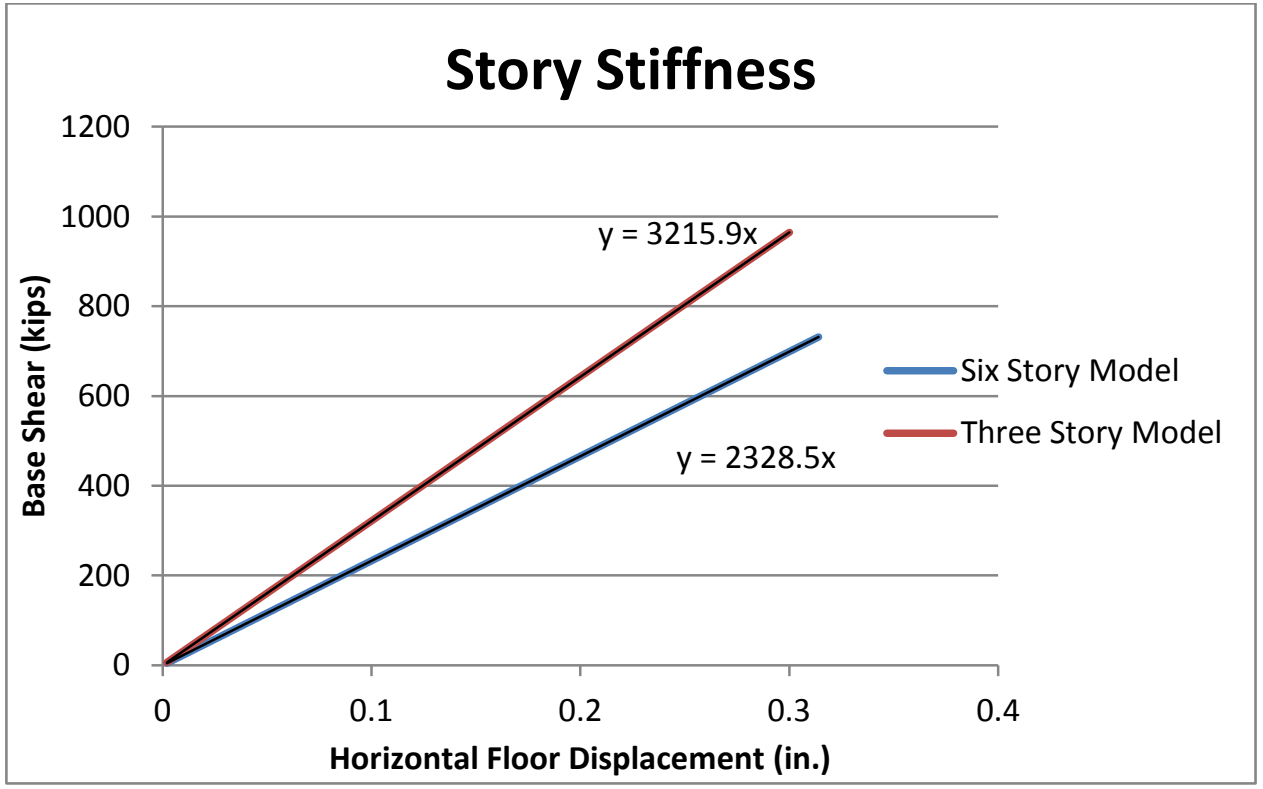

Figure 4.23: Identification of bottom-story stiffness for LA3 and LA6

\subsection{Modeling of Connecting Links}

For model LA3-A and LA6-A links were assumed to be elastic and axially rigid. A truss element with a large area of 1,000 $\mathrm{in}^{2}$ and steel modulus of elasticity of 29,000 ksi were assigned to each link to ensure such properties.

For the links in model LA3-B and LA6-B, the material was modeled using the GiuffréMenegotto-Pinto model. The elastic modulus of 29,000 ksi and yield strength of $50 \mathrm{ksi}$ was used. The links were considered using FBE in OpenSees. Selection of link size is presented in detail in Chapters 5 and 6 for LA3-B and LA6-B, respectively. 


\subsection{Modeling of Gravity Column}

A gravity column was modeled in this study to take into account the P-Delta effect. The column was placed adjacent to the existing structure as presented in Figures 4.1 and 4.2. The gravity load tributary to each braced frame (one-fourth and one-sixth of the entire gravity load for the three- and six-story CBF buildings, respectively) was applied at the gravity column at the corresponding floor levels. As a result, the gravity loads for the three-story CBF building were calculated to be 755 kips for the first and second stories and 709 kips for the third story. For the six-story model, the loads calculated had a value of 443 kips for the roof level and 472 kips for all the other levels.

The gravity column was modeled as elastic, with an elastic modulus of 29,000 ksi and a very low moment of inertia. The moment of inertia had a low value to avoid adding additional stiffness to the existing structure. This value was taken to be $1 \mathrm{in}^{4}$. The gravity column was expected to be axially rigid, thus an area of 5,000 $\mathrm{in}^{2}$ was used.

To observe the effect of the gravity column, the LA3 model was subjected to the 1989 Loma Prieta eartqhauke (station: Gilroy, scaled to have a probability of exceedance of $10 \%$ in 50 years). The maximum inter-story drift without the gravity column was calculated to be $0.84 \%$ and the maximum inter-story drift with the gravity column was $2.84 \%$. For this particular ground motion, the inter-story drift without the gravity column was less than the inter-story drift limit associated with life safety (which is $1.5 \%$ according to FEMA356). When the gravity column was introduced, the inter-story drift exceeded the limit associated with collapse prevention (which is $2 \%$ according to FEMA356). Figure 4.24 shows the displacement histories of the third story with and without the gravity column. 


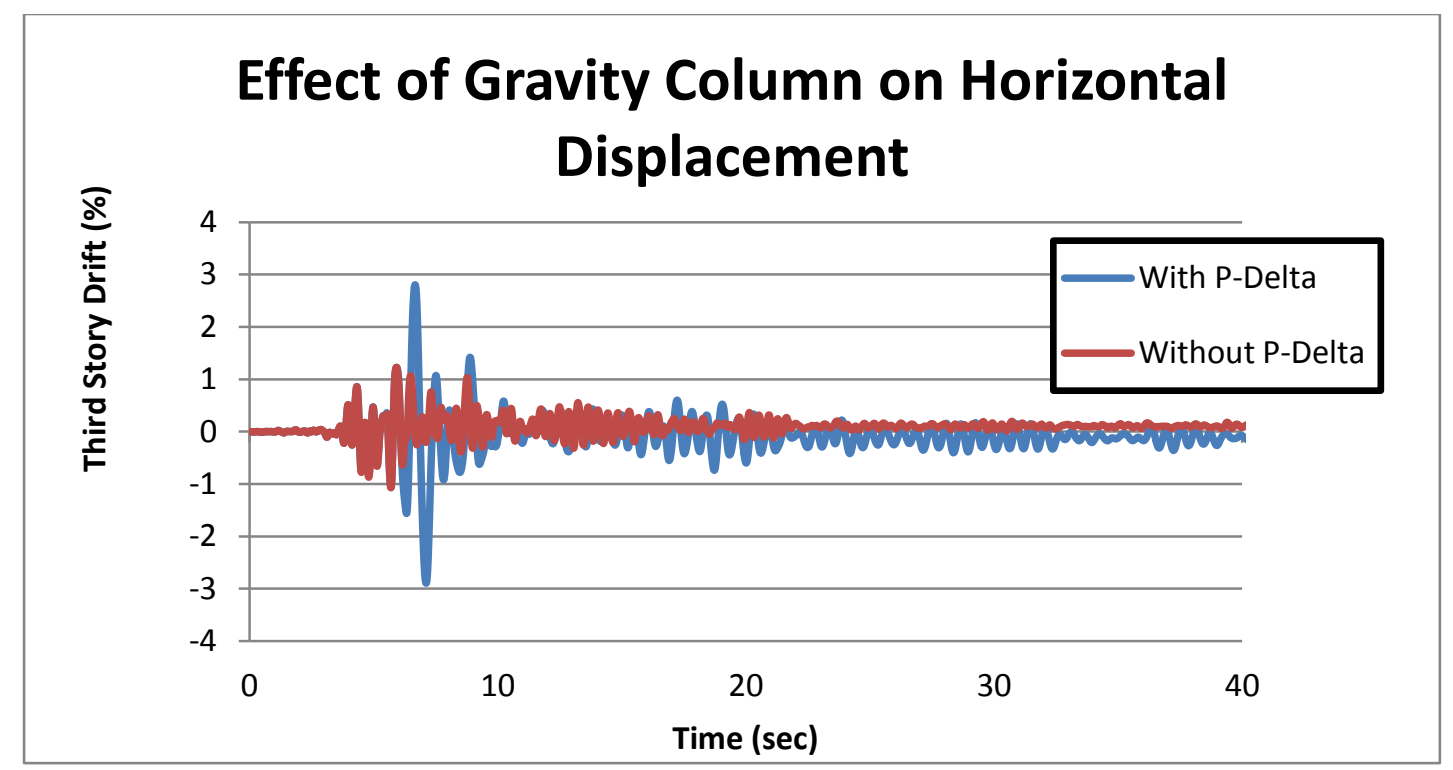

Figure 4.24: Comparison of inter-story drift histories of the third story of LA3 with and without P-Delta effect

Table 4-3 shows the maximum inter-story drifts for each story. The first story had an increase of $0.04 \%$ in inter-story drift while the second story remained the same. The third story, which is the soft story, was most affected with an increase of $2 \%$ in interstory drift. From the results obtained it was important to model the P-Delta effect to obtained more accurate results.

Table 4-3: Maximum inter-story drifts with and without P-Delta effect

\begin{tabular}{|c|c|c|}
\hline Level & $\begin{array}{c}\text { Max Drift without P-Delta } \\
\text { effect } \\
\%\end{array}$ & $\begin{array}{c}\text { Max Drift with P-Delta effect } \\
\%\end{array}$ \\
\hline First Story & 0.31 & 0.35 \\
\hline Second Story & 0.28 & 0.28 \\
\hline Third Story & 0.84 & 2.84 \\
\hline
\end{tabular}

\subsection{Validation of FE Models}

The FE models of LA3 and LA6, which were developed according to the assumptions and parameters described in the prior sections, were validated through comparison of 
fundamental periods with the published results. As discussed earlier, the previous research on LA3 and LA6 assumed pinned connections at the ends of each brace. Such models neglect the effect of gusset plates in providing extra rotational restraint for brace and/or rigid zone for beams and columns. Therefore, periods from the following two cases were both output for validation purpose: 1) the FBEs and rigid zones shown in Figure 4.8 for modeling of gusset plates were excluded and the pinned boundary conditions were assigned to the ends of each brace; and 2) the FBEs and rigid zones shown in Figure 4.8 were included at the brace ends for consideration of gusset plates.

Based on the seismic masses discussed in Chapter 3, the reactive masses was 1.678 kip$\mathrm{s}^{2} /$ in and $1.16 \mathrm{kip}-\mathrm{s}^{2} /$ in per floor per brace for the three- and six-story buildings, respectively. Table 4-4 shows the fundamental periods of the structures with and without consideration of gusset plates together with the published values.

Table 4-4: Fundamental period comparison

\begin{tabular}{|c|c|c|c|c|}
\hline \multirow{2}{*}{ Model } & \multicolumn{4}{|c|}{ Fundamental Period (sec) } \\
\cline { 2 - 5 } & $\begin{array}{c}\text { Uriz and } \\
\text { Mahin } \\
(2008)\end{array}$ & $\begin{array}{c}\text { McCormick et al. } \\
(2007)\end{array}$ & $\begin{array}{c}\text { Without } \\
\text { consideration of } \\
\text { gusset plates }\end{array}$ & $\begin{array}{c}\text { With } \\
\text { consideration of } \\
\text { gusset plates }\end{array}$ \\
\hline LA3 & 0.46 & 0.46 & 0.48 & 0.37 \\
\hline LA6 & 0.74 & 0.74 & 0.75 & 0.67 \\
\hline
\end{tabular}

As shown in Table 4-4, the developed models predict periods very similar to the published results if the gusset plate effects would be neglected in the models, indicating the adequacy of the models. The periods from the models which explicitly model the gusset plates are shorter than those with consideration of gusset plates. This is consistent with the fact that the FBEs and rigid zones added for consideration of gusset plates tend to increase stiffness of the structures. 
Based on the models with consideration of gusset plates, Figures 4.25 and 4.26 further illustrate the mode shapes of the first three vibration models for LA3 and LA6, respectively. Moreover, Table 4-5 presents periods of the first three periods of the considered buildings.

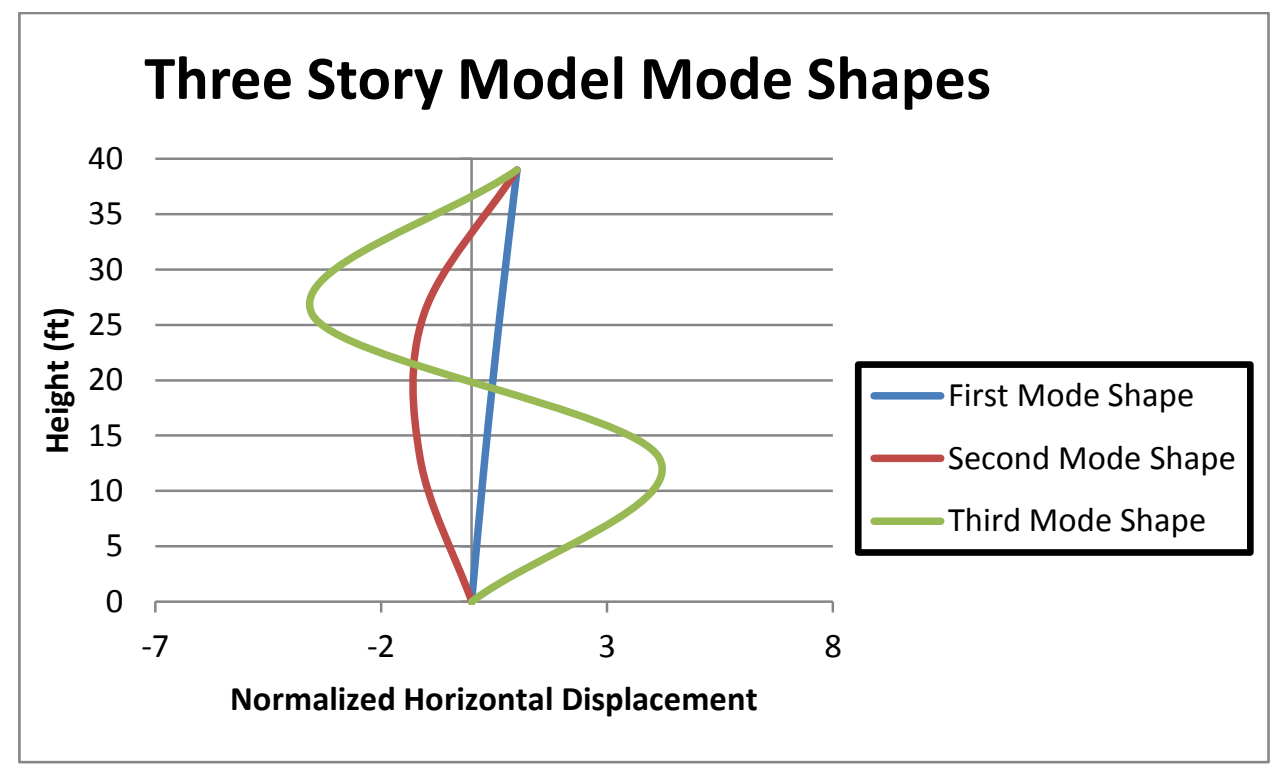

Figure 4.25: Mode shapes for LA3

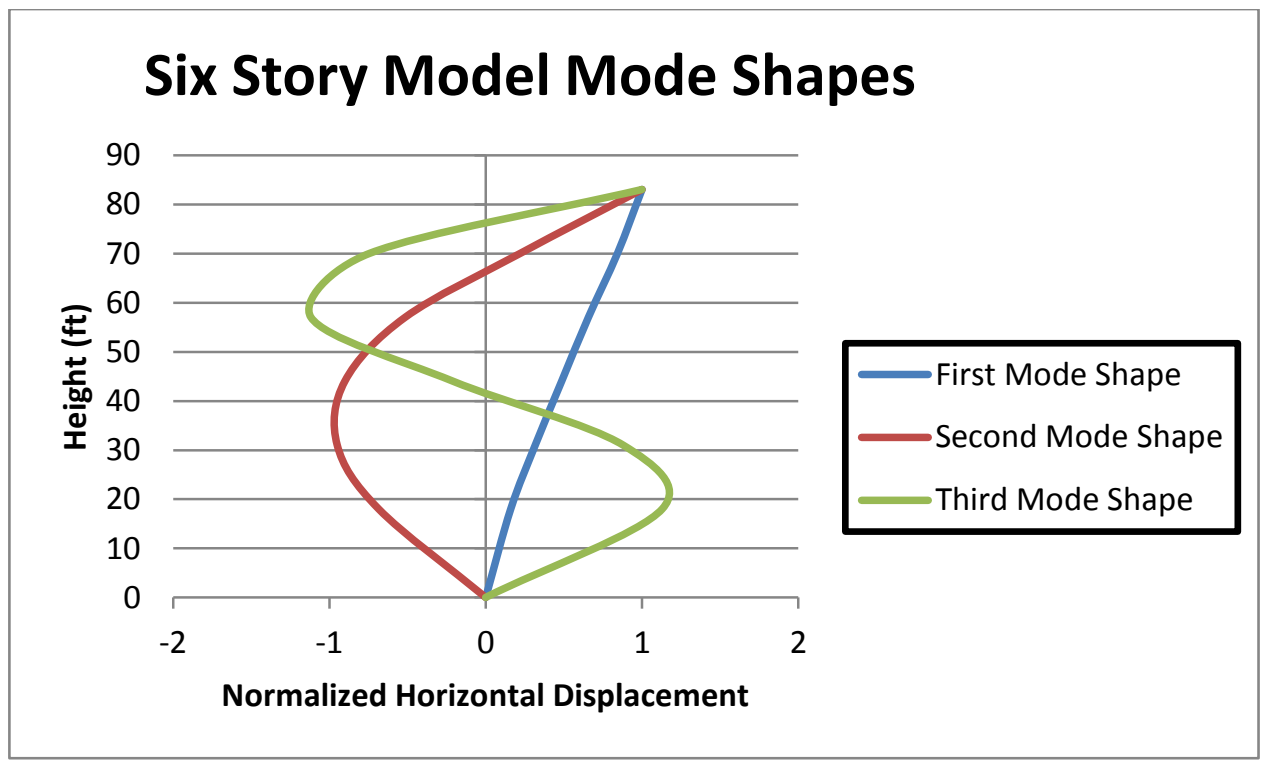

Figure 4.26: Mode shapes for LA6 
Table 4-5: First, second and third mode periods

\begin{tabular}{|c|c|c|}
\hline Mode & LA3 Model $(\mathrm{sec})$ & LA6 Model $(\mathrm{sec})$ \\
\hline $1^{\text {st }}$ & 0.37 & 0.67 \\
\hline $2^{\text {nd }}$ & 0.15 & 0.23 \\
\hline $3^{\text {rd }}$ & 0.09 & 0.13 \\
\hline
\end{tabular}




\subsection{Seismic Performance Evaluation of Three-Story Building}

\subsection{Impact of RC on Modal Properties}

Eigenvalue analyses were first conducted to evaluate the effect of RC on modal properties of the retrofitted system. For comparison purpose, three $\alpha$ values, 0.007 , 0.0768 and 1, which correspond to RCs with low, moderate, and high stiffness values, were compared here. Based on Eq.4.2, the corresponding RC moments of inertia are approximately 1,300, 31,000 and 420,000 in ${ }^{4}$,respectively. As mentioned in Chapter 4, the links connecting $\mathrm{RC}$ to the existing frame may be used to absorb hysteretic energy (when the links are pinned to existing frame but fixed to RC). Therefore, two models, denoted as LA3-A and LA3-B, which correspond to the systems consisting of links with and without energy dissipation capacity are considered here.

Table 5-1 shows the periods of LA3-A from eigenvalue analyses. It is found that the fundamental period of LA3-A remains at 0.37 seconds regardless of the $\mathrm{RC}$ stiffness. The fundamental period of LA3-A is very similar to LA3, i.e., the original building without $\mathrm{RC}$. This indicates that the RC in LA3-A, although redistributes story shear and interstory drift distribution along the height of the building, does not attract excessive earthquake induced base shear in the system. Different from the first mode, periods of LA3-A associated with the second and third modes tend to be shorter when a RC with larger stiffness is used in the system. Figures 5.1 to 5.3 further compares the mode shapes of LA3-A consisting of RC with different stiffness values. 
Table 5-1: Comparison of Periods from LA3-A models with different RC stiffness values

\begin{tabular}{|c|c|c|c|}
\hline \multirow{2}{*}{$\alpha$} & \multicolumn{3}{|c|}{ Period (Sec) } \\
\cline { 2 - 4 } & First Mode & Second Mode & Third Mode \\
\hline 0.007 & 0.37 & 0.15 & 0.09 \\
\hline 0.0768 & 0.37 & 0.14 & 0.07 \\
\hline 1 & 0.37 & 0.09 & 0.03 \\
\hline
\end{tabular}

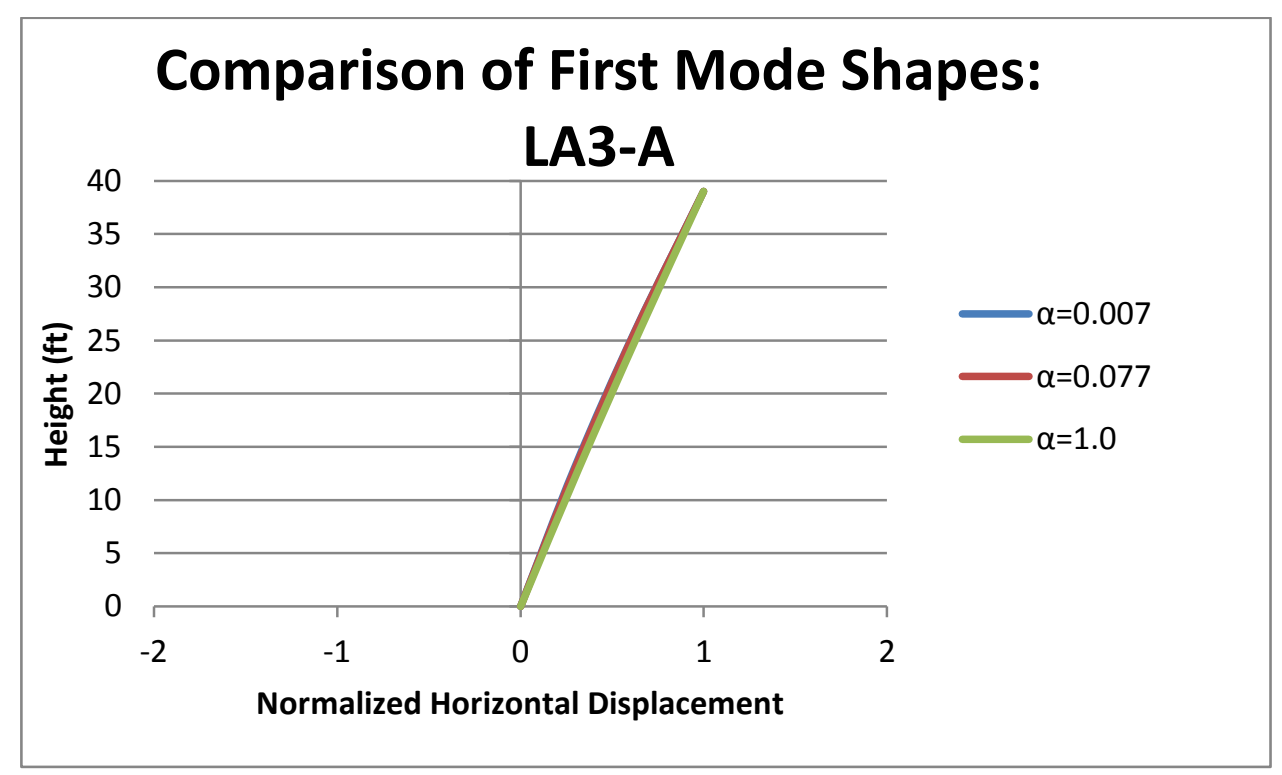

Figure 5.1: Comparison of first mode shape of LA3-A models with different RC stiffness values 


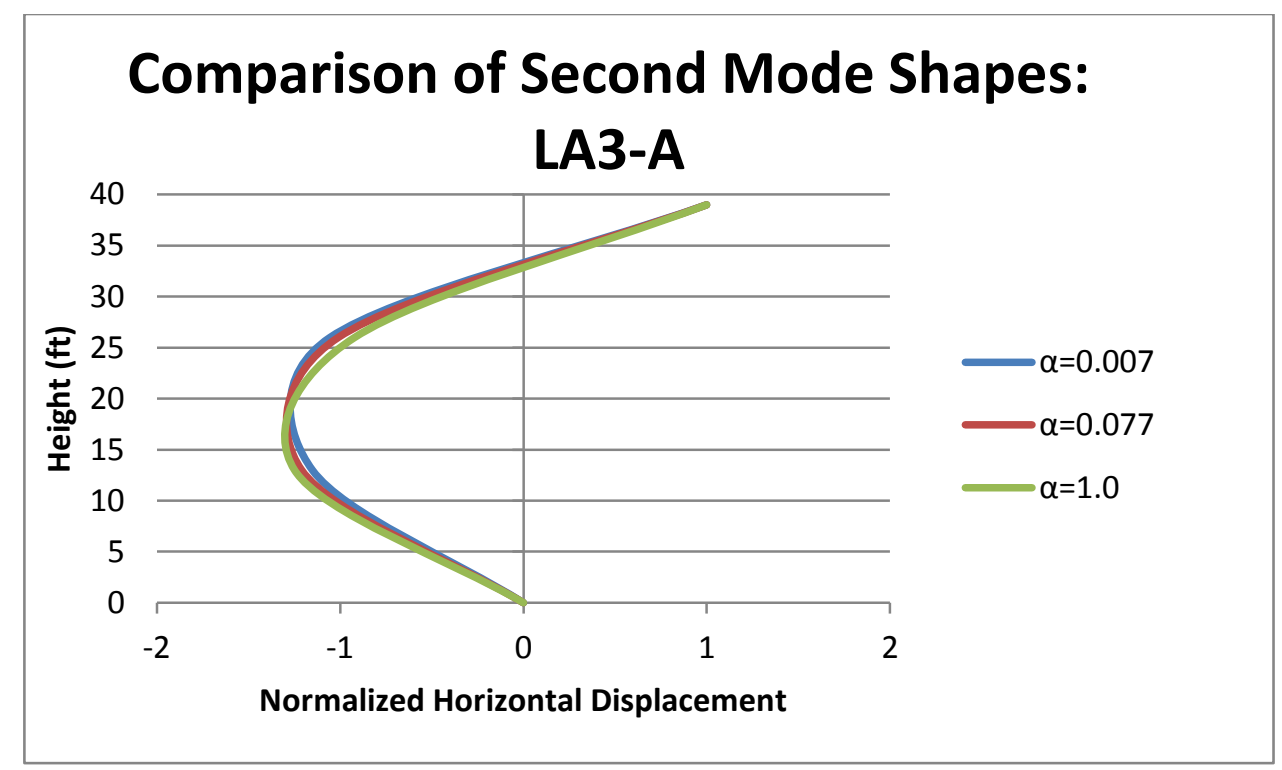

Figure 5.2: Comparison of second mode shape of LA3-A models with different RC stiffness values

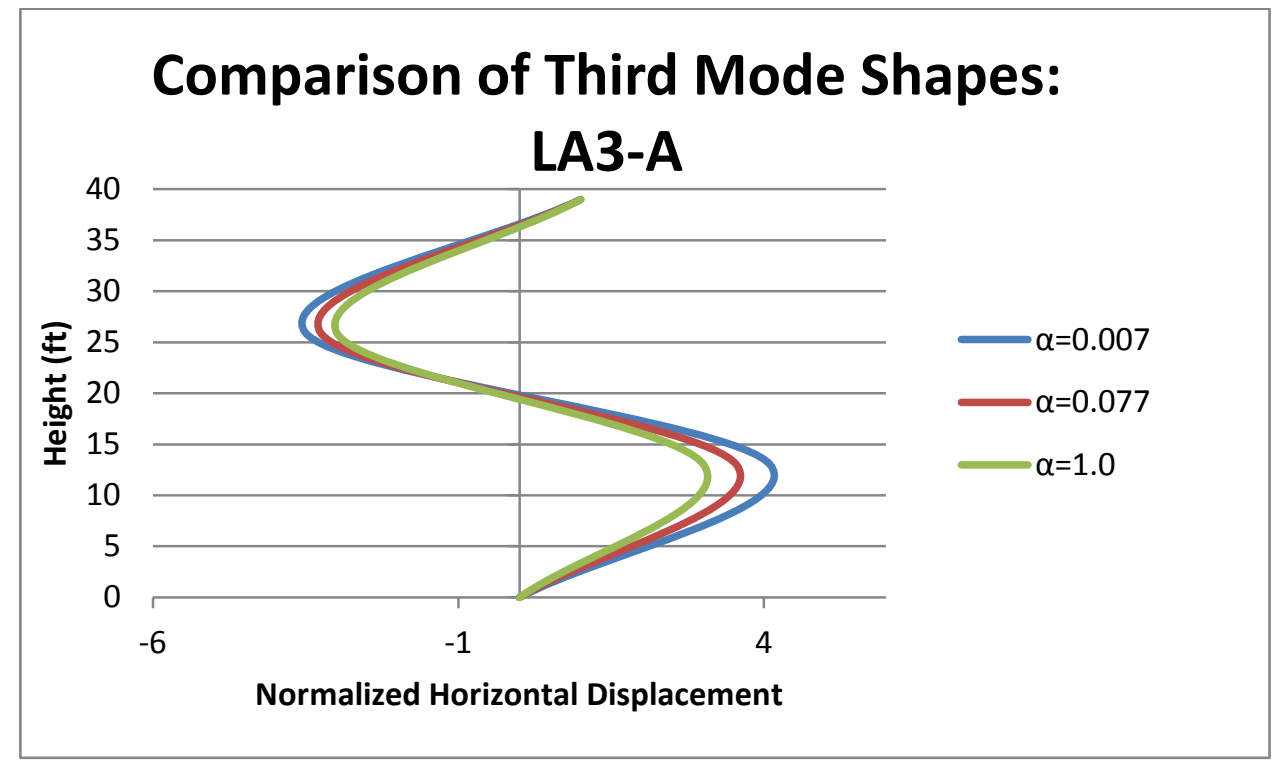

Figure 5.3: Comparison of third mode shape of LA3-A models with different RC stiffness values

In LA3-B,two 5 ft-long links consisting of W30x99 are assumed at all levels. Table 5-2 shows the periods of LA3-B from eigenvalue analyses. It was found that periods of LA3$\mathrm{B}$, although tend to be shorter when a RC with larger stiffness is used, are very similar to the corresponding results from LA3-A. This indicates that the links can contribute to the 
system hysteretic energy dissipation capacity but will not attract significant extra seismic forces. Figures 5.4 to 5.6 further compares the mode shapes of LA3-B when the RC is assigned different stiffness values. As shown, the difference in mode shapes is negligible among all considered cases.

Table 5-2: Comparison of Periods from LA3-B models with different RC stiffness values

\begin{tabular}{|c|c|c|c|}
\hline \multirow{2}{*}{$\alpha$} & \multicolumn{3}{|c|}{ Period (Sec) } \\
\cline { 2 - 4 } & First Mode & Second Mode & Third Mode \\
\hline 0.007 & 0.36 & 0.14 & 0.09 \\
\hline 0.0768 & 0.34 & 0.13 & 0.07 \\
\hline 1 & 0.34 & 0.09 & 0.05 \\
\hline
\end{tabular}

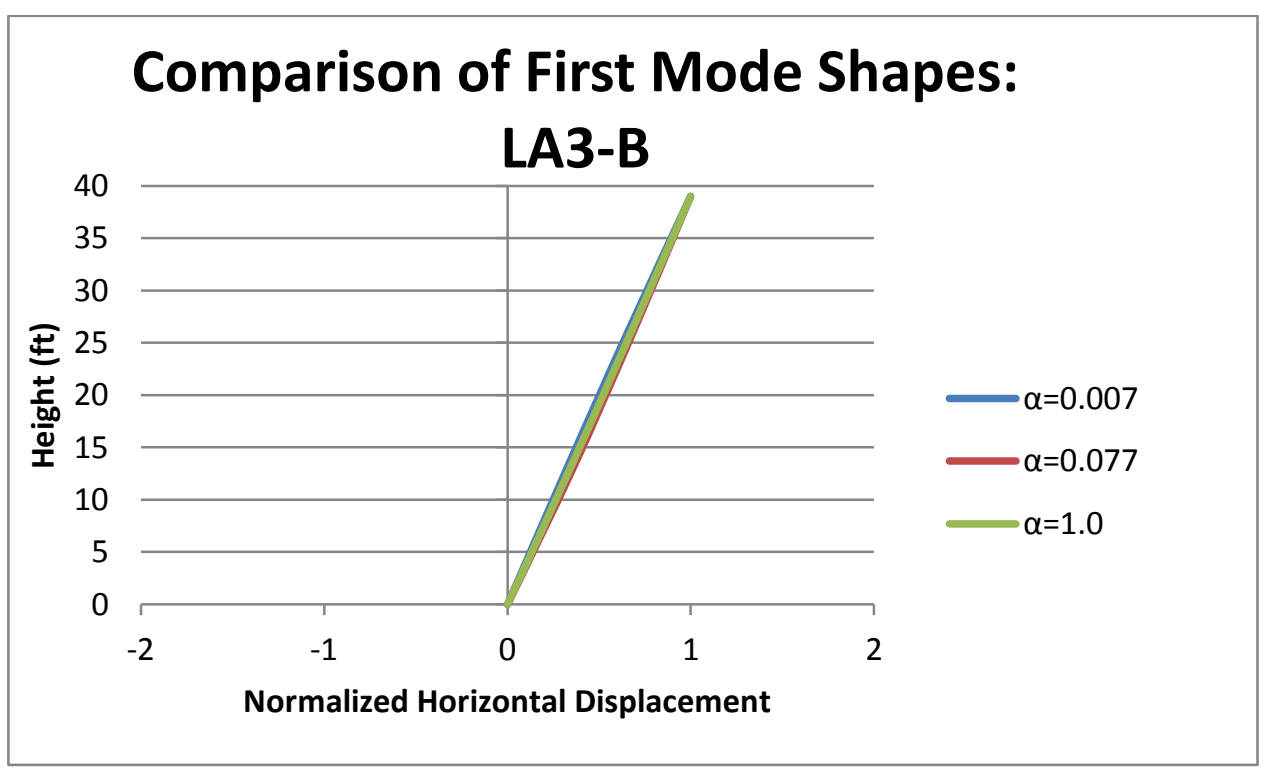

Figure 5.4: Comparison of first mode shape of LA3-B models with different RC stiffness values 


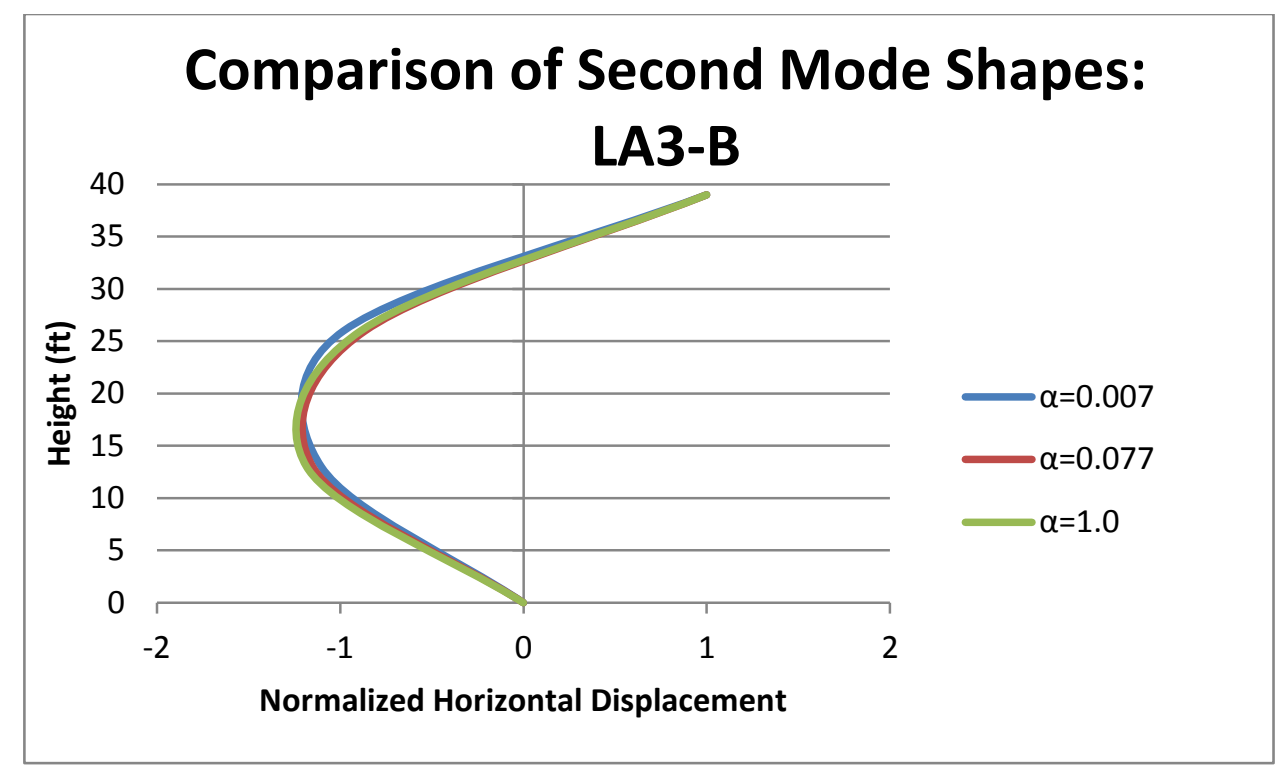

Figure 5.5: Comparison of second mode shape of LA3-B models with different RC stiffness values

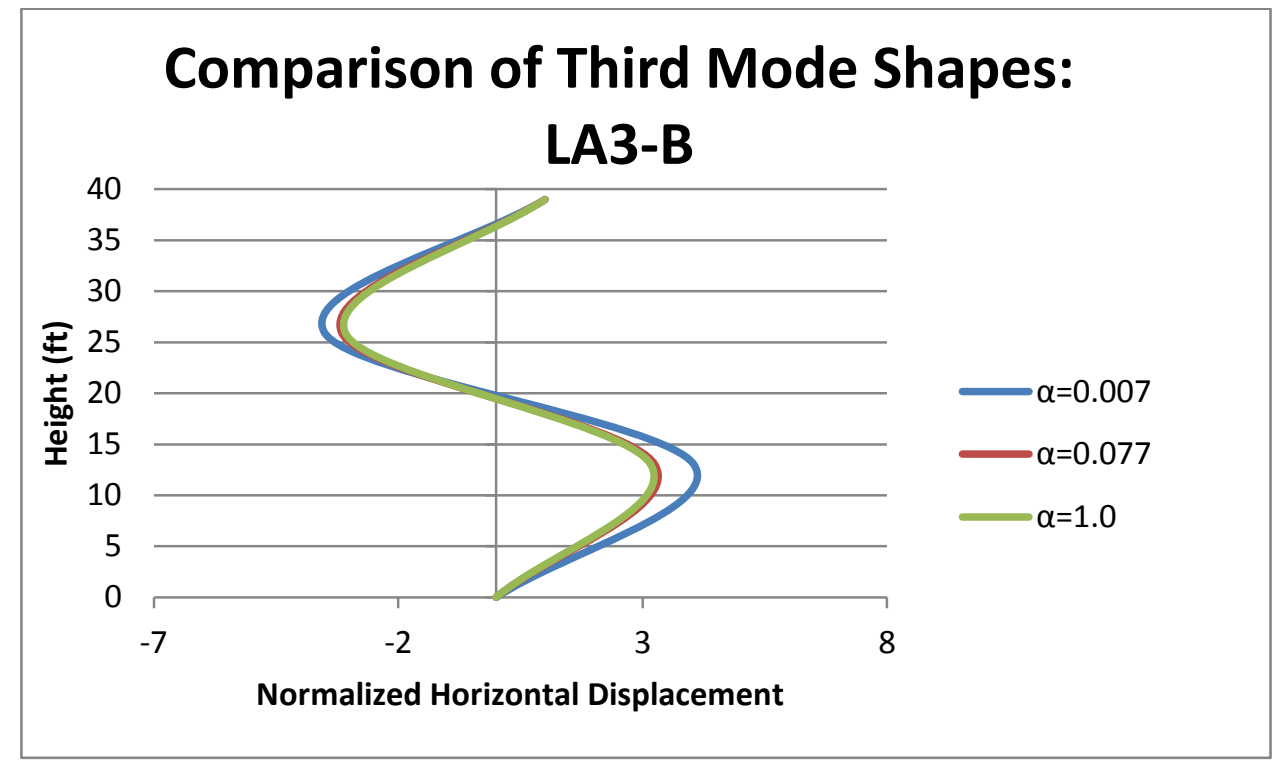

Figure 5.6: Comparison of third mode shape of LA3-B models with different RC stiffness values

\subsection{Nonlinear Static Pushover Analysis}

Nonlinear static pushover analyses are conducted in this section to investigate the contribution of RC on mitigation of soft-story failure in the 3-story CBF building. Given that nonlinear static pushover analysis cannot take into account hysteretic energy 
dissipation in the system, only LA3-A is considered here. To better understand the beneficial contribution of stiffer RC in mitigating drift concentration and hence avoiding soft-story failure, the stiffness ratio of $\mathrm{RC}, \alpha$, was increased from very small to very large during the analysis. As indicated by the results presented later, location of the soft-story failure depends on seismic force distribution along the height of the structure and it is necessary to consider different seismic force distributions in the analyses. As such, the Monte-Carlo simulation technique was used to consider the uncertainty in vertical seismic force distribution. The following sections present generation of lateral force distributions, determination of target displacements, response quantities of interest, and discussion of the analysis results.

\subsubsection{Random Seismic Force Distribution}

In a given structure, the lateral force distribution is an important parameter affecting the yielding progression and drift distribution. Typically, the lateral force distribution is estimated based on the assumed mass and stiffness distributions in the considered structure. However, due to the following effects: 1) redistribution of live masses; 2) strength and stiffness degradations caused by brace yielding, buckling and fracture; and 3) unexpected and non-uniform overstrength distribution in the system, the actual lateral force distribution during an earthquake may be quite different from that assumed in design . Therefore, there is a need to verify if the proposed retrofit strategy can successfully redistribute the inter-story drift and story shear along the height of a building when the lateral force distribution is varying within a practical range. 
In this investigation, the effect of varying seismic force distribution was considered using the Monte-Carlo simulation technique. Specifically, the seismic mass at each floor was randomly sampled around its nominal value such that the selected value is not greater than $150 \%$ of the masses of its adjacent floors. It is noted that this sampling criterion will produce random reactive mass distributions along the height of the building; but will not introduce any mass irregularities per ASCE 7-05 (ASCE 2005). A total of 500 mass distributions were generated for each considered stiffness ratio, $\alpha$. The generated mass distributions are converted to lateral force distributions based on the following equation provided in ASCE 7-05 (ASCE 2005):

$$
C_{v x}=\frac{w_{x} * h_{x}^{k}}{\sum_{i=1}^{n}\left(w_{i} * h_{i}^{k}\right)}
$$

where:

$\mathrm{w}_{\mathrm{x}}$ and $\mathrm{w}_{\mathrm{i}}=$ the portion of the total effective seismic weight of the structure $(\mathrm{W})$ located or assigned to Level $i$ or $x$

$h x$ and $h_{i}=$ normalized height from base to Level $i$ or $x$

$\mathrm{k}=$ an exponent related to the period of the structure

\subsubsection{Target Inter-story Drifts}

With the random seismic force distributions, the nonlinear static analyses were conducted. Slightly different from a conventional nonlinear static pushover analysis, which concludes when the roof reaches the predetermined target displacement; the analyses conducted in this investigation conclude when the maximum inter-story drift in the system reaches the inter-story drift limits associated with the performance objectives of immediate occupancy, life safety, and collapse prevention. As recommended by 
FEMA356 (FEMA 2000), the inter-story drifts associated with immediate occupancy, life safety and collapse prevention performance objectives for steel concentrically braced frames are 0.5, 1.5 and 2.0\%, respectively. According to FEMA 356 (FEMA 2000), a drift of $0.5 \%$ corresponds to negligible yielding and buckling of the braces; a drift of $1.5 \%$ corresponds to several braces yielding and buckling but not failing completely while some connections may fail completely; and under a drift of $2.0 \%$ many braces yield and buckle failing completely along with their connections.

\subsubsection{Responses Quantities of Interest}

The response quantities investigated in this project include moment and shear demands on RC, axial load demand on the link members connecting RC to existing frames; and more importantly, uniformity of inter-story drift distribution in the system. To quantify uniformity of the inter-story drift distributions, the following Drift Concentration Factor (DCF) is defined for each story:

$$
\mathrm{DCF}_{\mathrm{i}}=\left.\frac{\delta_{\mathrm{i}} / h_{\mathrm{si}}}{\Delta_{\text {roof }} / H}\right|_{\max \left(\delta_{1} / \mathrm{h}_{\mathrm{s} 1} \cdots \delta_{\mathrm{n}} / \mathrm{h}_{\mathrm{sn}}\right)=\text { target inter-story drift }}
$$

where $\mathrm{DCF}_{\mathrm{i}}=$ drift concentration factor of the $i^{\text {th }}$ story;

$$
\begin{aligned}
& \delta_{i}=\text { inter-story displacement of the } i^{\text {th }} \text { story } \\
& h_{s i}=\text { height of the } i^{\text {th }} \text { story } \\
& \Delta_{\text {roof }}=\text { roof displacement relative to foundation } \\
& H=\text { height of the building }
\end{aligned}
$$


Based on the definition, if the structure develops ideally uniform drift distribution under seismic forces, i.e., the structure remains straight when deflecting; DCF of any story is equal to 1.0. Additionally, DCF of a soft-story is greater than 1.0 whereas that of a "strong-story" is smaller than 1.0.

\subsubsection{Result Discussion}

During the nonlinear static pushover analyses, the stiffness ratio, $\alpha$, was varied from 0.007 to 2 creating the $\mathrm{RC}$ from extremely flexible to sufficiently rigid. A total of 30 values of $\alpha$ were considered. At each considered $\alpha$ value, a total of 500 sampled lateral force distributions were used in the nonlinear static analyses. The response quantities of interest were output when the maximum inter-story drift reaches the expected limits associated with immediate occupancy, life safety, and collapse prevention performance objectives. As a result, a total of 45,000 nonlinear static analyses were conducted for LA3-A.

\subsubsection{Discussion on DCF}

In the nonlinear static pushover analyses, it was observed that the soft story forms at either the first or third stories depending on the lateral load distribution. Based on the definition, the upper bound of DCF for LA3-A should be 3.0, which corresponds to the worst scenario for inter-story drift distribution, i.e., all the deformation concentrates in the soft story. On the other hand, when the system achieves the perfect sway mechanism, DCF at all stories should be the same and equal to 1.0.

Figure 5.7 shows the DCF results when collapse prevention is used as the performance objective. As shown, the building either experiences a soft-story failure in the first or 
third story levels. When a very flexible RC is used (i.e., when $\alpha$ is very small), the retrofitted system is very similar to the original system. As shown in Figure 5.7, DCF of the soft story is above 2.0 and even reaches 2.5 which is close to the upper bound of 3.0 , indicating formation of a severe soft-story failure in the system. As the RC stiffness ratio, $\alpha$, increases beyond 0.05 ; DCF of the all three stories quickly converged to 1.0 , indicating formation of the sway mechanism. Figure 5.8 further presents the maximum DCF value at each considered $\alpha$ value. As shown, there are two sudden drops in DCF: one occurs when $\alpha$ is between 0.01 and 0.02 ; and the other occurs when $\alpha$ is between 0.04 and 0.05 . Physically, each drop means that an additional story is fully yielded when the inter-story drift limit associated with the collapse prevention performance objective is reached.

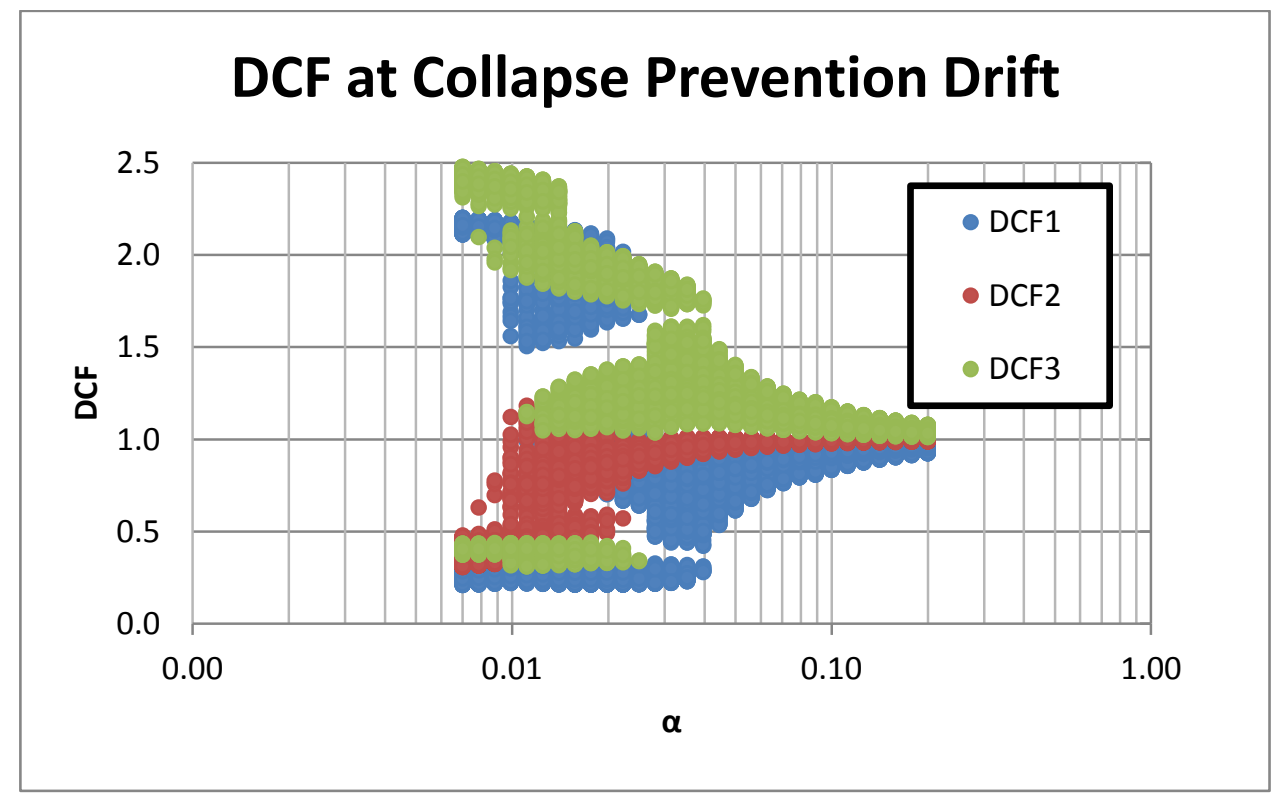

Figure 5.7: DCF for collapse prevention performance objective: LA3-A 


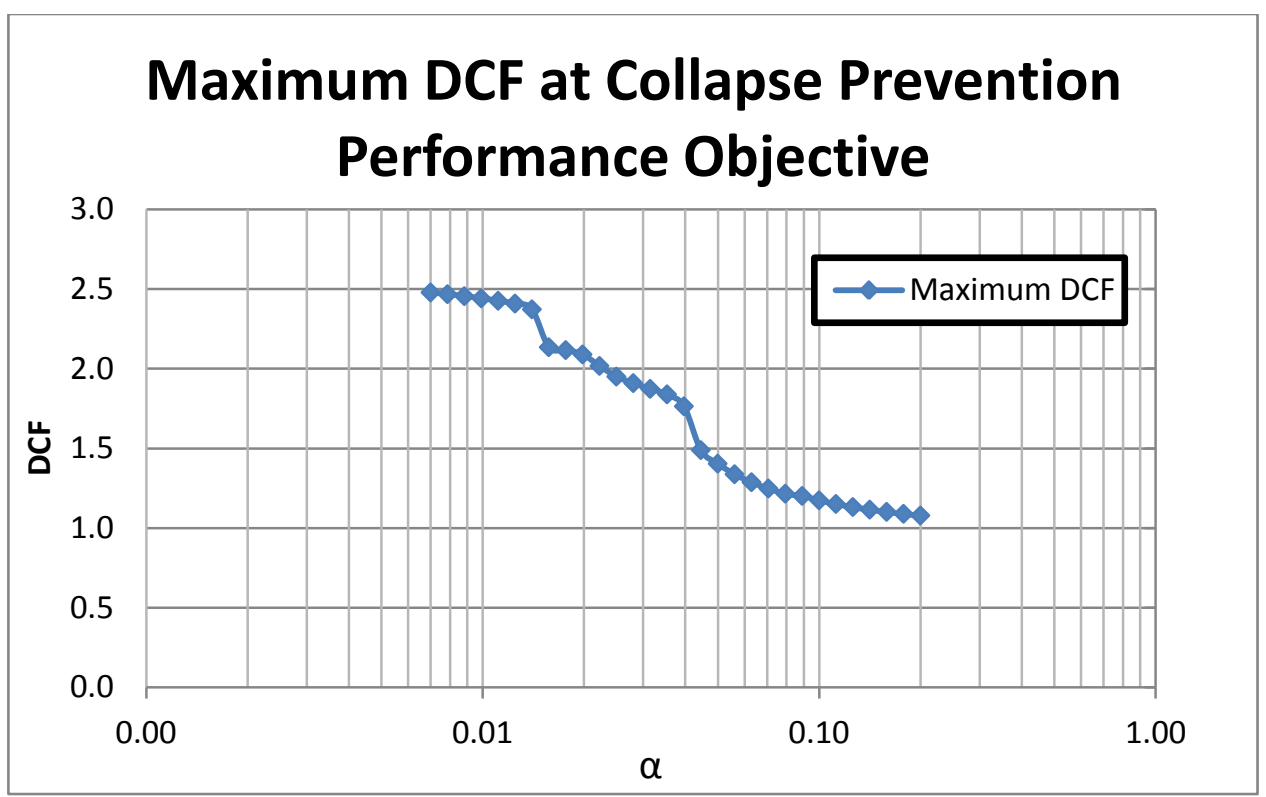

Figure 5.8: Maximum DCF for collapse prevention performance objective: LA3-A

When considering life safety as the target performance, the DCF results (see Figure 5.9) are similar to those from collapse prevention. Figure 5.10 presents the maximum DCF value at each considered $\alpha$ value. As shown, DCF converges to 1.0 as $\alpha$ increases. However, compared with the results from collapse prevention, a larger $\alpha$ is required to reach the same maximum DCF when life safety is used as performance target, indicating stiffer RC helps achieve a more satisfactory performance objective. 


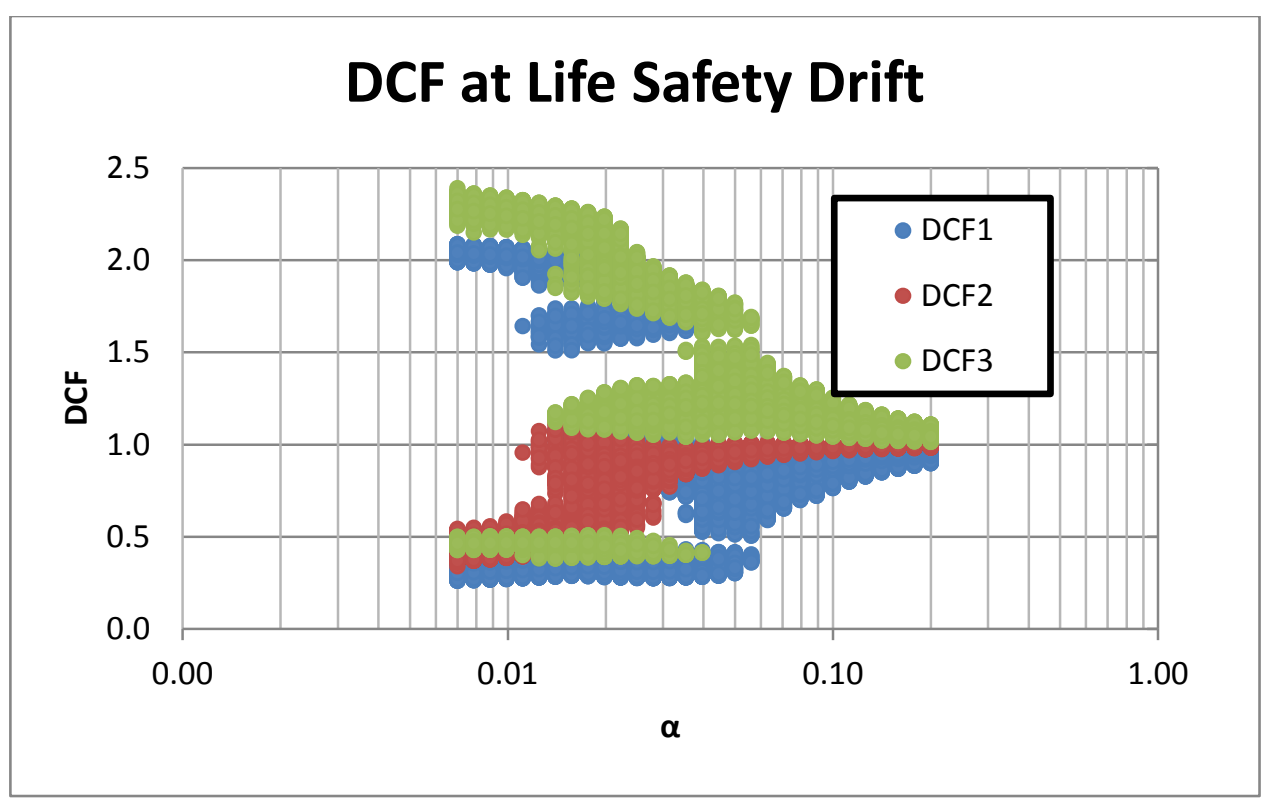

Figure 5.9: DCF for life safety performance objective: LA3-A

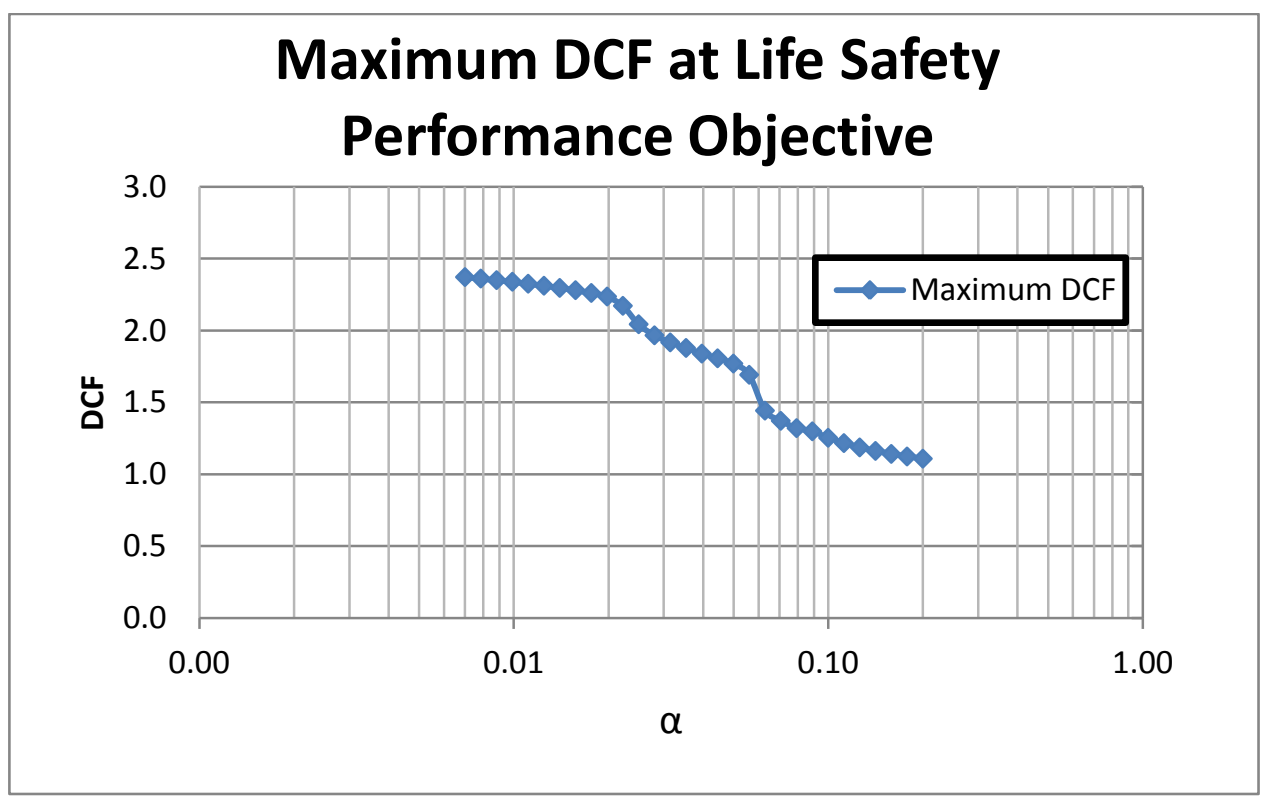

Figure 5.10: Maximum DCF for life safety performance objective: LA3-A

Figure 5.11 and 5.12 show the DCF results and maximum DCF results when immediate occupancy is used as the performance objective. Over the same range of $\alpha$, it is observed that DCF associated with immediate occupancy does not improve as much as those associated with life safety and collapse prevention, indicating that a larger $\alpha$, i.e., stiffer 
$\mathrm{RC}$, is required to achieve the same DCF. However, it should be noted that although the DCF associated with immediate occupancy is greater than those associated with life safety and collapse prevention at the largest $\alpha$ value considered; it may be acceptable since the maximum drift under immediate occupancy is relatively small (only $0.5 \%$ ) at which the story has not been fully yielded.

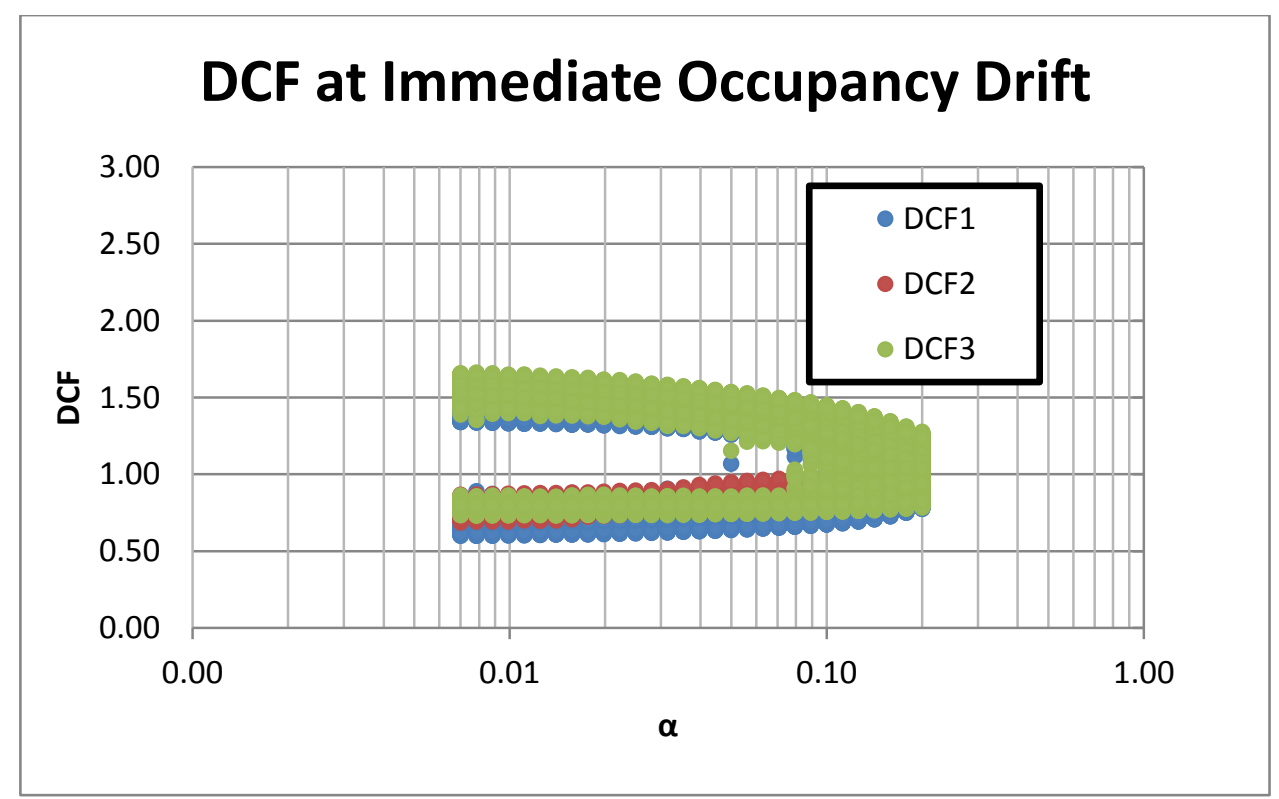

Figure 5.11: DCF for immediate occupancy performance objective: LA3-A 


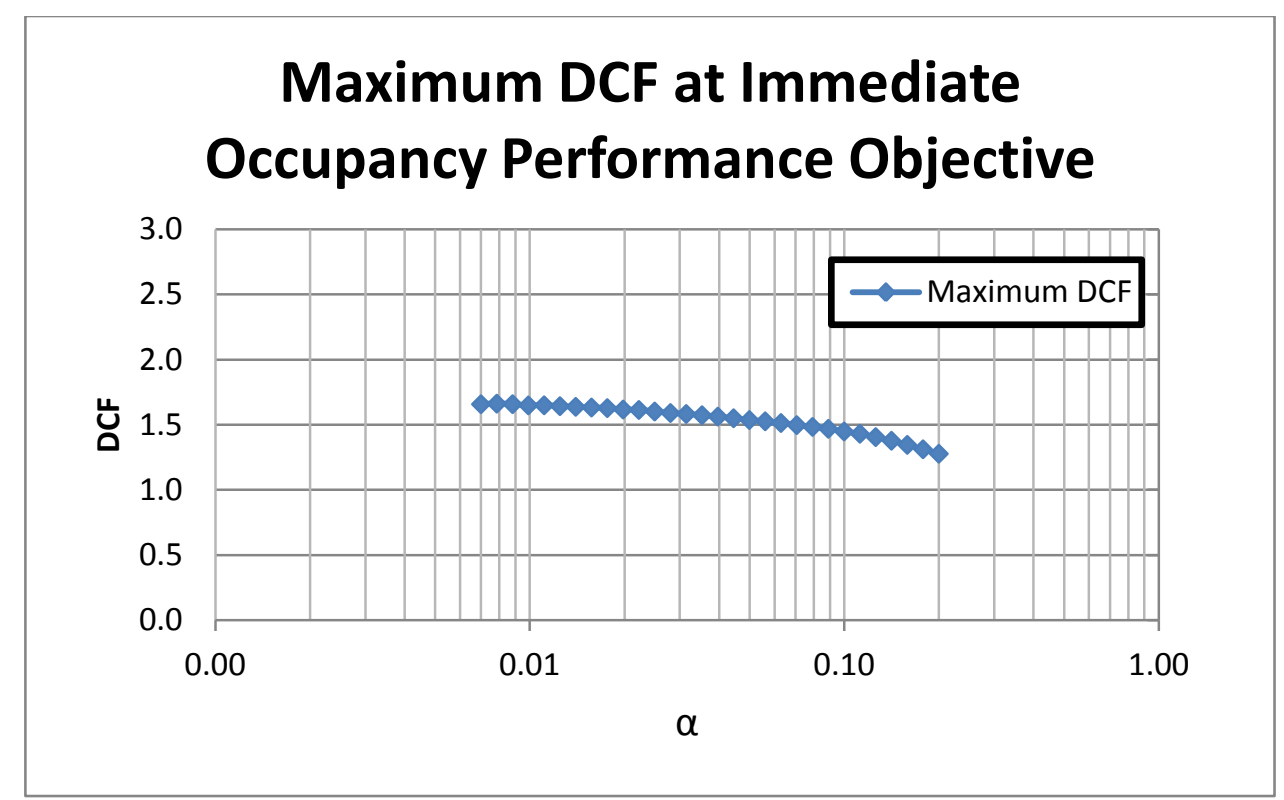

Figure 5.12: Maximum DCF for immediate occupancy performance objective: LA3-A

\subsubsection{Demands on $R C$}

Based on the results from nonlinear static pushover analyses, the shear and bending moment demands on the RC are investigated in this section. It is noted that the links are pinned to the $\mathrm{RC}$ and therefore there is no extra load along the longitudinal direction of the RC except its self-weight. It is assumed that the self-weight does not control the design of the RC; so the axial demands on $\mathrm{RC}$ is not discussed in this section. For comparison purpose, the shear and bending moment demands on the RC are normalized by the yielding strength of the bottom story of LA3, $\mathrm{V}_{1 \mathrm{y}}$, and its yielding overturning moment, $\mathrm{V}_{1 \mathrm{y}} \mathrm{h}_{\mathrm{s} 1}$, where $\mathrm{h}_{\mathrm{s} 1}$ is the first story height. To obtain $\mathrm{V}_{1 \mathrm{y}}$, a pushover analysis was conducted using a model only consisting of the bottom story of LA3; $\mathrm{V}_{1 \mathrm{y}}$ is identified as the strength corresponding to $1 \%$ drop in slope of the pushover curve. Figurer 5.13 shows the pushover curve of the bottom story of LA3. Figure 5.14 shows the slope of the pushover curve. As a result, $\mathrm{V}_{1 \mathrm{y}}$ is identified to be 900 kips and accordingly $\mathrm{V}_{1 \mathrm{y}} \mathrm{h}_{\mathrm{s} 1}$, was calculated to be 140,400 kip-in. 


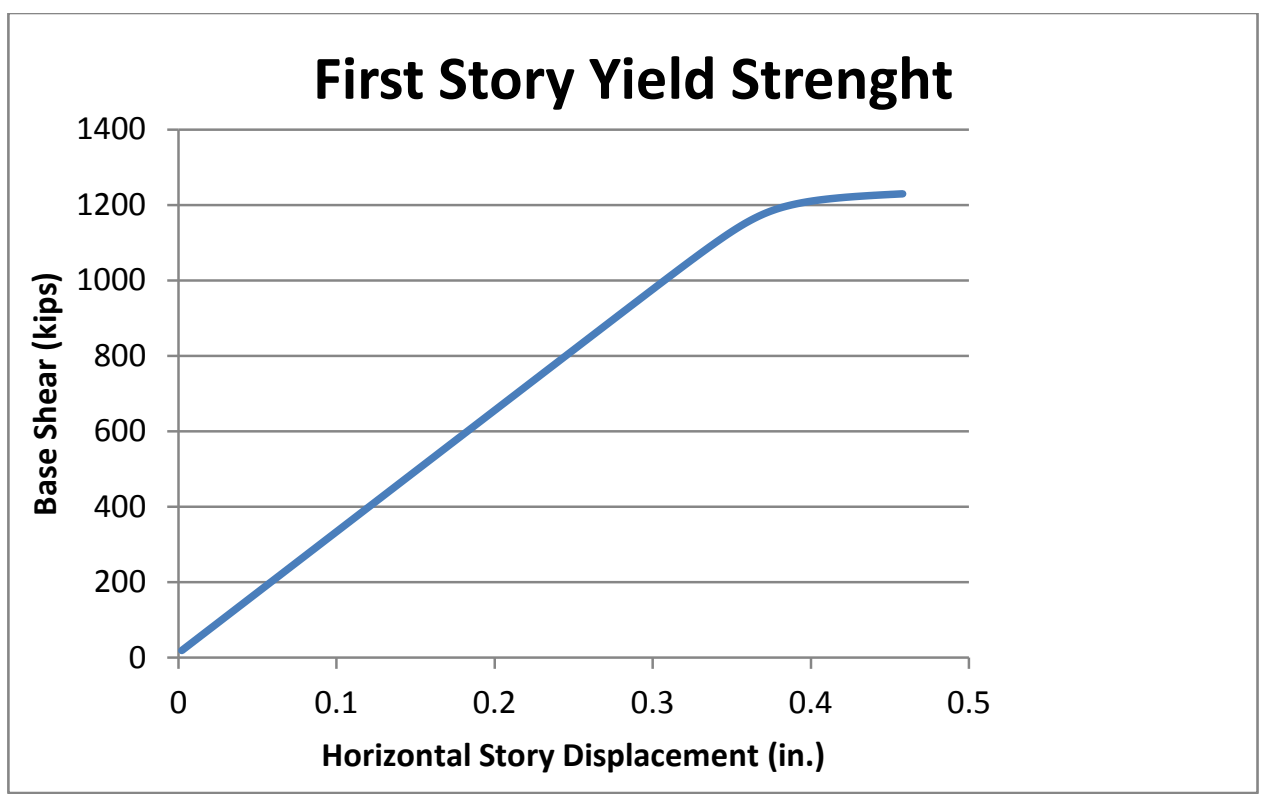

Figure 5.13: Pushover curve of bottom story of LA3-A

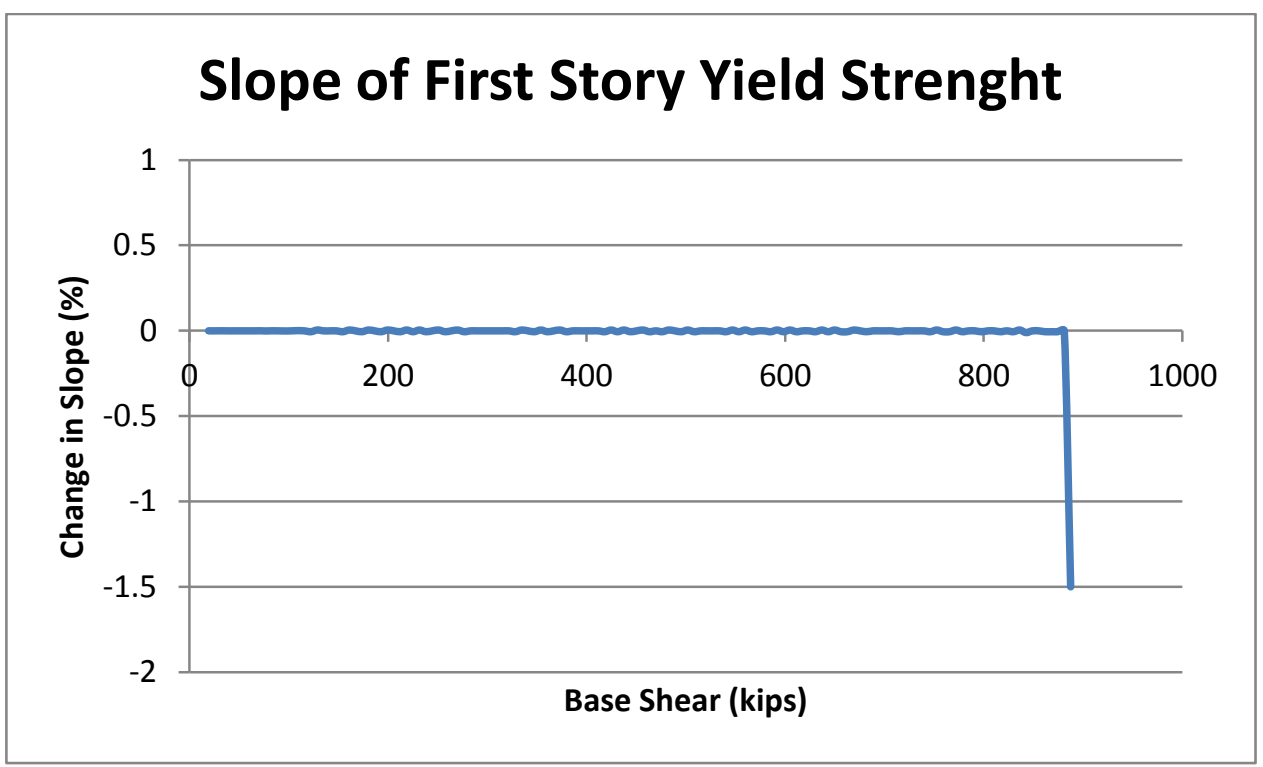

Figure 5.14: Slope of the pushover curve of bottom story of LA3-A

In order to develop recommendations on calculation of RC shear and bending moment demands, the maximum shear and bending moment demands from the 500 simulations were plotted for every $\alpha$ at each story level under each considered performance objective. It should be noted that the shear demand is constant over a RC segment at each story. It is 
also noted that premature $\mathrm{RC}$ failure should be avoided to achieve satisfactory performance in the retrofitted system. Moreover, it is recommended to design RC based on the maximum demand values.

Figures 5.15 to 5.17 show the normalized RC shear demands in each story and under each considered performance objective. As shown, the normalized RC shear demands converge to approximate $25 \%$ at all stories when $\alpha$ is greater than 0.04 and when collapse prevention and life safety are considered, indicating that a stiffer $\mathrm{RC}$ does not require larger shear demands. Under the performance of immediate occupancy, the normalized $\mathrm{RC}$ shear demands are lower than 25\% over the considered range of $\alpha$.

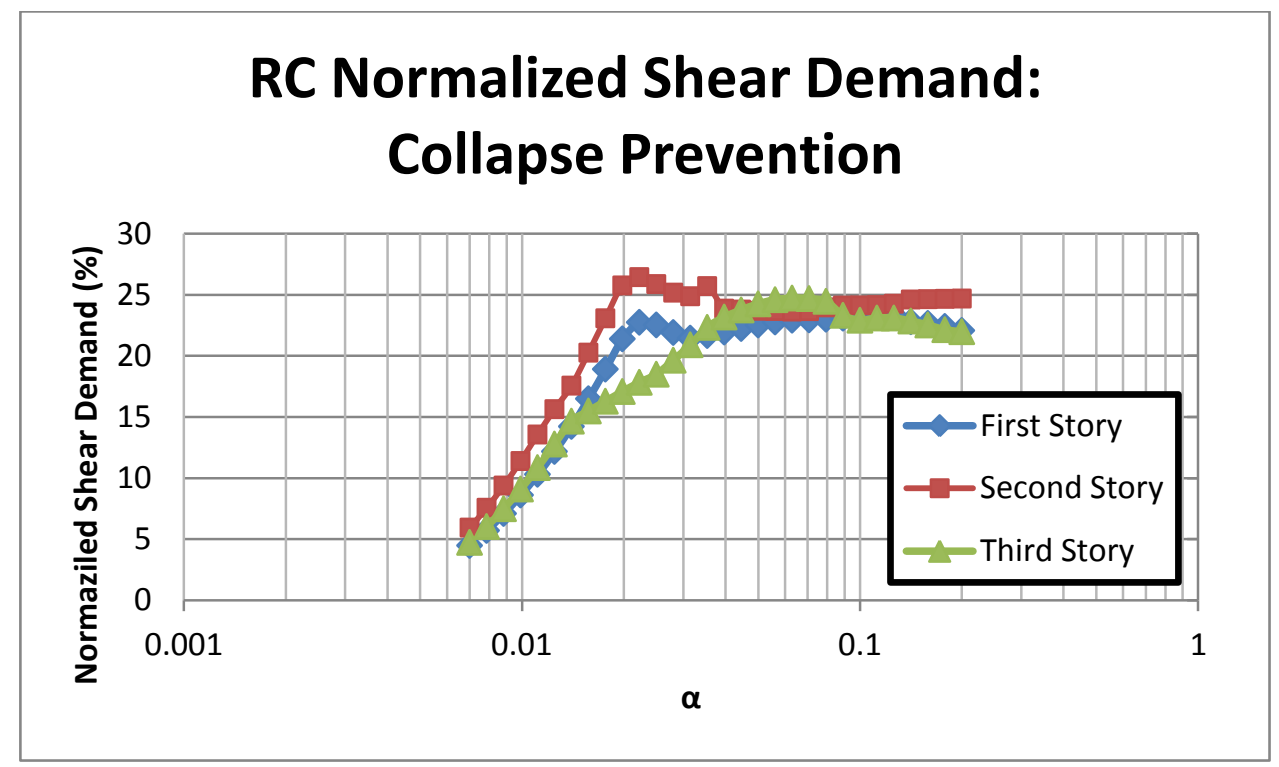

Figure 5.15: Maximum RC normalized shear demand considering collapse prevention performance objective: LA3-A 


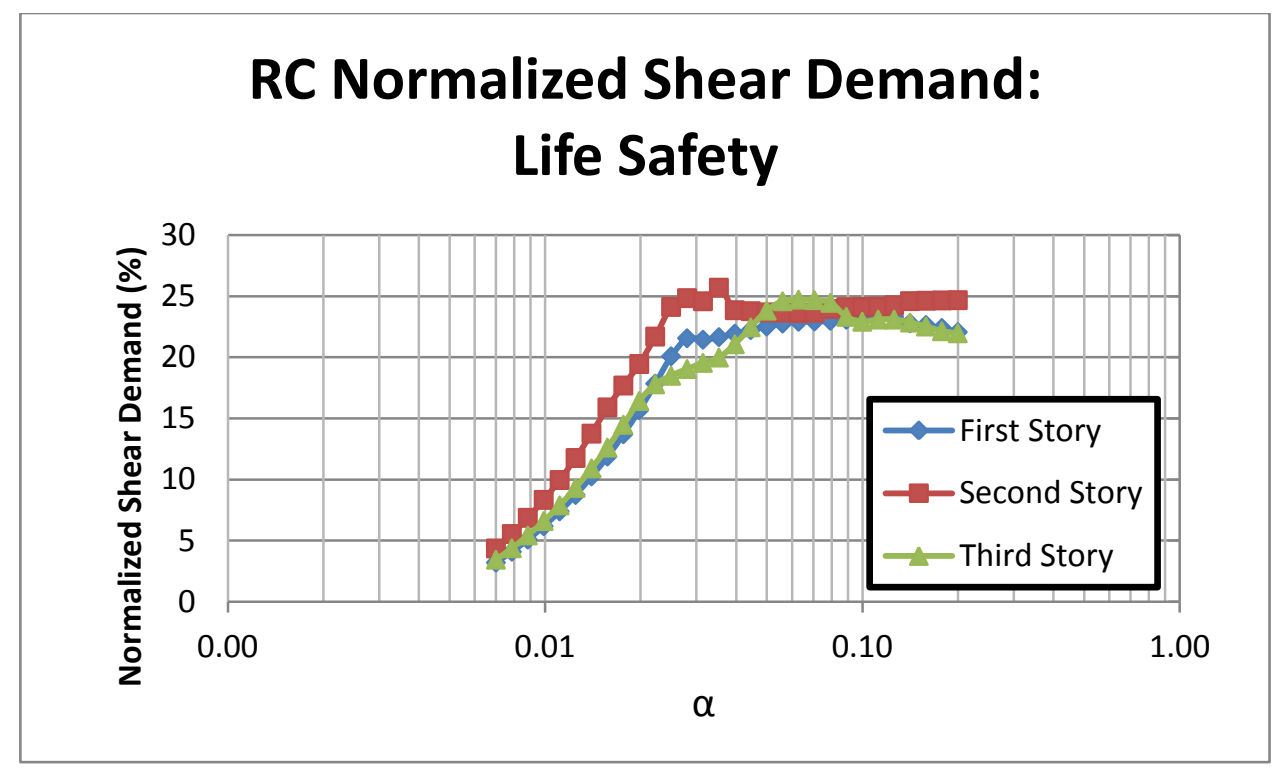

Figure 5.16: Maximum RC normalized shear demand considering life safety performance objective: LA3-A

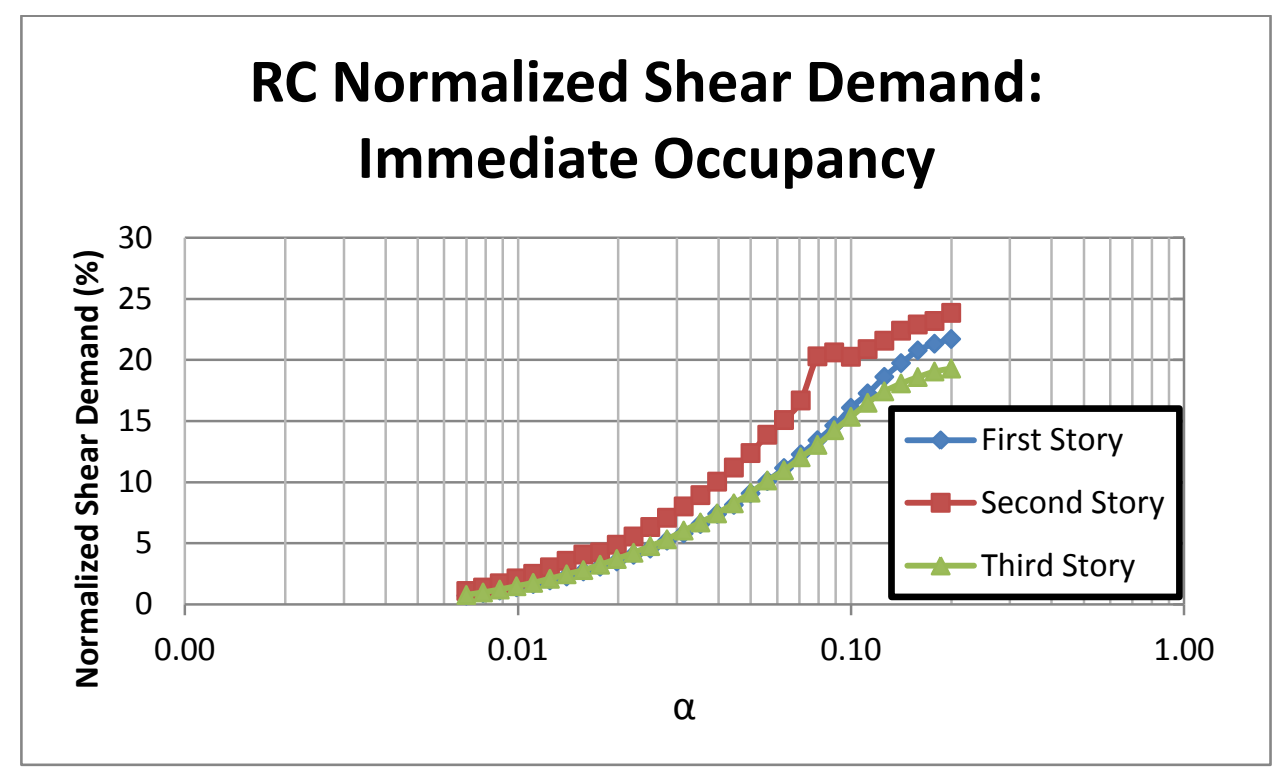

Figure 5.17: Maximum RC normalized shear demand considering immediate occupancy performance objective: LA3-A

The bending moment demand on the RC was also evaluated based on the results from nonlinear pushover analyses. Similar to the shear demands, the maximum moment demand of the 500 simulations was plotted for every $\alpha$ at each story level under each considered performance objective. Figures 5.18 to 5.20 show the maximum normalized 
bending moment demand for each story level under each considered performance objective. As shown, the maximum normalized bending moment under collapse prevention and life safety objectives increase rapidly when $\alpha$ is small but converge to about $25 \%$ when $\alpha$ is increased beyond a certain value (approximately 0.03 ). When considering immediate occupancy, the maximum normalized bending moment demand keeps increasing but is less than 25\% over the considered range of $\alpha$.

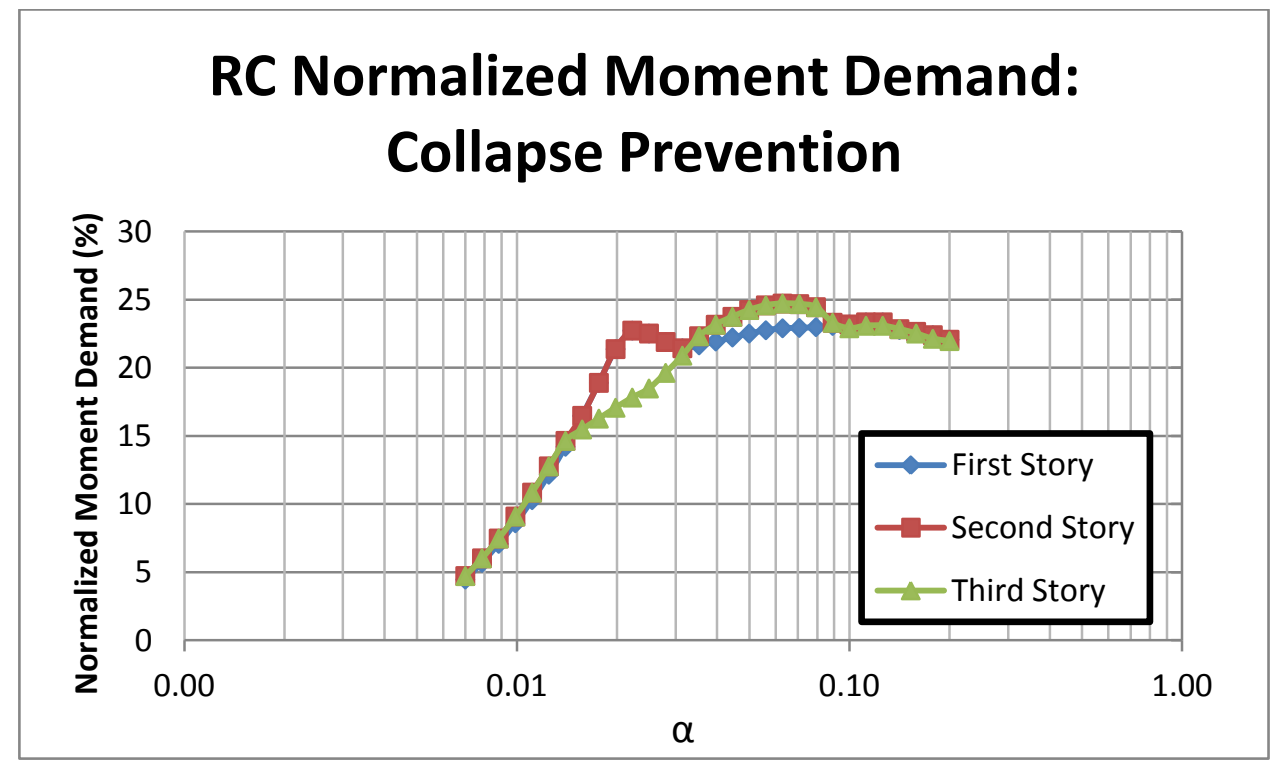

Figure 5.18: Maximum RC normalized moment demand considering collapse prevention performance objective: LA3-A 


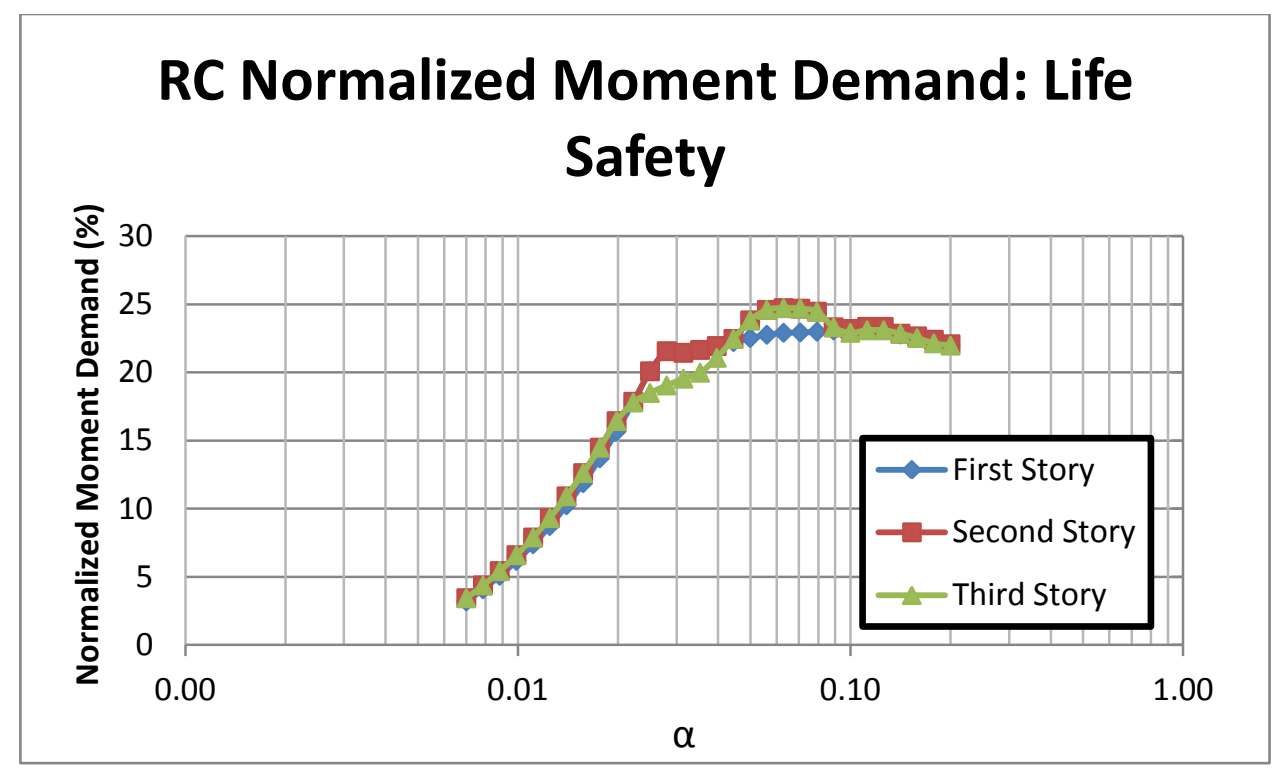

Figure 5.19: Maximum RC normalized moment demand considering life safety performance objective: LA3-A

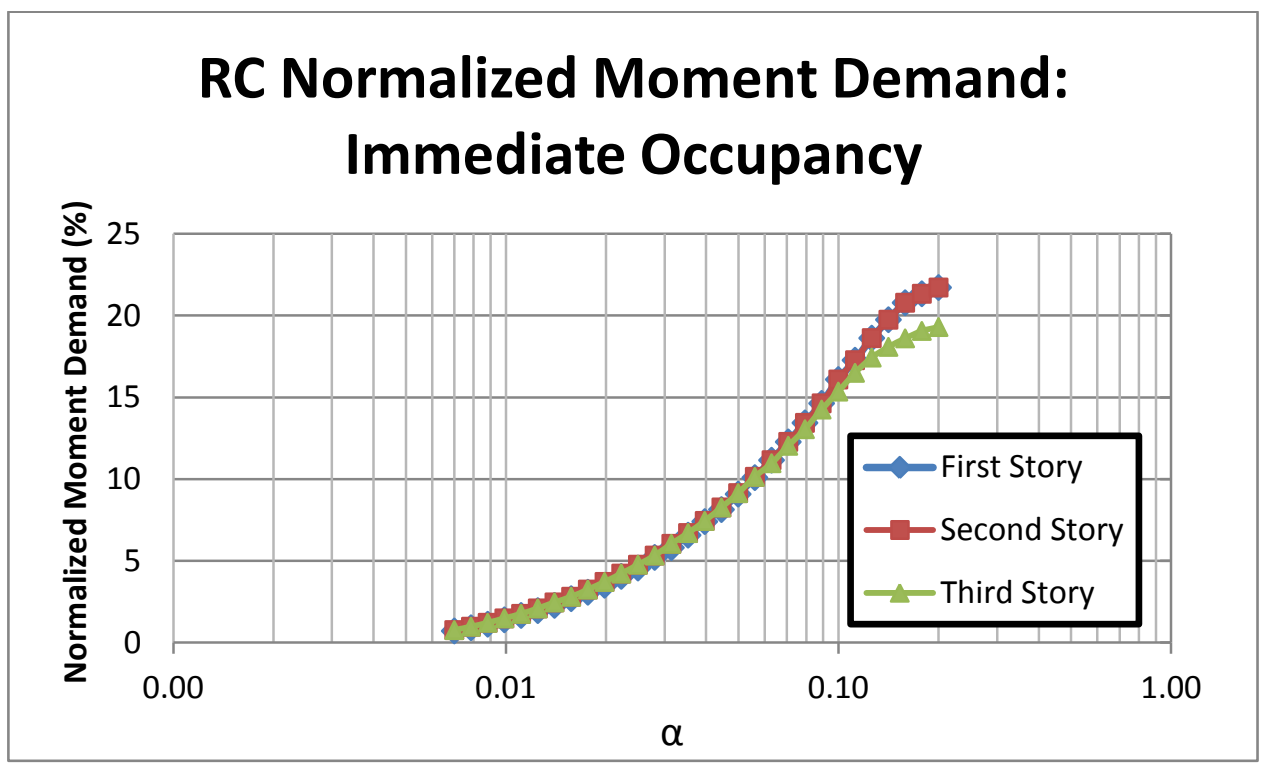

Figure 5.20: Maximum RC normalized moment demand considering immediate occupancy performance objective: LA3-A

\subsubsection{Demands on RC Links}

In addition to failure in $\mathrm{RC}$, the premature failure in $\mathrm{RC}$ links should also be avoid to ensure the expected performance from the retrofitted system. As mentioned before, in LA3-A, the links used to connect the existing structure to $\mathrm{RC}$ were assumed to be pinned 
on both sides. These boundary conditions only introduced axial load in the links. For comparison purpose, the link demands were also normalized by $\mathrm{V}_{1 \mathrm{y}}$. Figures 5.21 to 5.23 show the maximum normalized axial link demands for each story and for the three performance objectives. As shown, maximum normalized axial link demands increase rapidly when $\alpha$ is getting larger; but converge to a limit (approximately 50, 40, and 25\% for the links at the first, second and third floor levels, respectively) when $\alpha$ is increased beyond a certain limit. Also, it is observed that the maximum normalized axial link demand increases from base to roof level.

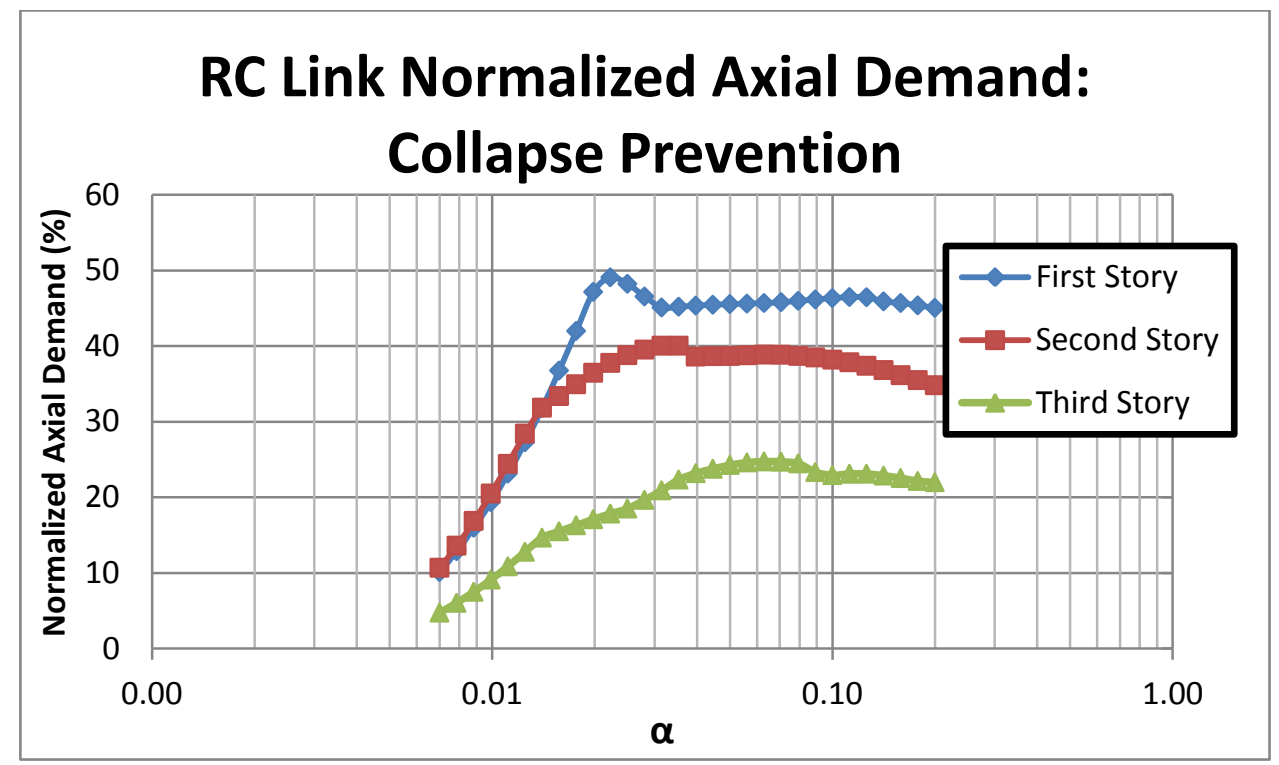

Figure 5.21: RC link normalized axial demand considering collapse prevention performance objective: LA3-A 


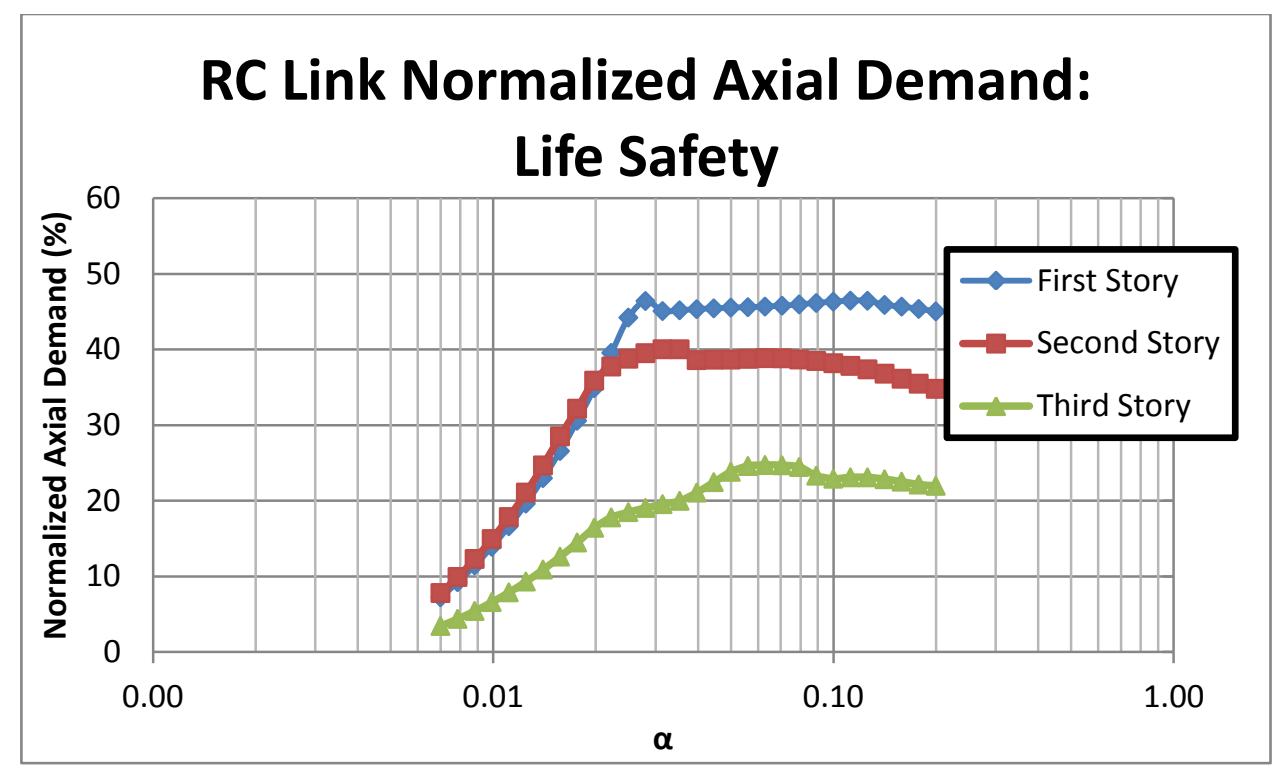

Figure 5.22: RC link normalized axial demand considering life safety performance objective: LA3-A

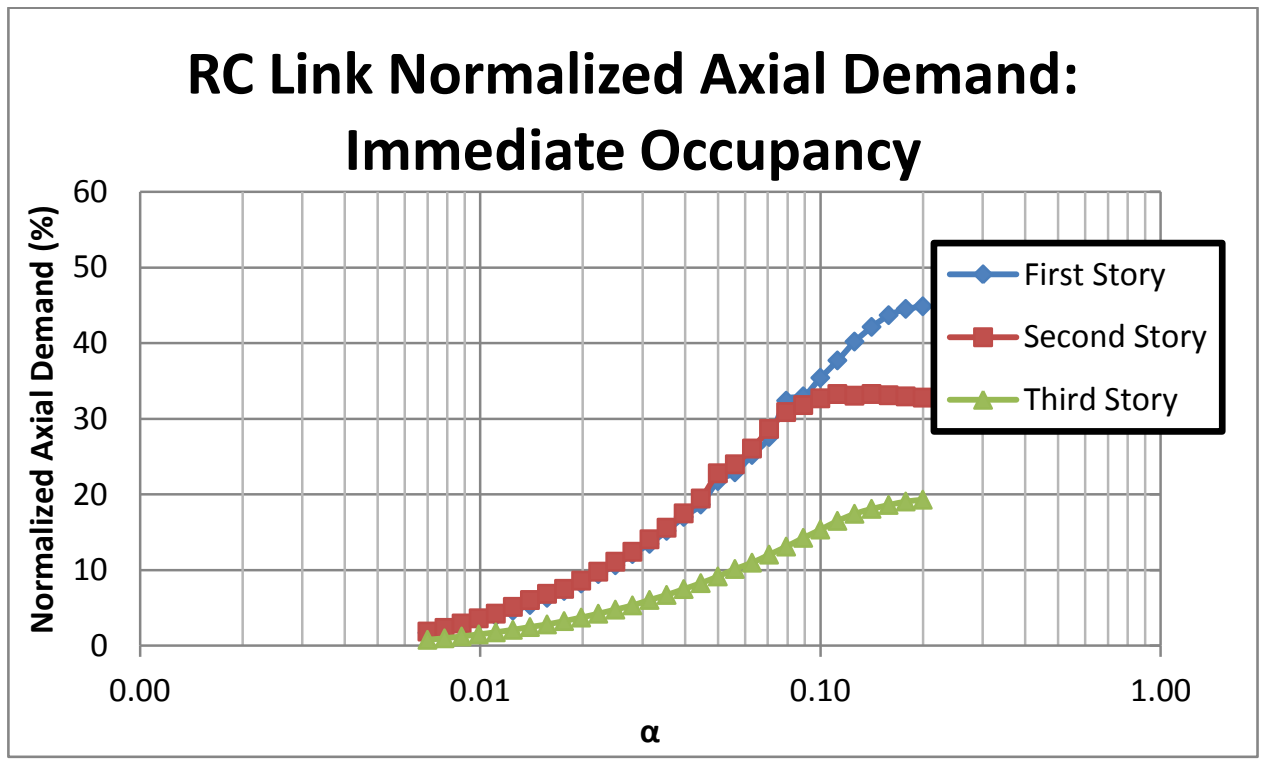

Figure 5.23: RC link normalized axial demand considering immediate occupancy performance objective: LA3-A

\subsection{Nonlinear Dynamic Analysis}

The nonlinear static analyses conducted in Section 5.2 help demonstrate the beneficial contribution of $\mathrm{RC}$ in mitigating inter-story drift concentration in low-rise $\mathrm{CBF}$ buildings. However, it should be noted that the nonlinear static analyses, while explicitly consider 
component yielding and buckling in the system, cannot capture brace rupture behavior caused by low-cycle fatigue, the consequent strength and stiffness degradation, and their impact on dynamic response of the system. This section extends the work to nonlinear dynamic analysis of the retrofitted system. The $\mathrm{RC}$ stiffness ratio, $\alpha$, was varied over a practical range in the analyses to illustrate the correlation between $\mathrm{RC}$ stiffness and system performance. Moreover, to compare the performance in the retrofitted systems consisting of links with and without energy dissipation feature, both LA3-A and LA3-B are considered. The following sections describes the ground motions selected for the nonlinear dynamic analysis; response quantities of interest; and discussion of the results.

\subsubsection{Selection of Ground Motions}

The ground motions used in this research are those developed for Los Angeles in the SAC Steel Project (available at: sacsteel.org). Three different suites of horizontal earthquake ground motions were considered and each suite consists of 20 earthquake records. Tables 5.3 to 5.5 provide details of the three suites of ground motions. The first suite of ground motions are scaled to have a probability of exceedance of $10 \%$ in 50 years, i.e. with a hazard level similar to a design basis earthquake (DBE); the second suite of ground motions were scaled to have a probability of exceedance of $2 \%$ in 50 years,i.e., with a hazard level comparable to a Maximum Considered Earthquake (MCE); and the last suite of ground motions include near-fault records. The first two suites of ground motions were considered to evaluate if the retrofitted systems could successfully satisfy the Best Safety Objective (BSO) according to FEMA 356; i.e., achieving collapse prevention and life safety under earthquake hazards with probabilities of exceedance of 2 and $10 \%$ in 50 years, respectively. The near-fault ground motions are also included in this 
investigation since prior research reported that framed building structures may be more vulnerable to soft-story failure when subjected to near-fault earthquakes (Alavi and Krawinkler, 2004). The analyses were extended to near-fault ground motions to confirm whether the $\mathrm{RC}$ is also effective in reducing inter-story drift concentration in buildings under near-fault earthquakes. It is noted that FEMA 356 does not have any recommendations on the inter-story drift limit associated with near-fault ground motions; but in this thesis the inter-story drift limit associated with $2 \%$ in 50 years earthquake (i.e., $2.0 \%$ ) is used for near-fault earthquakes. It is also recognized that all the earthquake records from each suite do not cause the same level of damage in the system. In this thesis, the specific earthquake records from each suite that cause inter-story drifts beyond the corresponding inter-story drift limit (e.g. $2 \%$ for collapse prevention) in LA3 (i.e., original building) are defined as critical earthquake records. Response spectra of the three suits of ground motions are provided in Appendix A. 
Table 5-3: Ground motions having a probability of exceedence of $2 \%$ in 50 years

(Sacsteel.org)

Details of Los Angeles Ground Motions Having a

Probability of Exceedence of $2 \%$ in 50 Years

\begin{tabular}{|c|c|c|c|c|c|c|c|c|}
\hline $\begin{array}{l}\text { SAC } \\
\text { Name }\end{array}$ & Record & \begin{tabular}{|l|} 
Earthquake \\
Magnitude
\end{tabular} & \begin{tabular}{|c|} 
Distance \\
$(\mathrm{km})$
\end{tabular} & \begin{tabular}{|l|} 
Scale \\
Factor \\
\end{tabular} & \begin{tabular}{|l|}
$\begin{array}{l}\text { Number } \\
\text { of Points }\end{array}$ \\
\end{tabular} & \begin{tabular}{|c|}
$\begin{array}{c}\text { DT } \\
\text { (sec) }\end{array}$ \\
\end{tabular} & \begin{tabular}{|c|}
$\begin{array}{c}\text { Duration } \\
\text { (sec) }\end{array}$ \\
\end{tabular} & $\begin{array}{c}\text { PGA } \\
\left(\mathrm{cm} / \sec ^{2}\right)\end{array}$ \\
\hline$\underline{L} 21$ & 1995 Kobe & 6.9 & 28 & 1.15 & 3000 & 0.02 & 59.98 & 1258.00 \\
\hline LA22 & 1995 Kobe & 6.9 & 3.4 & 1.15 & 3000 & 0.02 & 59.98 & 902.75 \\
\hline LA23 & 1989 Loma Prieta & 7 & 3.5 & 0.82 & 2500 & 0.01 & 24.99 & 409.95 \\
\hline$\underline{L A 24}$ & 1989 Loma Prieta & 1 & 3.5 & 0.82 & 2500 & 0.01 & 24.99 & 463.76 \\
\hline$\underline{\underline{L A 25}}$ & 1994 Northridge & 6.7 & 7.5 & 1.29 & 2990 & 0.005 & 14.945 & 851.62 \\
\hline$\underline{\underline{L A 26}}$ & 1994 Northridge & 6.7 & 7.5 & 1.29 & 2990 & 0.005 & 14.945 & 925.29 \\
\hline$\underline{L}$ LA27 & 1994 Northridge & 6.7 & 6.4 & 1.61 & 3000 & 0.02 & 59.98 & 908.70 \\
\hline LA28 & 1994 Northridge & 6.7 & 6.4 & 1.61 & 3000 & 0.02 & 59.98 & 1304.10 \\
\hline$\underline{L} 29$ & 1974 Tabas & 7.4 & 1.2 & 1.08 & 2500 & 0.02 & 49.98 & 793.45 \\
\hline$\underline{\mathrm{LA} 30}$ & 1974 Tabas & 7.4 & 1.2 & 1.08 & 2500 & 0.02 & 49.98 & 972.58 \\
\hline$\underline{L A 31}$ & Elysian Park (simulated) & 7.1 & 17.5 & 1.43 & 3000 & 0.01 & 29.99 & 1271.20 \\
\hline$\underline{\mathrm{LA3} 32}$ & Elysian Park (simulated) & 7.1 & 17.5 & 1.43 & 3000 & 0.01 & 29.99 & 1163.50 \\
\hline LA33 & Elysian Park (simulated) & 7.1 & 10.7 & 0.97 & 3000 & 0.01 & 29.99 & 767.26 \\
\hline LA34 & Elysian Park (simulated) & 7.1 & 10.7 & 0.97 & 3000 & 0.01 & 29.99 & 667.59 \\
\hline$\underline{\mathrm{LA3} 35}$ & Elysian Park (simulated) & 7.1 & 11.2 & 1.1 & 3000 & 0.01 & 29.99 & 973.16 \\
\hline$\underline{\mathrm{LA} 36}$ & Elysian Park (simulated) & 7.1 & 11.2 & 1.1 & 3000 & 0.01 & 29.99 & 1079.30 \\
\hline$\underline{\mathrm{LA33}}$ & Palos Verdes (simulated) & 7.1 & 1.5 & 0.9 & 3000 & 0.02 & 59.98 & 697.84 \\
\hline$\underline{\mathrm{LA33}}$ & Palos Verdes (simulated) & 7.1 & 1.5 & 0.9 & 3000 & 0.02 & 59.98 & 761.31 \\
\hline$\underline{L A 39}$ & Palos Verdes (simulated) & 7.1 & 1.5 & 0.88 & 3000 & 0.02 & 59.98 & 490.58 \\
\hline$\underline{\mathrm{LA} 40}$ & Palos Verdes (simulated) & 7.1 & 1.5 & 0.88 & 3000 & 0.02 & 59.98 & 613.28 \\
\hline
\end{tabular}


Table 5-4: Ground motions having a probability of exceedence of $10 \%$ in 50 years

(Sacsteel.org)

Details of Los Angeles Ground Motions Having a

Probability of Exceedence of $10 \%$ in 50 Years

\begin{tabular}{|c|c|c|c|c|c|c|c|c|}
\hline \begin{tabular}{|c|} 
SAC \\
Name \\
\end{tabular} & Record & \begin{tabular}{|l|} 
Earthquake \\
Magnitude
\end{tabular} & \begin{tabular}{|c|}
$\begin{array}{c}\text { Distance } \\
(\mathrm{km})\end{array}$ \\
\end{tabular} & \begin{tabular}{|c|} 
Scale \\
Factor \\
\end{tabular} & \begin{tabular}{|l|l|} 
Number \\
of Points
\end{tabular} & \begin{tabular}{|c||}
$\begin{array}{c}\text { DT } \\
\text { (sec) }\end{array}$ \\
\end{tabular} & $\begin{array}{c}\text { Duration } \\
(\mathrm{sec})\end{array}$ & $\begin{array}{c}\text { PGA } \\
\left(\mathrm{cm} / \mathrm{sec}^{2}\right)\end{array}$ \\
\hline$\underline{\mathrm{LA} 01}$ & Imperial Valley, 1940, El Centro & 6.9 & 10 & 2.01 & 2674 & 0.02 & 39.38 & 452.03 \\
\hline$\underline{\mathrm{LA} 02}$ & Imperial Valley, 1940, E1 Centro & 6.9 & 10 & 2.01 & 2674 & 0.02 & 39.38 & 662.88 \\
\hline$\underline{\mathrm{LA} 03}$ & Imperial Valley, 1979 , Array $\# 05$ & 6.5 & 4.1 & 1.01 & 3939 & 0.01 & 39.38 & 386.04 \\
\hline$\underline{\mathrm{LA04}}$ & Imperial Valley, 1979 , Array \#05 & 6.5 & 4.1 & 1.01 & 3939 & 0.01 & 39.38 & 478.65 \\
\hline$\underline{\mathrm{LA} 05}$ & Imperial Valley, 1979, Array \#06 & 6.5 & 1.2 & 0.84 & 3909 & 0.01 & 39.08 & 295.69 \\
\hline$\underline{\mathrm{LA} 06}$ & Imperial Valley, 1979, Array \#06 & 6.5 & 1.2 & 0.84 & 3909 & 0.01 & 39.08 & 230.08 \\
\hline$\underline{\mathrm{LA07}}$ & Landers, 1992, Barstow & 7.3 & 36 & 3.2 & 4000 & 0.02 & 79.98 & 412.98 \\
\hline$\underline{\mathrm{LA} 08}$ & Landers, 1992, Barstow & 7.3 & 36 & 3.2 & 4000 & 0.02 & 79.98 & 417.49 \\
\hline$\underline{\underline{L A 09}}$ & Landers, 1992, Yermo & 7.3 & 25 & 2.17 & 4000 & 0.02 & 79.98 & 509.70 \\
\hline$\underline{\mathrm{LA} 10}$ & Landers, 1992, Yermo & 7.3 & 25 & 2.17 & 4000 & 0.02 & 79.98 & 353.35 \\
\hline LA11 & Loma Prieta, 1989, Gilroy & 7 & 12 & 1.79 & 2000 & 0.02 & 39.98 & 652.49 \\
\hline$\underline{\underline{L A 12}}$ & Loma Prieta, 1989, Gilroy & 7 & 12 & 1.79 & 2000 & 0.02 & 39.98 & 950.93 \\
\hline$\underline{\underline{L A 13}}$ & Northridge, 1994, Newhall & 6.7 & 6.7 & 1.03 & 3000 & 0.02 & 59.98 & 664.93 \\
\hline$\underline{\underline{L A 14}}$ & Northridge, 1994, Newhall & 6.7 & 6.7 & 1.03 & 3000 & 0.02 & 59.98 & 644.49 \\
\hline$\underline{\mathrm{LA} 15}$ & Northridge, 1994, Rinaldi RS & 6.7 & 7.5 & 0.79 & 2990 & 0.005 & 14.945 & 523.30 \\
\hline$\underline{\mathrm{LA} 16}$ & Northridge, 1994 , Rinaldi RS & 6.7 & 7.5 & 0.79 & 2990 & 0.005 & 14.945 & 568.58 \\
\hline LA17 & Northridge, 1994, Sylmar & 6.7 & 6.4 & 0.99 & 3000 & 0.02 & 59.98 & 558.43 \\
\hline$\underline{\underline{L A 18}}$ & Northridge, 1994, Sylmar & 6.7 & 6.4 & 0.99 & 3000 & 0.02 & 59.98 & 801.44 \\
\hline$\underline{\underline{L A 19}}$ & North Palm Springs, 1986 & 6 & 6.7 & 2.97 & 3000 & 0.02 & 59.98 & 999.43 \\
\hline$\underline{\underline{L A 20}}$ & North Palm Springs, 1986 & 6 & 6.7 & 2.97 & 3000 & 0.02 & 59.98 & 967.61 \\
\hline
\end{tabular}


Table 5-5: Near-Field Ground Motions

(Sacsteel.org)

Details of Near-Field Ground Motions Derived from Historical Acceleration Records

\begin{tabular}{|c|c|c|c|}
\hline \begin{tabular}{|c|} 
SAC \\
Name
\end{tabular} & Record & \begin{tabular}{|l|} 
Earthquake \\
Magnitude
\end{tabular} & \begin{tabular}{|c|} 
Distance \\
$(\mathrm{km})$
\end{tabular} \\
\hline NF01 & Tabas, 1978 & 7.4 & 1.2 \\
\hline NF02 & Tabas, 1978 & 7.4 & 1.2 \\
\hline NF03 & Loma Prieta, 1989, Los Gatos & 7 & 3.5 \\
\hline NF04 & Loma Prieta, 1989, Los Gatos & 7 & 3.5 \\
\hline NF05 & Loma Prieta, 1989, Lex. Dam & 7 & 6.3 \\
\hline NF06 & Loma Prieta, 1989, Lex. Dam & 7 & 6.3 \\
\hline NF07 & C. Mendocino, 1992, Petrolia & 7.1 & 8.5 \\
\hline NF08 & C. Mendocino, 1992, Petrolia & 7.1 & 8.5 \\
\hline NF09 & Erzincan, 1992 & 6.7 & 2 \\
\hline NF10 & Erzincan, 1992 & 6.7 & 2 \\
\hline NF11 & Landers, 1992 & 7.3 & 1.1 \\
\hline NF12 & Landers, 1992 & 7.3 & 1.1 \\
\hline NF13 & Nothridge, 1994, Rinaldi & 6.7 & 7.5 \\
\hline NF14 & Nothridge, 1994, Rinaldi & 6.7 & 7.5 \\
\hline NF15 & Nothridge, 1994, Olive View & 6.7 & 6.4 \\
\hline NF16 & Nothridge, 1994, Olive View & 6.7 & 6.4 \\
\hline NF17 & Kobe, 1995 & 6.9 & 3.4 \\
\hline NF18 & Kobe, 1995 & 6.9 & 3.4 \\
\hline NF19 & Kobe, 1995, Takatori & 6.9 & 4.3 \\
\hline NF20 & Kobe, 1995, Takatori & 6.9 & 4.3 \\
\hline
\end{tabular}

\subsubsection{Response Quantities of Interest}

During the nonlinear dynamic analysis for each earthquake, the maximum inter-story drift in the system was output. It is noted that complete results of maximum inter-story drift from each earthquake under each considered $\mathrm{RC}$ stiffness ratio, $\alpha$, are provided in Appendix B. The median of the maximum inter-story drifts from all considered 
earthquakes is selected as a response quantity of interest and discussed in detail in the following section. Moreover, demands on RC and links, and impacts of brace rupture and links with hysteretic energy absorption capacity are discussed.

\subsubsection{Result Discussion}

\subsubsection{Median of the Maximum Inter-story Drifts}

Figure 5.24 shows the median of the maximum inter-story drifts resulting from all ground motions with a hazard level of $10 \%$ in 50 years. As shown, the median of the maximum inter-story drifts from all earthquake records reduces from 0.88 to $0.5 \%$ as $\mathrm{RC}$ stiffness increases. It is noted that among the 20 ground motions corresponding to a probability of exceedence of $10 \%$ in 50 years, 7 ground motions are critical earthquake records; and 5 out of the 7 ground motions cause inter-story drift in LA3 even greater than 2.0\%, i.e., the limit associated with collapse prevention. In all 7 cases, LA3 experiences a soft-story failure at either the first or third stories. To better understand the contribution of the RC, the median of the maximum inter-story drifts resulting from the 7 critical earthquake records is shown in Figure 5.25. As shown, the median of the maximum inter-story drifts reduces from $2.0 \%$ (which is greater than the limit of $1.5 \%$ associated with life safety) to a level below $1.0 \%$, indicating stiffer RC enables successful achievement of life safety objective under critical ground motions. Also identified from Figure 5.25, the minimum value of $\alpha$ required for life safety target is about 0.03 . 


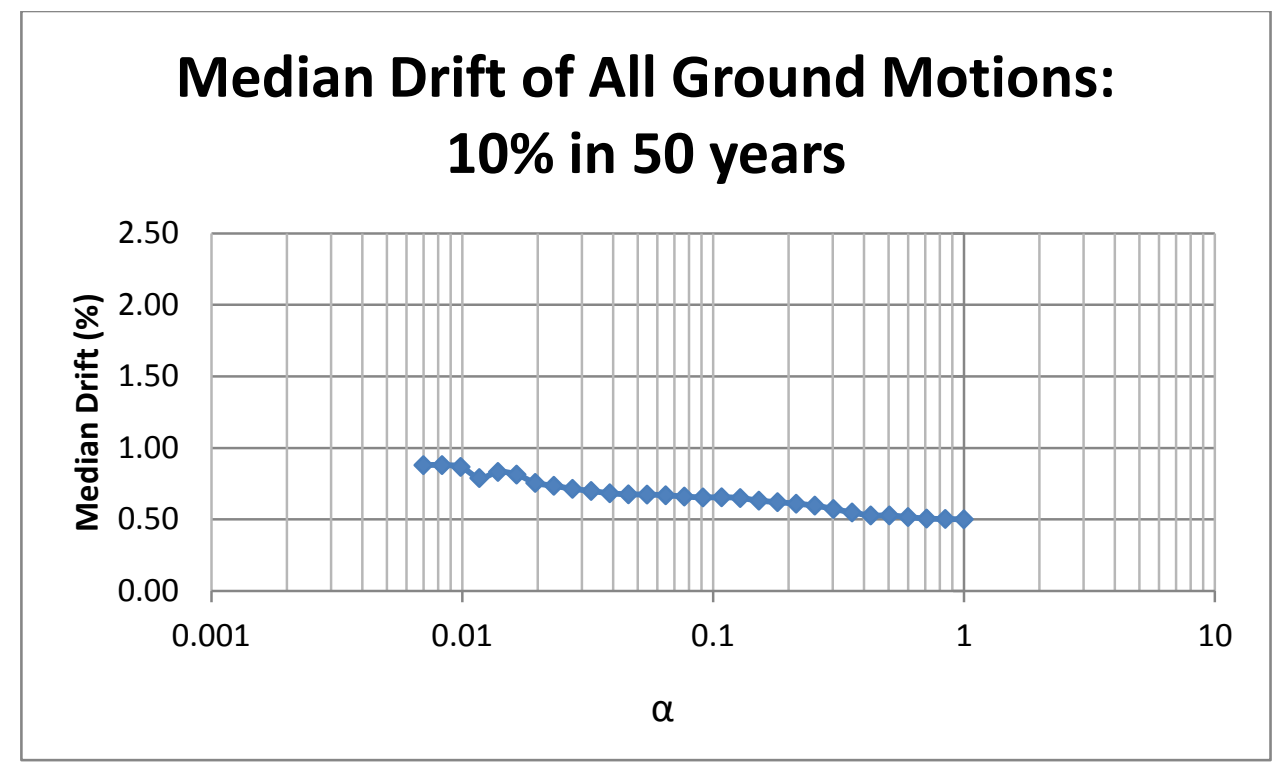

Figure 5.24: Median of the maximum inter-story drifts from all ground motions (10\% in 50 years)

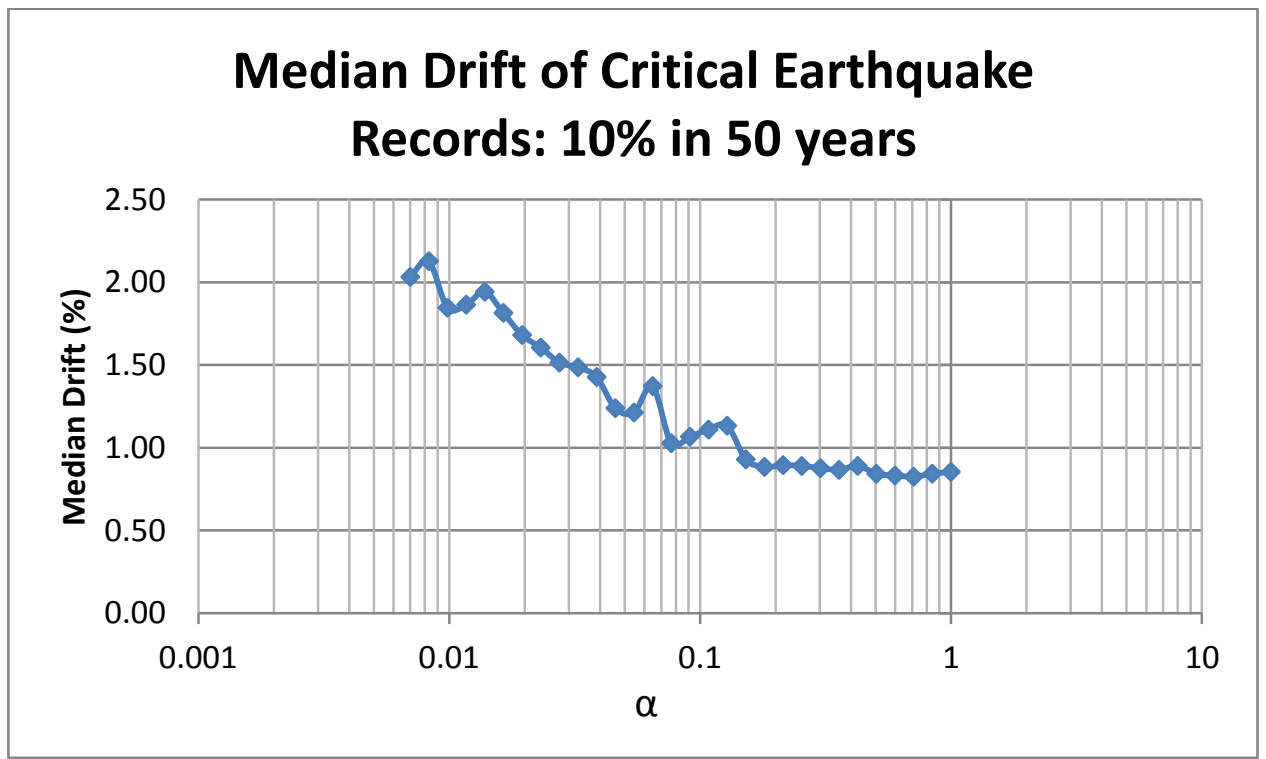

Figure 5.25: Median of the maximum inter-story drifts from critical earthquake records (10\% in 50 years)

Considering the 20 ground motions from the suite corresponding to $2 \%$ in 50 years, a similar trend was observed. Figure 5.26 shows the median of the maximum inter-story drifts from all the ground motions of this suite. Figure 5.27 shows the median of the maximum inter-story drifts from the critical earthquake records of this suite. As shown, if 
all earthquakes are considered, median of the maximum inter-story drifts reduce from $5.1 \%$ (beyond $2.5 \%$ the limit associated with collapse prevention) to $1.5 \%$ (well below the limit associated with collapse prevention). However, focusing on the results from critical records, the retrofitted system, although exhibits reduced median of the maximum inter-story drifts; fails to achieve the collapse prevention target over the considered range of $\alpha$. Therefore, additional hysteretic energy dissipation features should be introduced in the system to reduce the maximum inter-story drifts, i.e., LA3-B should be considered. Detailed results of LA3-B under earthquakes corresponding to $2 \%$ in 50 years are presented in Section 5.3.2.5.

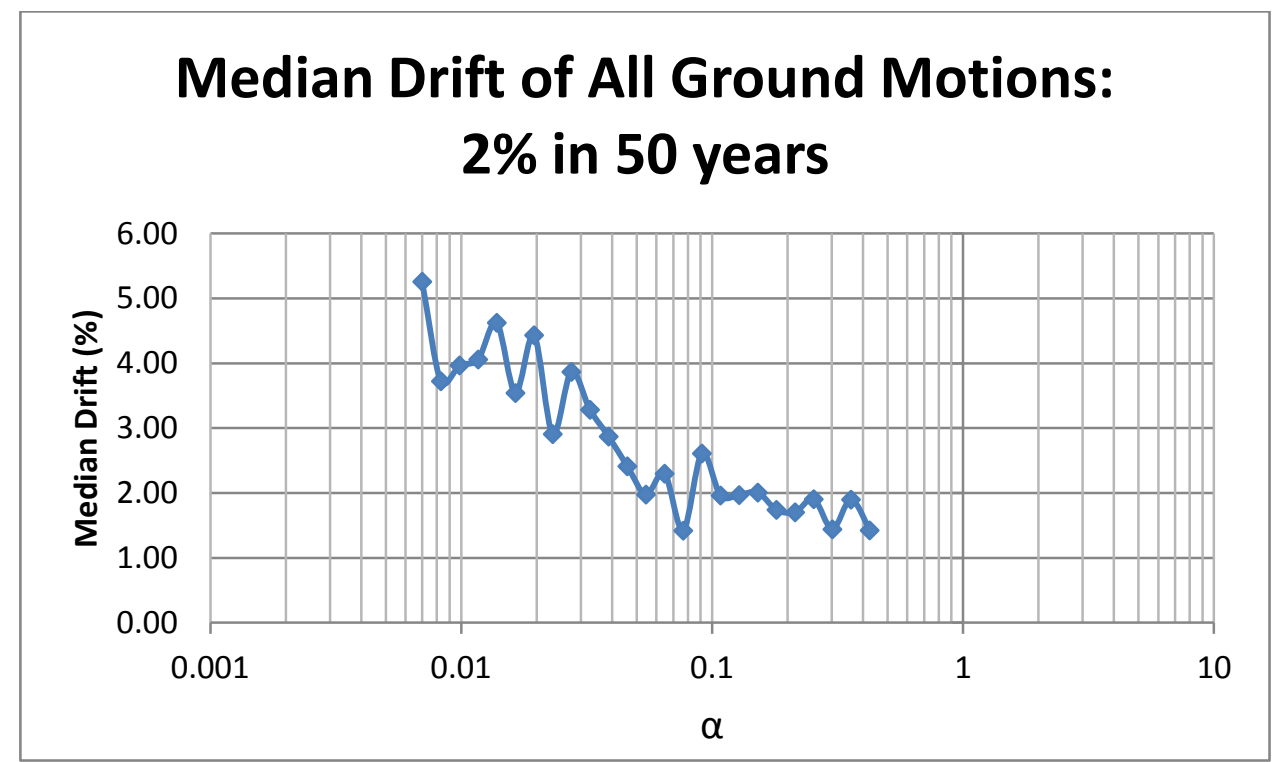

Figure 5.26: Median of the maximum inter-story drifts from all ground motions ( $2 \%$ in $\mathbf{5 0}$ years) 


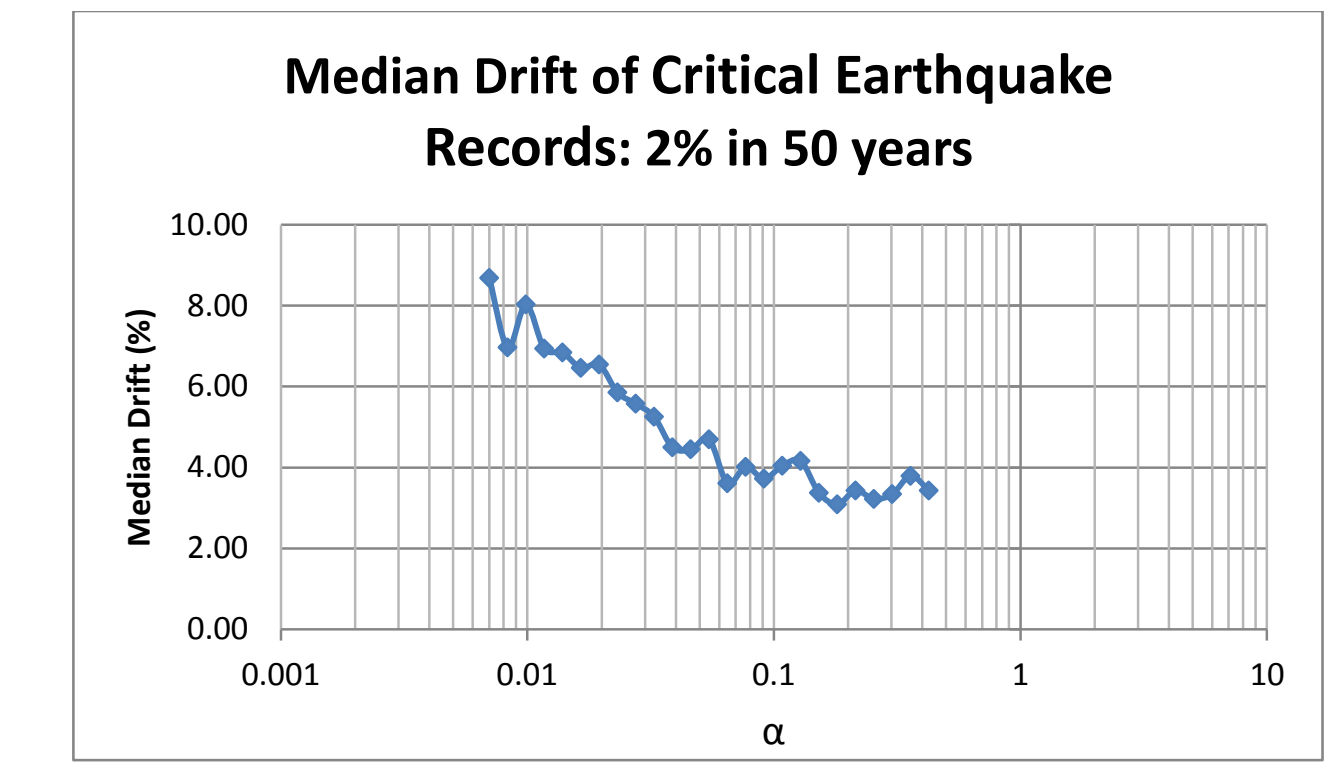

Figure 5.27: Median of the maximum inter-story drifts from critical earthquake records ( $2 \%$ in 50 years)

Figure 5.28 shows the median of the maximum inter-story drifts from all the ground motions of the near-fault earthquakes suite. Figure 5.29 shows the median of the maximum inter-story drifts from the critical earthquake records of this suite. As shown, if all earthquakes are considered, median of the maximum inter-story drifts reduce from $1.5 \%$ (which is below $2.0 \%$, the limit associated with collapse prevention) to $1.0 \%$. Focusing on the results from critical records, the retrofitted system, median of the maximum inter-story drifts reduce from approximate $8 \%$ to (far beyond $2.0 \%$, which is the limit associated with collapse prevention) to a level below $2.0 \%$ over the considered range of $\alpha$. As identified from Figure 5.29, the minimum value of $\alpha$ required for collapse prevention in near-field earthquakes is about 0.06 . 


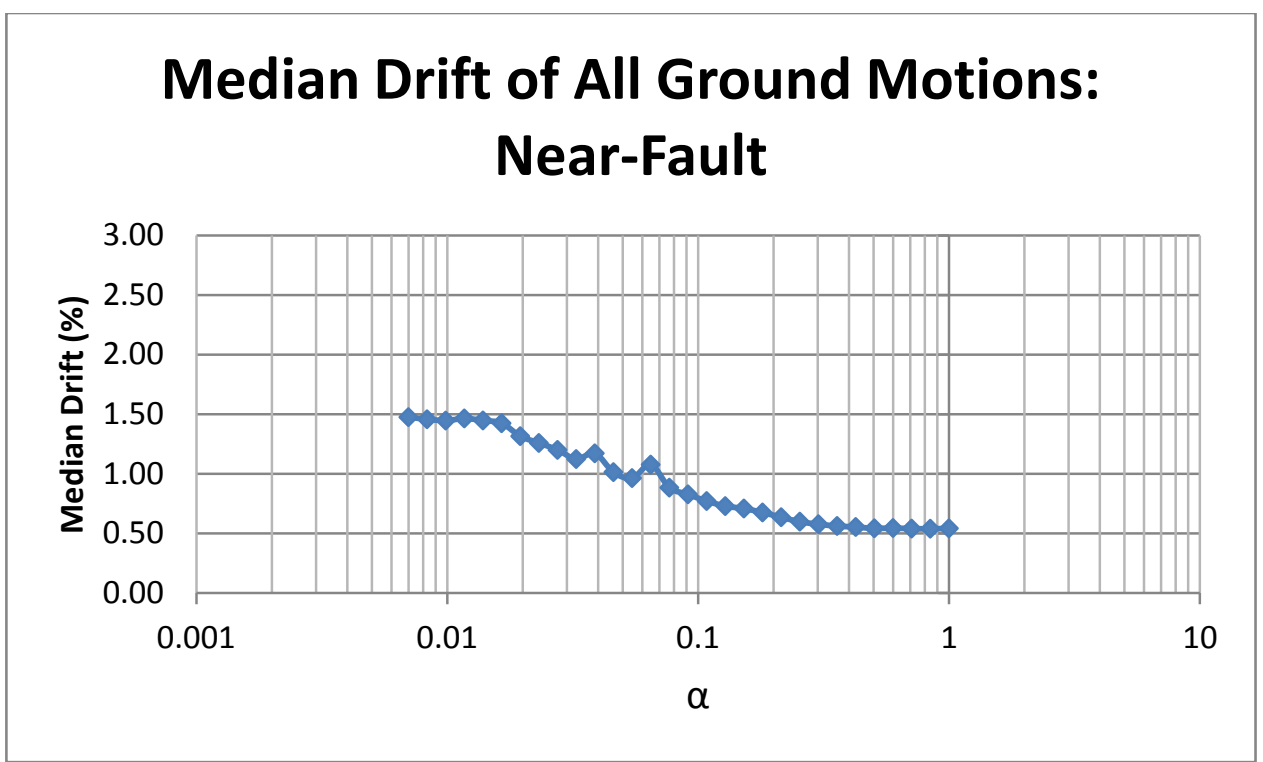

Figure 5.28: Median of the maximum inter-story drifts from all ground motions (near-fault)

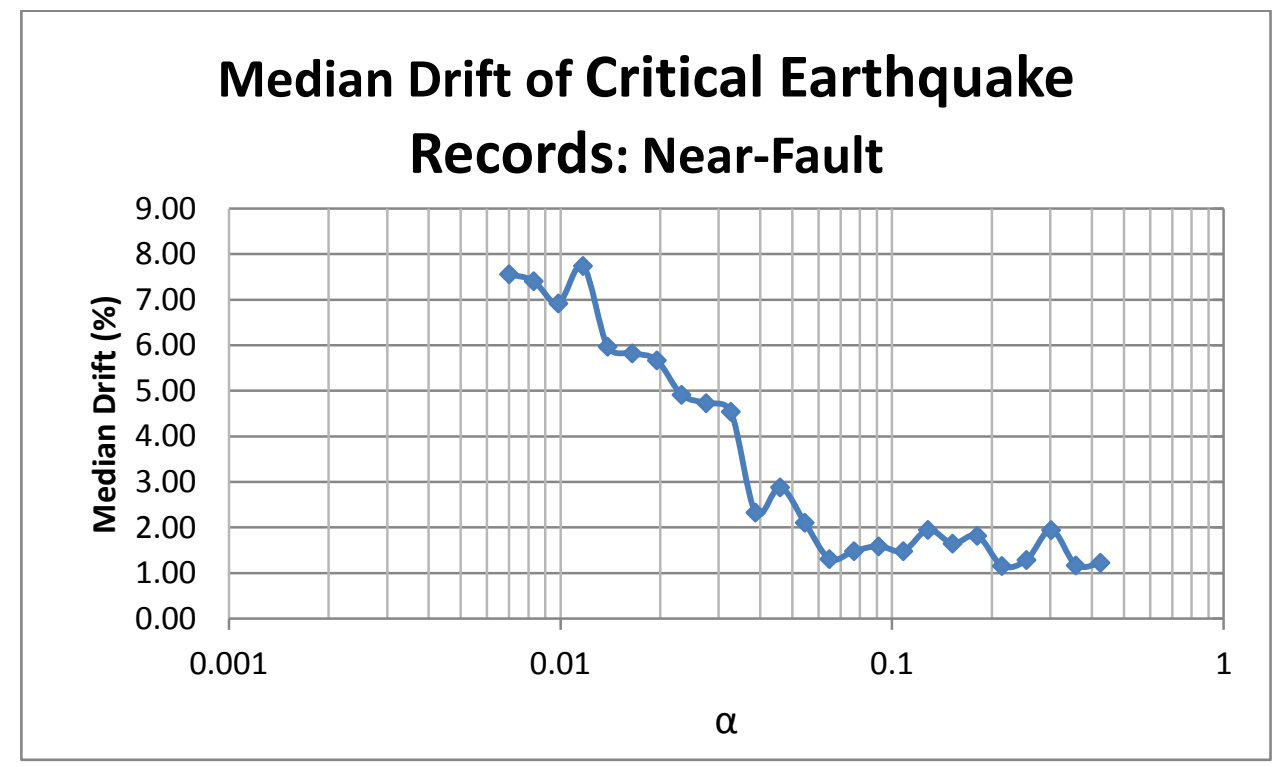

Figure 5.29: Median of the maximum inter-story drifts from critical earthquake records (near-fault)

\subsubsection{Demands on $R C$}

This section presents the median values of the maximum shear and bending moment demands from each ground motion of the three sets of ground motions. For comparison purpose, the shear and bending moment demands are normalized by $V_{1 y}$ and $V_{1 y} h_{s 1}$, respectively. Figures 5.30, 5.32, and 5.34 presents shear demands from each earthquake 
suite; Figures 5.31, 5.33 and 5.35 present bending moment demands from each earthquake suite.

Compared with the normalized RC shear demands from nonlinear pushover analyses (see Figures 15 to 17 ) which converge to be about $25 \%$, the shear demands from nonlinear dynamic analyses are higher (up to $30 \%$ under earthquakes corresponding to $10 \%$ in 50 years; up to $35 \%$ under near-fault earthquakes; and up to $60 \%$ under earthquakes corresponding to $2 \%$ in 50 years). Similarly, the normalized RC bending moment demands from nonlinear dynamic analyses are also higher (up to $30 \%$ under earthquakes corresponding to $10 \%$ in 50 years; up to $35 \%$ under near-fault earthquakes; and up to $60 \%$ under earthquakes corresponding to $2 \%$ in 50 years) than those from nonlinear pushover analysis (see Figures 18 to 20 ) which converge to be about $25 \%$. Larger RC demands are observed from the results from nonlinear dynamic analysis because the FE models used in nonlinear dynamic analysis can capture the rupture behavior of braces. When braces rupture, sudden strength and stiffness degradations are expected in the system, resulting in excessive demands on RC. The observation that the demands from the earthquakes corresponding to $2 \%$ in 50 years are highest is consistent with the fact the braces are more likely to rupture in a stronger earthquake. 


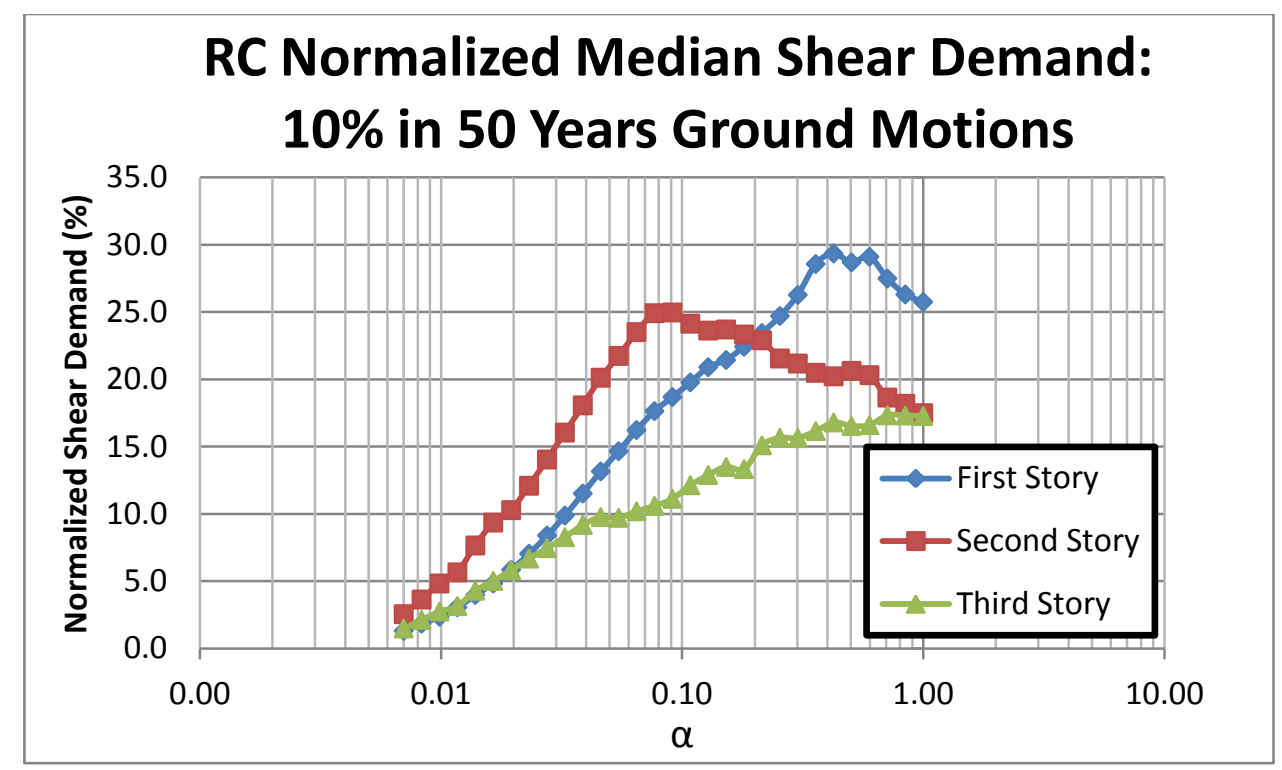

Figure 5.30: Normalized median shear demand in RC (Earthquakes corresponding to $10 \%$ in 50 years)

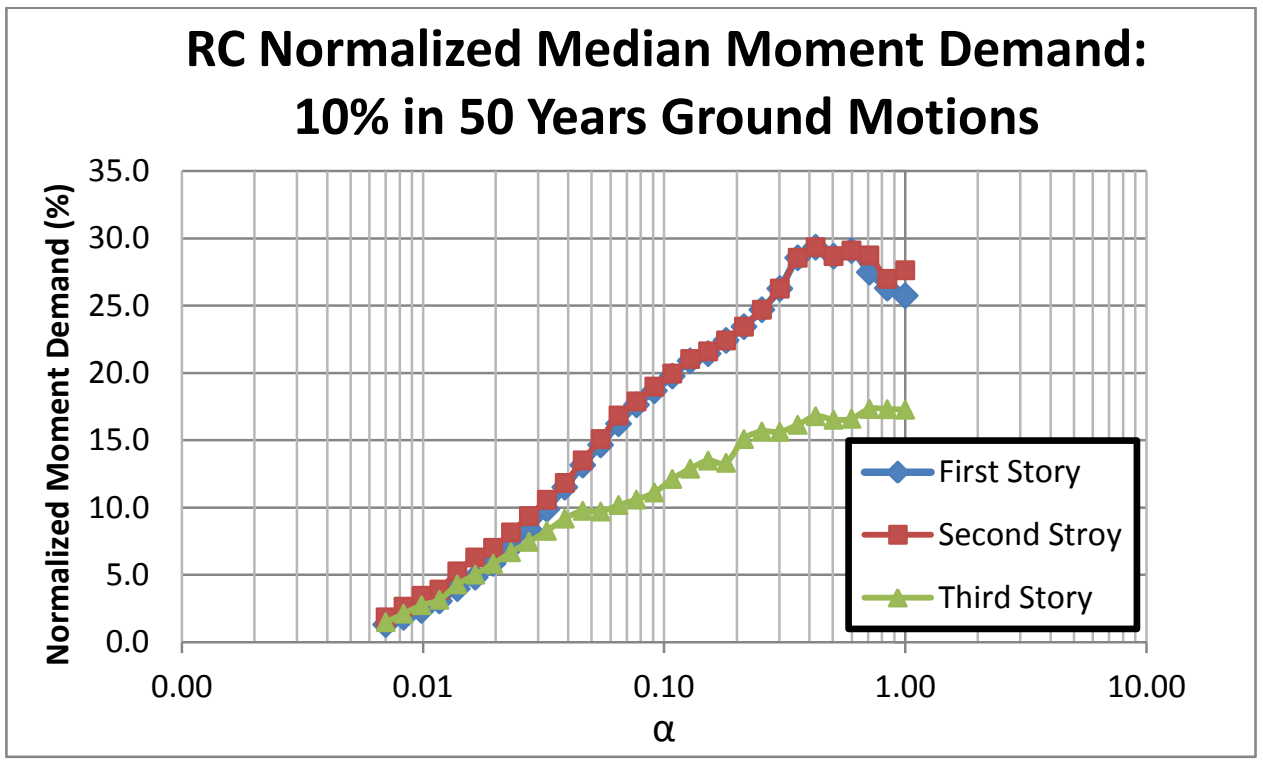

Figure 5.31: Normalized median bending moment demand in RC (Earthquakes corresponding to $10 \%$ in 50 years) 


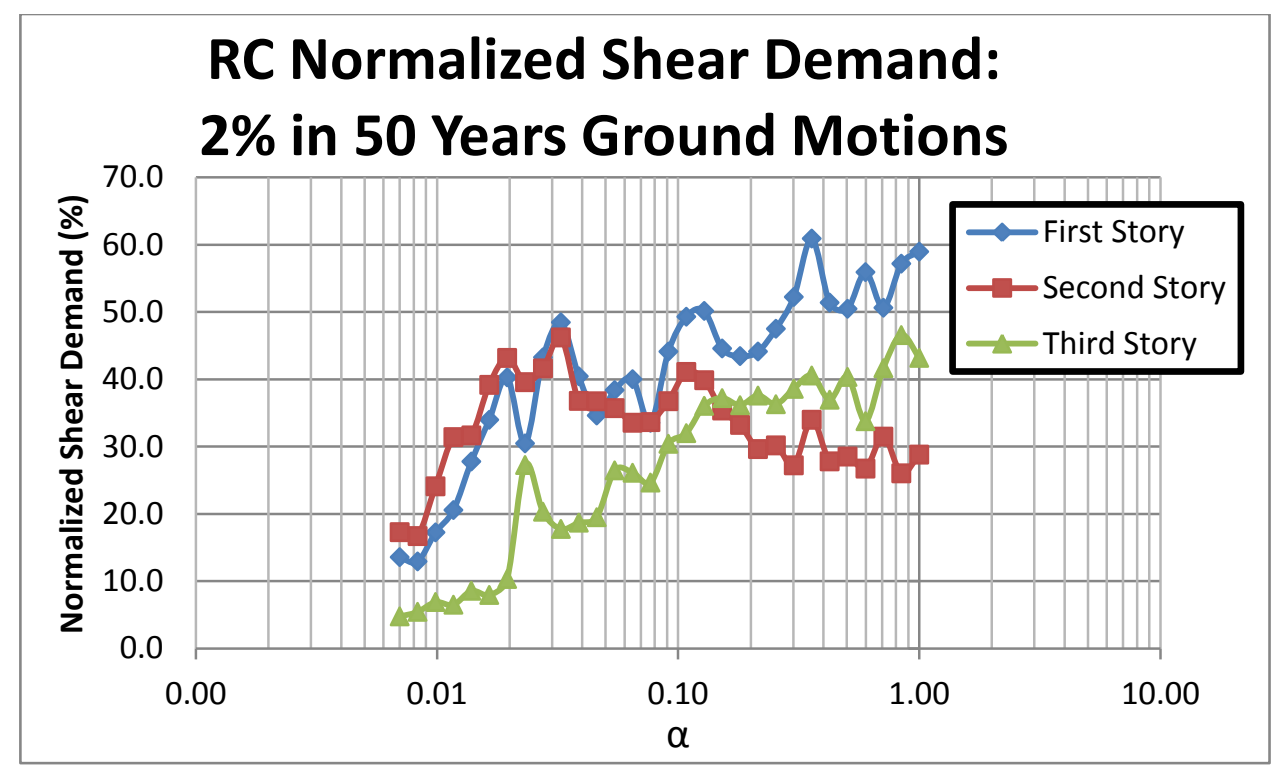

Figure 5.32: Normalized median shear demand in RC (Earthquakes corresponding to $2 \%$ in 50 years)

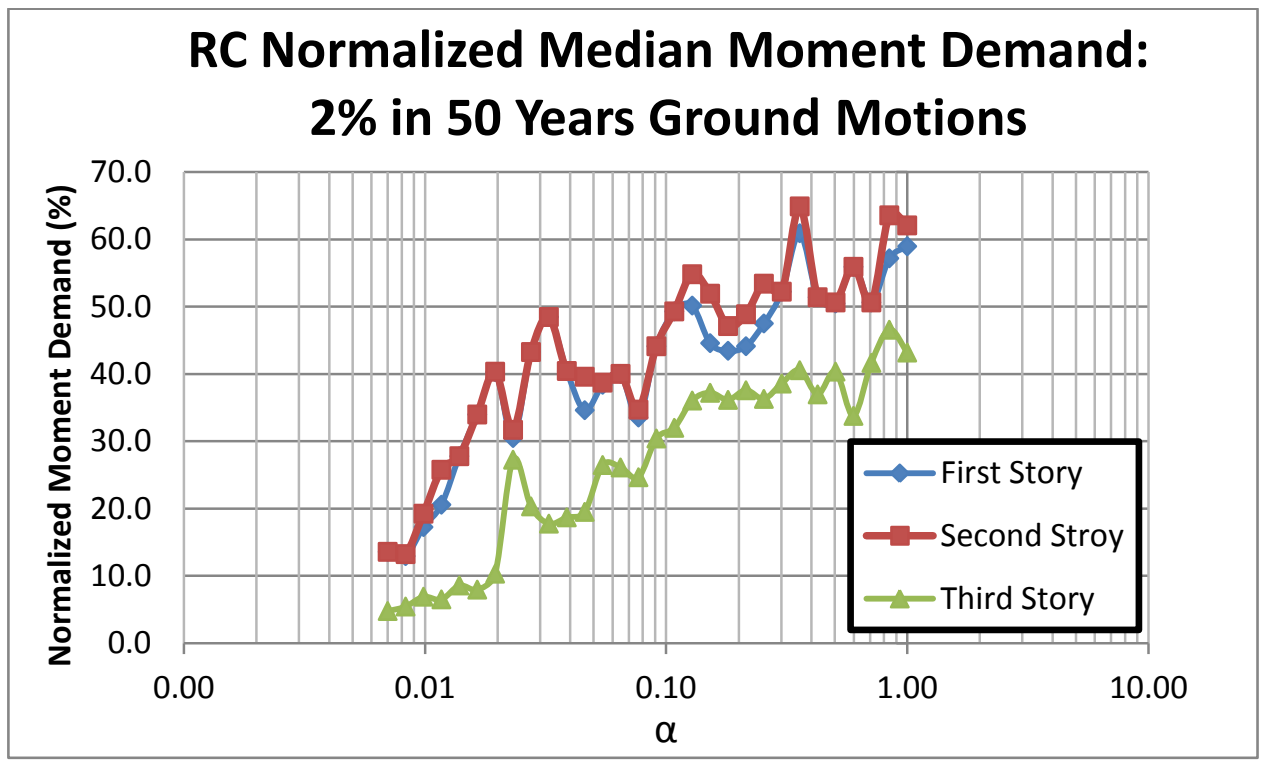

Figure 5.33: Normalized median bending moment demand in RC (Earthquakes corresponding to $2 \%$ in 50 years) 


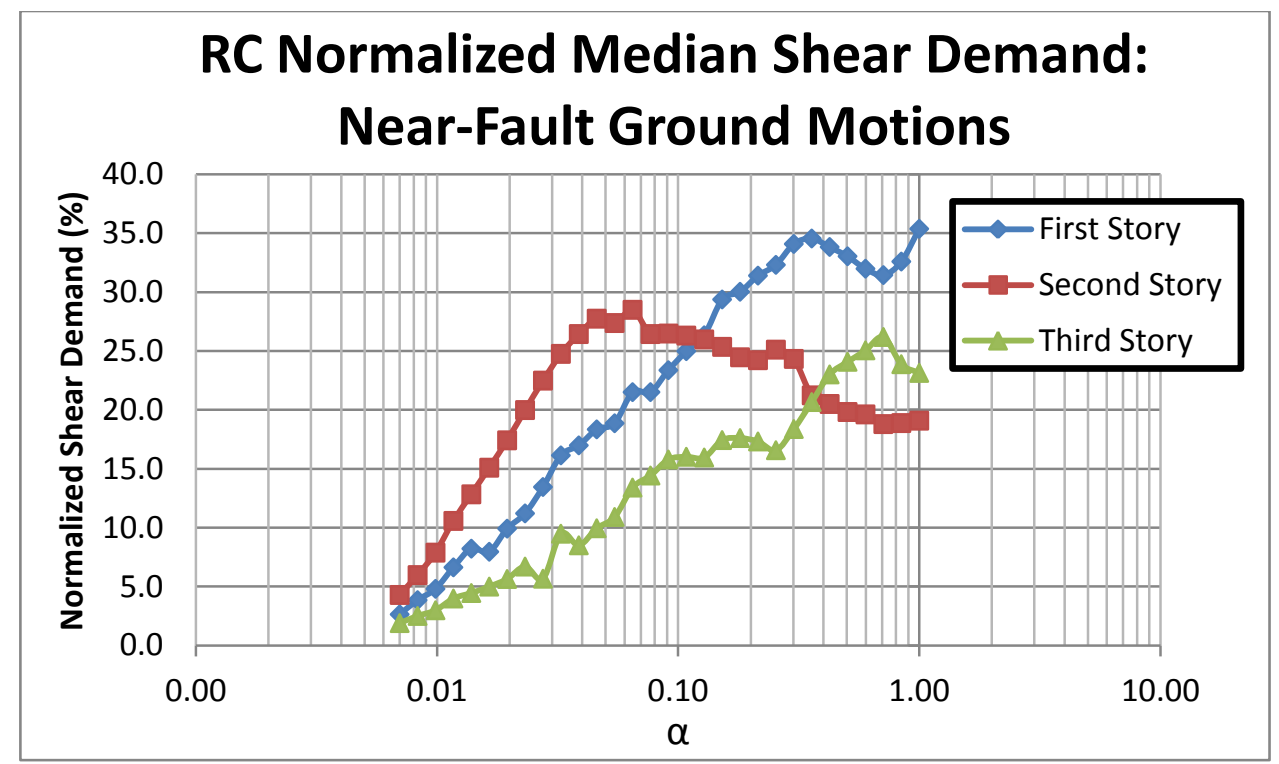

Figure 5.34: Normalized median shear demand in RC (Near-Fault Earthquakes)

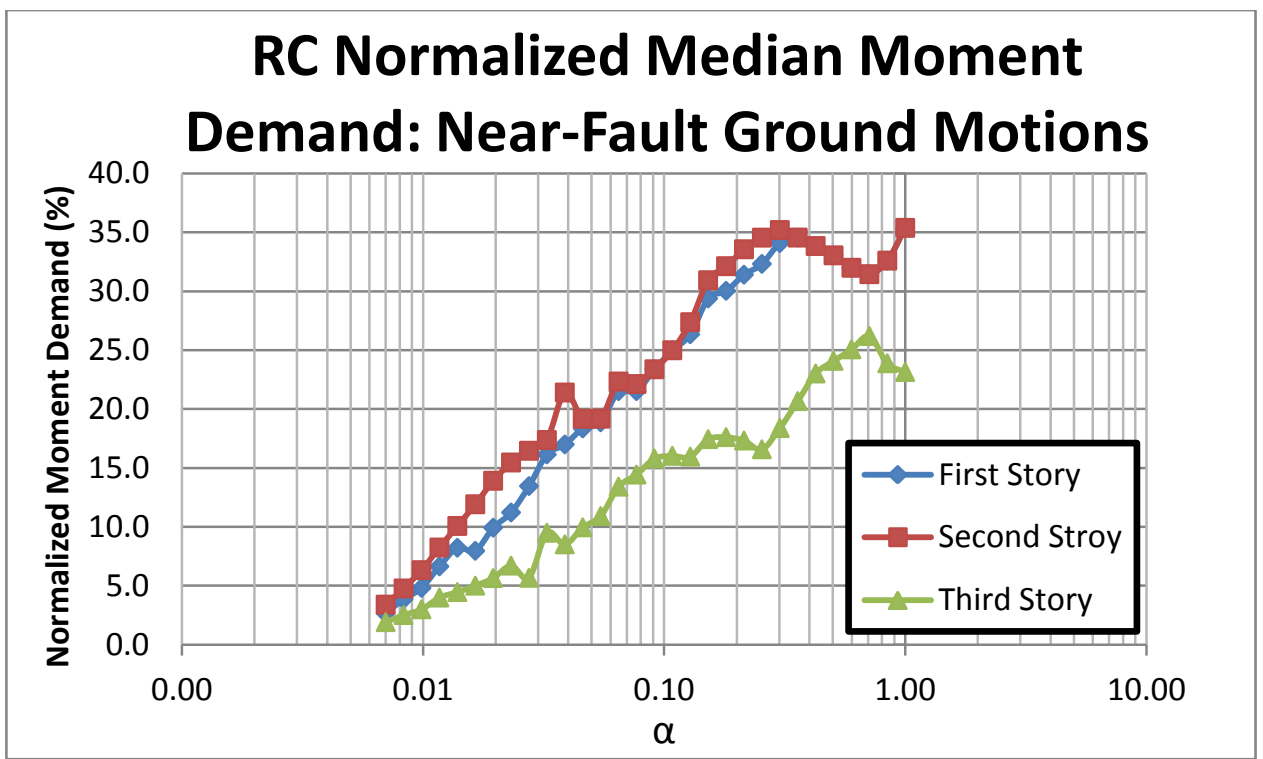

Figure 5.35: Normalized median bending moment demand in RC (Near-Fault Earthquakes)

\subsubsection{Link Demands}

The axial demand on the links was also of interest. Similarly, it was normalized by $V_{1 y}$. Figures 5.36 to 5.38 show the median of the maximum normalized axial demand for the two links working in parallel for the three sets of ground motions for every $\alpha$. The link demands predicted from the ground motions corresponding to $10 \%$ in 50 years and from 
the near-fault ground motions are very similar to the nonlinear pushover analysis results (see Figures 5.21 to 5.23). However, the link demands from the earthquakes corresponding to $2 \%$ in 50 years are significantly larger since the braces are more likely to rupture in this level of earthquakes and the links will be further loaded when brace ruptures result in strength and stiffness degradations.

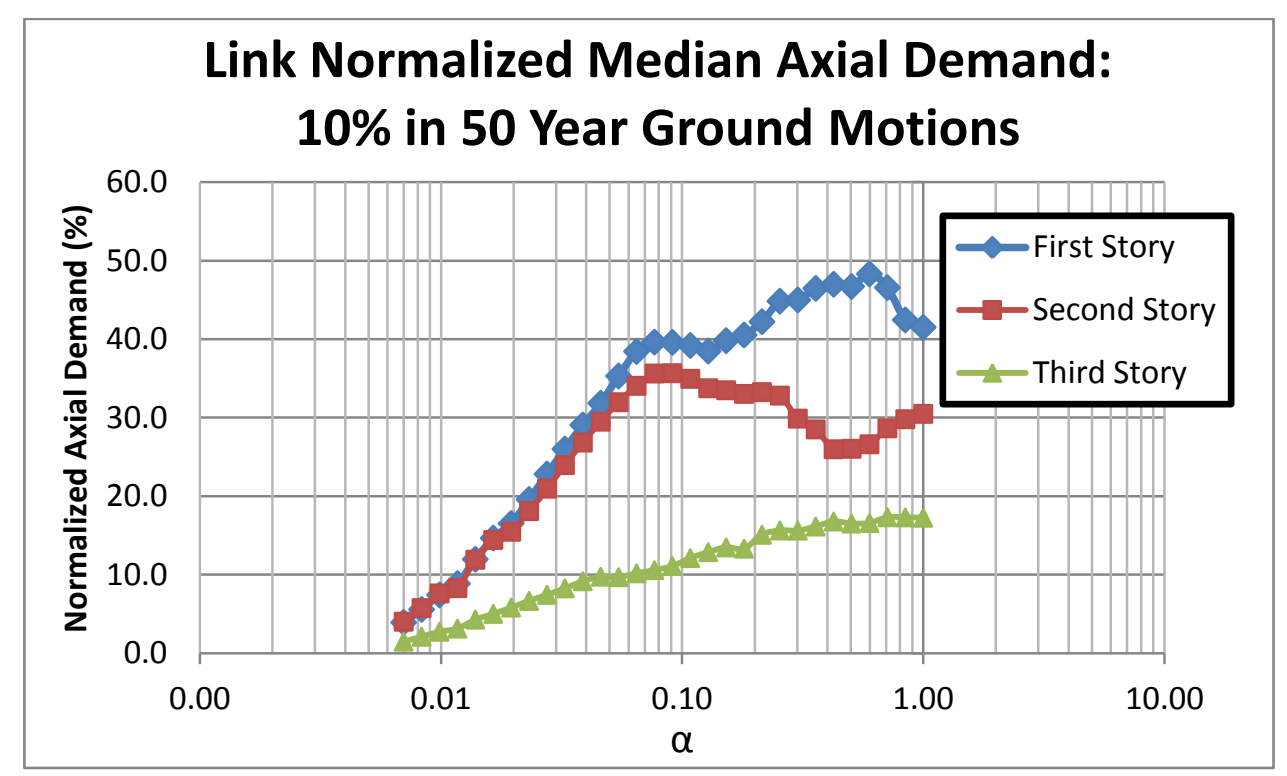

Figure 5.36: Normalized median axial demand in links (Earthquakes corresponding to $10 \%$ in 50 years)

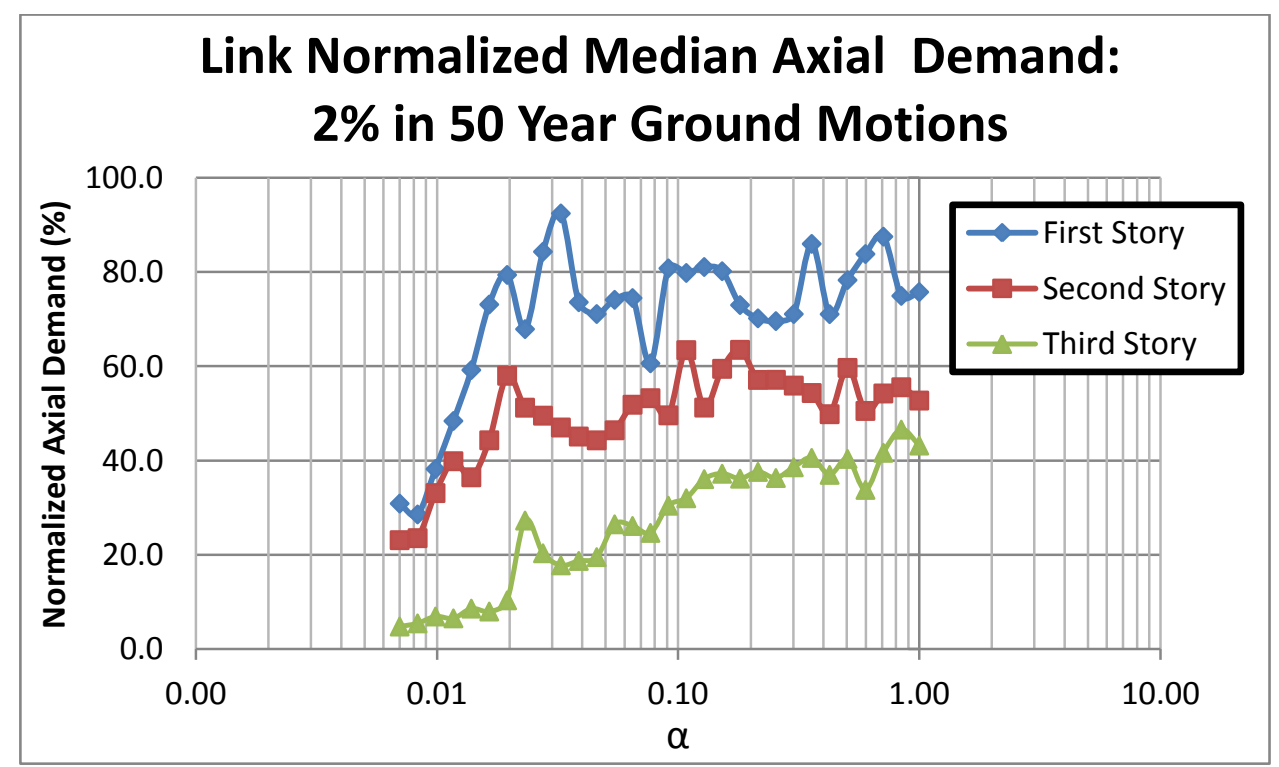

Figure 5.37: Normalized median axial demand in links (Earthquakes corresponding to 2\% in 50 years) 


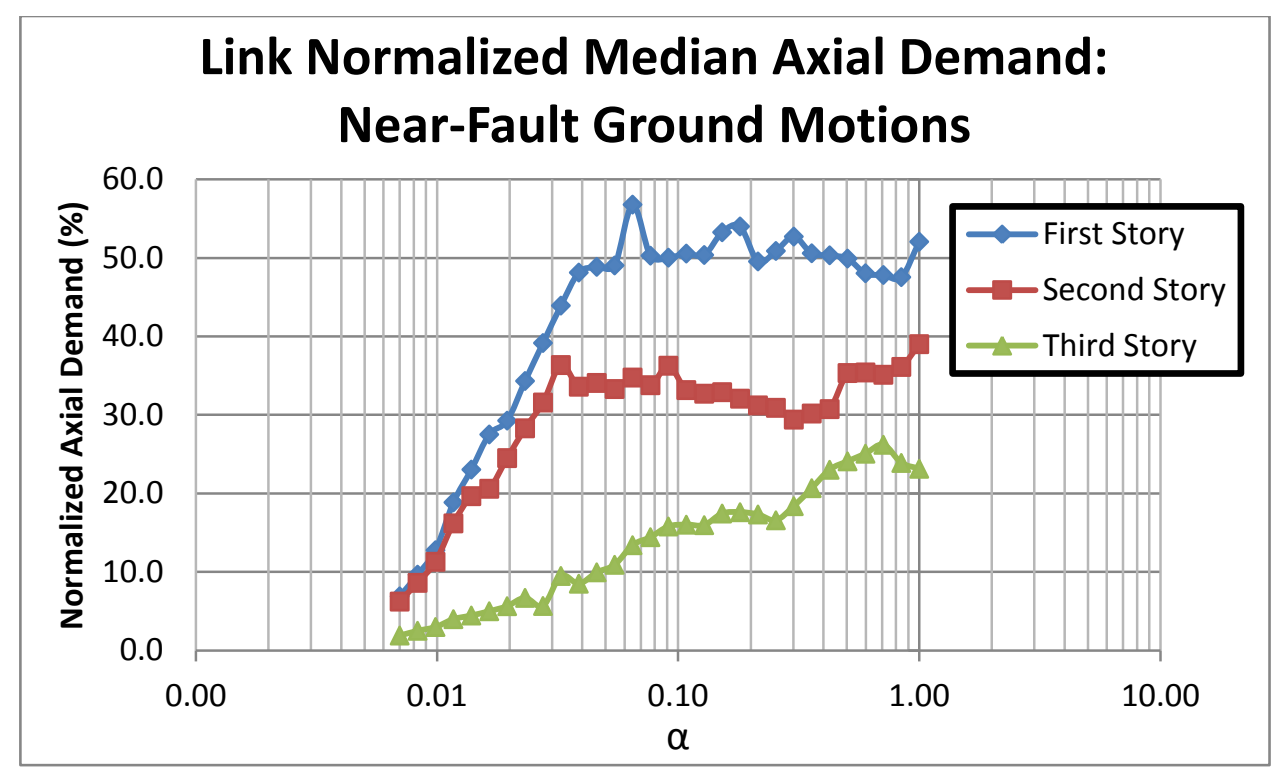

Figure 5.38: Normalized median axial demand in links (Near-Fault Earthquakes)

\subsubsection{Fracture of Braces}

As discussed in the previous sections, the original CBF is vulnerable to soft-story failure due to the brace rupture caused by low-cycle fatigue. Without $\mathrm{RC}$, the seismic force cannot be transferred to a lower story or foundation when braces fracture at a certain story. The implementation of RC allows for other stories without brace ruptured to get engaged, and preventing in many cases complete fracture of the braces. To better understand the effect of the $\mathrm{RC}$ on minimizing brace ruptures, the axial force histories in all braces of model LA3 and LA3-A under earthquake record LA10 are compared in Figures 5.39 and 5.40. As shown, the bottom-story braces in LA3 are completely fractured under the earthquake, causing a maximum drift of $9.49 \%$ in the system (far beyond the collapse prevention limit). However, with the implementation of a RC (having an $\alpha$ value of 1) in LA3-A, the maximum drift is reduced to $1.01 \%$ (well below the life safety limit) and no braces are ruptured during the earthquake as shown in Figure 5.40 . 

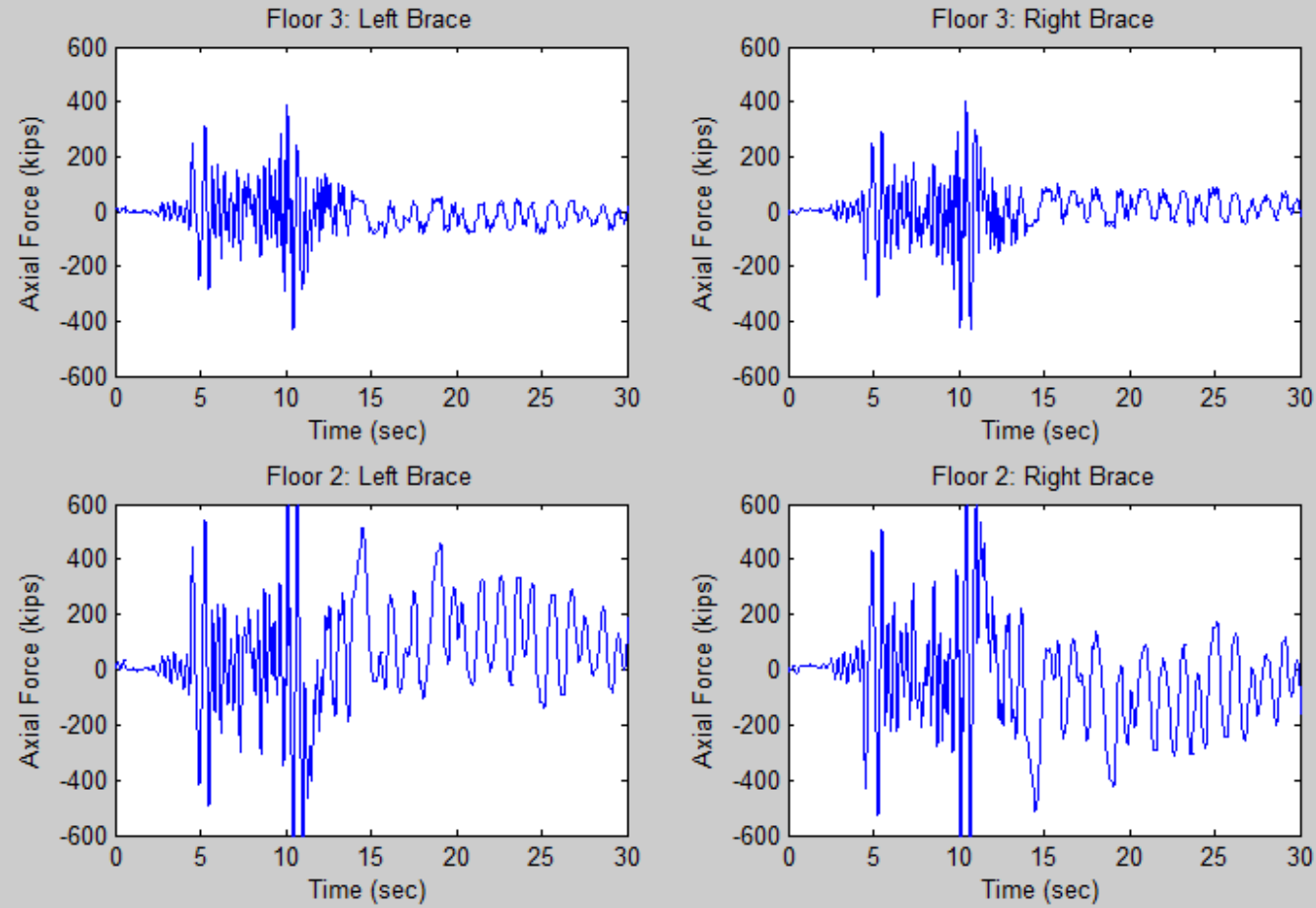

Floor 1: Left Brace
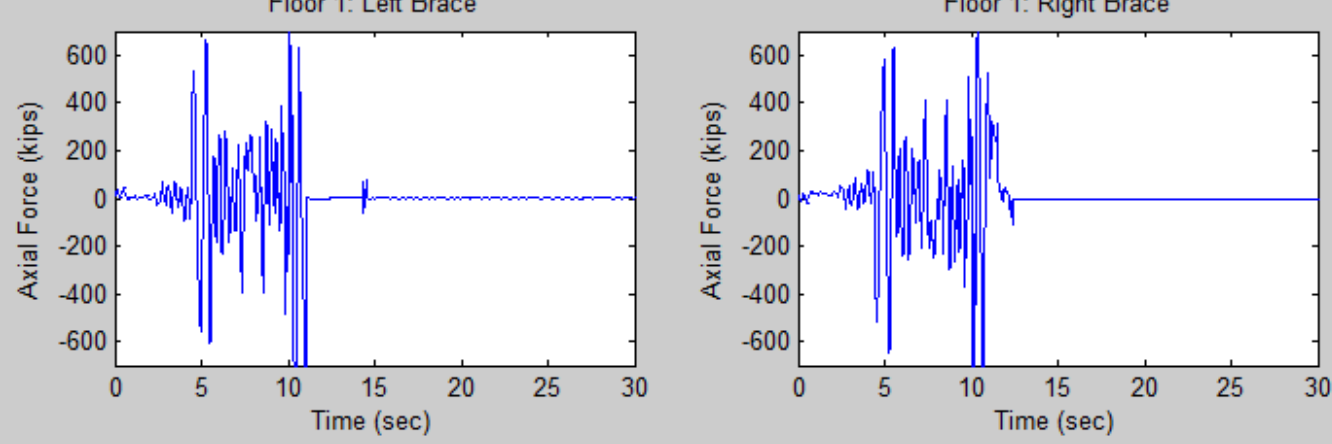

Figure 5.39: Brace axial force history in LA3 under ground motion LA10 


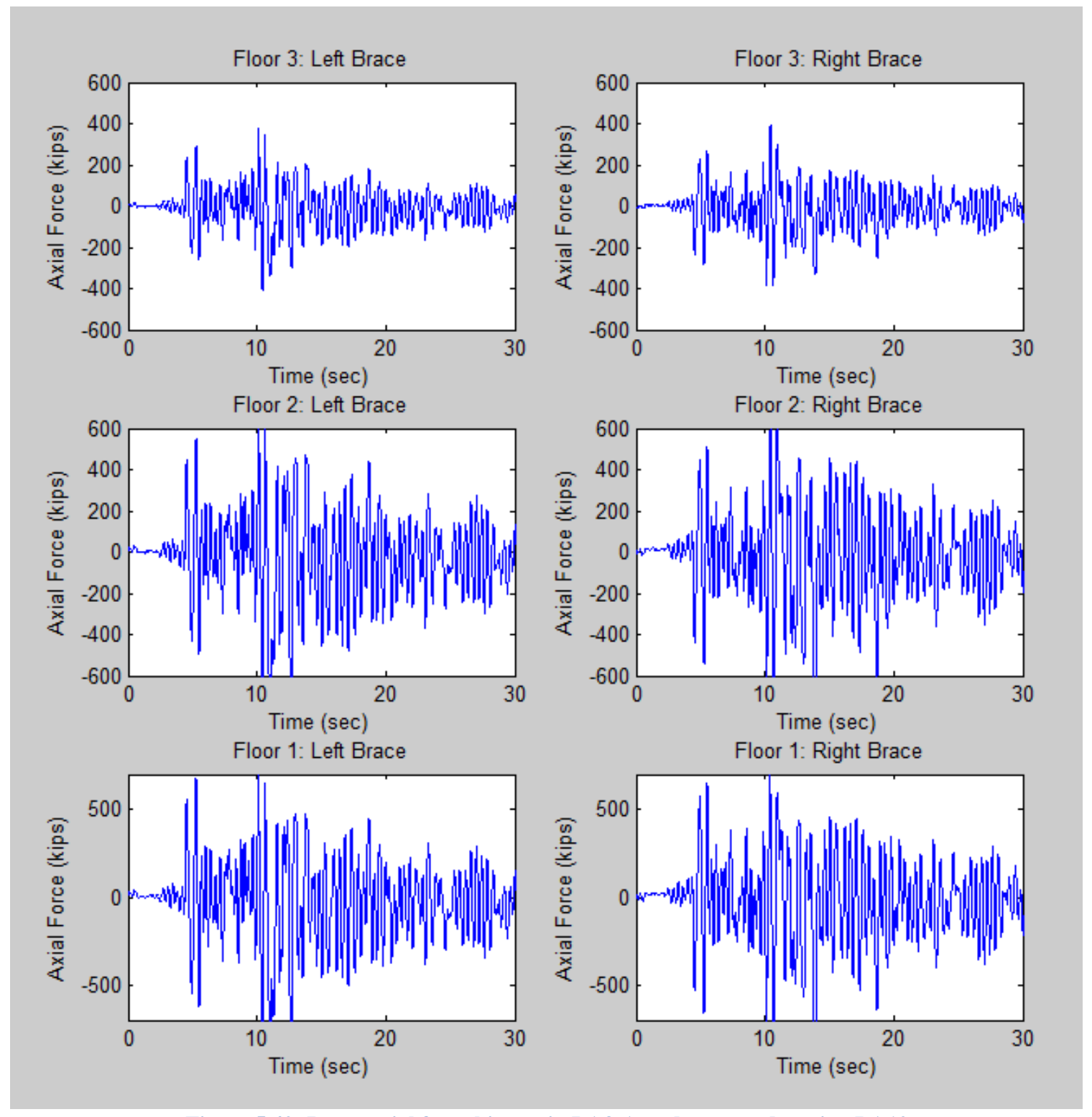

Figure 5.40: Brace axial force history in LA3-A under ground motion LA10

\subsubsection{Benefits from Links with Energy Dissipation Capacity}

As discuss in the previous sections, the links may be installed with energy dissipation capacity to further reduce the inter-story drifts. The links in LA3-B were designed based on the maximum axial force demand of the three stories obtained from the nonlinear static pushover analysis. They were designed to have full moment capacity while transferring the maximum axial load. Based on Bruneau et al. (2011), it was necessary to 
have two wide flange members working in parallel at each floor. The member selected was a W30X99 and was used at each of the three stories of LA3-B.

In the case of the $10 \%$ in 50 years ground motions, LA3-A is sufficient to reduce the median of maximum inter-story drifts below the target limit. However, having the links with energy dissipation capacity, LA3-B, as shown in Figure 5.41, reduces the median of maximum inter-story drifts to a value lower than the target performance at a smaller $\alpha$, thus leading to a more economical design of RC. At the range of larger $\alpha$, the performance with and without energy dissipation capacity are similar (see Figure 5.41). Considering the $2 \%$ in 50 years ground motions, LA3-A was not sufficient to reduce the median of maximum inter-story drifts to a value lower than the collapse prevention drift. Introducing links with energy dissipation capacity helps reduce the drift below the target inter-story drift as seen in Figure 5.42. As seen in Figure 5.43, having the links with energy dissipation capacity in LA3-B under the near-fault ground motions, the median of maximum inter-story drifts can be reduced, particularly over the range of smaller $\alpha$.

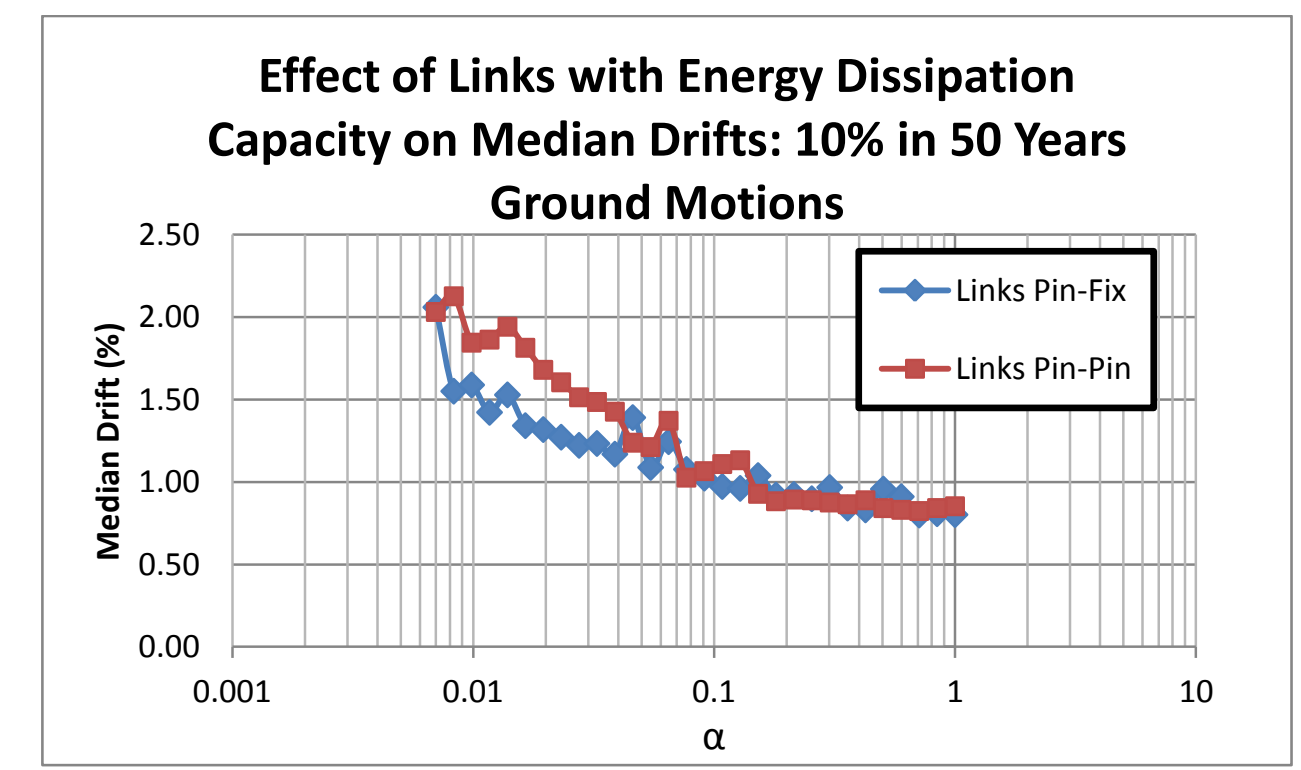

Figure 5.41: Comparison of median of maximum inter-story drifts: LA3-A vs LA3-B (Earthquakes corresponding to $10 \%$ in $\mathbf{5 0}$ years) 


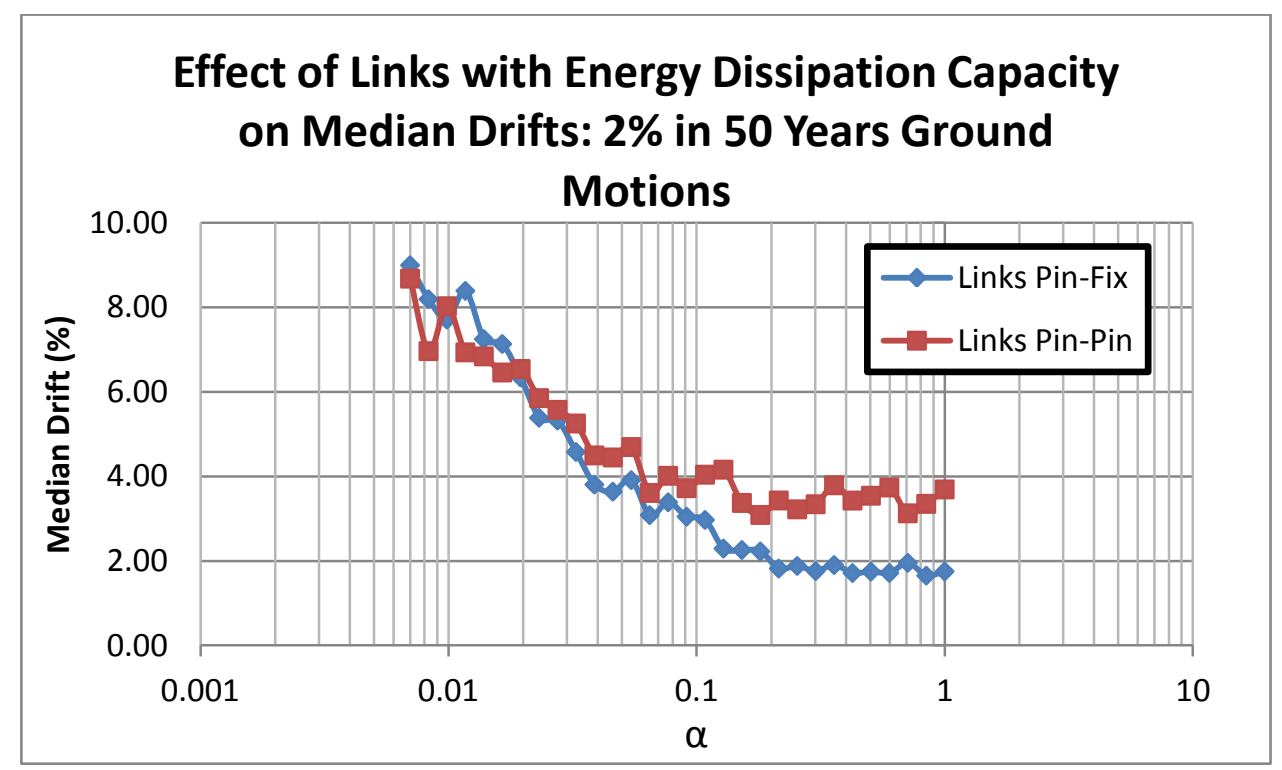

Figure 5.42: Comparison of median of maximum inter-story drifts: LA3-A vs LA3-B (Earthquakes corresponding to $2 \%$ in 50 years)

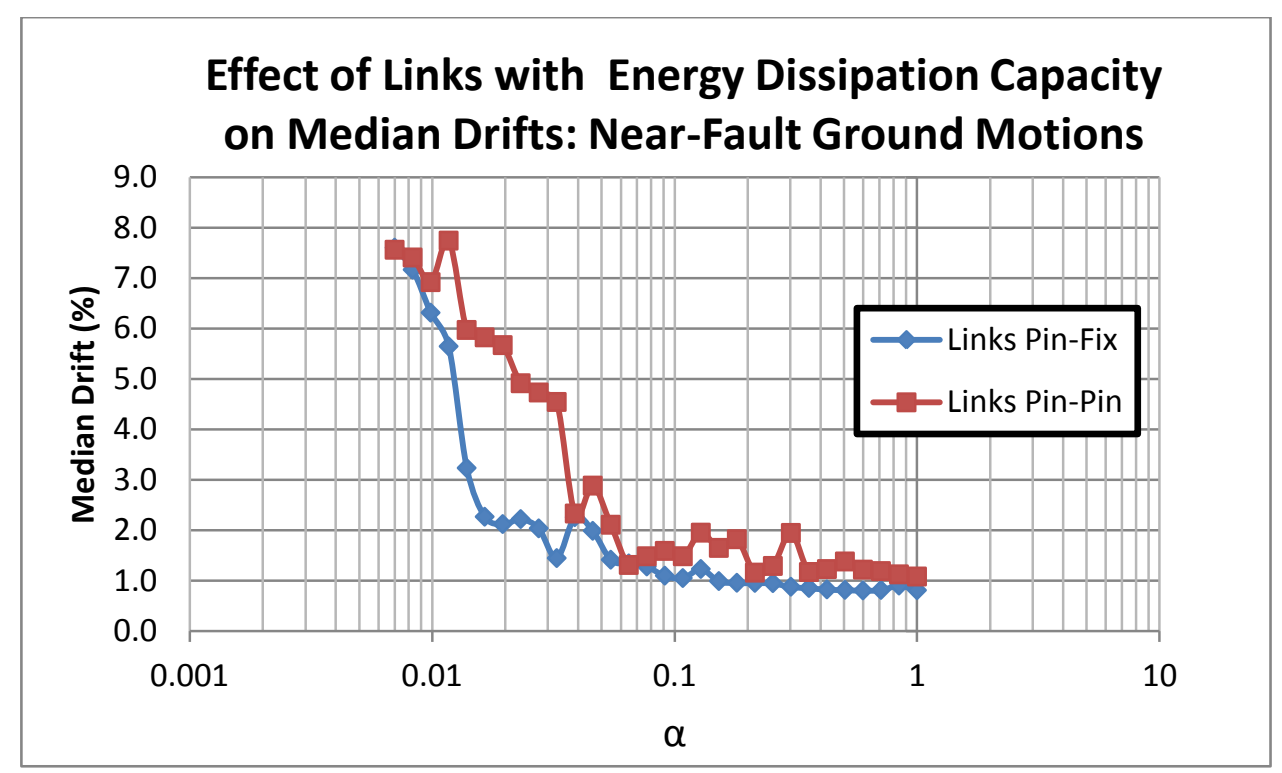

Figure 5.43: Comparison of median of maximum inter-story drifts: LA3-A vs LA3-B (Near-Fault Earthquakes)

The normalized shear and bending moment demands on RC of LA3-B are shown in Figures 5.44 to 5.49. Compared with the corresponding results for LA3-A (see Figures 5.30 to 5.35), the normalized median shear and bending moment of the RC are larger in 
the segment controlling the RC design in LA3-B for the three sets of ground motions. The demands increase because the links fixed to the RC tends to increase the system stiffness and consequently attract larger seismic forces on the system, causing larger shear and bending moment demands on the RC of LA3-B.

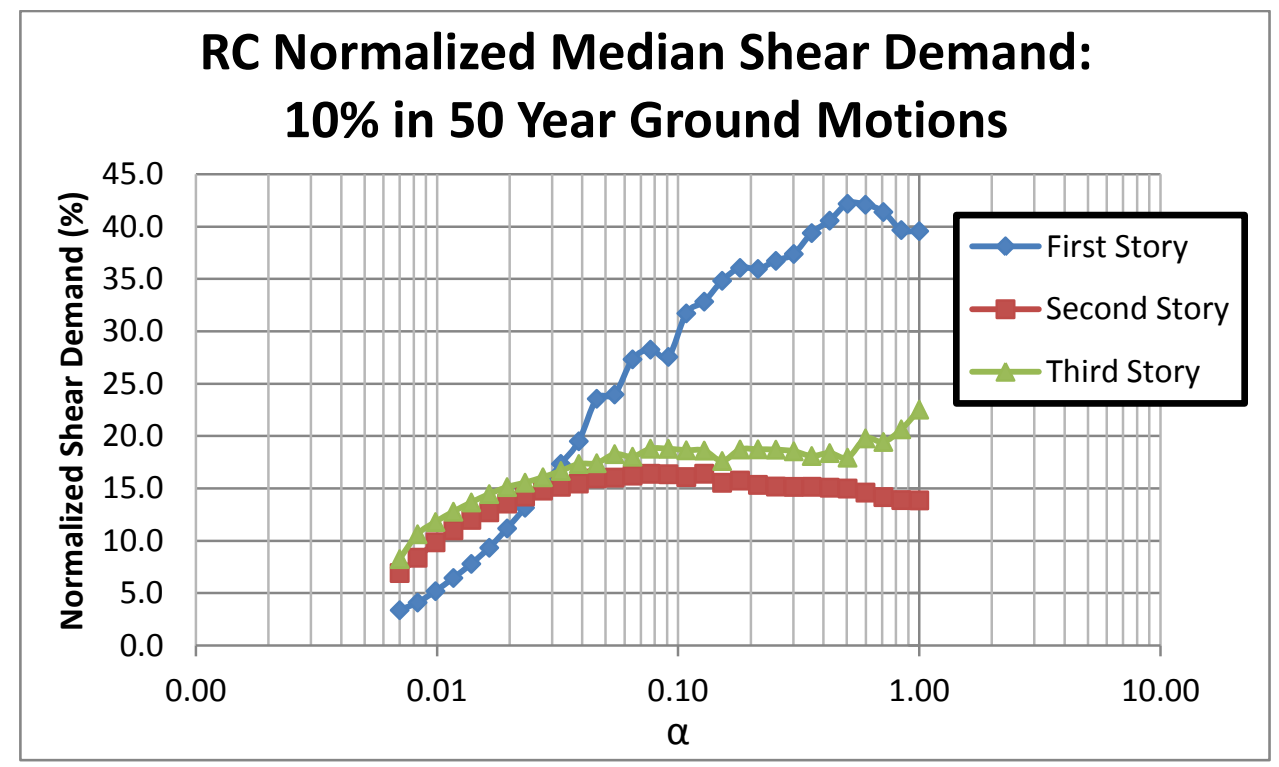

Figure 5.44: Normalized median shear demand on RC in LA3-B (Earthquakes corresponding to $10 \%$ in 50 years)

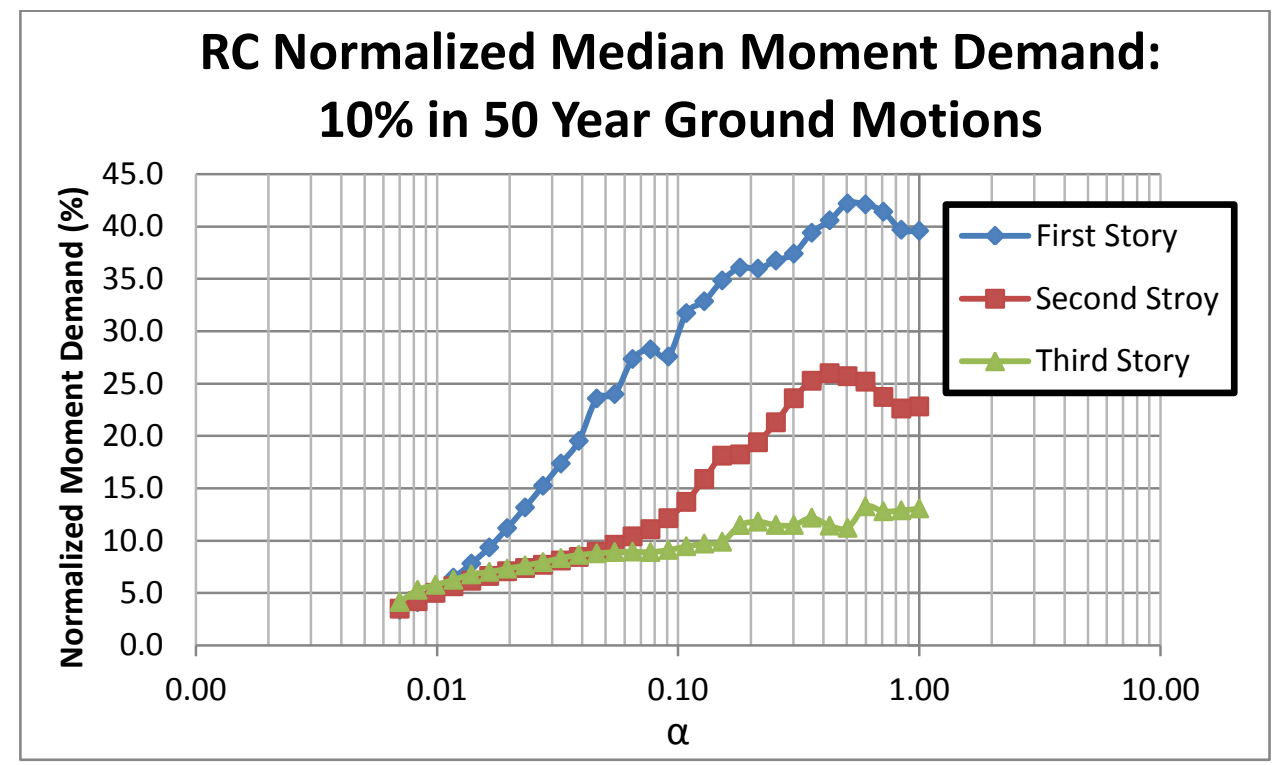

Figure 5.45: Normalized median bending moment demand on RC in LA3-B (Earthquakes corresponding to $10 \%$ in 50 years) 


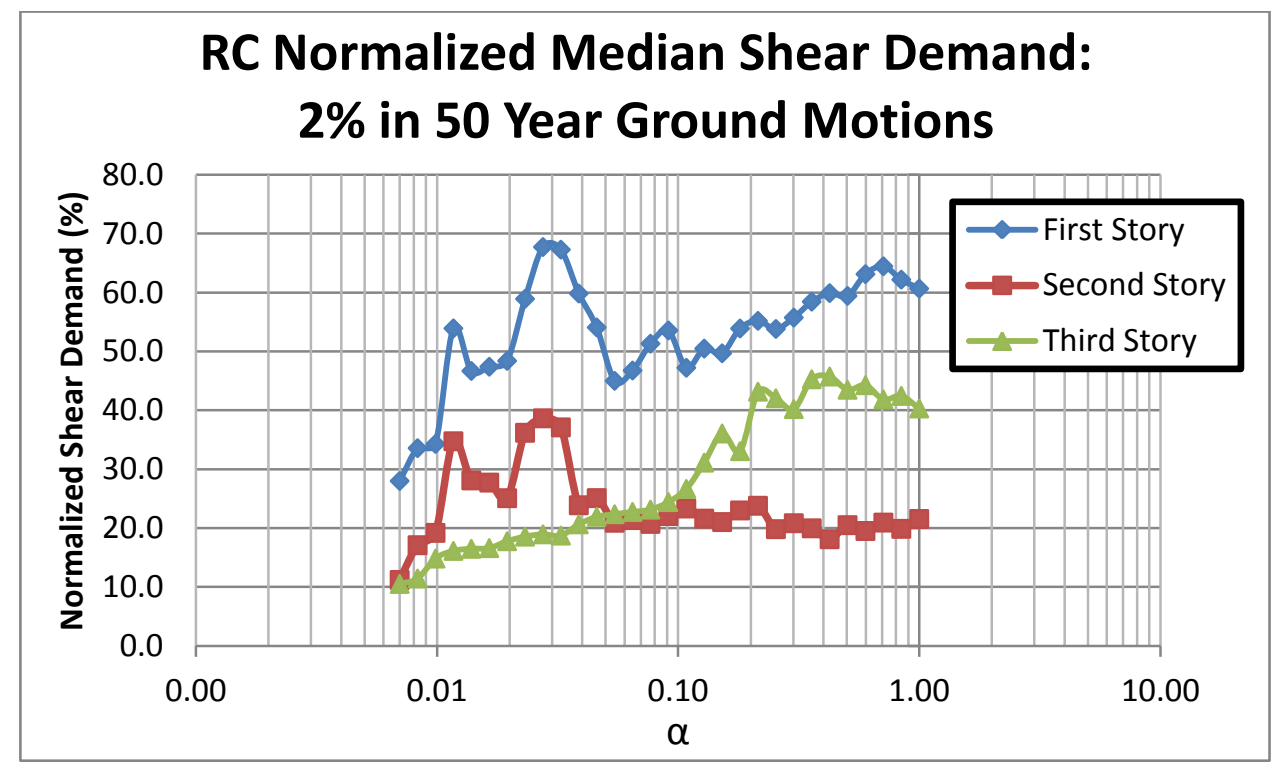

Figure 5.46: Normalized median shear demand on RC in LA3-B (Earthquakes corresponding to $2 \%$ in 50 years)

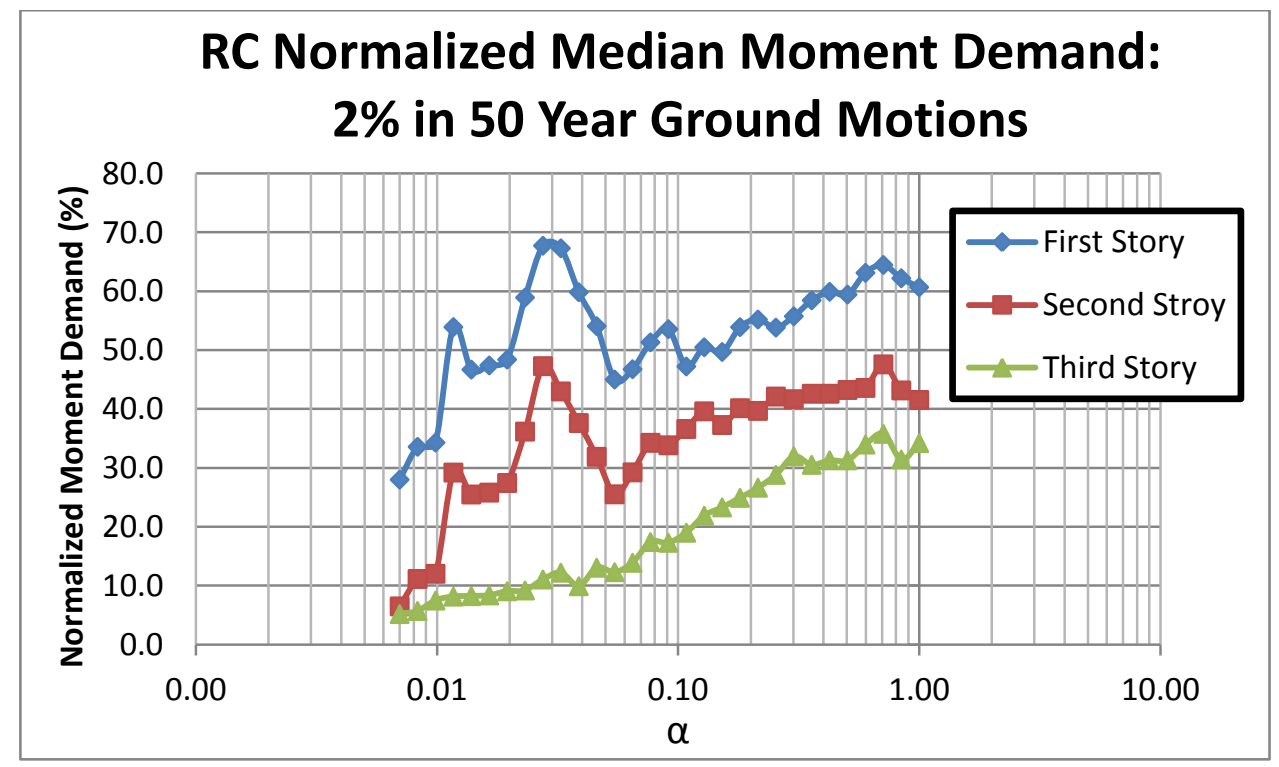

Figure 5.47: Normalized median bending moment demand on RC in LA3-B (Earthquakes corresponding to $2 \%$ in 50 years) 


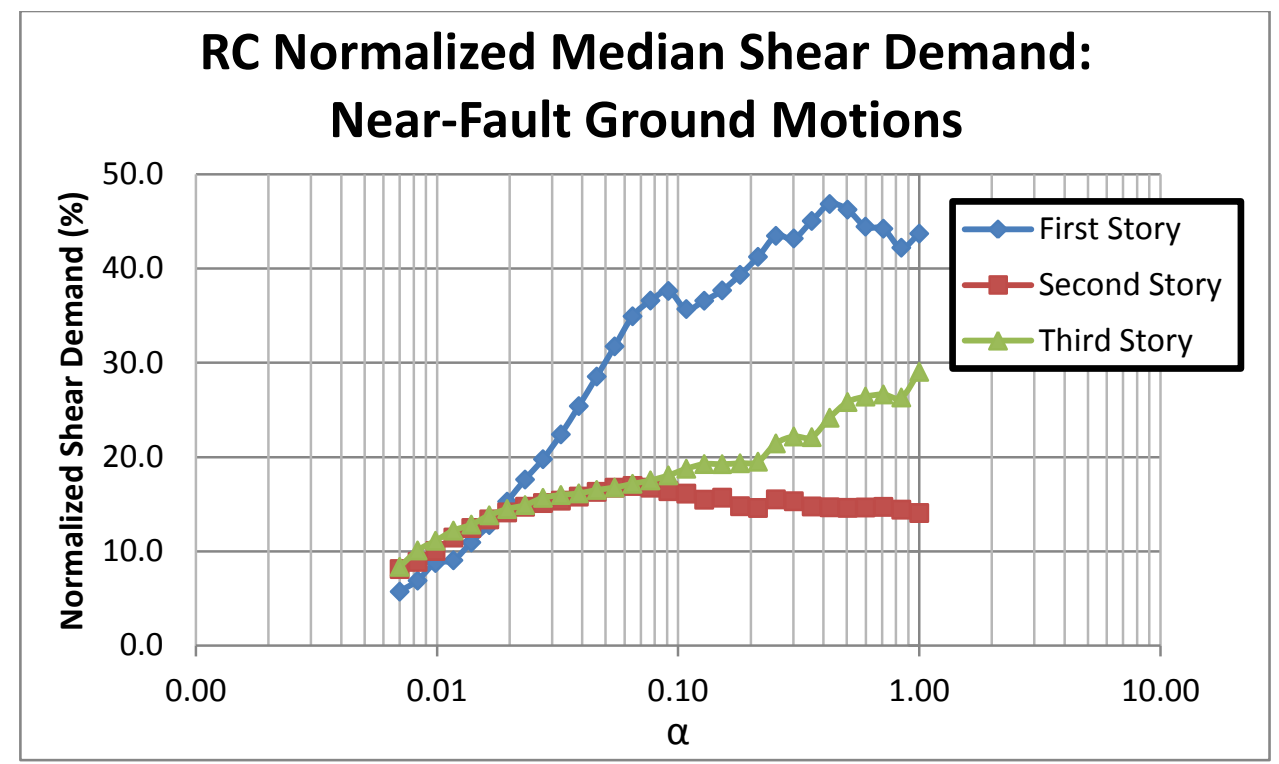

Figure 5.48: : Normalized median shear demand on RC in LA3-B (Near-Fault Earthquakes)

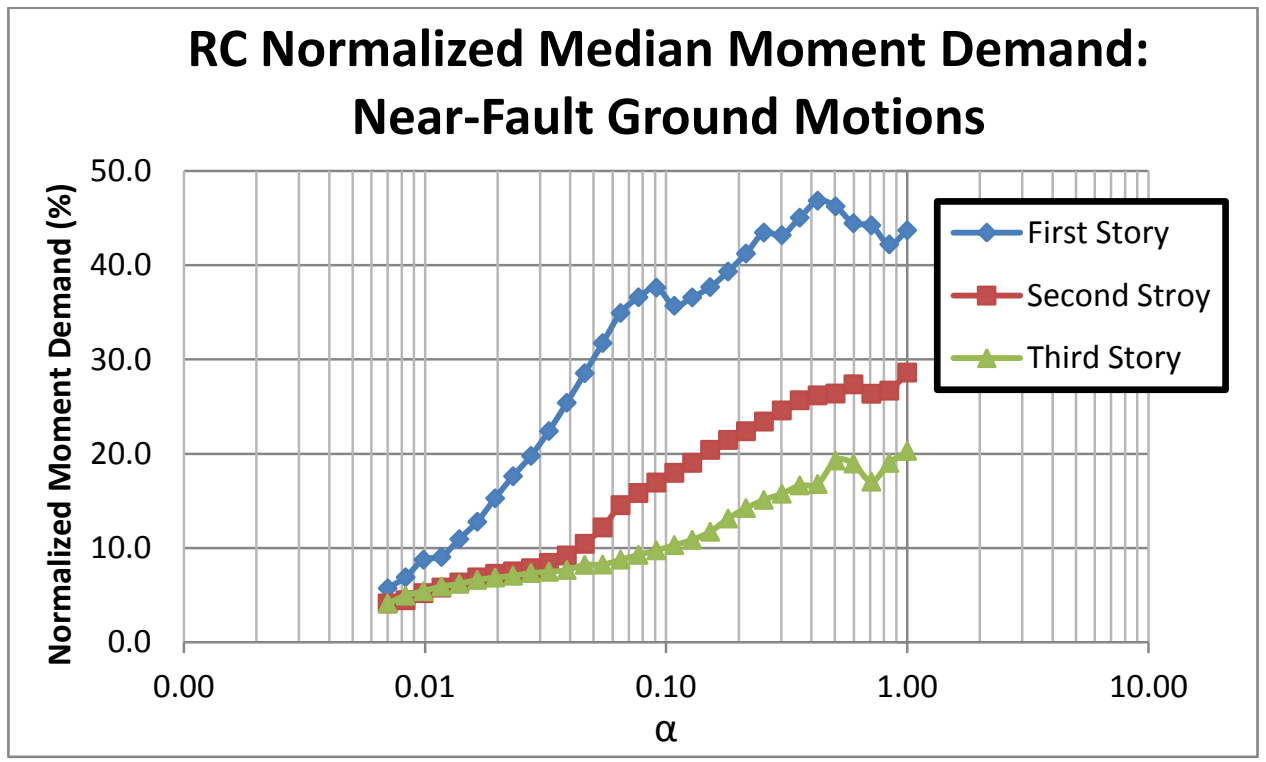

Figure 5.49: Normalized median bending moment demand on RC in LA3-B (Near-Fault Earthquakes)

The axial load demand on the links, which is normalized by $\mathrm{V}_{1 \mathrm{y}}$, is very similar to the values obtained from LA3-A, indicating that links with energy dissipation capacity do not impact the axial demand on the links. Having the links fixed to the RC introduces shear and moment to the links. As seen in the Figures 5.50 to 5.58, the moment demands, 
normalized by $\mathrm{V}_{1 \mathrm{y}}$, on links are increasing with the increase of $\alpha$ and then reach a plateau beyond a certain value of $\alpha$. The moment demands plateau because the links reach their plastic moment capacity. Accordingly, the shear demands also plateau, which is observed in results from all three suits of ground motions.

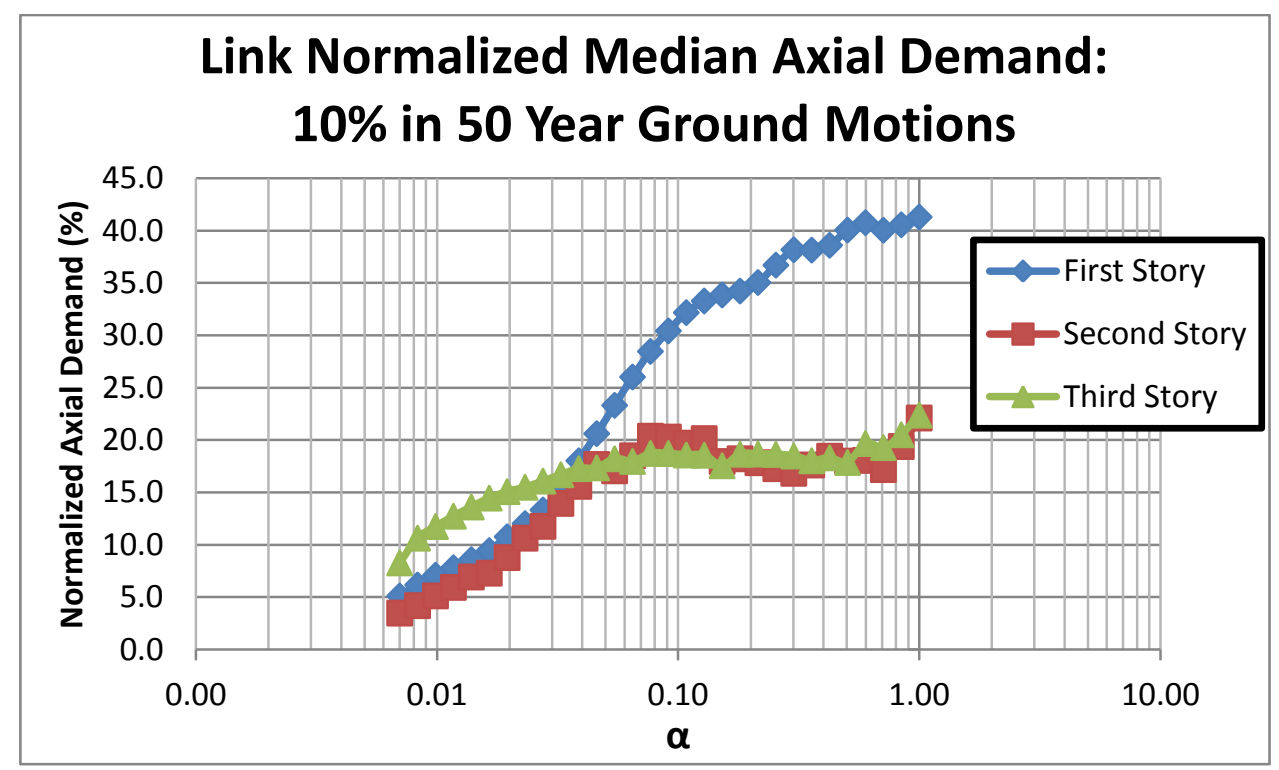

Figure 5.50: Normalized median axial demand in Links of LA3-B (Earthquakes corresponding to $10 \%$ in 50 years)

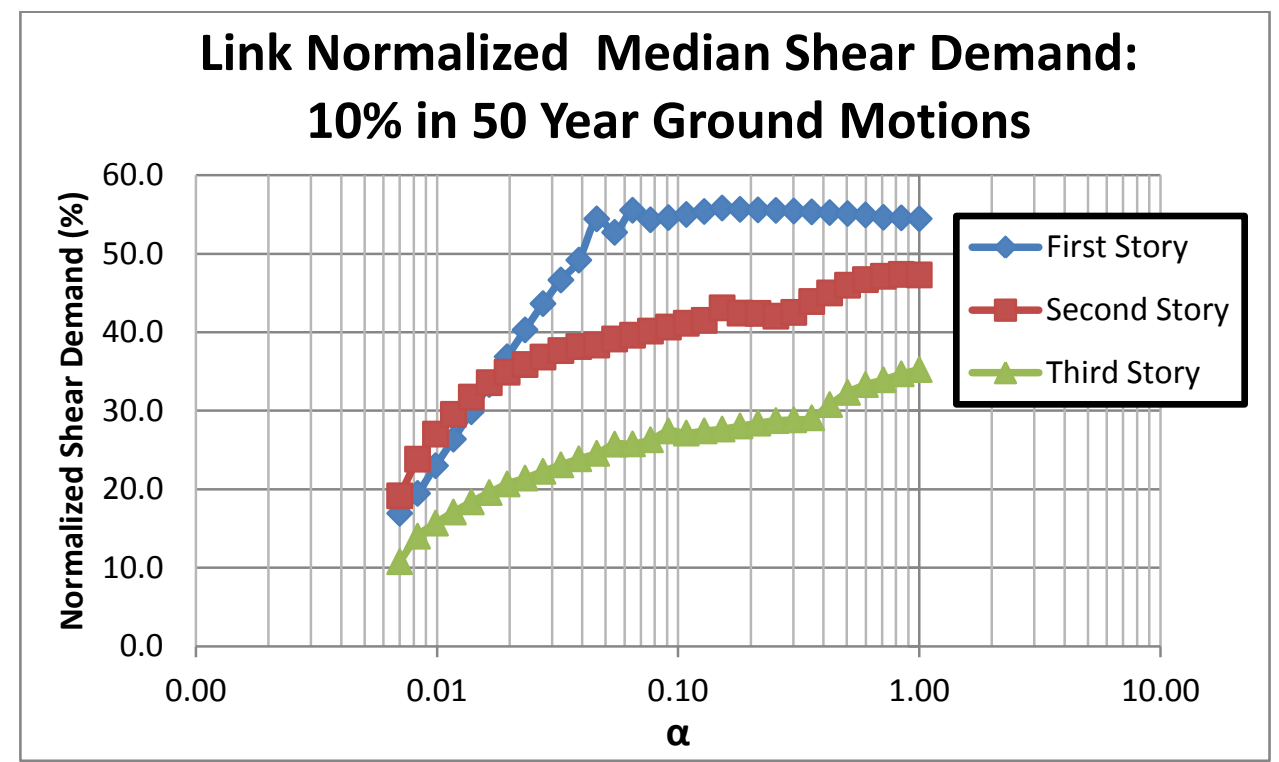

Figure 5.51: Normalized median shear demand in links of LA3-B (Earthquakes corresponding to $10 \%$ in 50 years ) 


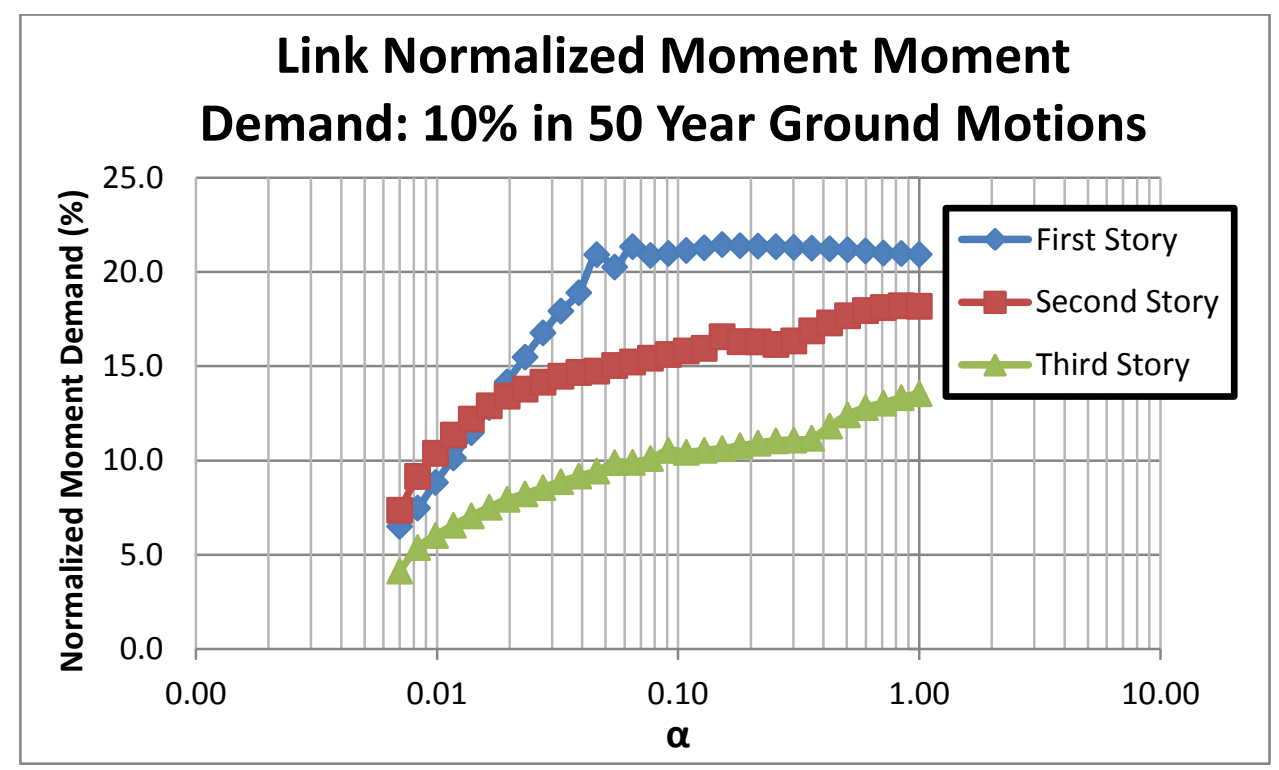

Figure 5.52: : Normalized median bending moment demand in links of LA3-B (Earthquakes corresponding to $10 \%$ in 50 years )

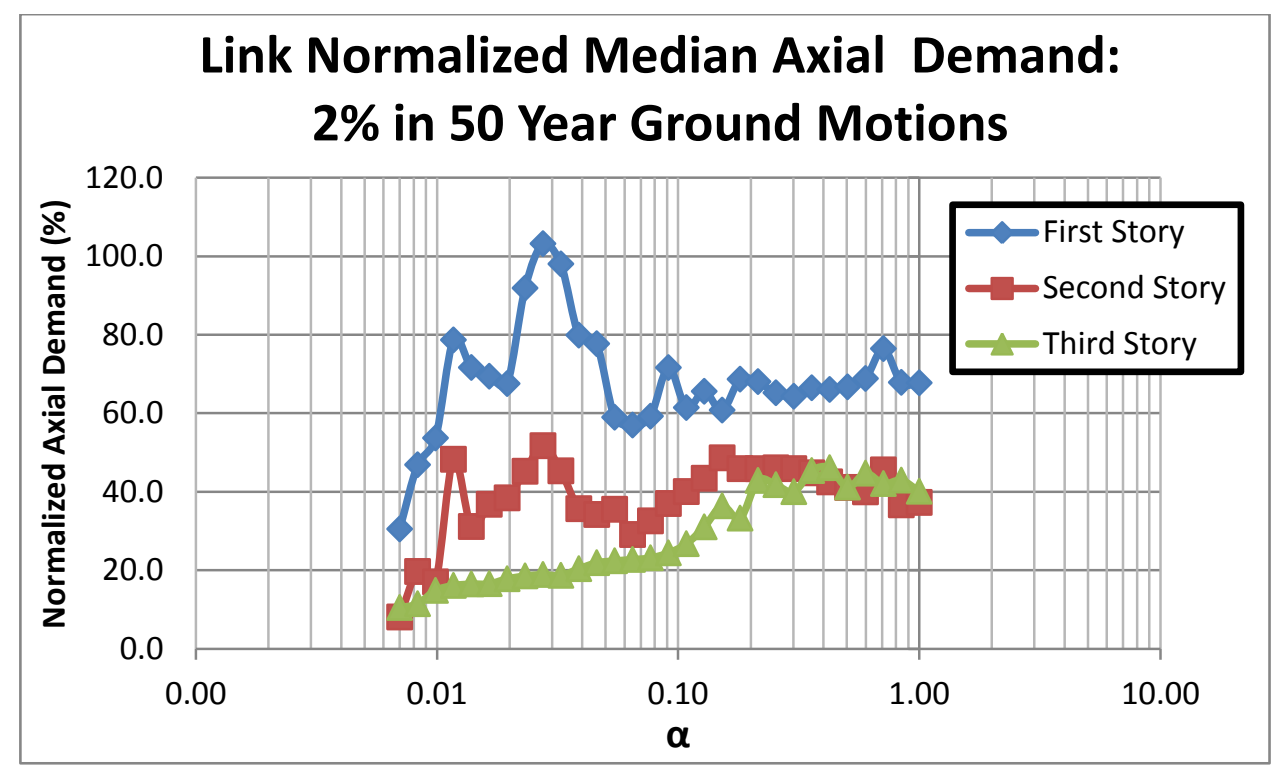

Figure 5.53: : Normalized median axial demand in links of LA3-B (Earthquakes corresponding to $2 \%$ in $\mathbf{5 0}$ years ) 


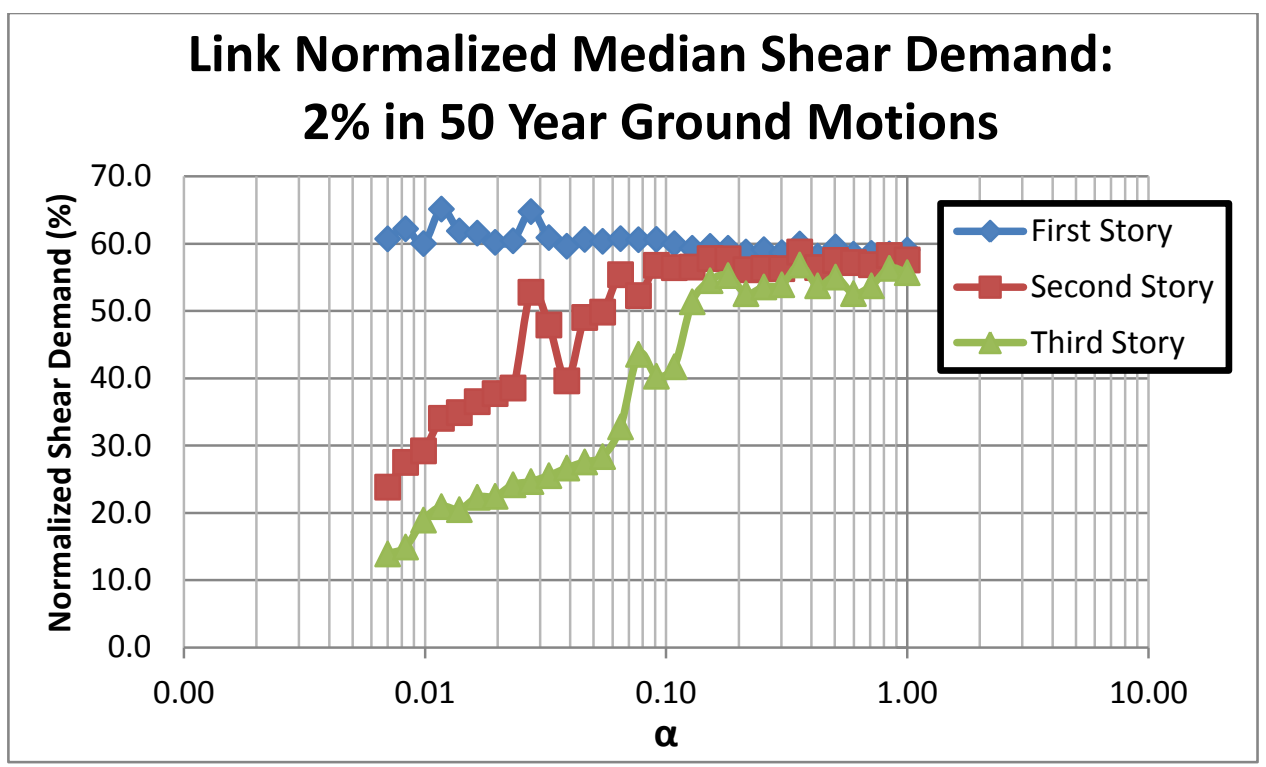

Figure 5.54: Normalized median shear demand in links of LA3-B (Earthquakes corresponding to $2 \%$ in 50 years )

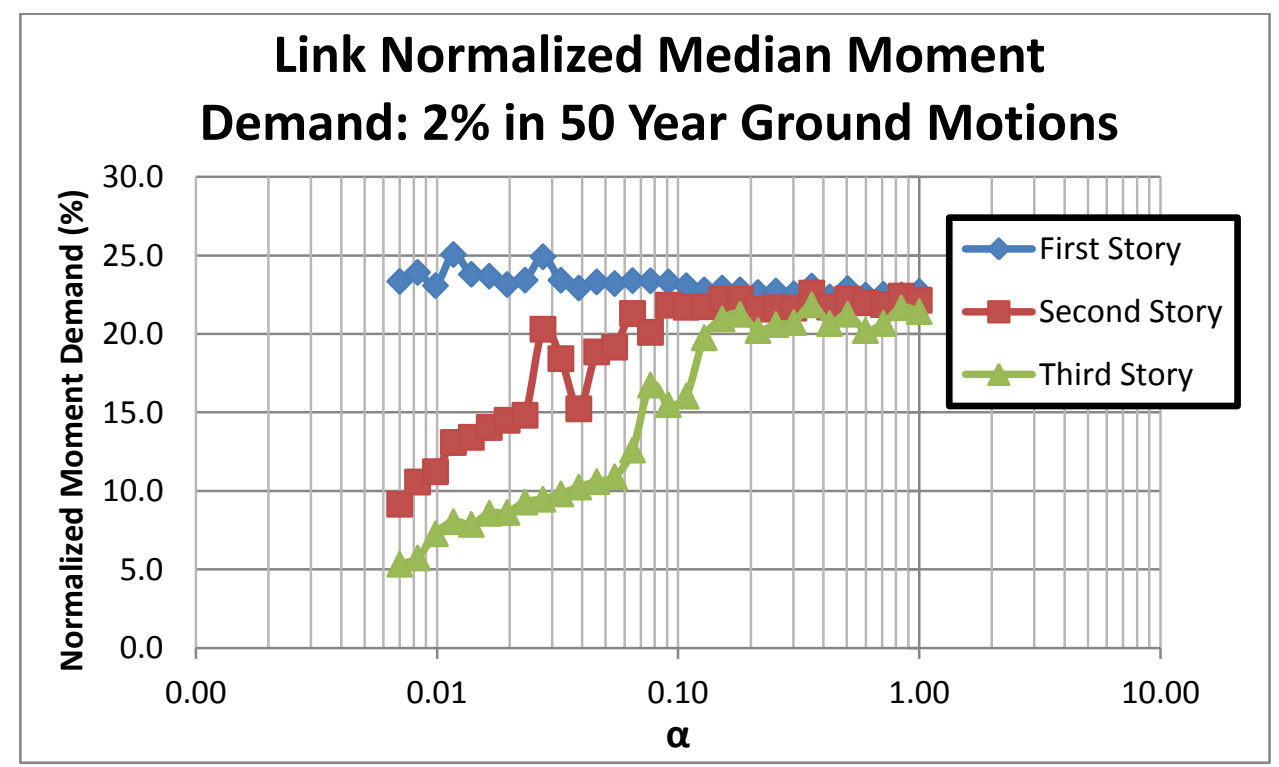

Figure 5.55: Normalized median moment demand in links of LA3-B (Earthquakes corresponding to $2 \%$ in 50 years ) 


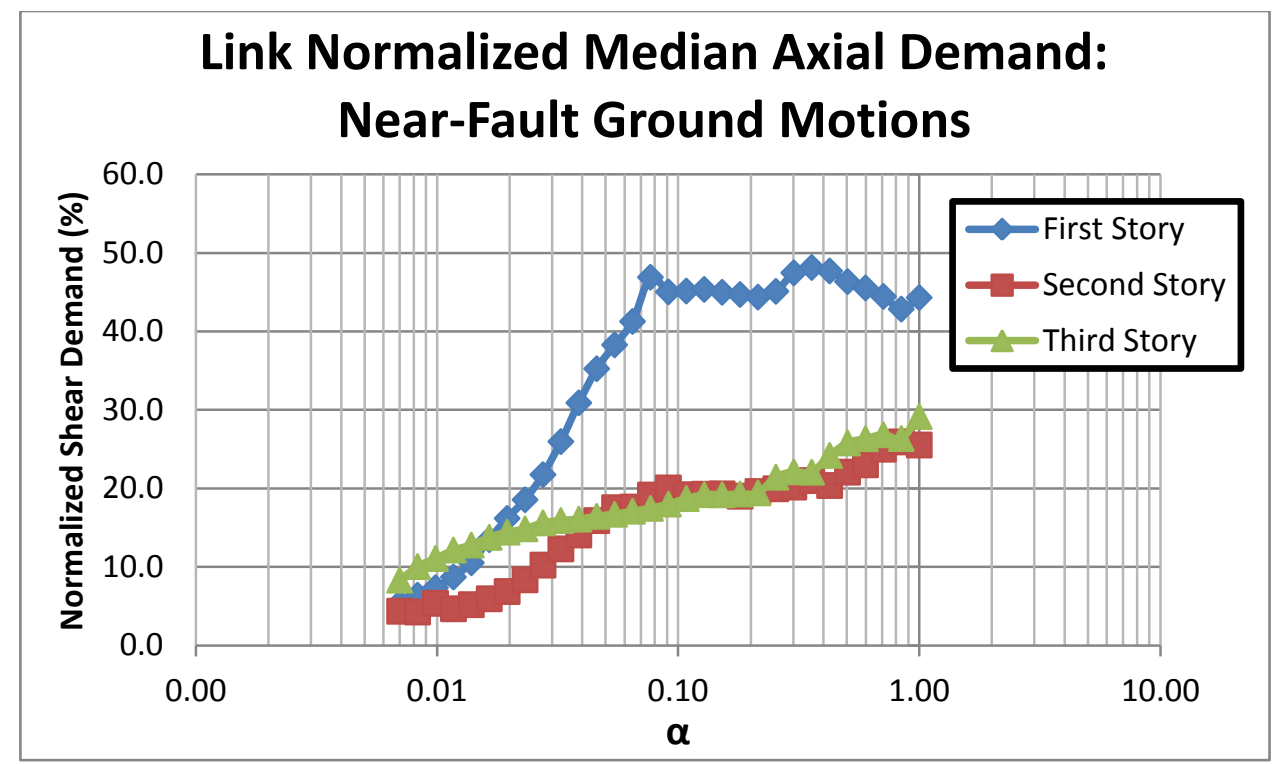

Figure 5.56: Normalized median axial demand in links of LA3-B (Near-Fault Earthquakes)

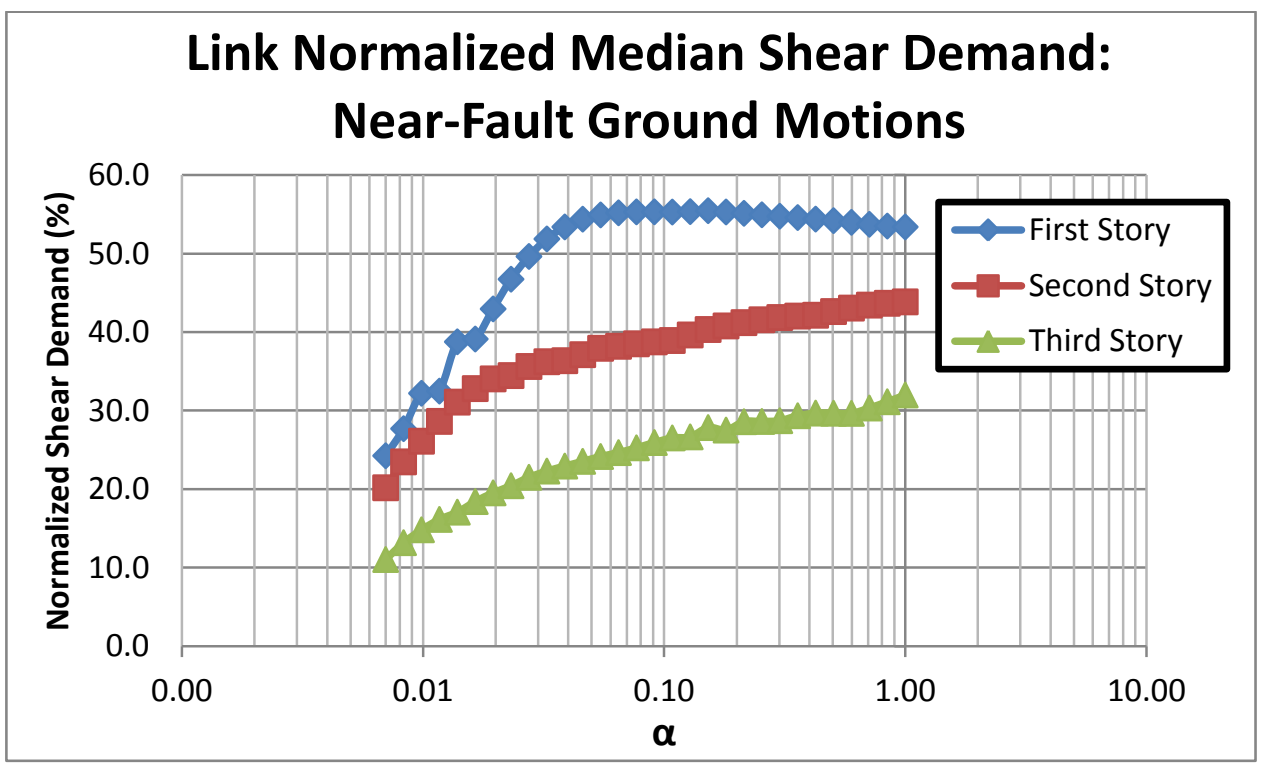

Figure 5.57: Normalized median shear demand in links of LA3-B (Near-Fault Earthquakes) 


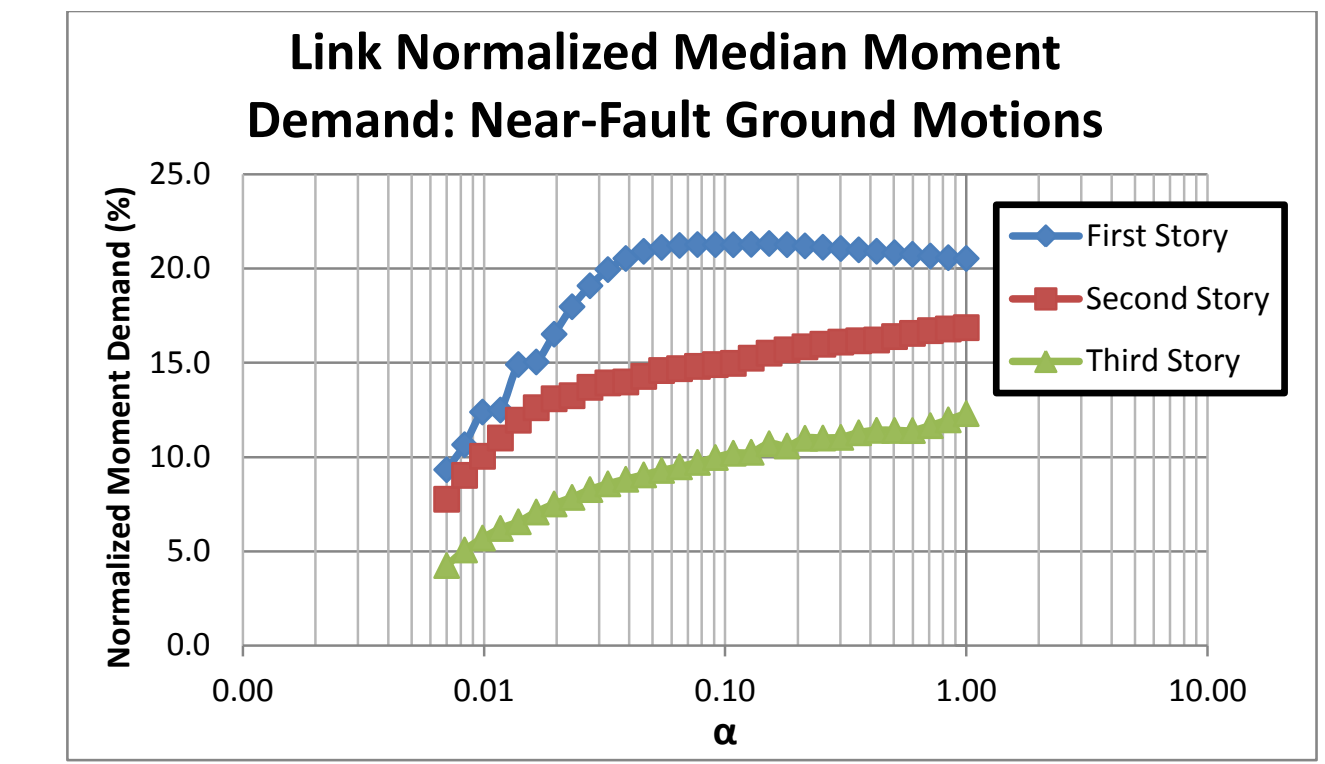

Figure 5.58: Normalized median bending moment demand in links of LA3-B (Near-Fault Earthquakes)

In summary, based on the result comparisons between LA3-A and LA3-B, it is found that having the links with energy dissipation capacity allows the inter-story drifts to drop below the target level more rapidly. Under the $2 \%$ in 50 years earthquakes, LA3-A exhibits inter-story drifts larger than the collapse prevention limit; introducing additional hysteretic energy dissipation capacity in LA3-B successfully transforms the system seismic performance, meeting the collapse prevention requirement. Under the $10 \%$ in 50 years earthquakes and near-fault earthquakes, LA3-A can reduce the inter-story drifts below the limits associated with life safety and collapse prevention; however the same system with extra hysteretic energy dissipation capacity (i.e., LA3-B) either offers reduced inter-story drifts with the same RC stiffness or requires less stiff RC to achieve the same inter-story drifts. 


\subsection{Demonstration Retrofit using Reinforced Concrete RC}

Results shown in Sections 5.2 and 5.3 demonstrate the adequacy of RC in retrofit of lowrise $\mathrm{CBF}$ buildings. As a logic extension, this section presents design of a reinforced concrete RC for LA3 based on the results from Section 5.3. Nonlinear dynamic analyses are repeated to confirm the performance predicted in Section 5.3 is achievable with the designed reinforced concrete RC.

The reinforced concrete $\mathrm{RC}$ was designed based on the lowest stiffness at which all three ground motions met their performance objective (i.e., LA3-B was used because LA3-A did not meet the performance objectives). From Figures 5.41 to 5.43 , the $\alpha$ value that governed the design was 0.2 , which corresponds to the ground motions having a probability of exceedence of $2 \%$ in 50 years. At that particular $\alpha$ value the bending moment demand was $57 \%$ of $\mathrm{V}_{1 \mathrm{y}}{ }^{*} \mathrm{~h}_{1}$ and the shear demand was $57 \%$ of $\mathrm{V}_{1 \mathrm{y}}$. However it should be noted that the wall was designed based on flexure and displacement demands; it was assumed the wall was capacity protected against shear failure. Moreover, the RC was designed to remain essentially elastic under the displacement and bending moment demands.

The material model used for the core was assumed to be the Mander Model with the properties as presented in Table 5.3. The model for the unconfined concrete was assumed to be Todeschini Parabolic Model, with properties as shown in Table 5.4. Furthermore, the longitudinal steel material model was Giuffré-Menegotto-Pinto (see section 4.1 for details) with yield strength of $60 \mathrm{ksi}$. In the OpenSees model, the reinforced concrete RC was considered using FBE. 
Table 5-6: Mander Model Properties

\begin{tabular}{|c|c|}
\hline Property & Value \\
\hline Concrete Strength $\left(\mathrm{f}_{\mathrm{c}}\right)$ & $4 \mathrm{ksi}$ \\
\hline Initial Elastic Modulus of Concrete $\left(\mathrm{E}_{\mathrm{c}}\right)$ & $3,605 \mathrm{ksi}$ \\
\hline Maximum Stress $\left(\mathrm{f}_{\mathrm{c}, \max }\right)$ & $5.2 \mathrm{ksi}$ \\
\hline Strain at Maximum Compressive Stress $\left(\varepsilon_{\mathrm{c}}\right)$ & $0.0029 \mathrm{in} / \mathrm{in}$ \\
\hline Ultimate Stress $\left(\mathrm{f}_{\mathrm{u}}{ }_{\mathrm{u}}\right)$ & $1.04 \mathrm{ksi}$ \\
\hline Ultimate Strain $\left(\varepsilon_{\mathrm{cu}}\right)$ & $.05 \mathrm{in} / \mathrm{in}$ \\
\hline
\end{tabular}

Table 5-7: Todeshini Parabolic Model

\begin{tabular}{|c|c|}
\hline Property & Value \\
\hline Maximum Stress $\left(\mathrm{f}_{\mathrm{c}} \mathrm{c}\right)$ & $4 \mathrm{ksi}$ \\
\hline Strain at Maximum Stress $\left(\mathrm{e}_{\mathrm{psu}}\right)$ & 0.003 \\
\hline Ultimate Stress $\left(\mathrm{f}_{\mathrm{cu}}\right)$ & $0.8 \mathrm{ksi}$ \\
\hline Ultimate Strain $\left(\mathrm{e}_{\mathrm{cu}}\right)$ & 0.01 \\
\hline
\end{tabular}

Based on the flexural stiffness and bending moment demands the following (Figure 5.59) cross section was used.

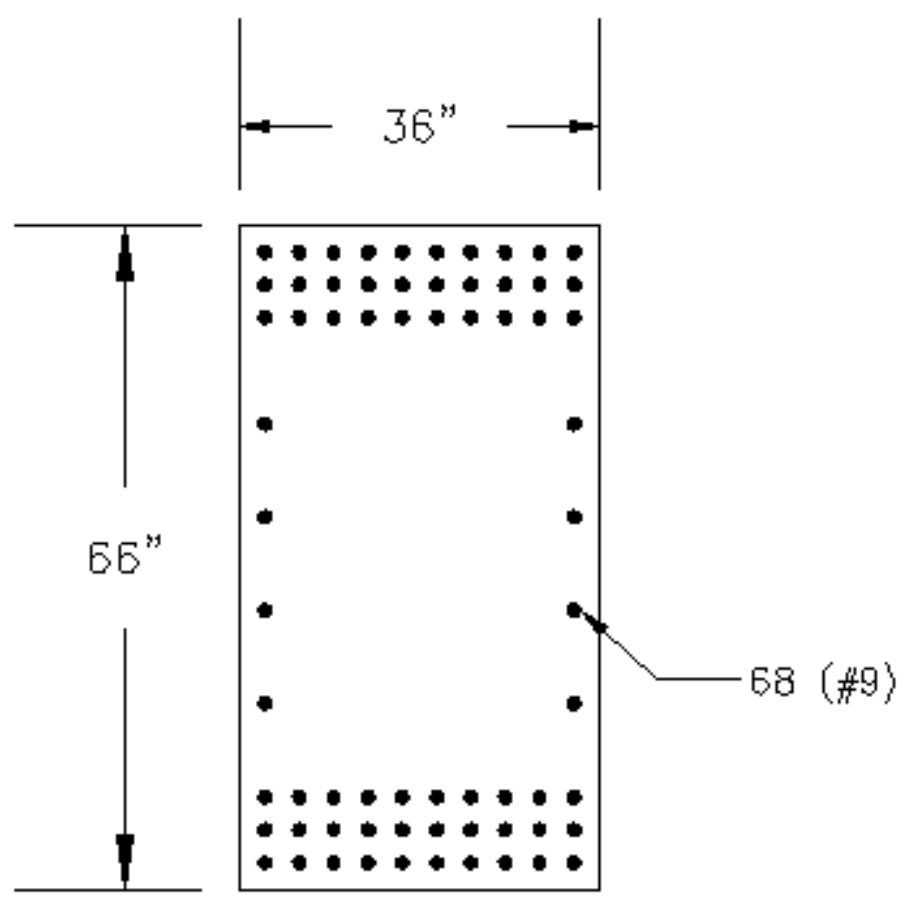

Figure 5.59: Reinforced concrete RC cross-section for LA3-B 
From the nonlinear dynamic analyses, it was concluded that the reinforced concrete RC behaved very similar to the elastic RC used in section 5.3. Tables 5-8 to 5-10 present the results for both the elastic and reinforced RC. It is noted that the median drift was taken from the critical earthquake records and the shear and bending moment demands were taken from all ground motions. Having comparable results indicates that the more satisfactory results from the simplified RC model is achievable. Also, it should be noted that the cross section can be reduced if prestressed concrete or high strength concrete is used.

Table 5-8: Comparison of elastic RC and reinforced concrete $\mathrm{RC}$ under $\mathbf{1 0 \%}$ in 50 years suite

\begin{tabular}{|c|c|c|}
\hline \multirow{2}{*}{ Response quantity of interest } & \multicolumn{2}{|c|}{$10 \%$ in 50 years Suite } \\
\cline { 2 - 3 } & Elastic RC & Reinforced Concrete RC \\
\hline $\begin{array}{c}\text { Median Drift from critical } \\
\text { earthquakes }\end{array}$ & $1.07 \%$ & $0.77 \%$ \\
\hline Median Shear Demand on RC & $37 \%$ & $37 \%$ \\
\hline Median Moment Demand on RC & $37 \%$ & $37 \%$ \\
\hline Median Axial Demand on Links & $35 \%$ & $38 \%$ \\
\hline Median Shear Demand on Links & $55 \%$ & $54 \%$ \\
\hline Median Moment Demand on links & $22 \%$ & $20 \%$ \\
\hline
\end{tabular}

Table 5-9: Comparison of elastic RC and reinforced concrete RC under $2 \%$ in 50 years suite

\begin{tabular}{|c|c|c|}
\hline \multirow{2}{*}{ Response quantity of interest } & \multicolumn{2}{|c|}{$2 \%$ in 50 years Suite } \\
\cline { 2 - 3 } & Elastic RC & Reinforced Concrete RC \\
\hline Median Drift & $1.82 \%$ & $1.75 \%$ \\
\hline Median Shear Demand on RC & $56 \%$ & $56 \%$ \\
\hline Median Moment Demand on RC & $56 \%$ & $56 \%$ \\
\hline Median Axial Demand on Links & $68 \%$ & $63 \%$ \\
\hline Median Shear Demand on Links & $60 \%$ & $57 \%$ \\
\hline Median Moment Demand on links & $26 \%$ & $22 \%$ \\
\hline
\end{tabular}


Table 5-10: Comparison of elastic $\mathrm{RC}$ and reinforced concrete $\mathrm{RC}$ under near-fault suite

\begin{tabular}{|c|c|c|}
\hline \multirow{2}{*}{ Response quantity of interest } & \multicolumn{2}{|c|}{ Near-Fault Suite } \\
\cline { 2 - 3 } & Elastic RC & Reinforced Concrete RC \\
\hline Median Drift & $0.95 \%$ & $.84 \%$ \\
\hline Median Shear Demand on RC & $41 \%$ & $44 \%$ \\
\hline Median Moment Demand on RC & $41 \%$ & $44 \%$ \\
\hline Median Axial Demand on Links & $45 \%$ & $48 \%$ \\
\hline Median Shear Demand on Links & $56 \%$ & $54 \%$ \\
\hline Median Moment Demand on links & $22 \%$ & $20 \%$ \\
\hline
\end{tabular}




\subsection{Seismic Performance Evaluation of Six-Story Building}

\subsection{Impact on Modal Properties}

Similar to LA3-A and LA3-B, two cases were considered for the six-story building: i.e., one case (called LA6-A) with RC connected to the existing frame via links pinned on either side and the other case (LA6-B) with RC connected to the existing frame via links pinned to the frame and fixed to the RC. To observe the impacts of RC on the six-story building modal properties, eigenvalue analyses were done on the LA6-A and LA6-B models. Three $\alpha$ values $(0.0066,0.115$ and 2$)$ were selected for comparison purpose, which correspond to the RC having low, moderate and high stiffness. Based on EQ.4.2 the corresponding moments of inertia $\left(\mathrm{I}_{\mathrm{RC}}\right)$ were calculated to be $20,87,000$ and $\left.1,600,000 \mathrm{in}^{4}\right)$.

Table 6-1 presents the periods of LA6-A from the eigenvalue analyses. It is noted that the fundamental period of the structures remains identical regardless of the RC stiffness, but the second and third mode periods in LA6-A are shorter with larger RC stiffness. Figures 6.1 to 6.3 shows the comparison of the first three modes shapes of LA6-A with the three RC stiffness considered. It is noted that the mode shapes are similar for all $\alpha$.

Table 6-1: Comparison of periods from LA6-A with different RC stiffness values

\begin{tabular}{|c|c|c|c|}
\hline \multirow{2}{*}{$\alpha$} & \multicolumn{3}{|c|}{ Period (sec) } \\
\cline { 2 - 4 } & First Mode & Second Mode & Third Mode \\
\hline 0.0066 & 0.67 & 0.23 & 0.12 \\
\hline 0.115 & 0.67 & 0.22 & 0.12 \\
\hline 2 & 0.67 & 0.14 & 0.05 \\
\hline
\end{tabular}




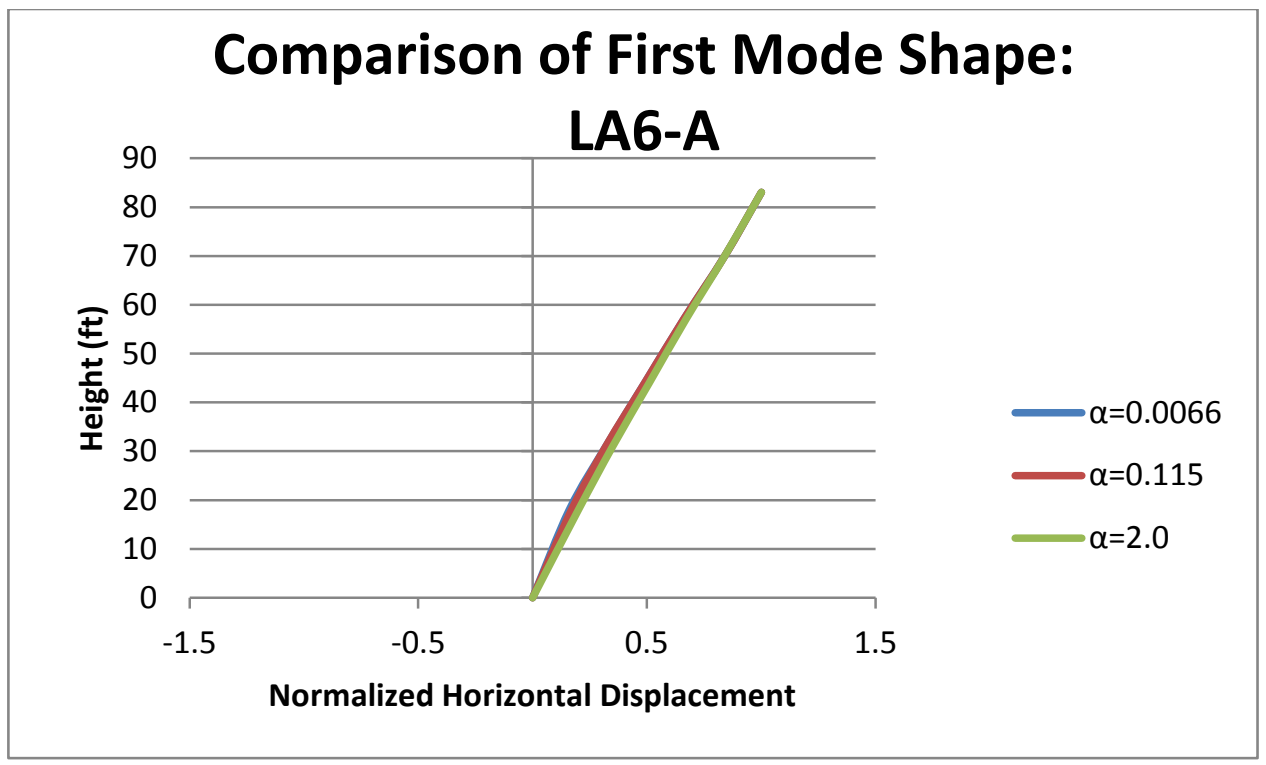

Figure 6.1: Comparison of first mode shape of LA6-A models with different RC stiffness values

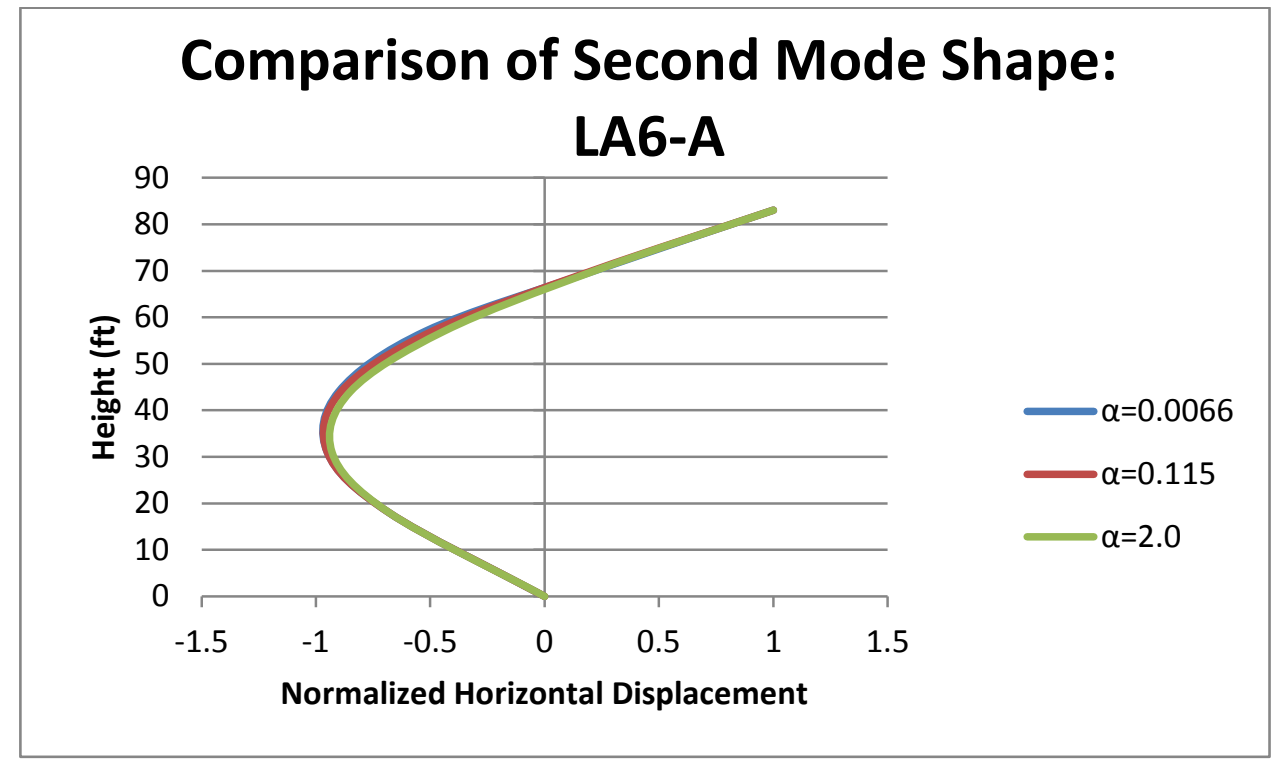

Figure 6.2: Comparison of second mode shape of LA6-A models with different RC stiffness values 


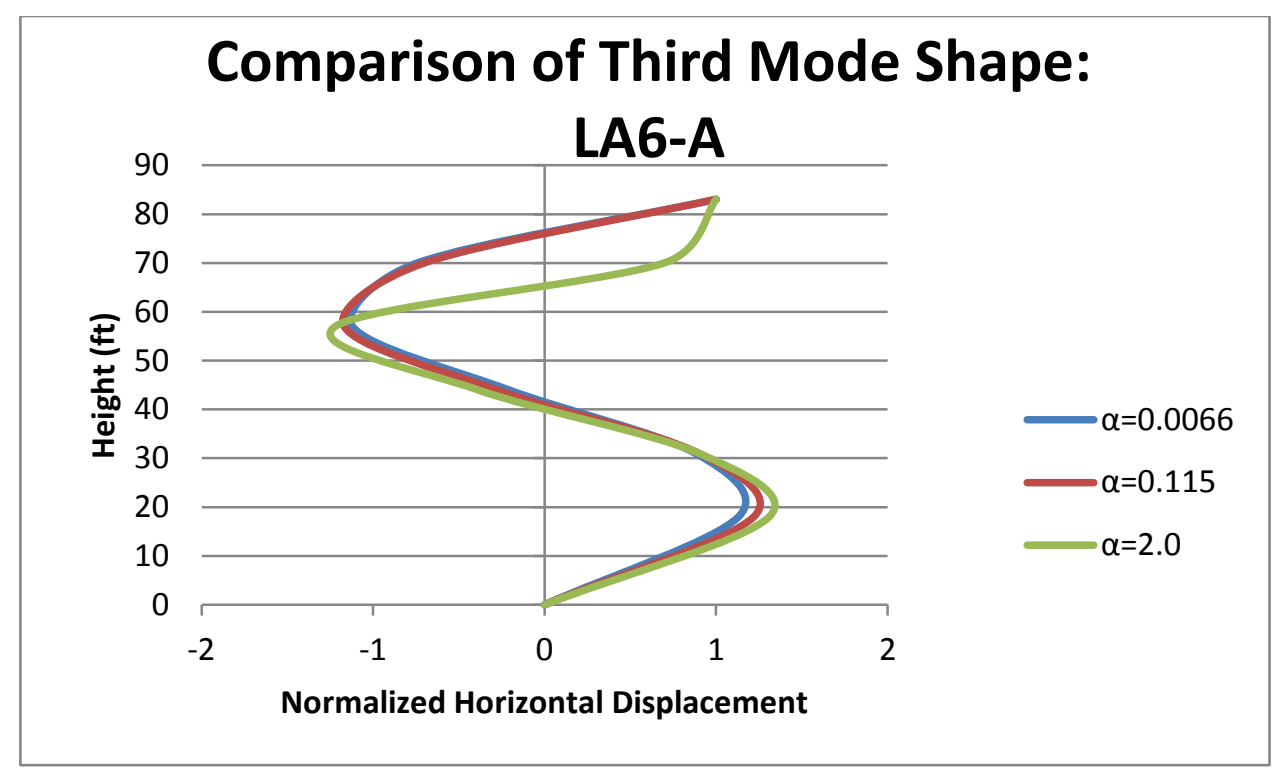

Figure 6.3: Comparison of third mode shape of LA6-A models with different RC stiffness values

Eigenvalue analyses were also conducted on LA6-B to evaluate the impacts of the RC on the modal properties. The links used were assumed to be two $5 \mathrm{ft}-$ longW30x99 for all levels. Table 6-2 presents the first three modal periods of LA6-B. It was observed that the fundamental period reduced as the RC stiffness increased. This indicated that the fixed end connections of the links in LA6-B while contribute to the system hysteretic energy dissipation capacity may attract extra seismic forces on the system. It is noted from Figures 6.4 to 6.6 that the modal properties remain similar for the three $\alpha$ 's considered.

Table 6-2: Comparison of periods from LA6-B with different $\mathrm{RC}$ stiffness values

\begin{tabular}{|c|c|c|c|}
\hline \multirow{2}{*}{$\alpha$} & \multicolumn{3}{|c|}{ Period (sec) } \\
\cline { 2 - 4 } & First Mode & Second Mode & Third Mode \\
\hline 0.0066 & 0.67 & 0.23 & 0.12 \\
\hline 0.115 & 0.56 & 0.14 & 0.06 \\
\hline 2 & 0.56 & 0.14 & 0.05 \\
\hline
\end{tabular}




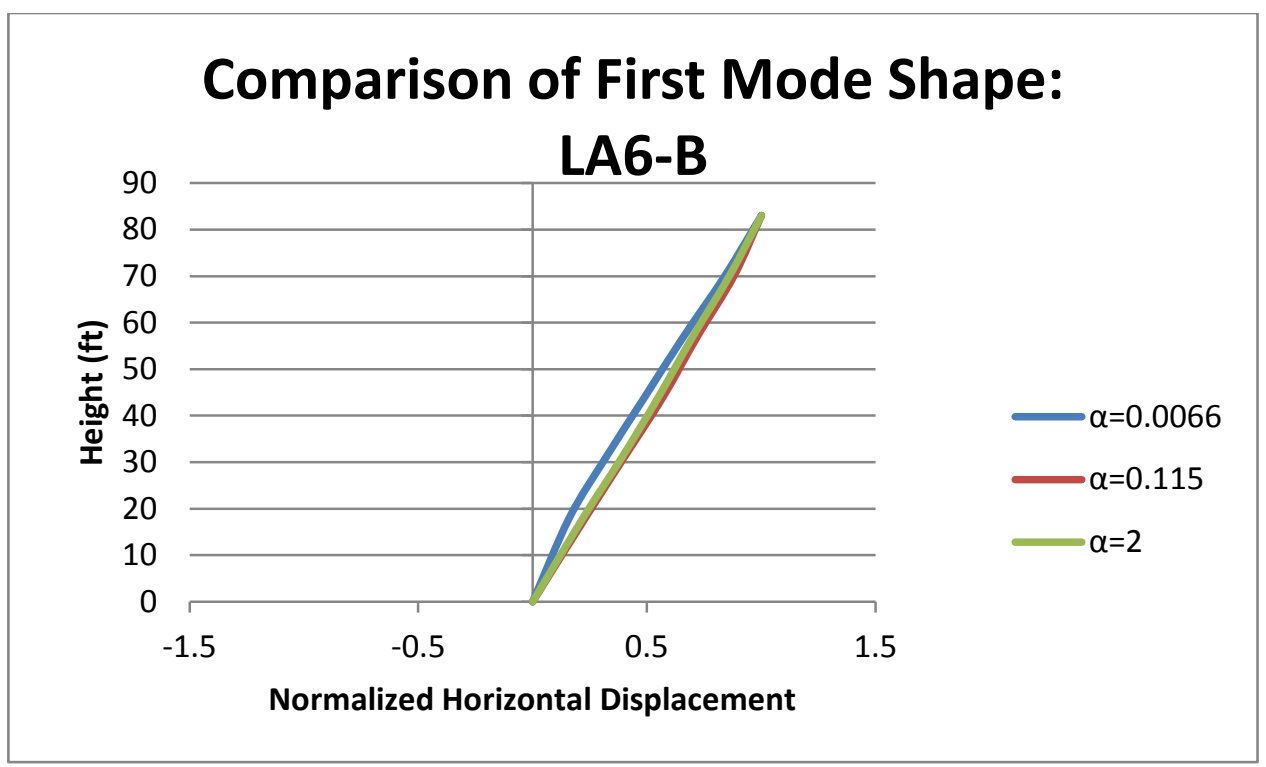

Figure 6.4: Comparison of first mode shape of LA6-B models with different RC stiffness values

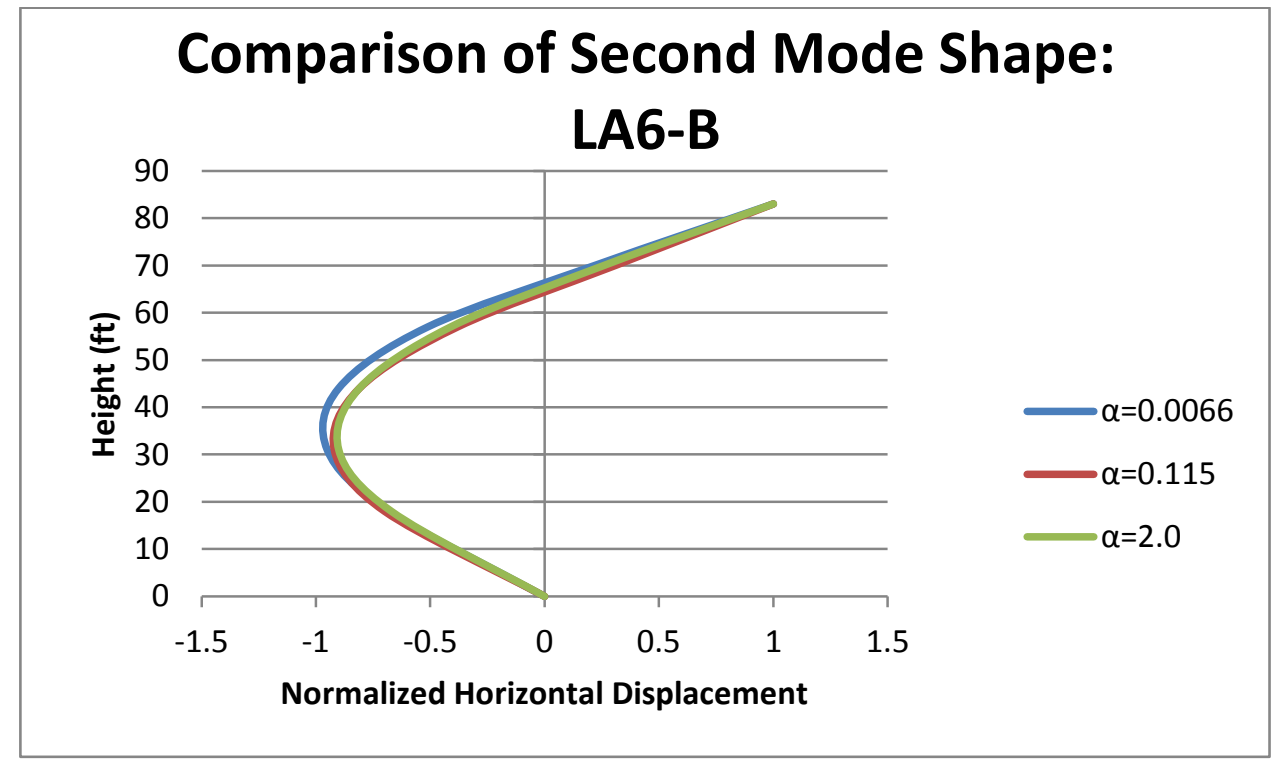

Figure 6.5: Comparison of second mode shape of LA6-B models with different RC stiffness values 


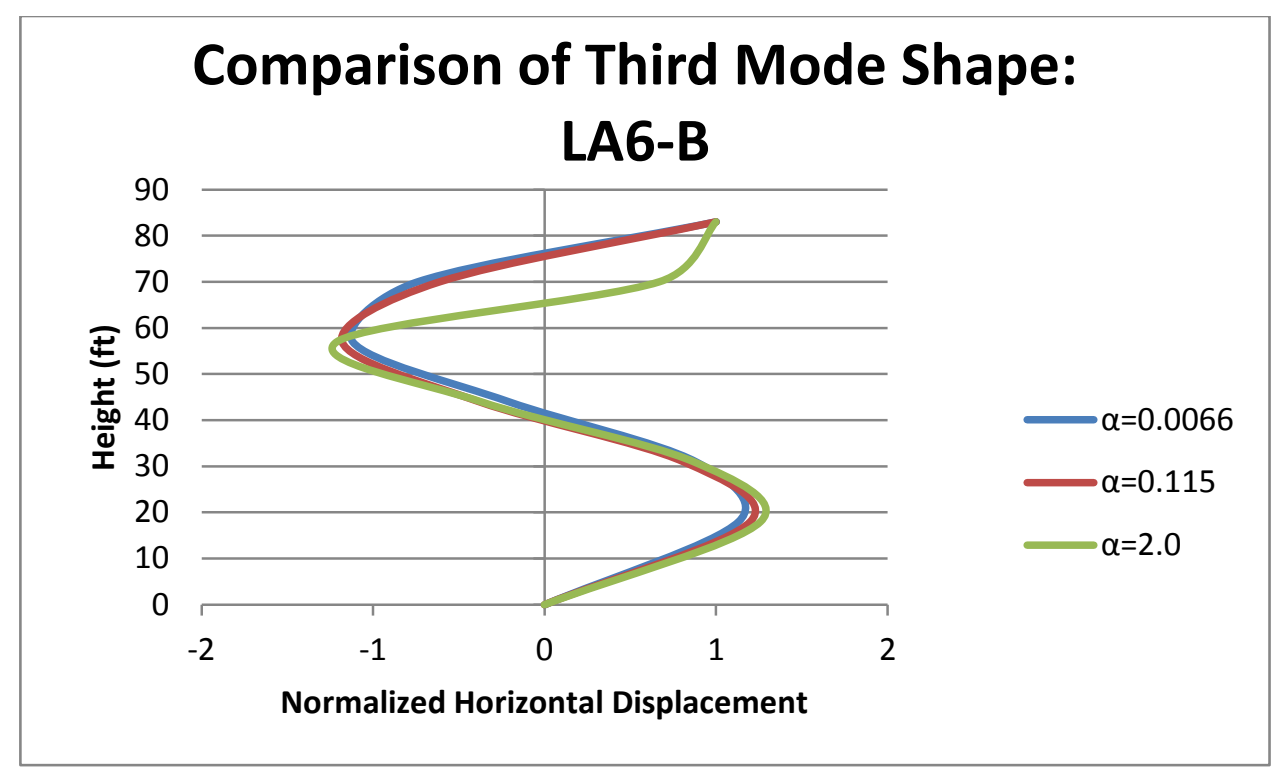

Figure 6.6: Comparison of third mode shape of LA6-B models with different RC stiffness values

\subsection{Nonlinear Static Pushover Analysis}

Similar to LA3-A, nonlinear static pushover analysis was also conducted on LA6-A to investigate the contribution of the RC on mitigation of soft-story failure in the six-story building. Fifteen $\alpha$ values were varied from 0.0066 to 2 which modeling the RC varying from very flexible to rigid. The load distribution was obtained using the same method presented in section 5.2.1 of this thesis; however, only 250 load distributions were used due to the large computational time. Furthermore, the target interstory drift were the same as those presented in section 5.2.2 of this thesis. As a result, a total of 11,250 analyses were conducted

\subsubsection{Result Discussion}

The response quantities of interests were outputted when the maximum inter-story drift reached the expected levels associated with immediate occupancy, life safety and 
collapse prevention performance objectives. In the next sections a discussion for the response quantities of interests, ie., DCF, demands on RC and RC links, are provided.

\subsubsection{Discussion on DCF}

From the nonlinear static pushover analysis, it was observed that the soft story forms mostly in the first story level. However, it is noted that very few times the fifth and sixth story forms the soft-story. Based on the definition, the upper bound of DCF for LA6-A should be 4.61 for the soft-story level and 0 for all other stories which correspond to a perfect soft-story failure, i.e., all deformation concentrates on the soft-story. The lower bound of DCF for LA6-A should be 1 for all story levels, which corresponds to a desirable perfect sway mechanism.

Figure 6.7 shows the DCF results from the pushover analysis considering collapse prevention as the performance objective. It is evident that the soft story happens in the first story most of the time. However, in very rare cases the fourth, fifth and sixth story have the soft-story failure, depending on the RC stiffness and lateral force distribution. When a very flexible $\mathrm{RC}$ is used (i.e., when $\alpha$ is very small) the largest DCF is approximately 2.5 which corresponds to a soft-story mechanism. As the stiffness ratio, $\alpha$ ,is increased beyond 0.2 the DCF converges to 1 very rapidly indicating that a sway mechanism is formed. Figure 6.8 further presents the maximum DCF for each of the $15 \alpha$ values considered. As shown, between an $\alpha$ value of 0.1 and 0.2 there is a sudden drop in DCF indicating that the braces from all floor levels have engaged, thus having a sway mechanism. 


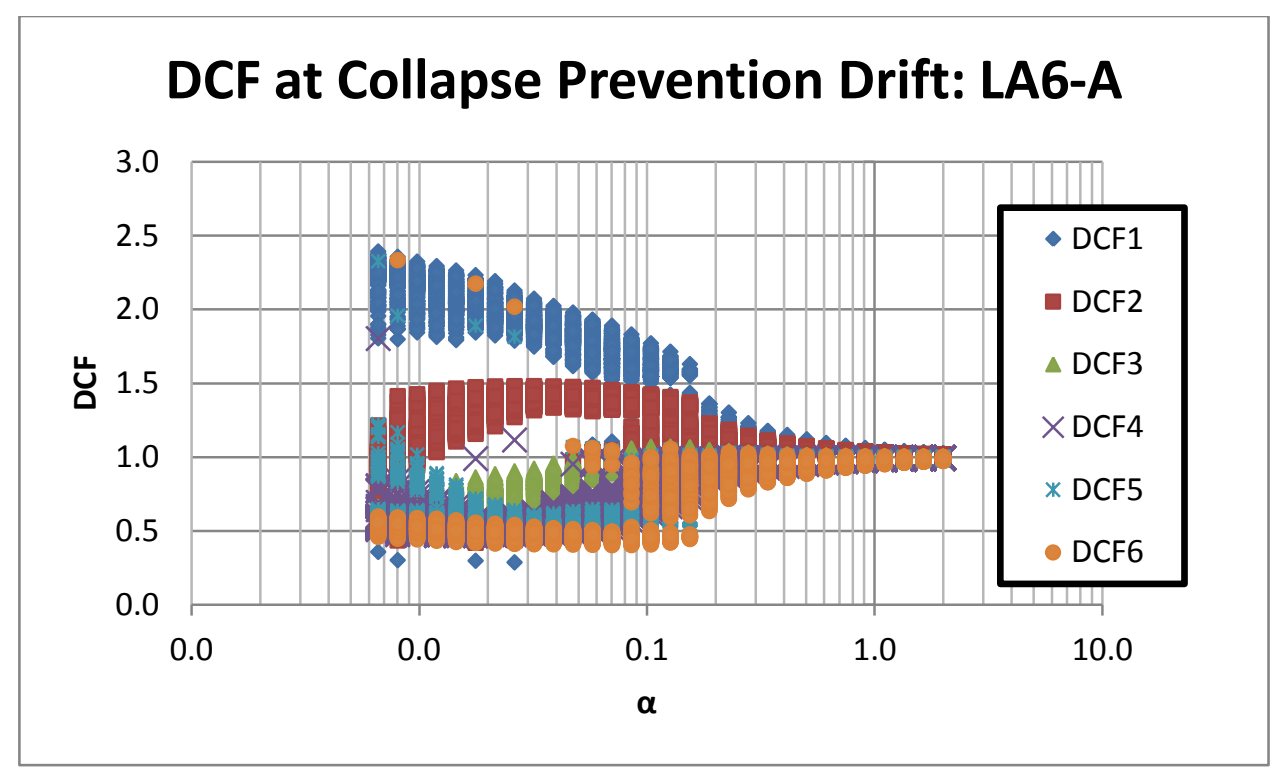

Figure 6.7: DCF for collapse prevention performance objective: LA6-A

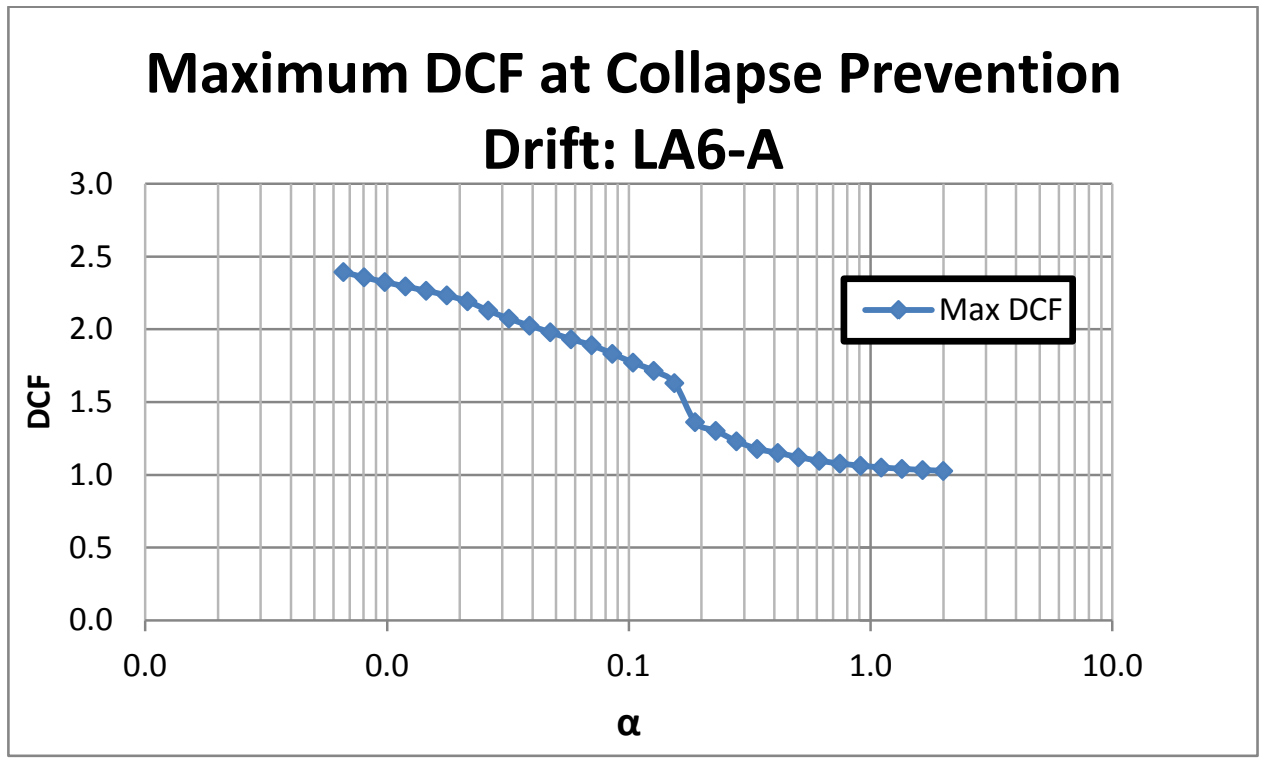

Figure 6.8: Maximum DCF for collapse prevention performance objective: LA6-A

Considering life safety as the target performance, DCF results (see Figure 6.9) similar to those from collapse prevention were obtained. Figure 6.10 shows the maximum DCF of each of the $15 \alpha$ values considered. Similar to the collapse prevention, the DCF also 
converges to 1 at higher RC stiffness; however, a larger $\alpha$ is required to form the sway mechanism. In addition, the same drop in DCF is observe but at a higher RC stiffness.

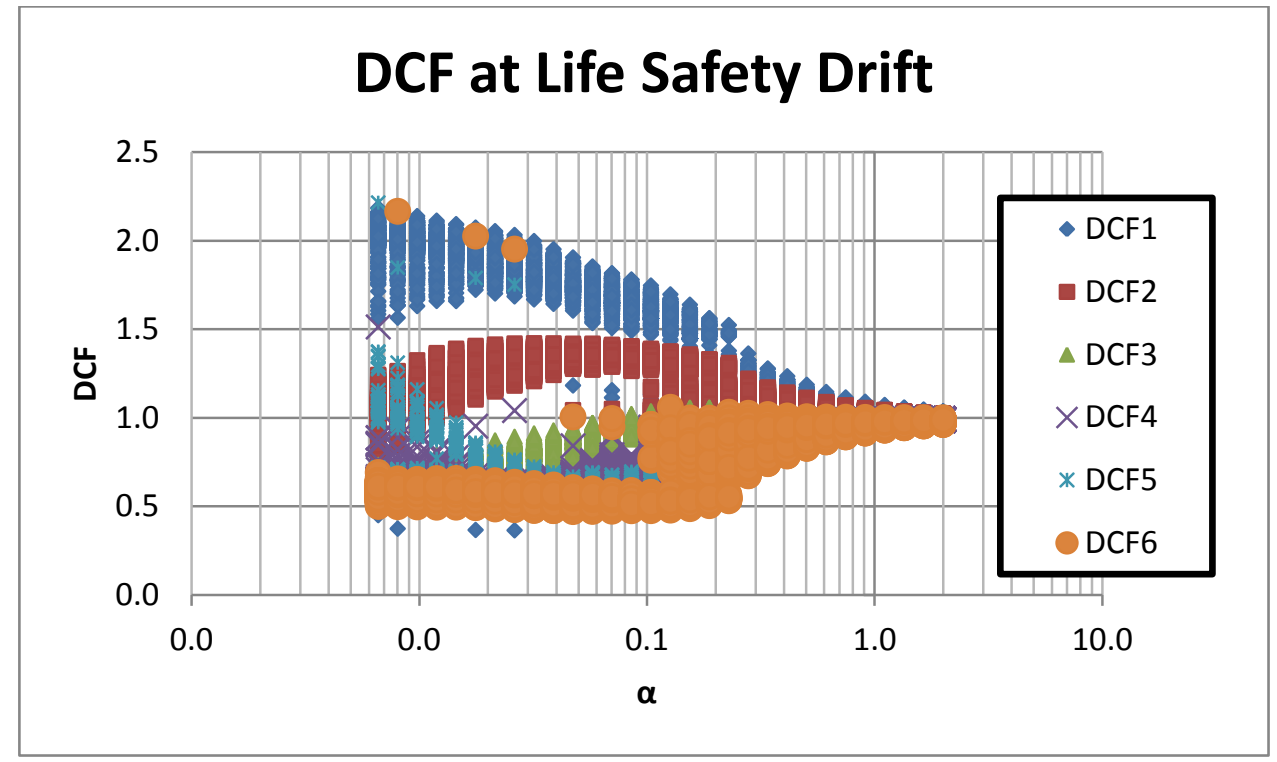

Figure 6.9: DCF for life safety performance objective: LA6-A

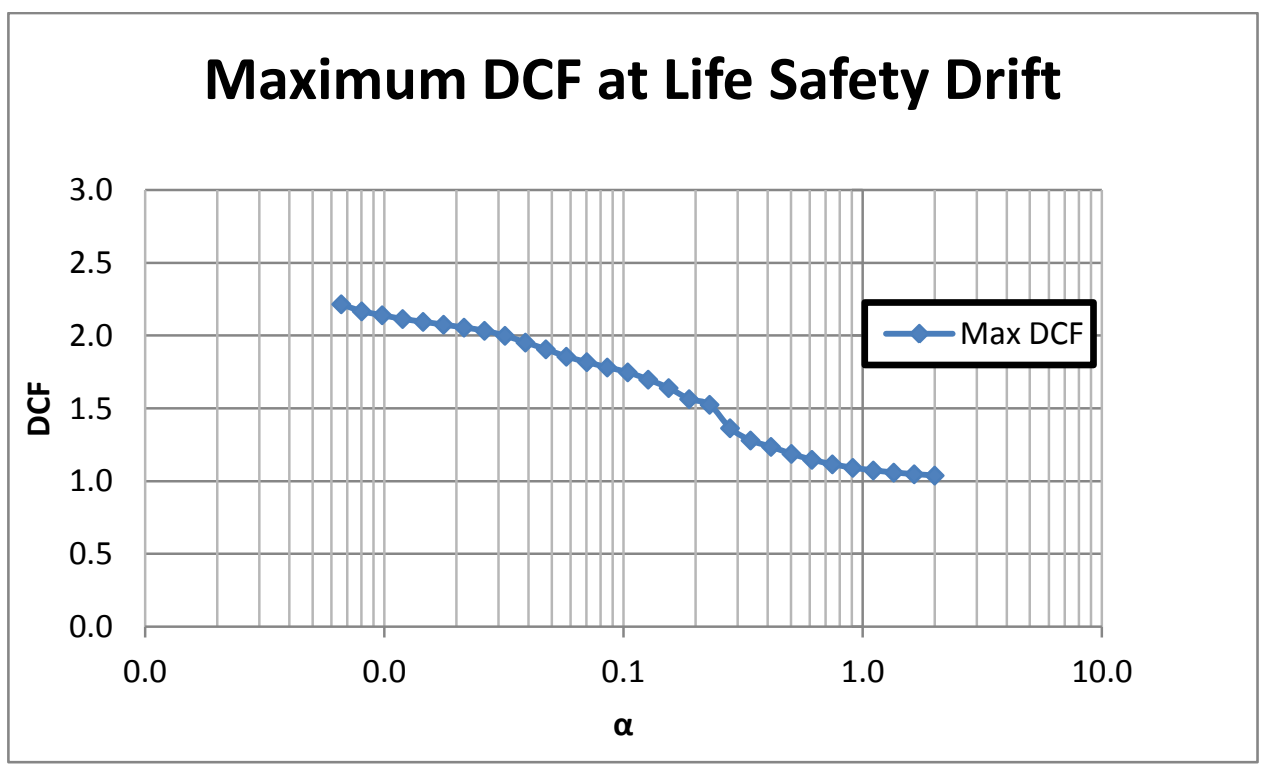

Figure 6.10: Maximum DCF for life safety performance objective: LA6-A

The results obtained from considering immediate occupancy as the performance objective were slightly different from those from collapse prevention and life safety. From Figure 
6.11 and 6.12, it is noted that over the same range of $\alpha$ values the DCF does not improve significantly. This indicated that a larger RC stiffness value is required to ensure uniformity of inter-story drift distribution. However, although the inter-story drift distribution is not that uniform, it may be acceptable since the inter-story drift associated with immediate occupancy is low at which no story has been fully yielded.

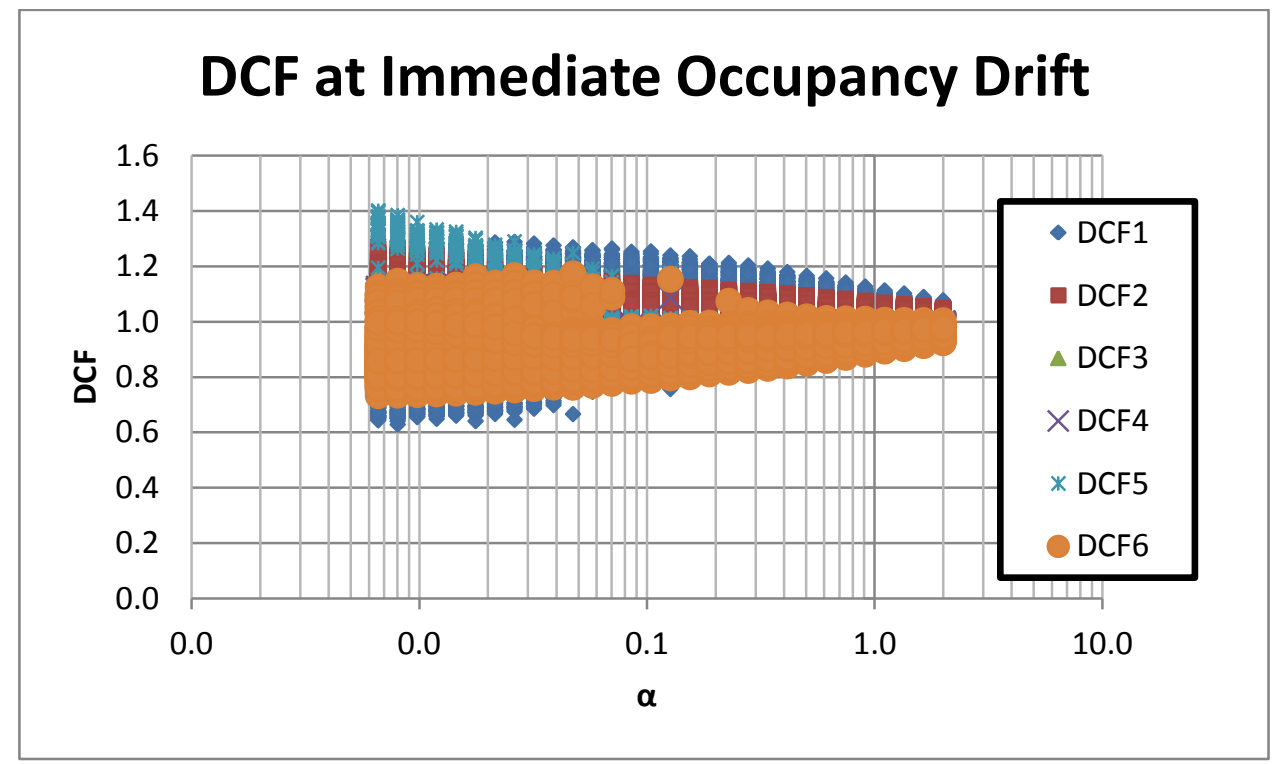

Figure 6.11: DCF for immediate occupancy performance objective: LA6-A

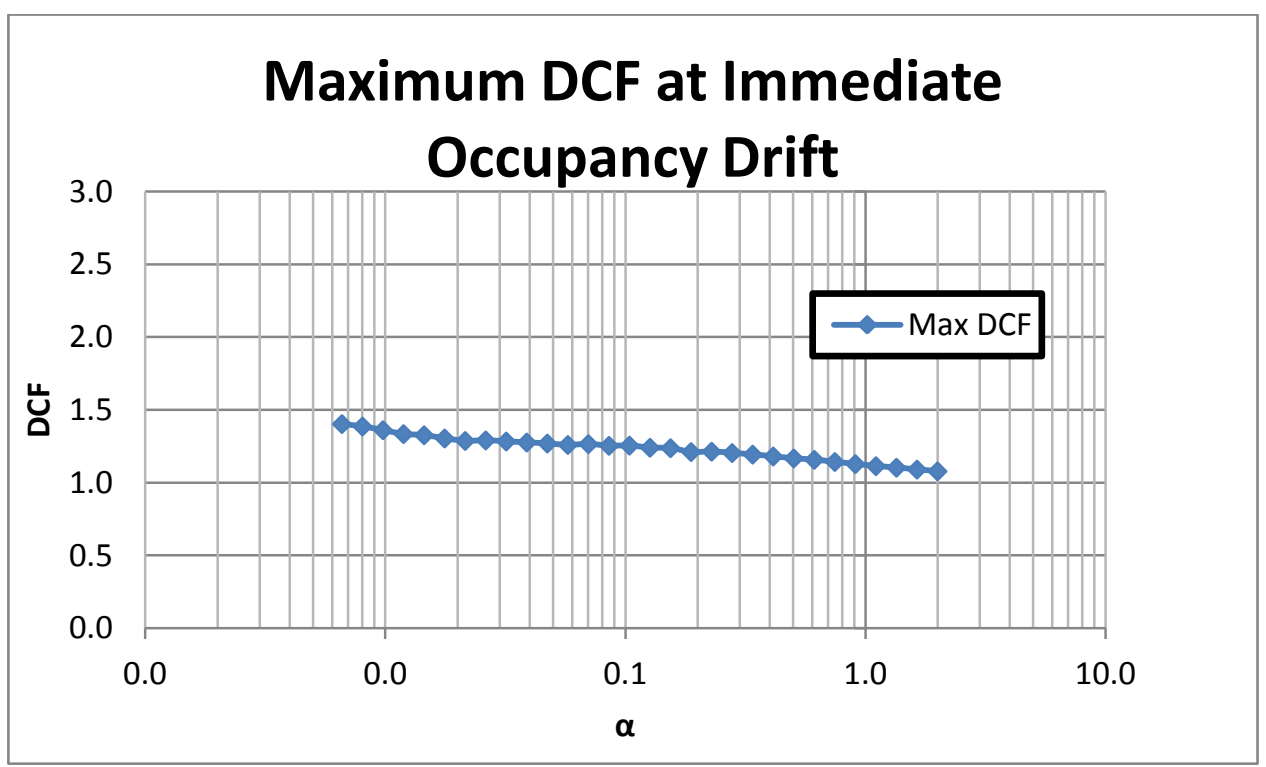

Figure 6.12 Maximum DCF for immediate occupancy performance objective: LA6-A 


\subsubsection{Demands on $R C$}

The shear and moment demands on RC are investigated in this section based on the nonlinear static pushover analysis. Due to the link connections (pinned on both sides) there is no extra load along the longitudinal direction of the RC except its self-weight. However, it is assumed that the axial load does not control the design of the RC therefore the axial demands on the $\mathrm{RC}$ are not discuss in this section. The shear and bending moment demands on the $\mathrm{RC}$ were normalized by the yield strength of the bottom story of LA6, $\mathrm{V}_{1 \mathrm{y}}$, and its yielding overturning moment, $\mathrm{V}_{1 \mathrm{y}}{ }^{*} \mathrm{~h}_{\mathrm{s} 1}$ for comparison purposes. The yield strength of the bottom story of LA6 was obtained by doing a pushover analysis and was determine to be at where the slope had a change of $1 \%$ or more. As a result, $\mathrm{V}_{1 \mathrm{y}}$ is identified to be 1000 kips and accordingly $\mathrm{V}_{1 \mathrm{y}}{ }^{*} \mathrm{~h}_{\mathrm{s} 1}$, was calculated to be $216,000 \mathrm{in}^{4}$. Figure 6.13 and 6.14 show the results of the nonlinear static pushover analysis and the slope of the nonlinear static pushover analysis, respectively.

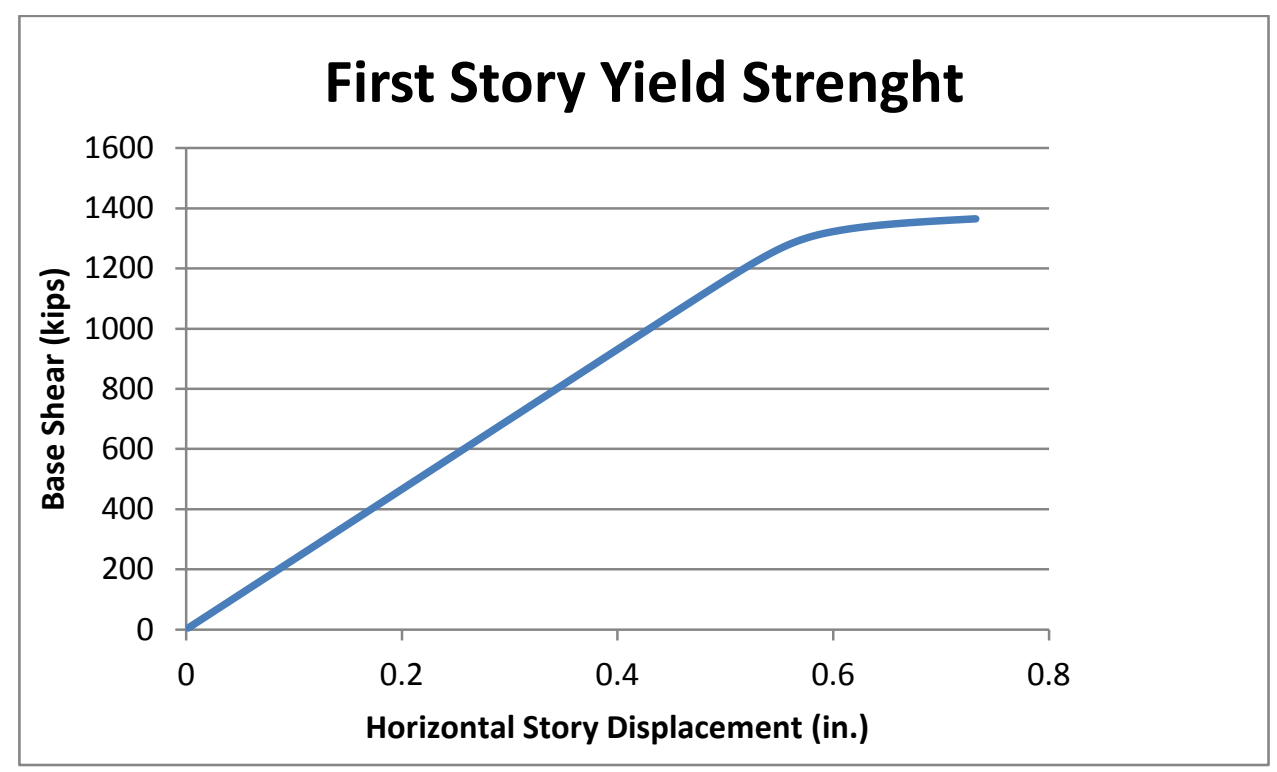

Figure 6.13: Nonlinear static pushover curve of bottom story of LA6 


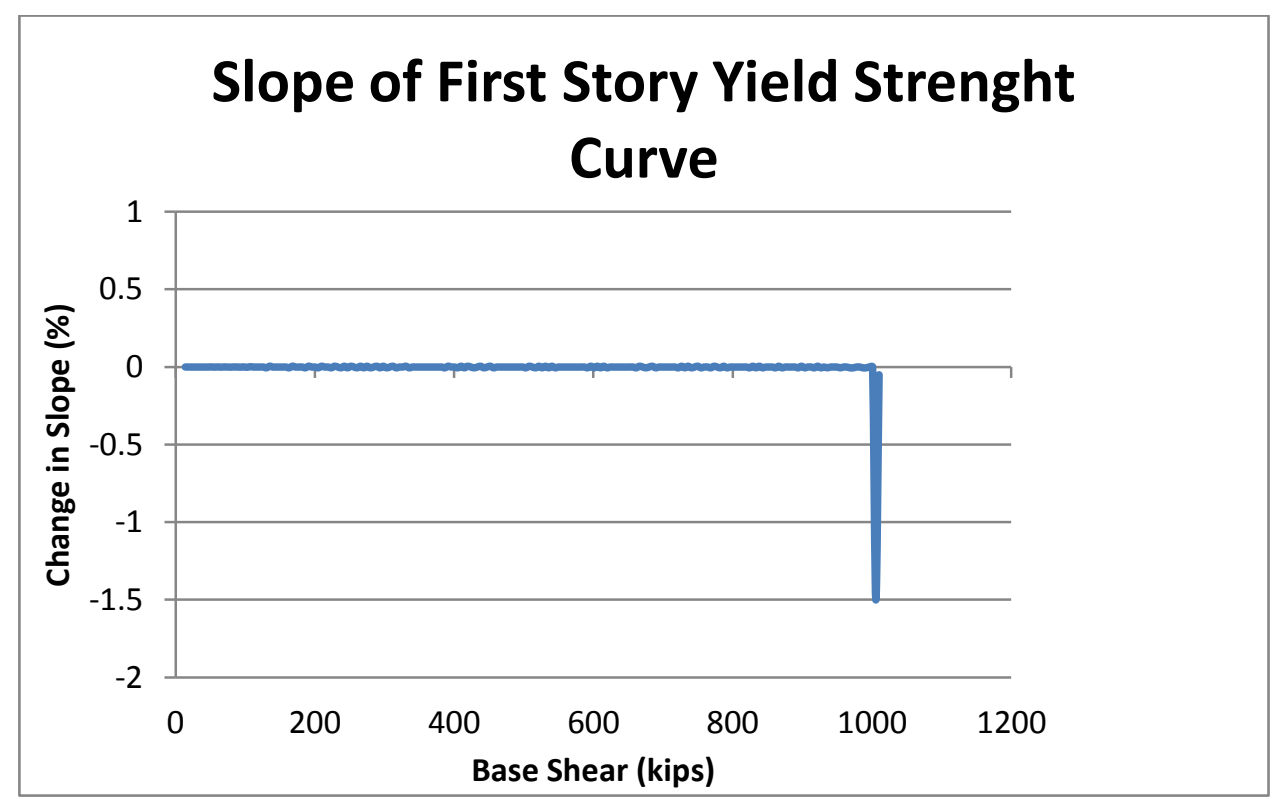

Figure 6.14: Slope of the nonlinear static pushover curve of bottom story of LA6

The maximum shear and bending moment demands were plotted for the 250 simulations for every $\alpha$ at each story level under each considered performance objective in order to develop recommendation on the RC. It should be noted that the shear demand is constant over the RC segment at each story. In order to achieve satisfactory performance in the retrofitted system, the RC should be design to remain essentially elastic. Furthermore, it is recommended to design $\mathrm{RC}$ based on the maximum demand values.

Figures 6.15 to 6.17 show the normalized RC shear demands in each story and under each considered performance objective. For the performance objective corresponding to collapse prevention and life safety, it is observe that after an $\alpha$ value of 0.2 the shear demands on the first, fourth and sixth story levels converges to approximately $33 \%$. The third, fifth level converge to about $19 \%$ while the second level converges to $24 \%$. This indicated that a stiffer RC does not require larger shear demands. Also, under the 
performance objective of immediate occupancy the shear demands are lower than $25 \%$, thus do not govern the design of RC.

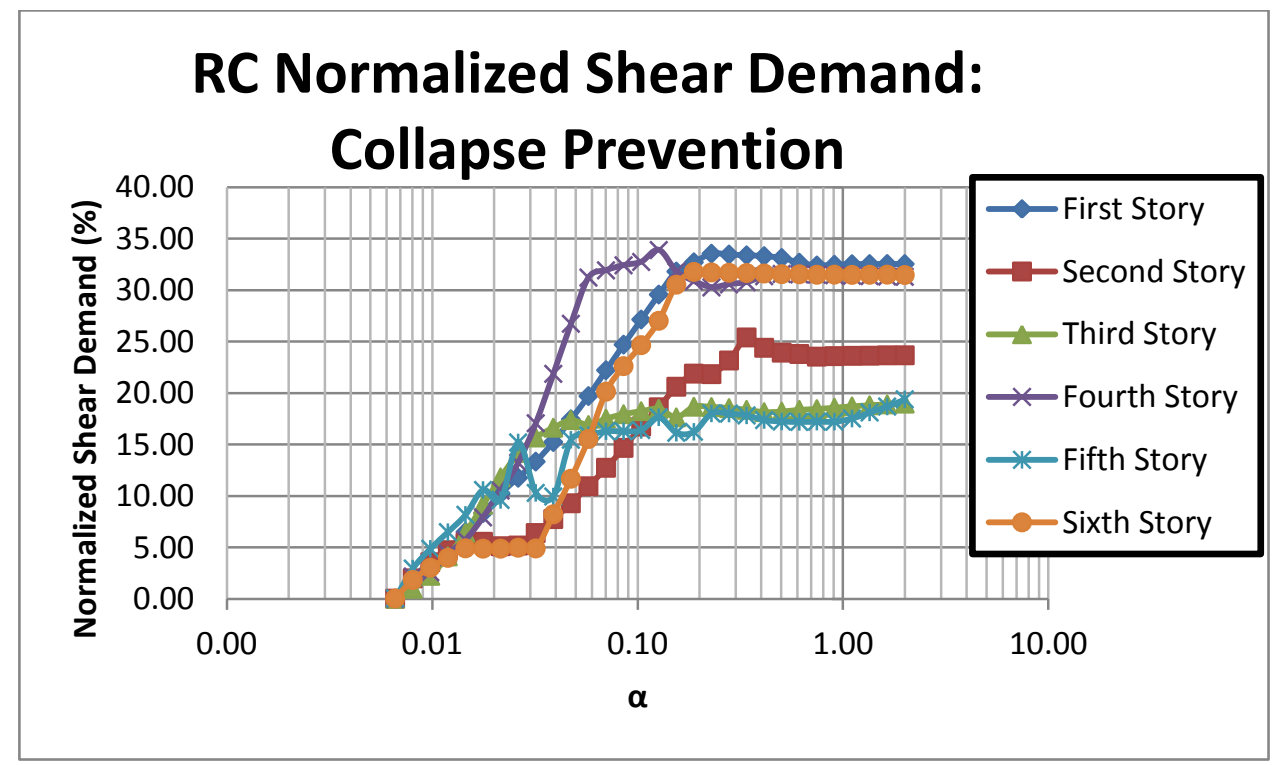

Figure 6.15: Maximum RC normalized shear demand considering collapse prevention performance objective: LA6-A

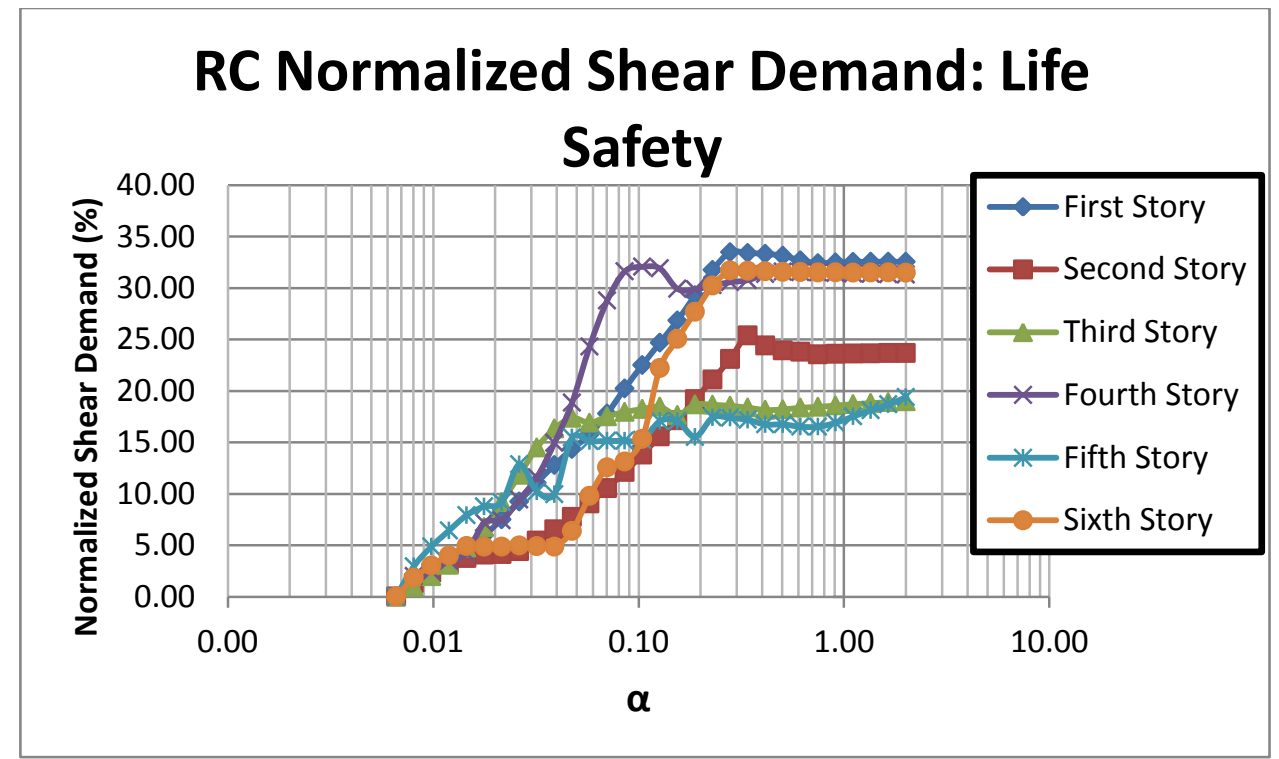

Figure 6.16: Maximum RC normalized shear demand considering life safety performance objective: LA6-A 


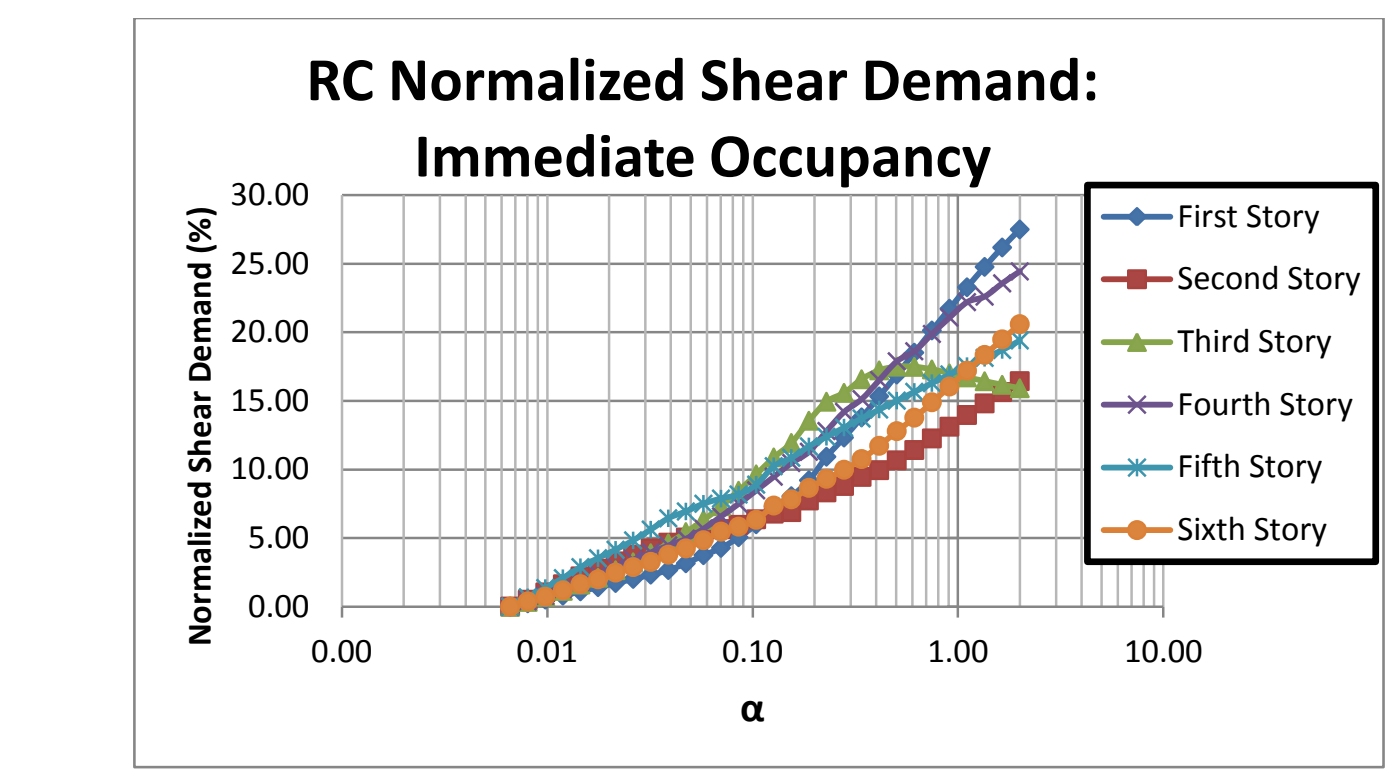

Figure 6.17: Maximum RC normalized shear demand considering immediate occupancy performance objective: LA6-A

The bending moment demand on the $\mathrm{RC}$ was also evaluated based on the results from the nonlinear static pushover analysis. The maximum normalized bending moment demand of the 250 simulations was plotted (see Figures 6.18 to 6.20 ) for every $\alpha$ at each story level under each considered performance objective. A similar trend was observed as in the shear demands, the moment demand on RC converges after an $\alpha$ value of 0.3 . The second, third and fourth story level converge to approximately $50 \%$, the first and fifth story level converge to $32 \%$ and the sixth story level converge to $21 \%$. This indicated that after an $\alpha$ value of 0.3 the RC does not have extra bending moment demand because the structure has reached a sway mechanism (i.e., from Figure 6.8 and 6.10 the DCF is very close to 1). When considering immediate occupancy as the performance objective, the moment demand increases over the range of $\alpha$ 's considered but is less than the other performance objectives, thus it does not govern RC design. 


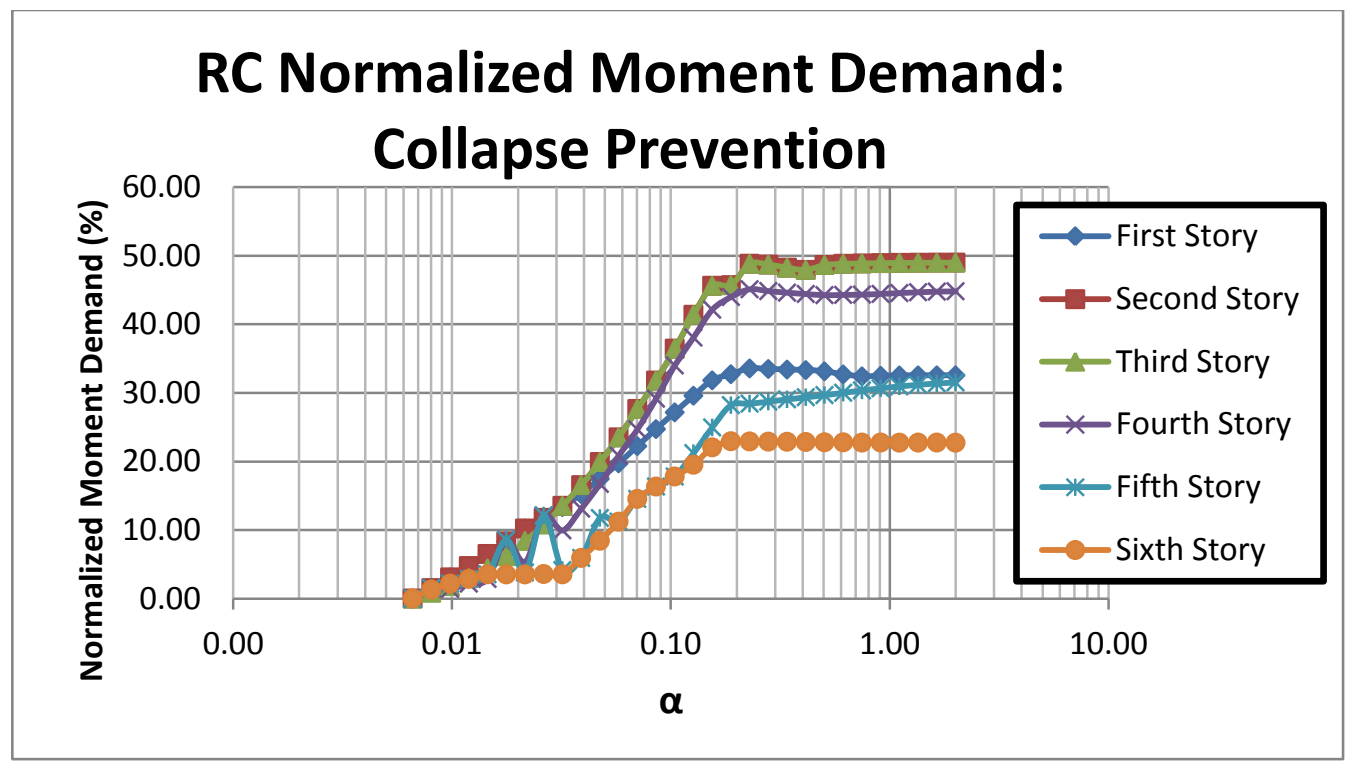

Figure 6.18: Maximum RC normalized moment demand considering collapse prevention performance objective: LA6-A

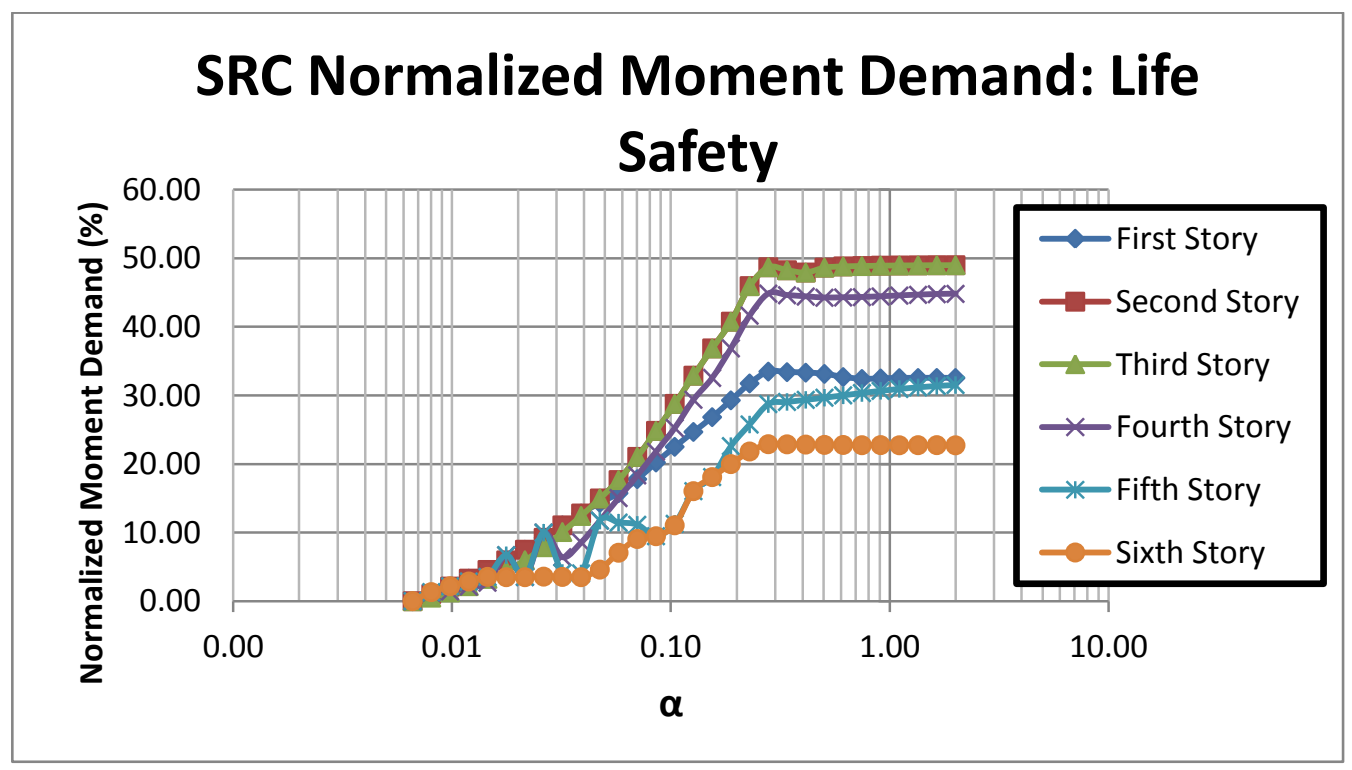

Figure 6.19: Maximum RC normalized moment demand considering life safety performance objective: LA6-A 


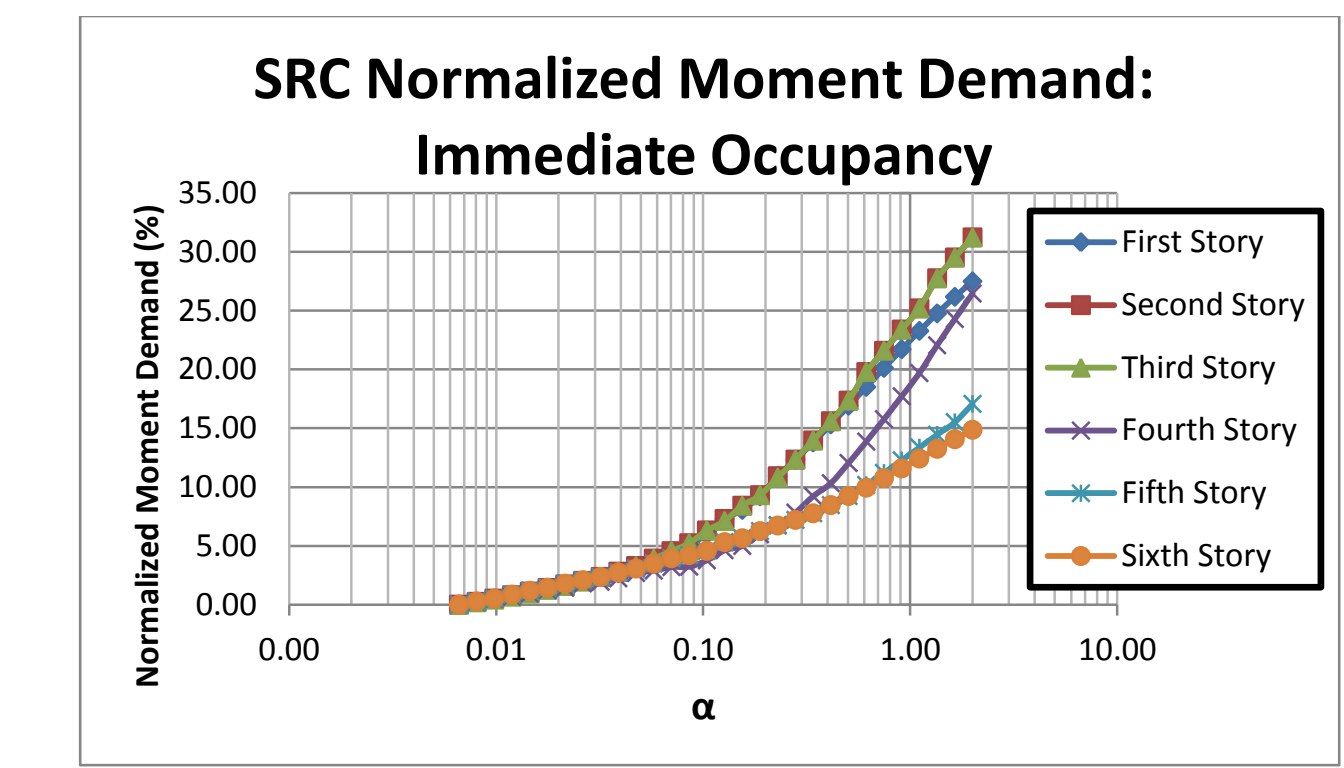

Figure 6.20: Maximum RC normalized moment demand considering immediate occupancy performance objective: LA6-A

\subsubsection{Demand on RC Links}

To ensure expected performance of the retrofitted system, premature failure of the RC links should be avoided. Due to the links boundary conditions of LA6-A (i.e., pinned on both sides) only axial load is introduced on the links. The axial demands on the links were also normalized by $\mathrm{V}_{1 \mathrm{y}}$, for comparison purposes. Figures 6.21 to 6.23 show the maximum normalized axial demands for each story and for the tree performance objectives. When considering the performance objectives corresponding to collapse prevention and life safety, the axial demand converges after an $\alpha$ value of 0.3 . The second story converges to about $38 \%$ while the other stories converge to $33 \%$. This occurs because after an $\alpha$ value of 0.3 the building has reached a sway mechanism, hence any larger RC stiffness does not further enhance the performance of the building. It is noted that when considering immediate occupancy as the performance objective the axial demand keeps increasing over the $\alpha$ values considered but does not exceed the values 
from collapse prevention and life safety performance objective, thus it does not govern the design of RC.

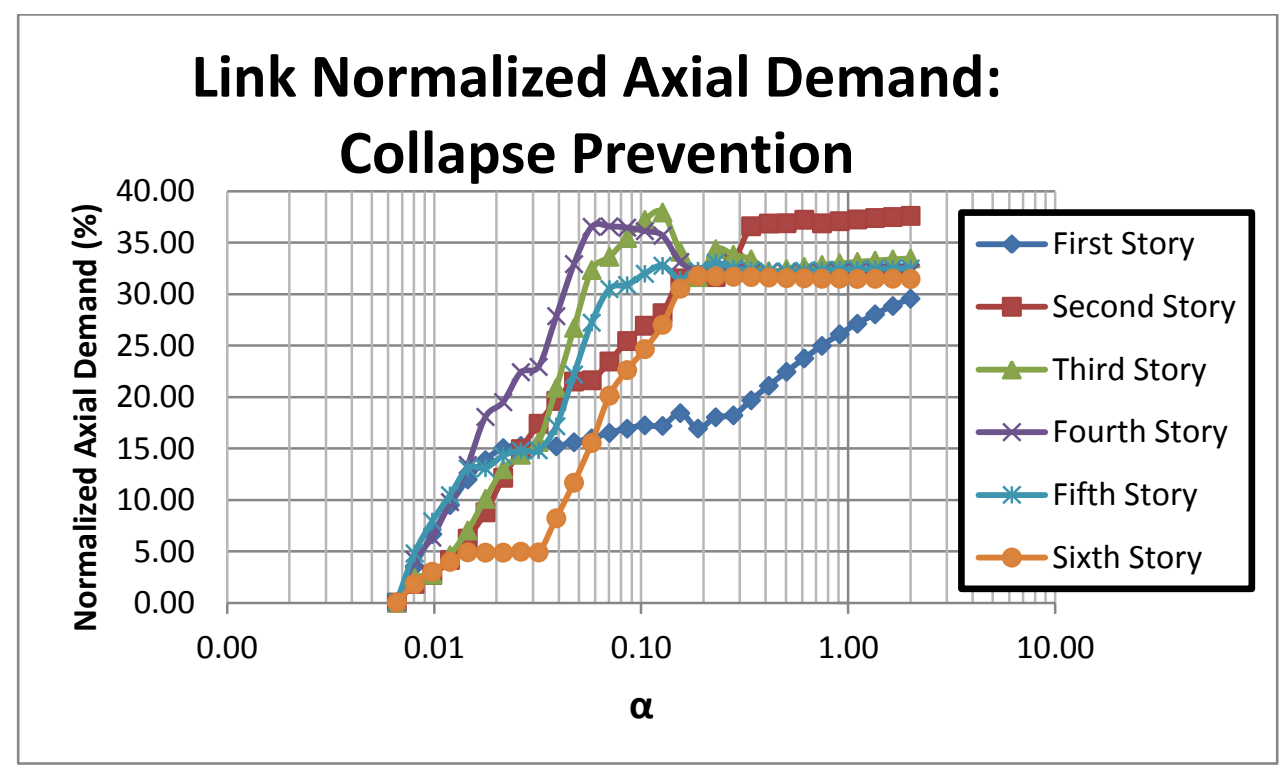

Figure 6.21: RC links normalized maximum axial demand considering collapse prevention performance objective: L6-A

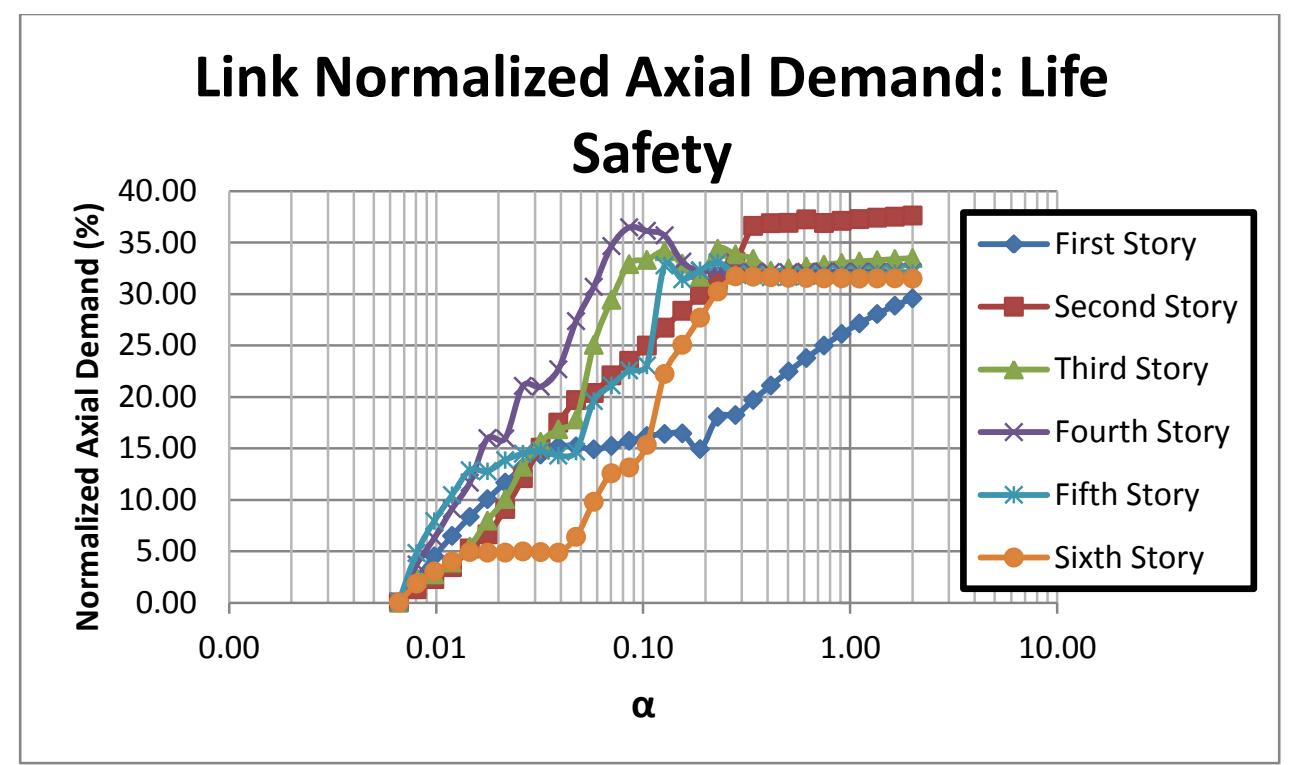

Figure 6.22: RC links normalized maximum axial demand considering life safety performance objective: L6-A 


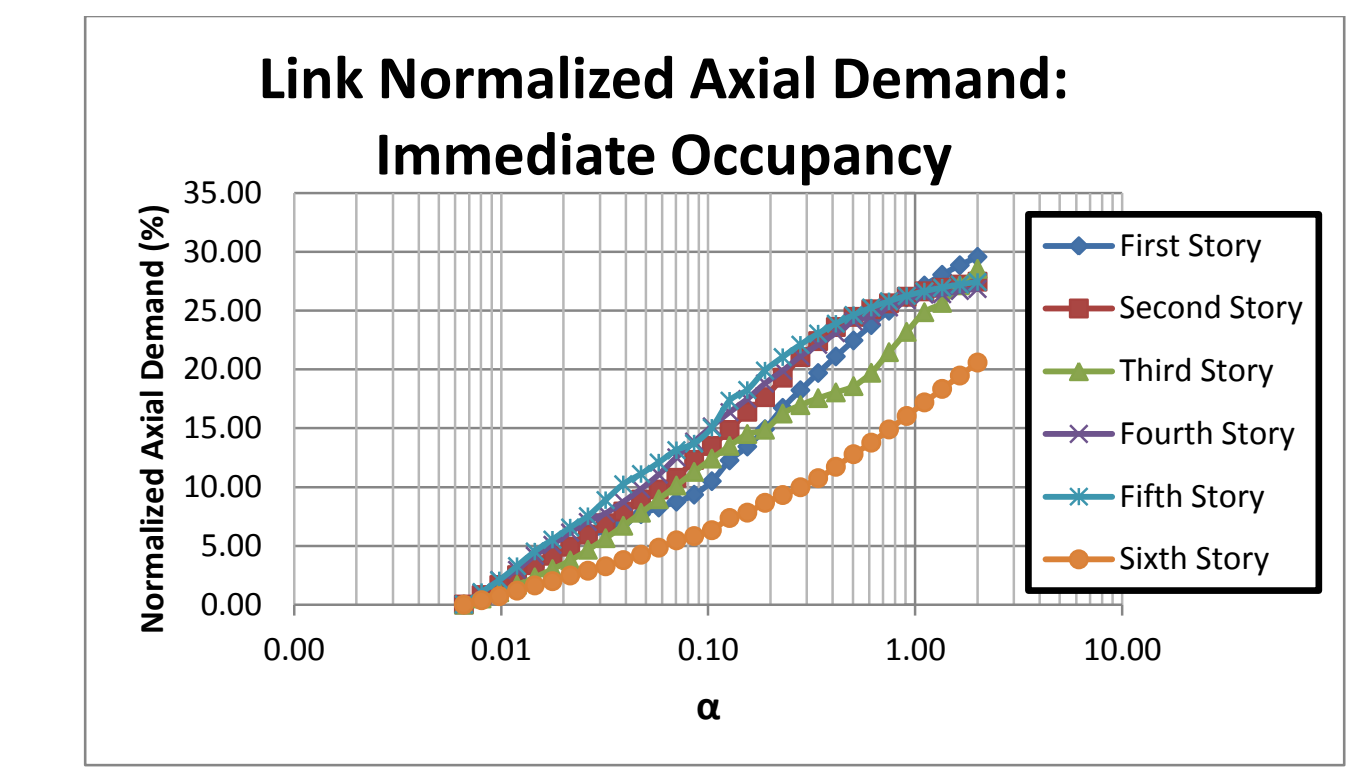

Figure 6.23: RC links normalized maximum axial demand considering immediate occupancy performance objective: L6-A

\subsection{Nonlinear Dynamic Analysis}

Nonlinear static analyses were conducted in section 6.2 to help demonstrate the beneficial contribution of $\mathrm{RC}$ in mitigating inter-story drift concentration in mid-rise $\mathrm{CBF}$ buildings. As discuss in Chapter 5, nonlinear static analysis explicitly considers components yielding and buckling in the system; however, it does not consider brace rupture behavior caused by low-cycle fatigue, the consequent strength and stiffness degradation, and their impact on dynamic response of the system. Nonlinear dynamic analyses were conducted to address these issues. The $\alpha$ values was varied between 0.0066 and 2 (i.e., the same as nonlinear static analyses) to observe the behavior of the system under different RC stiffness values. Also, both LA6-A and LA6-B were considered to compare performances of the retrofitted systems having the links with and without the hysteretic energy dissipation feature. It should be noted that the same ground motions were considered as 
those mentioned in section 5.3.1. The following sections describe the response quantities of interests and the discussion of the results.

\subsubsection{Response Quantities of Interest}

The maximum inter-story drifts were outputted for every ground motion during the nonlinear dynamic analysis. The maximum inter-story drifts for each earthquake under each considered RC stiffness ratio, $\alpha$, are provided in Appendix B. It should be noted that the median of the maximum inter-story drifts from all considered earthquakes is selected as a response quantity of interest and discuss in detail in the following section.

Furthermore, demands on RC and links, and links with hysteretic energy absorption capacity are discussed.

\subsubsection{Result Discussion}

\subsubsection{Median of the Maximum Inter-Story Drifts}

Figure 6.24 shows the median of the maximum interstory drifts corresponding to all ground motions from the $10 \%$ in 50 year suite. As shown, the drifts of all earthquake records reduce from $1.0 \%$ to $0.6 \%$ as RC stiffness increases. From the 20 ground motions considered in the $10 \%$ in 50 year suite, it is noted that only 4 ground motions cause LA6 to exceed the life safety performance objective drift (i.e., 4 ground motions are critical earthquake records). Furthermore, 2 out of the 4 critical earthquake records cause the building to exceed the collapse prevention drift (2\%). It is noted that the critical earthquake records create a soft-story failure at the first floor level of LA6. Due to the large amount of ground motions that are not considered critical earthquake record, the median of the maximum inter-story drift were plotted (see Figure 6.25) for the 4 critical 
earthquakes. As shown, the inter-story drift is able to be reduced from $2 \%$ to $1.2 \%$, indicating that stiffer RC enables successful achievement of the life safety objective under critical ground motions. Also, it is noted that an $\alpha$ value of 0.2 is required to successfully redistribute the drifts along the height of the building to avoid exceeding the life safety drift under critical ground motions.

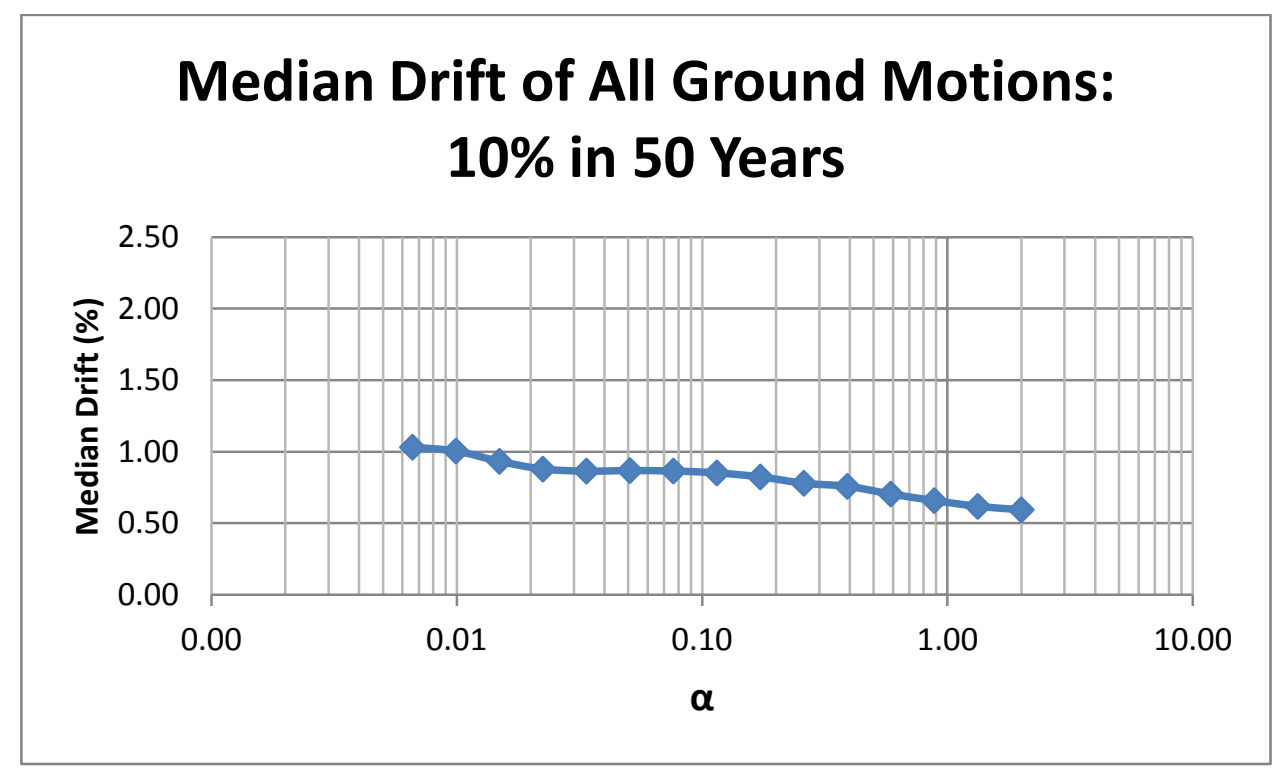

Figure 6.24: Median of the maximum inter-story drifts from all ground motions (10 in 50 years) of LA6-A 


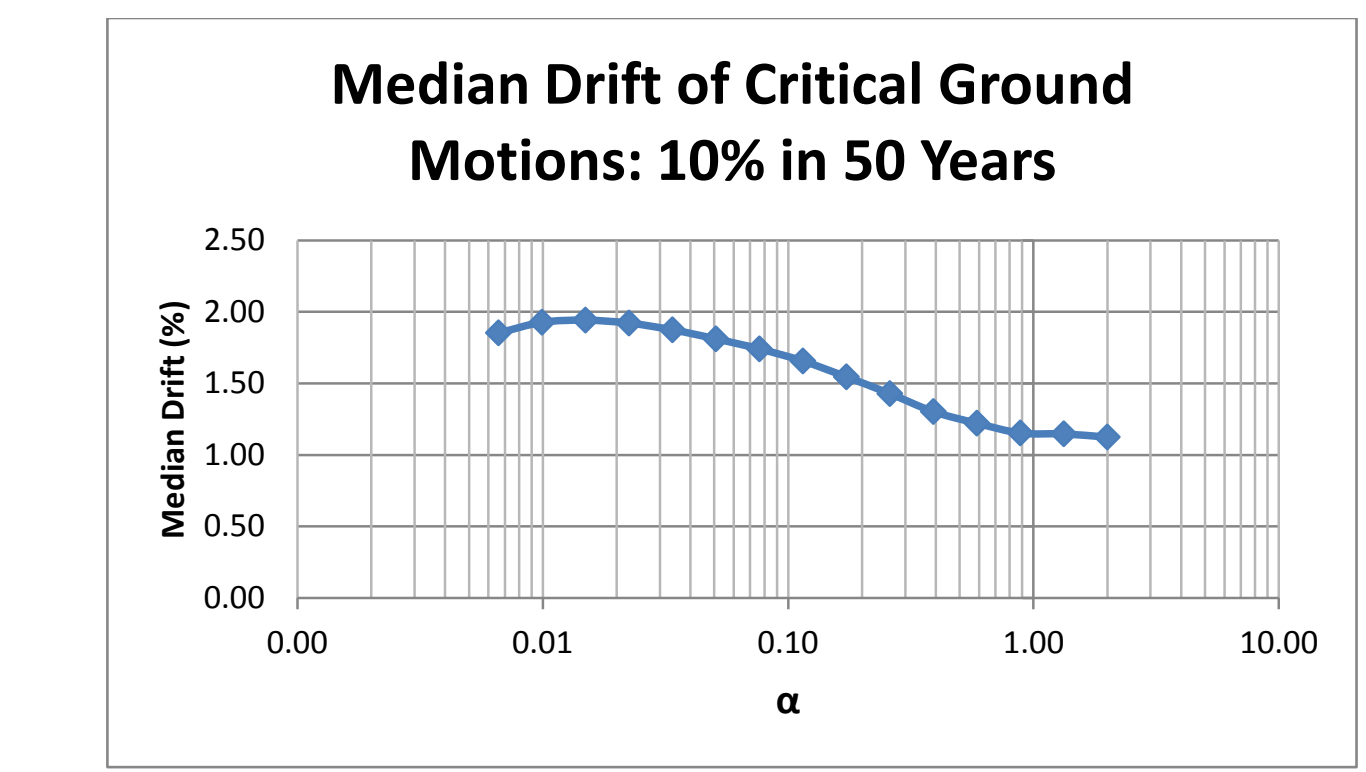

Figure 6.25: Median of the maximum inter-story drifts from critical earthquake record (10\% in 50 years) of LA6-A

Considering the $2 \%$ in 50 year suite, a similar trend was observed. Figure 6.26 shows the median of the maximum interstory drifts for each $\alpha$ considered. It is observe that the drift is able to be reduced to collapse prevention drift (1.93\%). Figure 6.27 shows the median of the maximum drifts of each $\alpha$ for the critical earthquake records. It is noted that out of the 20 ground motions 18 were tagged as critical earthquake records. With the implementation of $\mathrm{RC}$ the median of the maximum drifts were able to be reduced from $12.86 \%$ (beyond the limit associated with collapse prevention) to $2.1 \%$ which does not satisfy the FEMA356 requirements. Although the retrofitted system was able to redistribute the interstory drift and avoid soft story failure, further energy dissipation is required, i.e., LA6-B should be considered. Details results of LA6-B under earthquakes corresponding to $2 \%$ in 50 years are presented in section 6.3.2.4. 


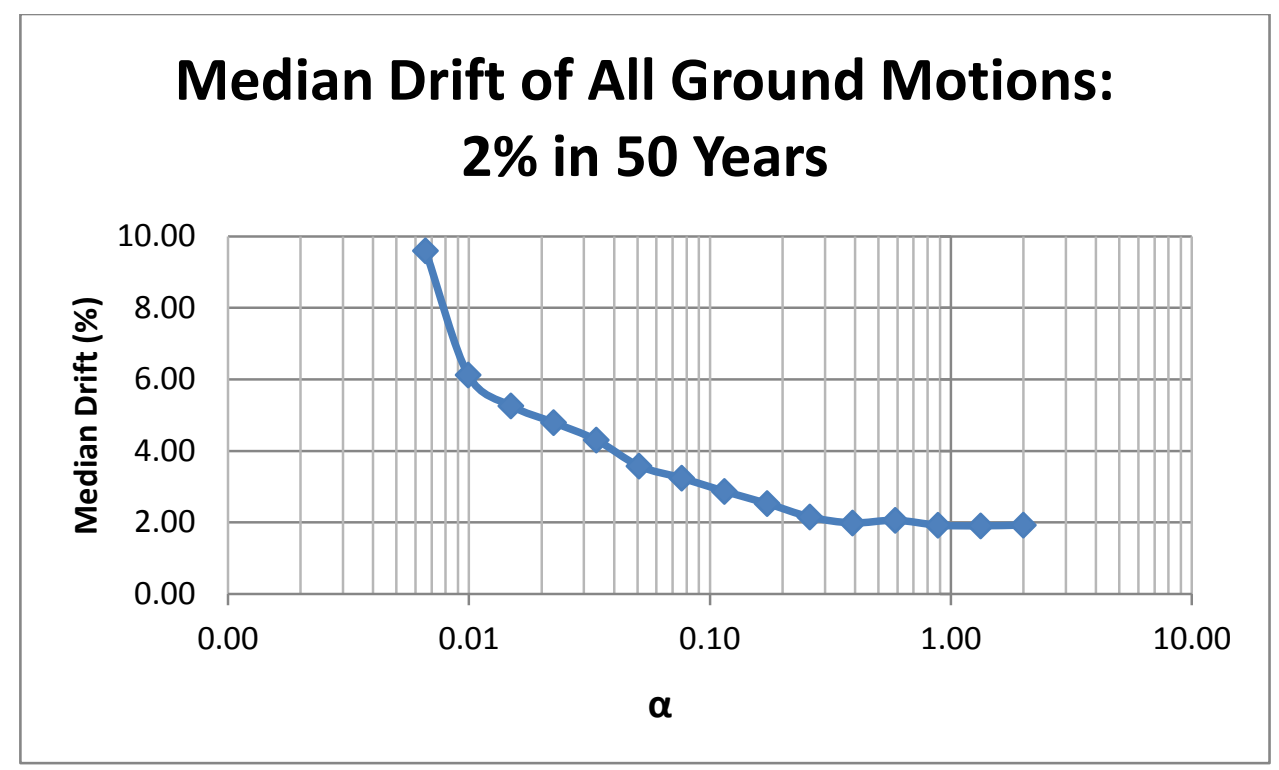

Figure 6.26: Median of the maximum inter-story drifts from all ground motions ( $2 \%$ in 50 years) of LA6-A

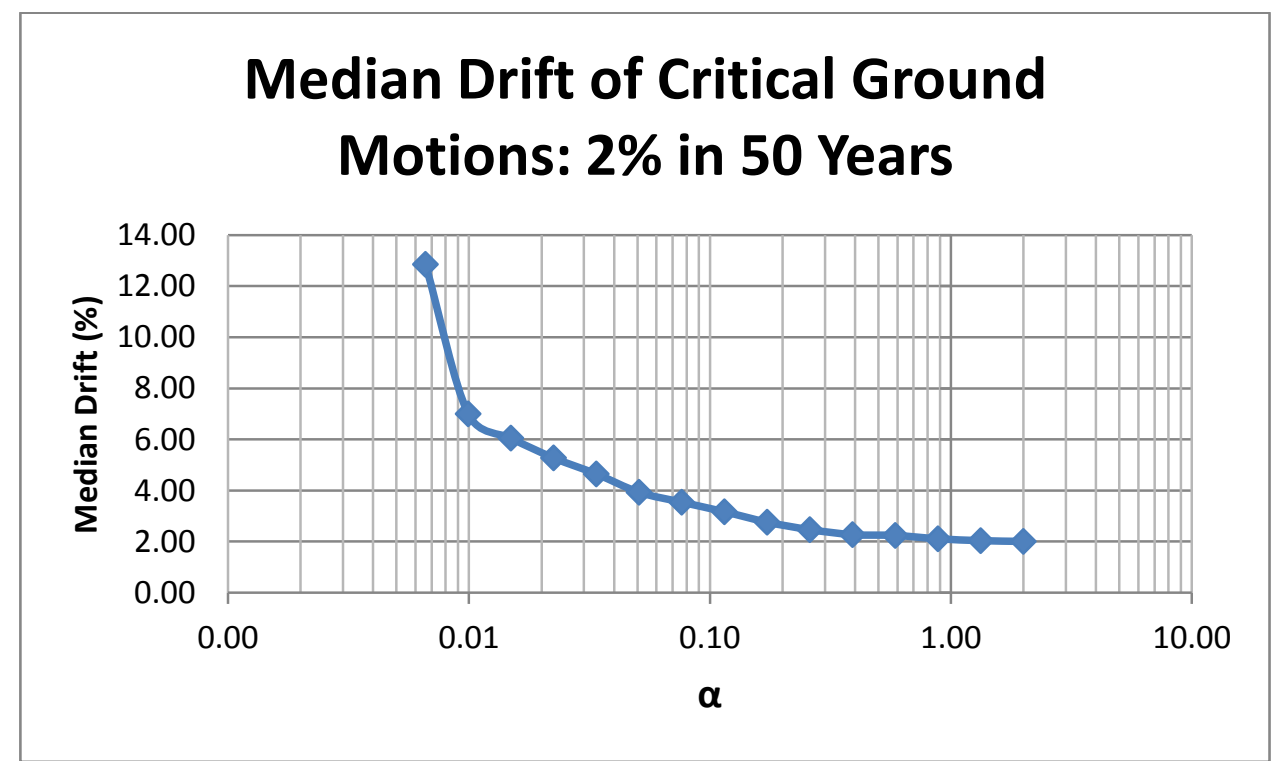

Figure 6.27: Median of the maximum inter-story drifts from critical earthquake record ( $2 \%$ in 50 years) of LA6A

Considering the suite corresponding to near-fault ground motions, the maximum interstory drift of all earthquakes reduces from $1.54 \%$ to $0.88 \%$. It should be noted that when considering all the ground motions the median drift does not exceed the collapse prevention performance objective drift. Out of the 20 ground motions 10 were identified 
as critical earthquake records. Figure 6.29 shows the median of the maximum inter-story drifts for the critical earthquake records. Although the maximum considered RC stiffness does not successfully reduce the median drift to a value less than $2 \%$ (collapse prevention performance drift), it is noted that the drift reduces from $9.36 \%$ to $2.91 \%$. In order to reduce the drift bellow the collapse performance drift, links with energy dissipation capacity are required. For impact of links with energy dissipation capacity under nearfault ground motions refer to section 6.3.2.4.

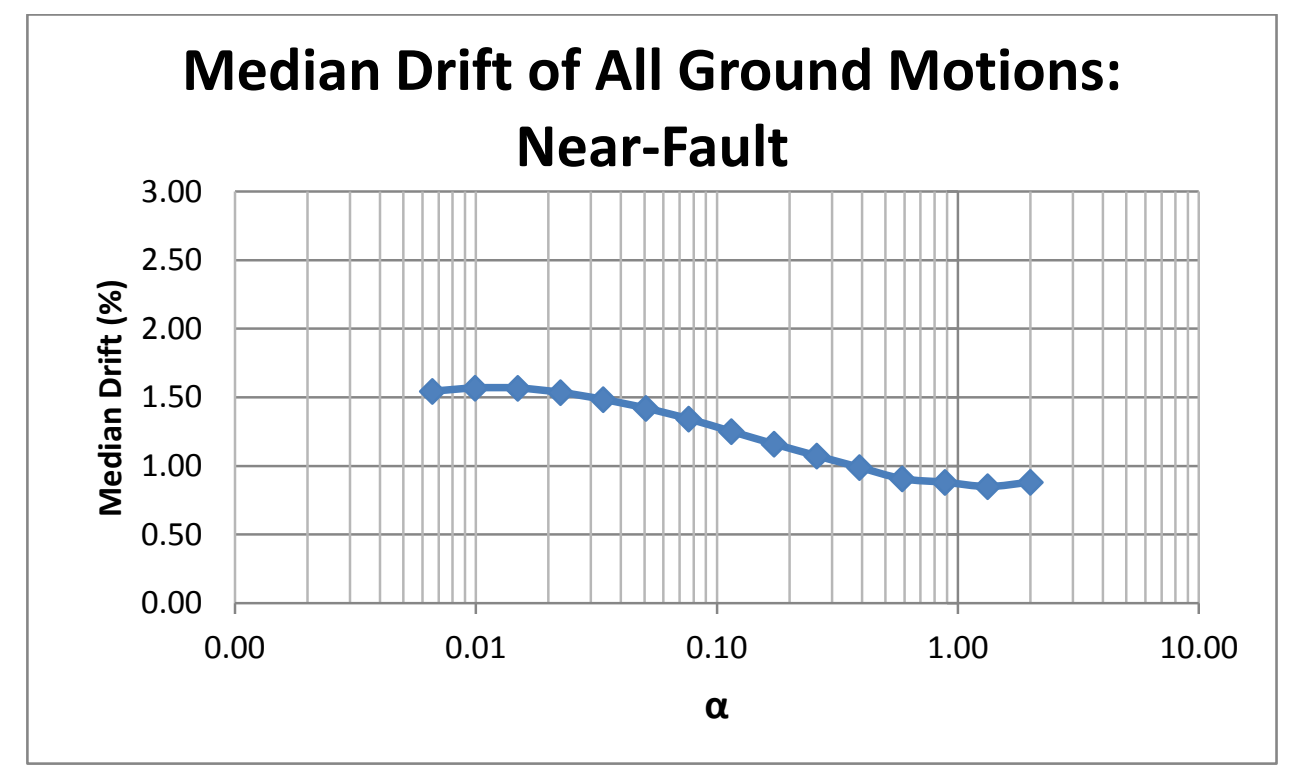

Figure 6.28: Median of the maximum inter-story drifts from all ground motions (near-fault) of LA6-A 


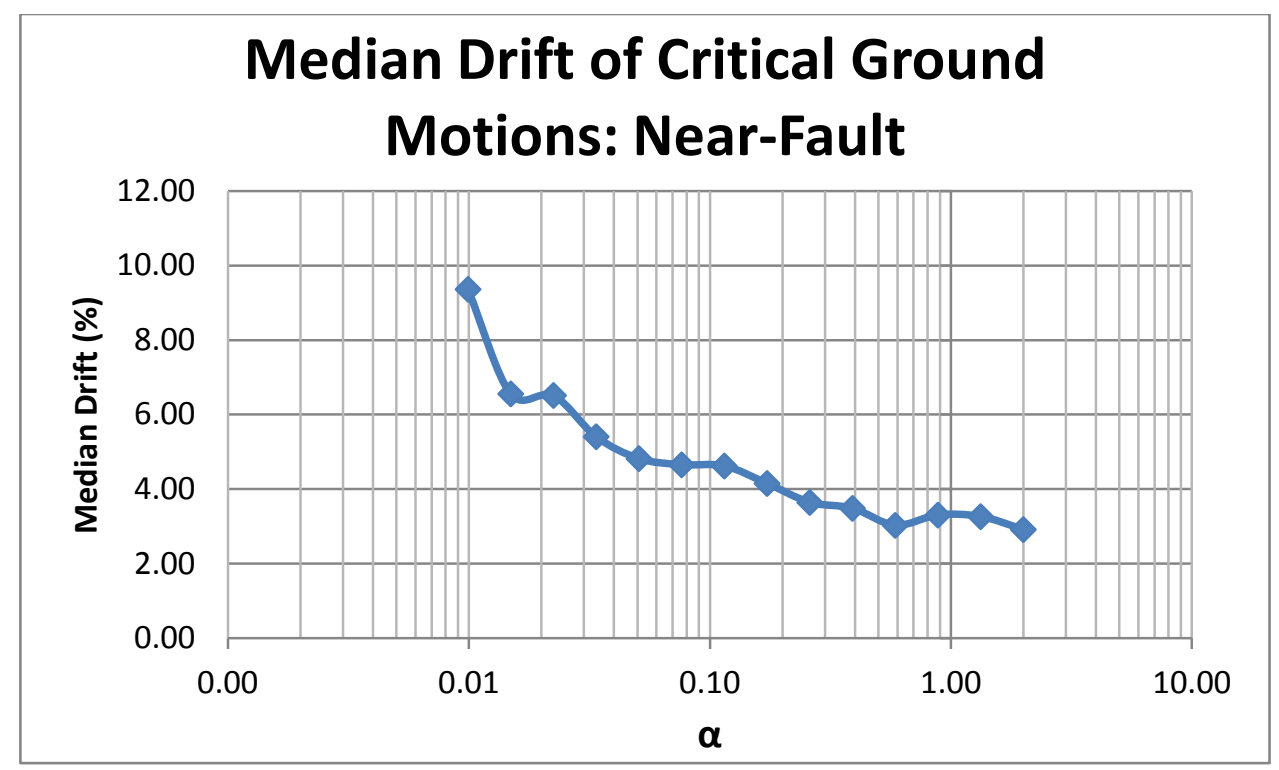

Figure 6.29: Median of the maximum inter-story drifts from critical earthquake record (near-fault) of LA6-A

\subsubsection{Demands on $R C$}

This section presents the median values of the maximum shear and bending moment demands from each ground motion of the three sets of ground motions. For comparison purpose, the shear and bending moment demands are normalized by $\mathrm{V}_{1 \mathrm{y}}$ and $\mathrm{V}_{1 \mathrm{y}} \mathrm{h}_{\mathrm{s} 1}$, respectively. . Figures $6.30,6.32$, and 6.34 present shear demands from each earthquake suite; Figures 6.31, 6.33 and 6.35 present bending moment demands from each earthquake suite.

Compared to the normalized shear demand from the pushover analyses (see Figures 6.15 to 6.17), the shear demands from nonlinear analyses are higher. Also, compared to the normalized bending moment demand from nonlinear static pushover analyses (see Figures 6.18 to 6.20 ), the normalized bending moment demand from the nonlinear dynamic analyses is higher. Higher demands from nonlinear dynamic analyses are expected because the FE models used can capture the rupture of the brace due to low- 
cycle fatigue or excessive yielding. As discuss in Chapter 5, when braces rupture sudden strength and stiffness degradations are expected in the system, resulting in excessive demands on RC. The observation that the demands from the earthquakes corresponding to $2 \%$ in 50 years are the highest is consistent with the fact the braces are more likely to rupture in a stronger earthquake.

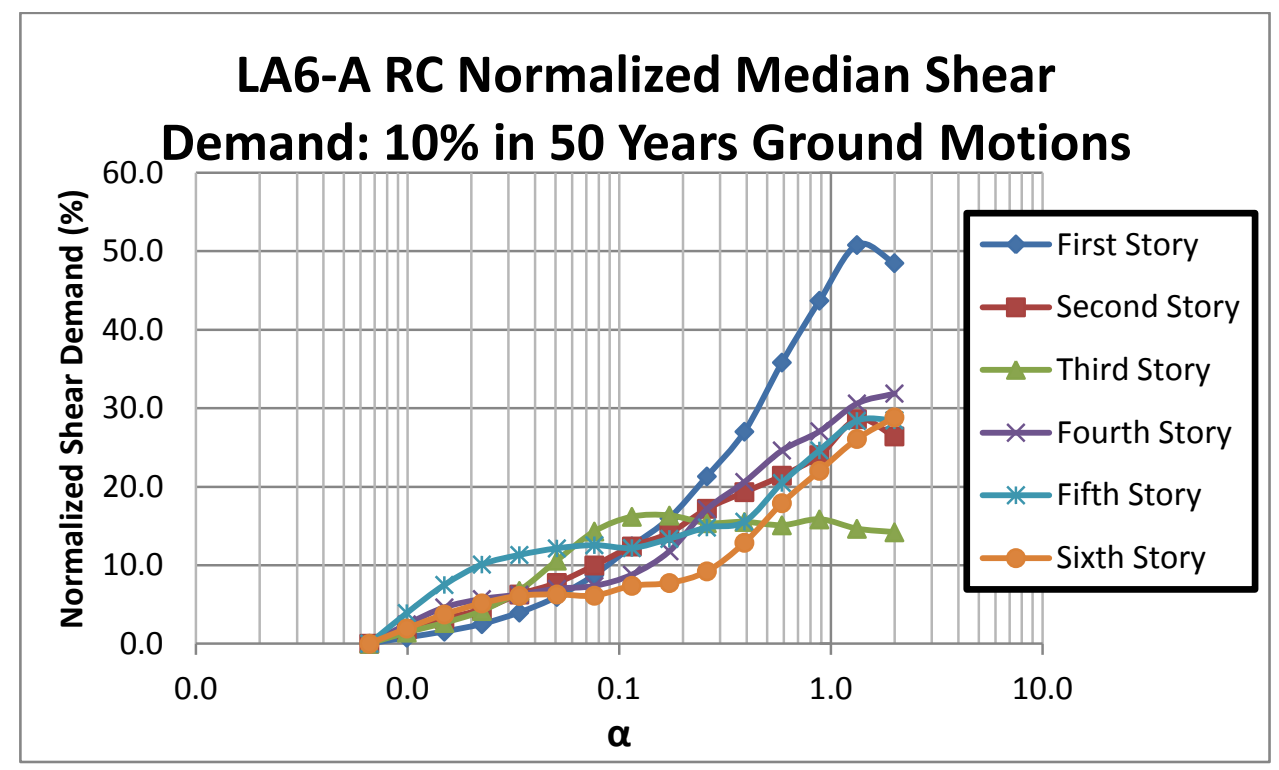

Figure 6.30: Normalized median shear demand in RC for LA6-A (Earthquakes corresponding to $10 \%$ in $\mathbf{5 0}$ years) 


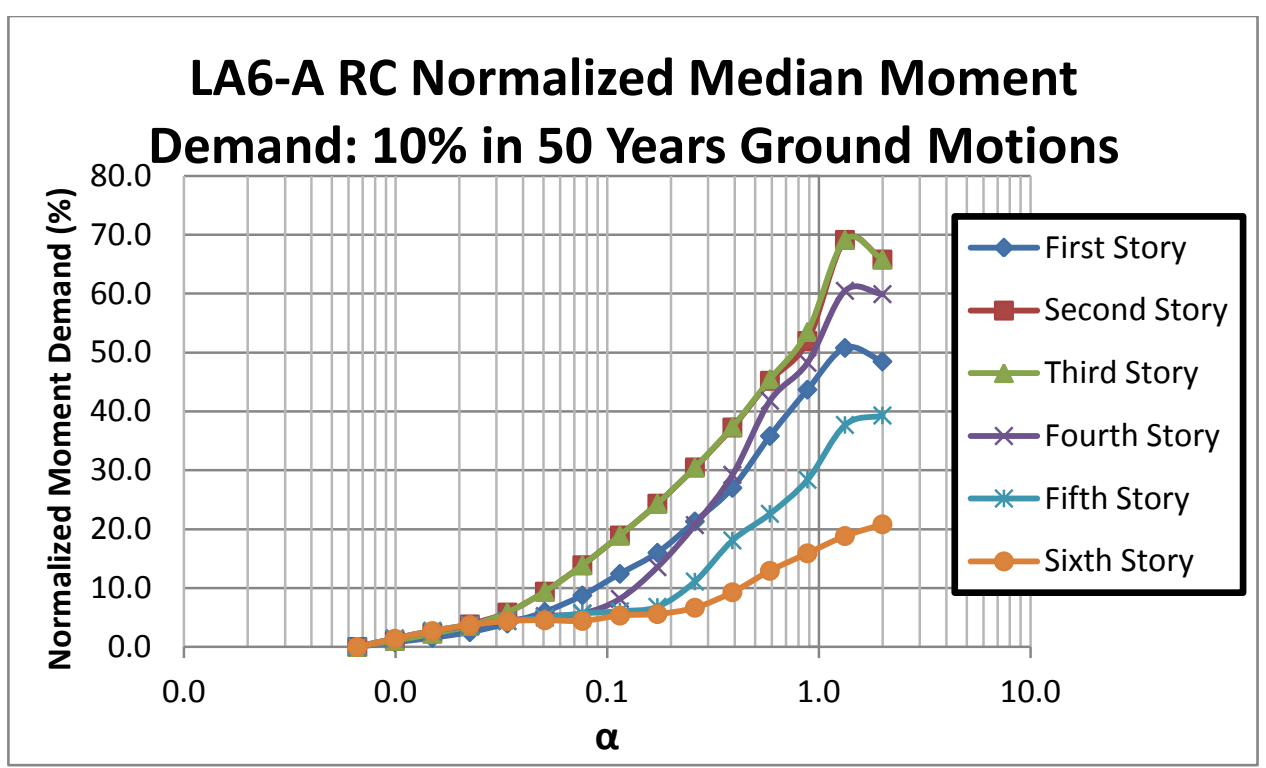

Figure 6.31: Normalized median bending moment demand in RC for LA6-A (Earthquakes corresponding to $10 \%$ in 50 years)

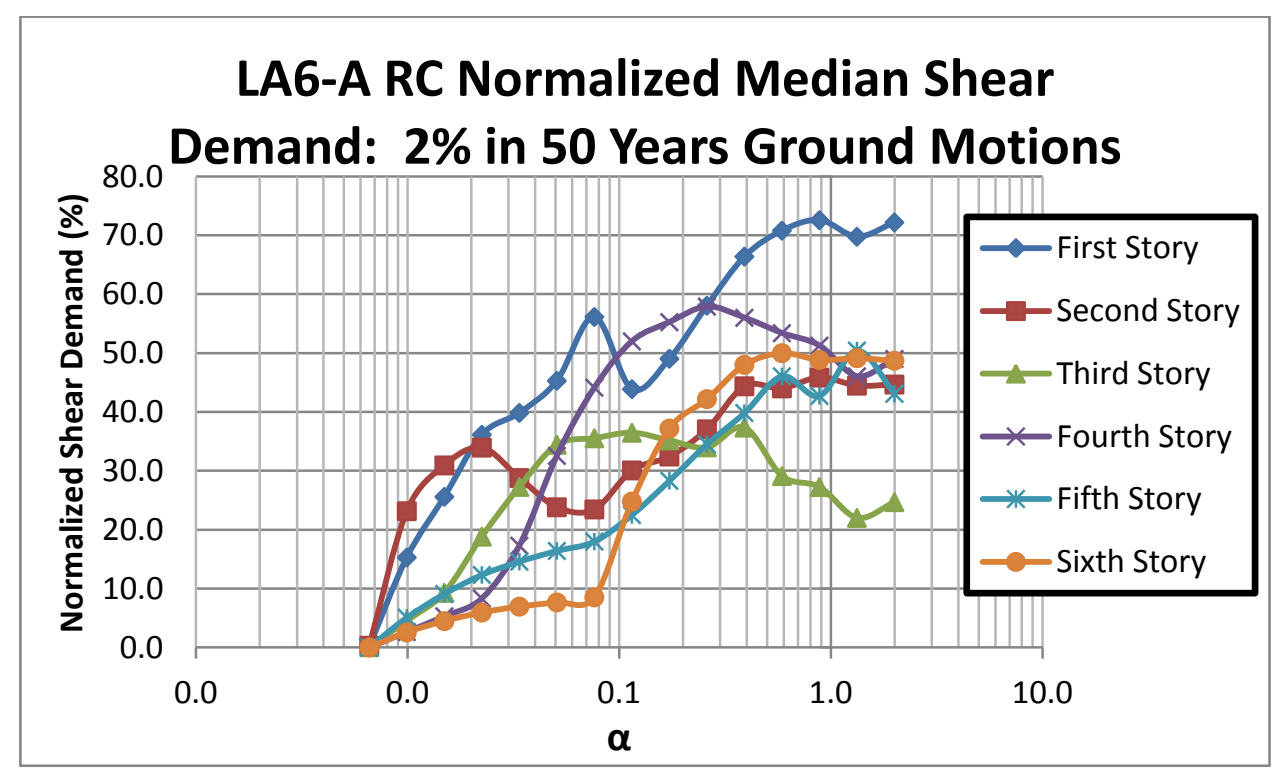

Figure 6.32: Normalized median shear demand in RC for LA6-A (Earthquakes corresponding to $2 \%$ in 50 years) 


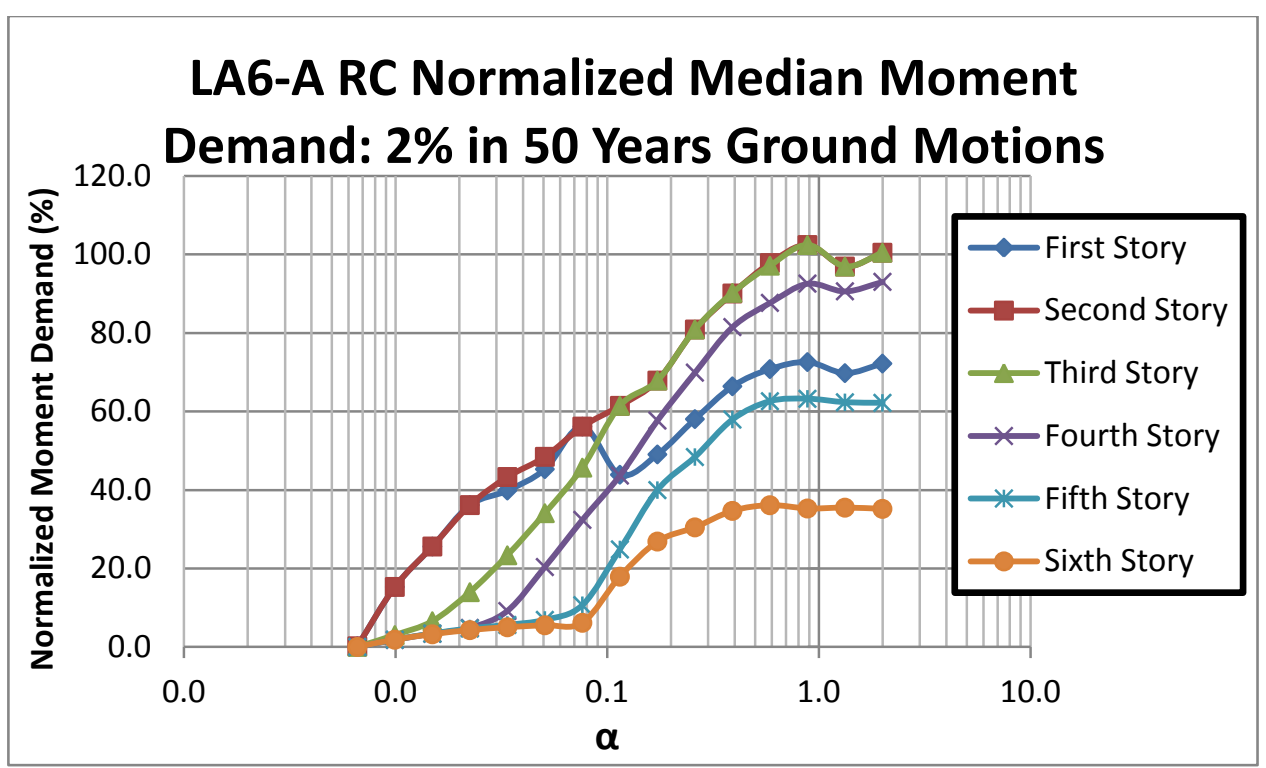

Figure 6.33: Normalized median bending moment demand in RC for LA6-A (Earthquakes corresponding to $2 \%$ in 50 years)

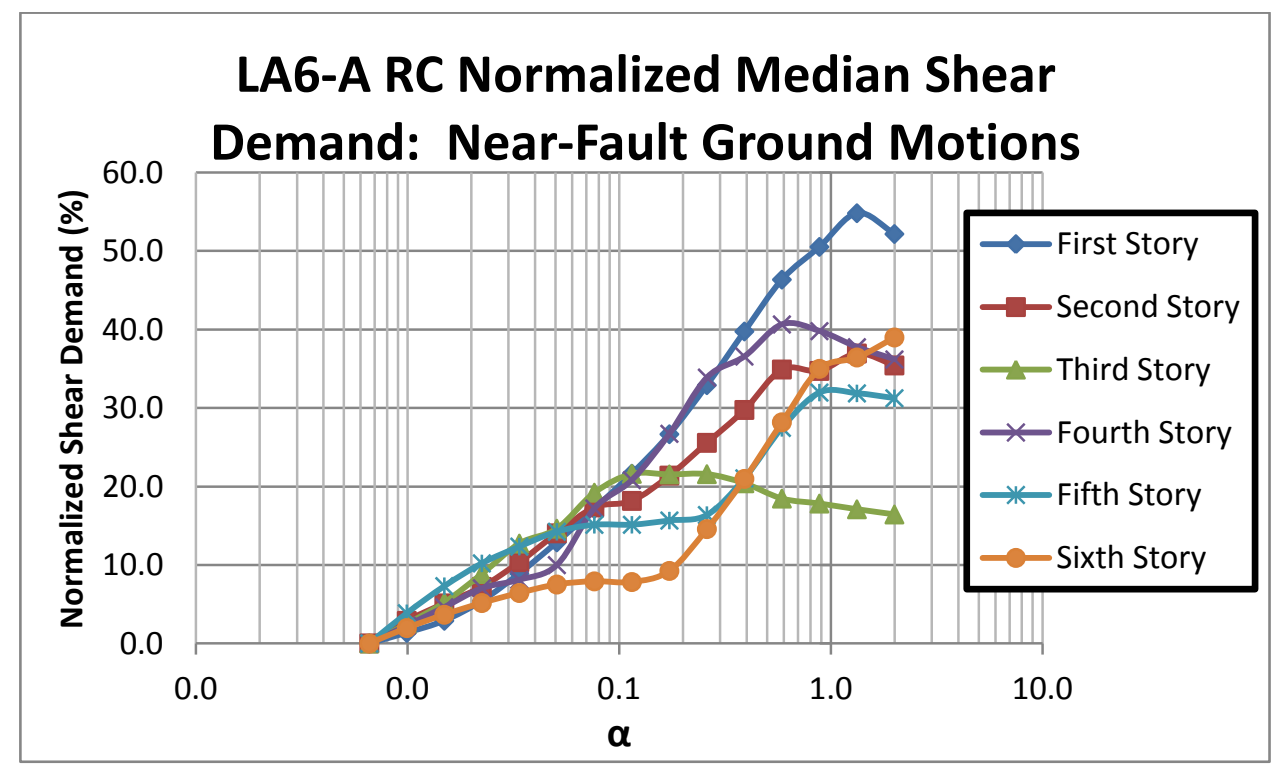

Figure 6.34: Normalized median shear demand in RC for LA6-A (Earthquakes corresponding to near-fault) 


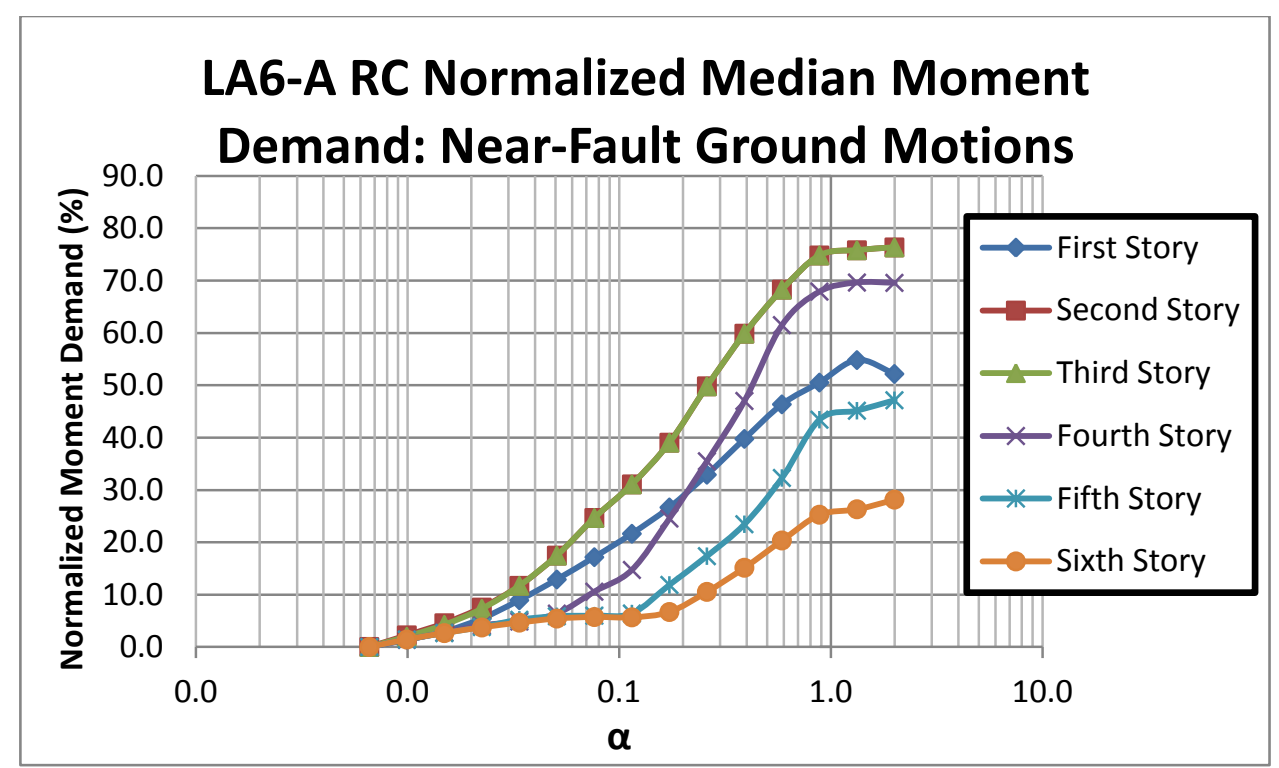

Figure 6.35: Normalized median bending moment demand in RC for LA6-A (Earthquakes corresponding to near-fault)

\subsubsection{Links Demands}

The axial demand on the links was also investigated for nonlinear dynamic analyses.

Similarly, the axial demand was normalized by $\mathrm{V}_{1 \mathrm{y}}$, for comparison purposes. Figure 6.36 to 6.38 show the median of the maximum normalized axial demand for links for the three sets of ground motions of every $\alpha$. The suite corresponding to $10 \%$ in 50 years has very similar results compared to the nonlinear static analysis (see Figure 6.21 to 6.23).

However, due to the fact that braces are more likely to fracture in earthquakes corresponding to $2 \%$ in 50 years and near-fault suites, the axial demand on the links is significantly higher because the seismic shear is redistributed through them. 


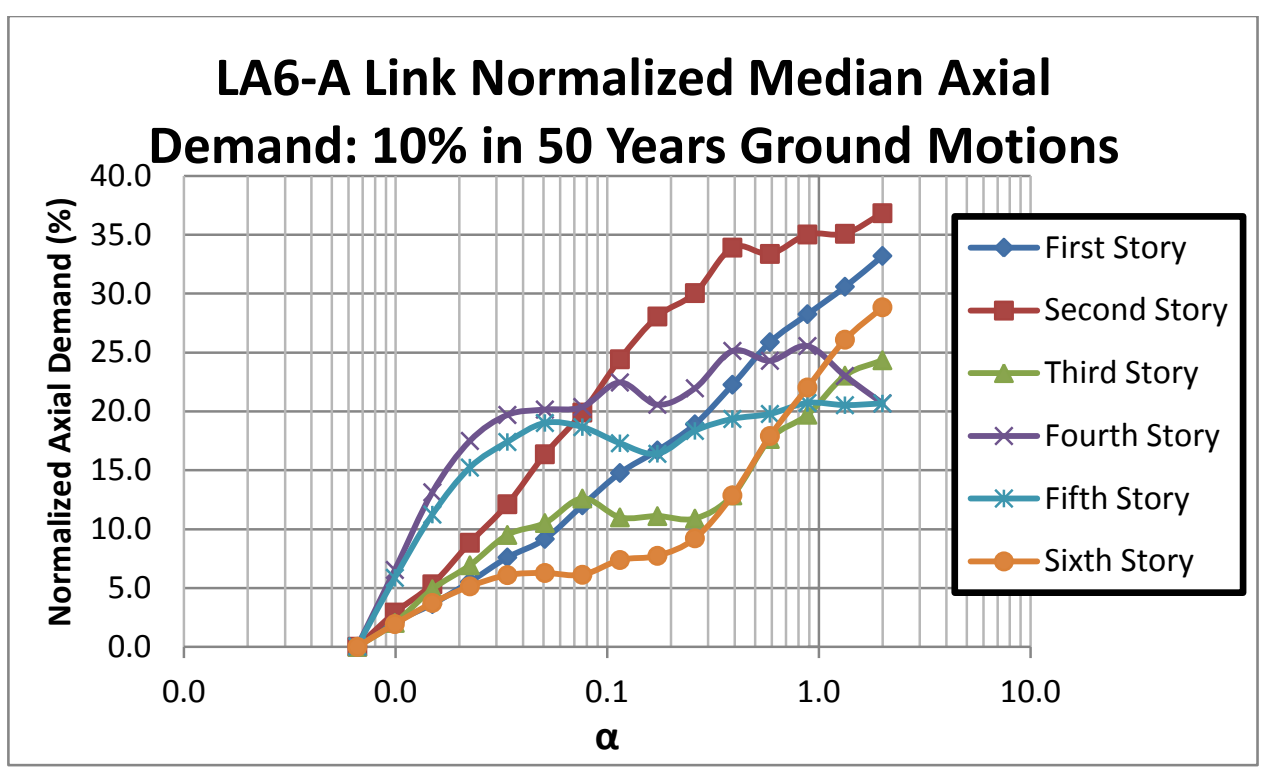

Figure 6.36: Normalized median axial demand in links for LA6-A (Earthquakes corresponding to $\mathbf{1 0} \%$ in $\mathbf{5 0}$ years)

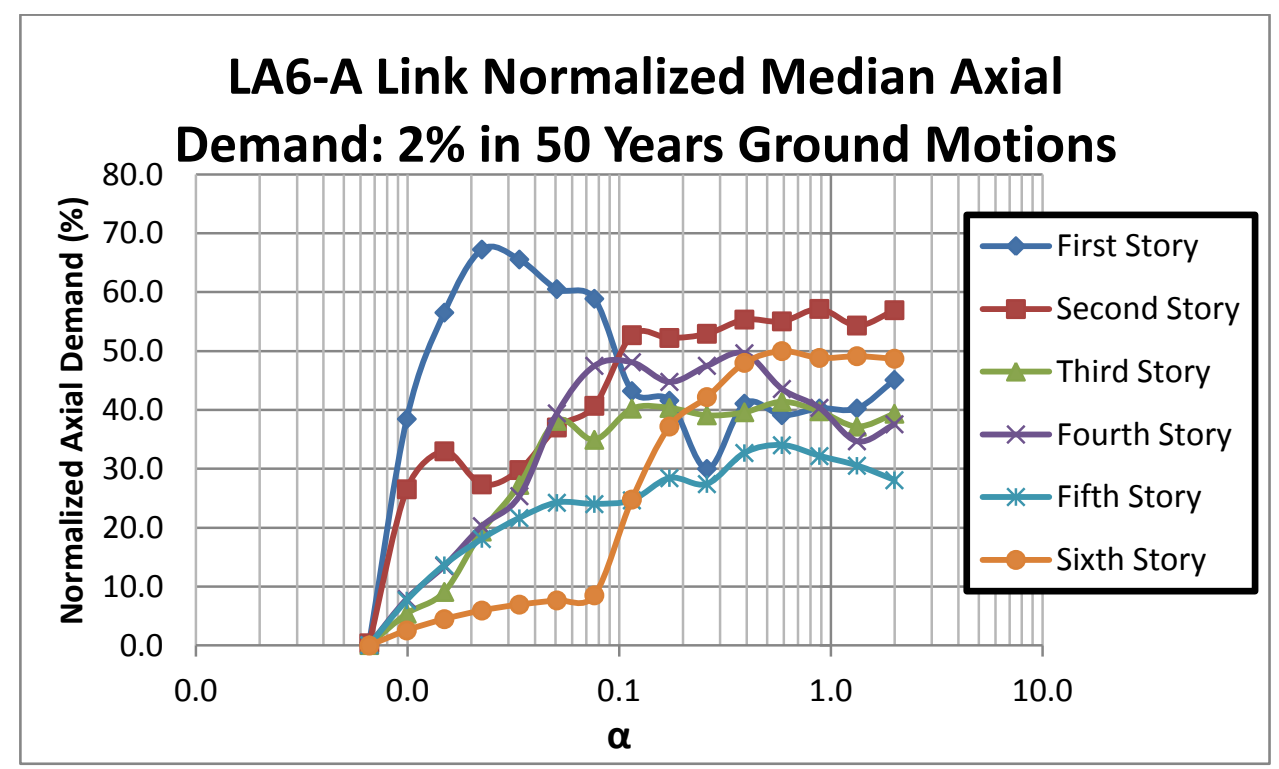

Figure 6.37: Normalized median axial demand in links for LA6-A (Earthquakes corresponding to $2 \%$ in 50 years) 


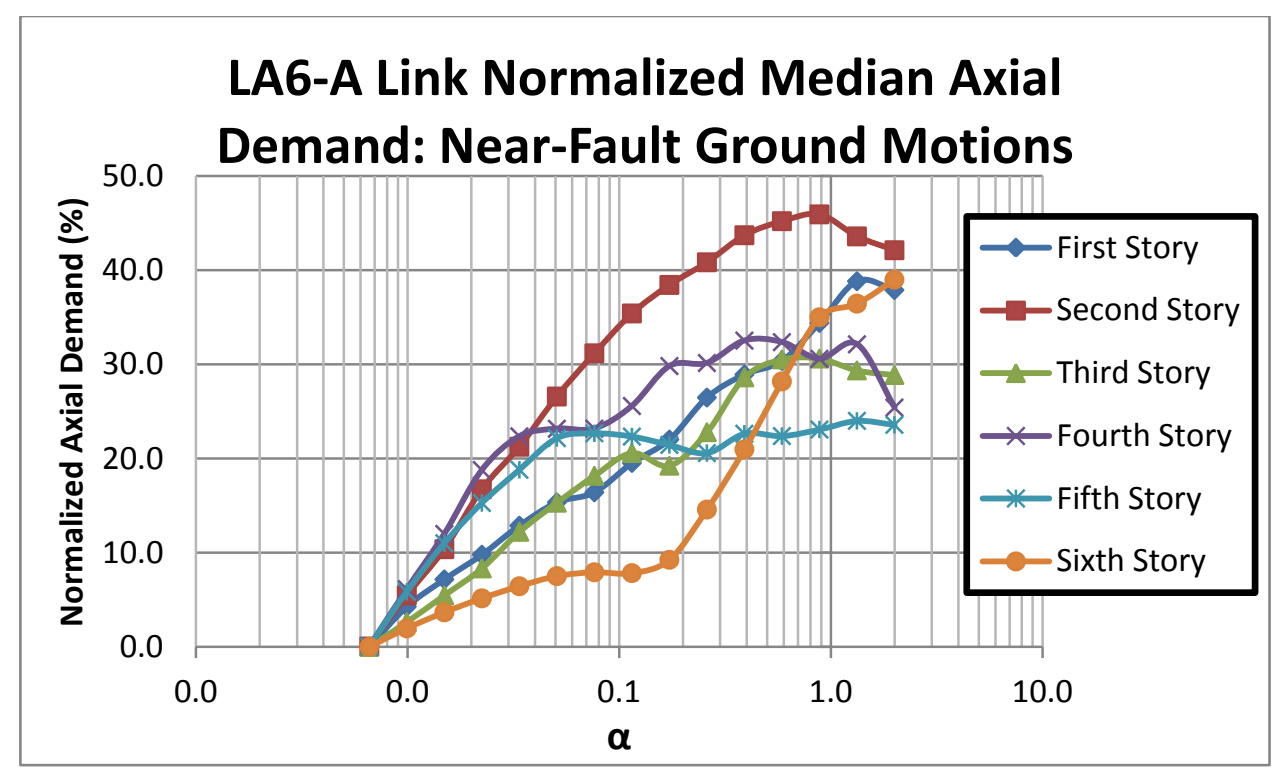

Figure 6.38: Normalized median axial demand in links for LA6-A (Earthquakes corresponding to near-fault)

\subsubsection{Benefits from Links with Energy Dissipation Capacity}

To further reduce the maximum inter-story drifts, the links may be installed with energy dissipation capacity. As mentioned before, model LA6-B corresponds to the links being fixed to RC, having energy dissipation capacity. The links were designed in a similar manner as described in Chapter 5.3.2.5 (i.e., designed to have full moment capacity while transferring the maximum axial load from nonlinear static analyses). It was necessary to have two wide flange members working in parallel at each floor. The member selected was a W30X99 and was used at each of the six stories of LA6-B.

Comparing the results from the $10 \%$ in 50 years suite, having the links pinned on both sides is sufficient to reduce bellow the target limit (1.5\%). However, adding the energy dissipation capacity to the links, LA6-B, helps reduce the drift bellow the target limit (see Figure 6.41) at a smaller $\alpha$, thus leading to a more economical design of RC. Also, at higher RC stiffness LA6-B has a smaller drift than LA6-A, resulting in less damage of 
the structure. Furthermore, when considering the $2 \%$ in 50 years suite, LA6-A did not satisfy the FEMA356 requirements. LA6-B does further reduce the drift to a value less than the target limit (see Figure 6.42). This is due to the additional strength the fixed links add to the overall system and the energy absorption. Similarly, model LA6-A does not satisfy the target drift when considering the near-fault suite, thus links with energy dissipation capacity are required. LA6-B can reduce the median of the maximum interstory drifts bellow the target drift (2\%), particularly over the range of smaller $\alpha$. It is also noted that LA6-B is able to reduce the drift to a value lower than the life safety drift, hence resulting in significantly less damage of the structure.

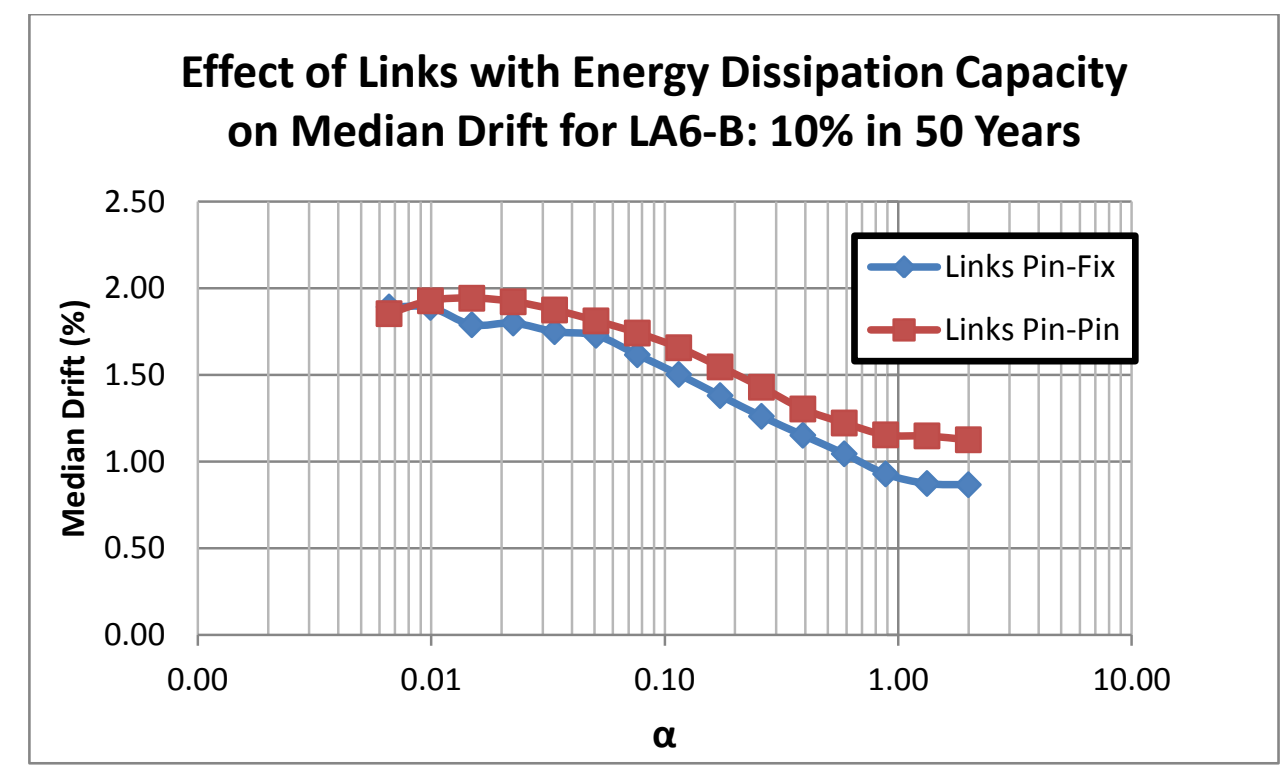

Figure 6.39: Comparison of median of maximum inter-story drifts: LA6-A vs LA6-B (Earthquakes corresponding to $10 \%$ in 50 years) 


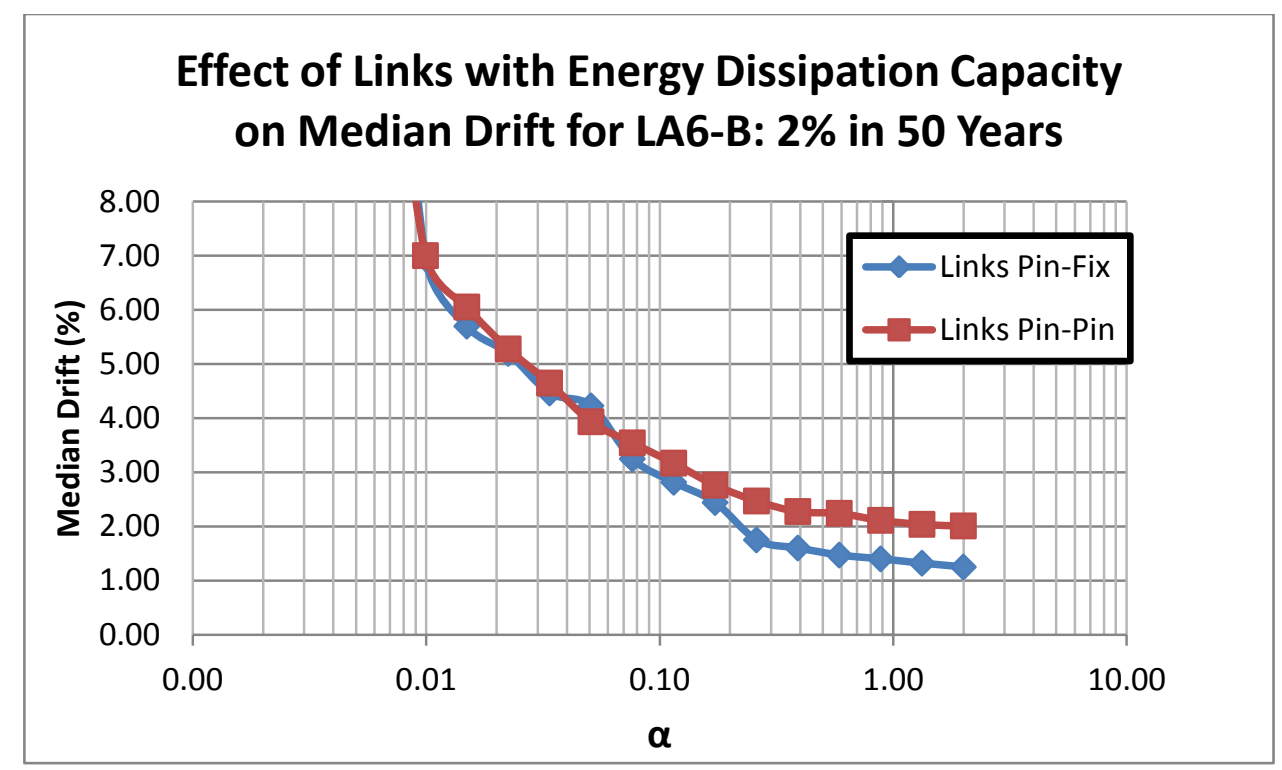

Figure 6.40: Comparison of median of maximum inter-story drifts: LA6-A vs LA6-B (Earthquakes corresponding to $2 \%$ in 50 years)

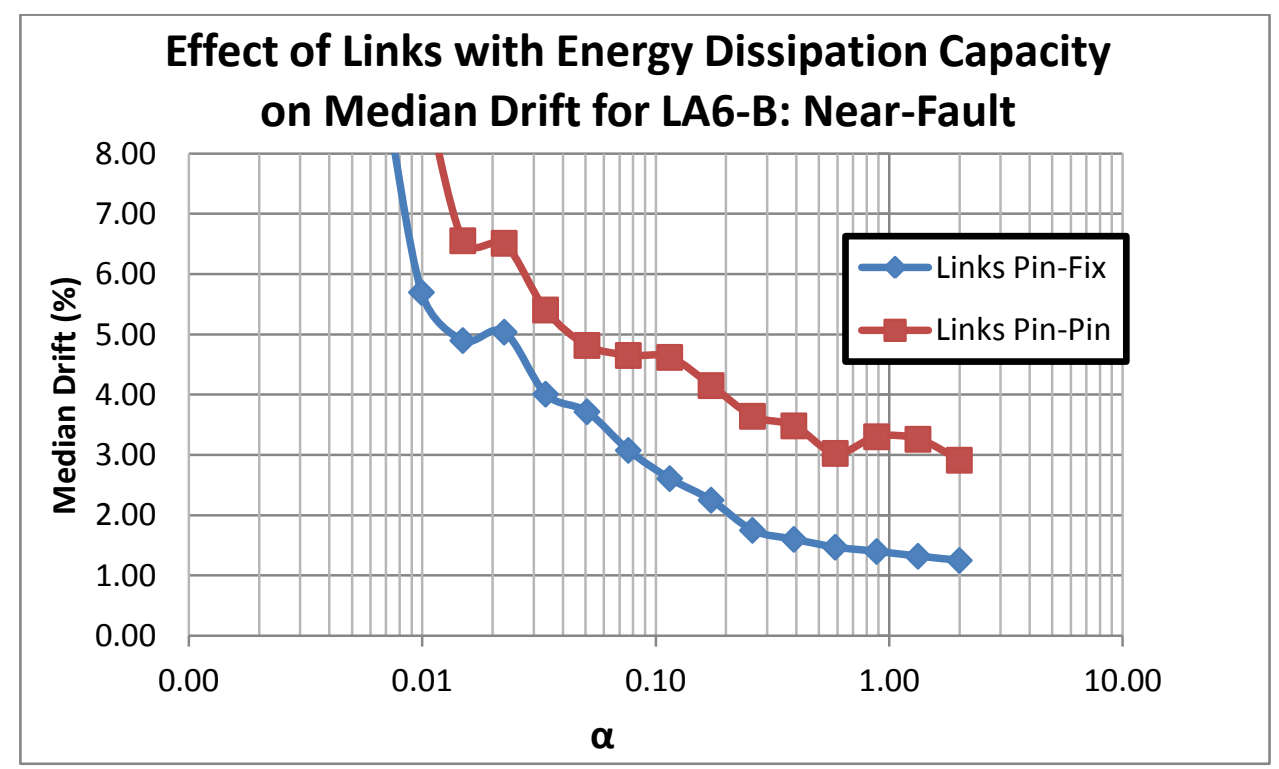

Figure 6.41: Comparison of median of maximum inter-story drifts: LA6-A vs LA6-B (Near-Fault Earthquakes)

The normalized shear and bending moment demands on RC of LA6-B are shown in Figures 6.42 to 6.47. Compared with the corresponding results for LA6-A (see Figures 6.30 to 6.35 ), the normalized median shear and bending moment of the RC are larger in the segment controlling the RC design in LA6-B for the three sets of ground motions. 
The demands increase because the links fixed to the RC tends to increase the system stiffness and consequently attract larger seismic forces on the system, causing larger shear and bending moment demands on the RC of LA6-B.

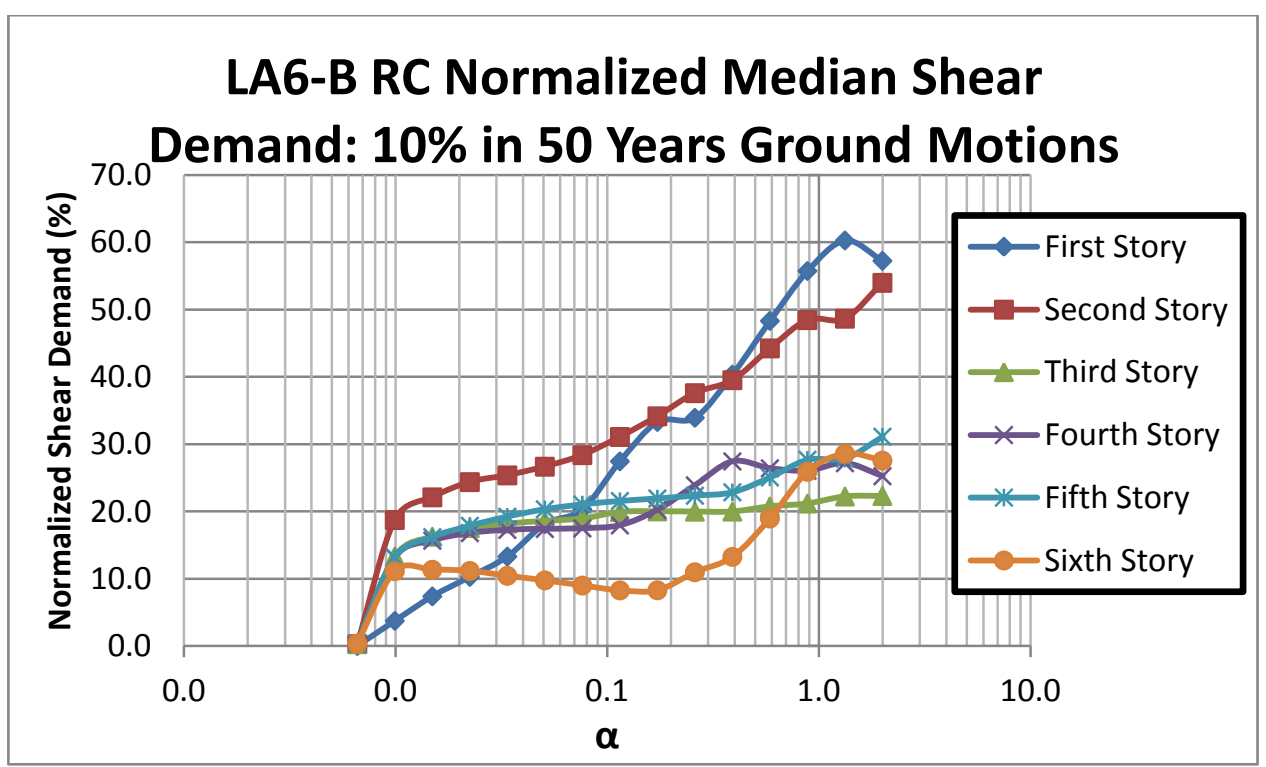

Figure 6.42: Normalized median shear demand on RC in LA6-B (Earthquakes corresponding to $10 \%$ in 50 years)

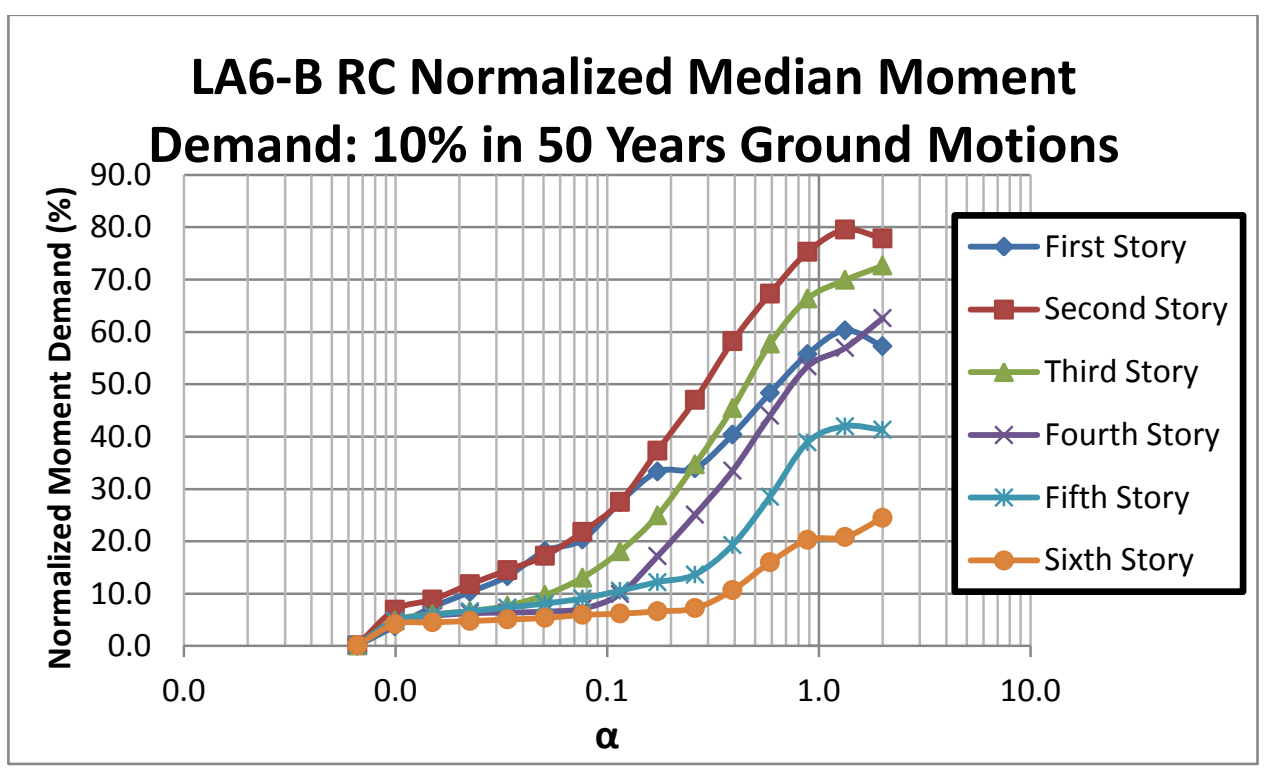

Figure 6.43: Normalized median bending moment demand on RC in LA6-B (Earthquakes corresponding to $10 \%$ in 50 years) 


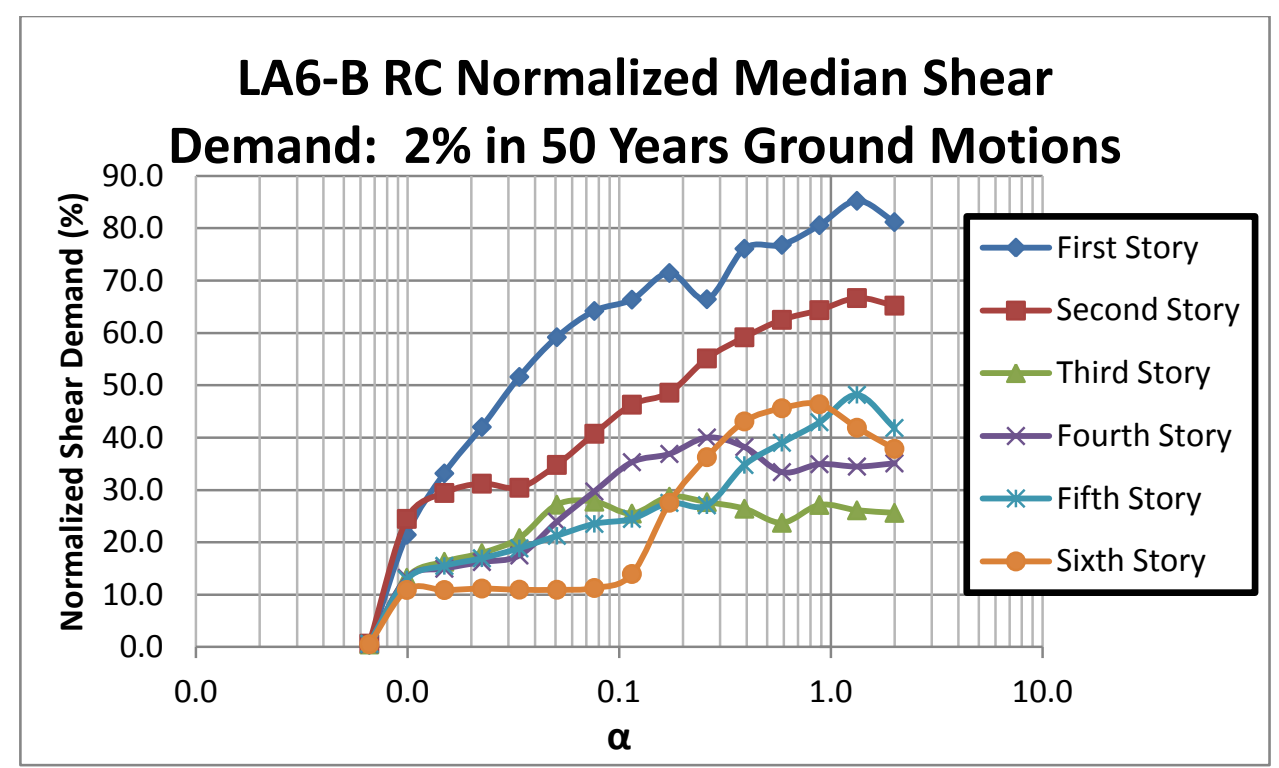

Figure 6.44: Normalized median shear demand on RC in LA6-B (Earthquakes corresponding to $2 \%$ in 50 years)

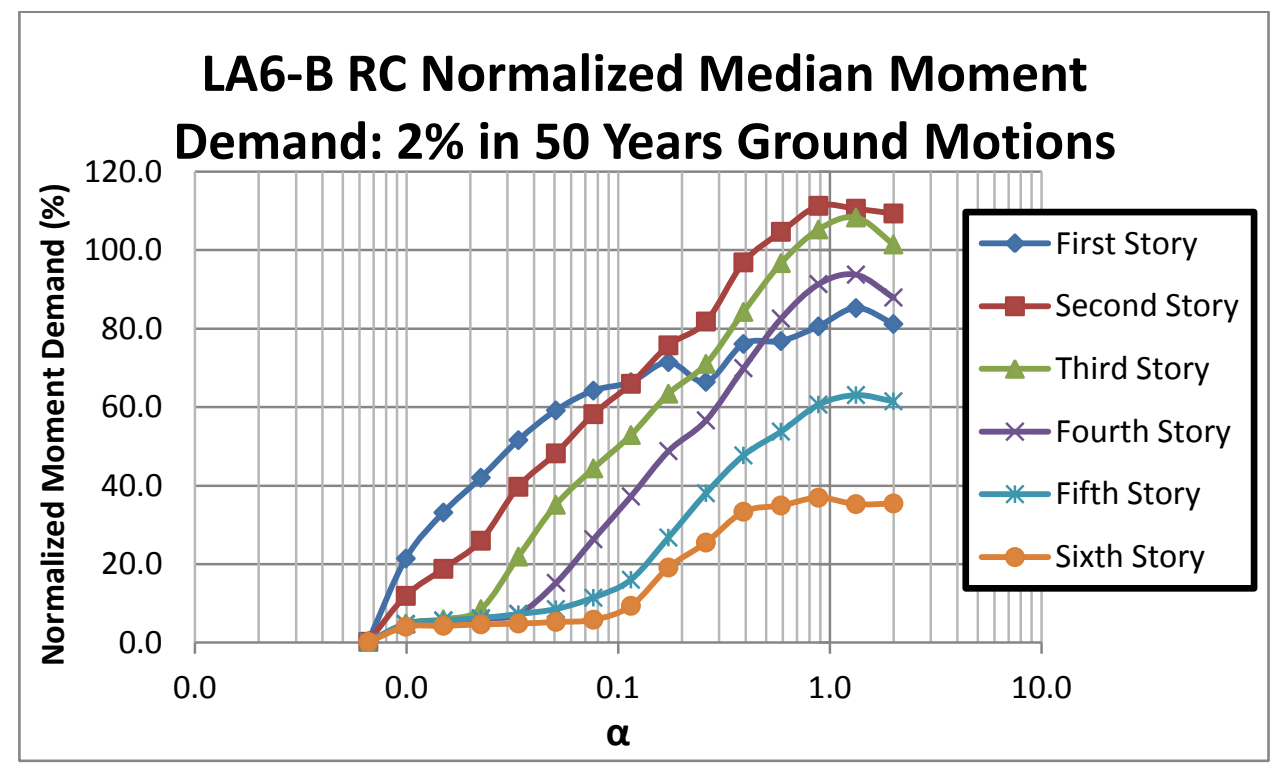

Figure 6.45: Normalized median bending moment demand on RC in LA6-B (Earthquakes corresponding to $2 \%$ in 50 years) 


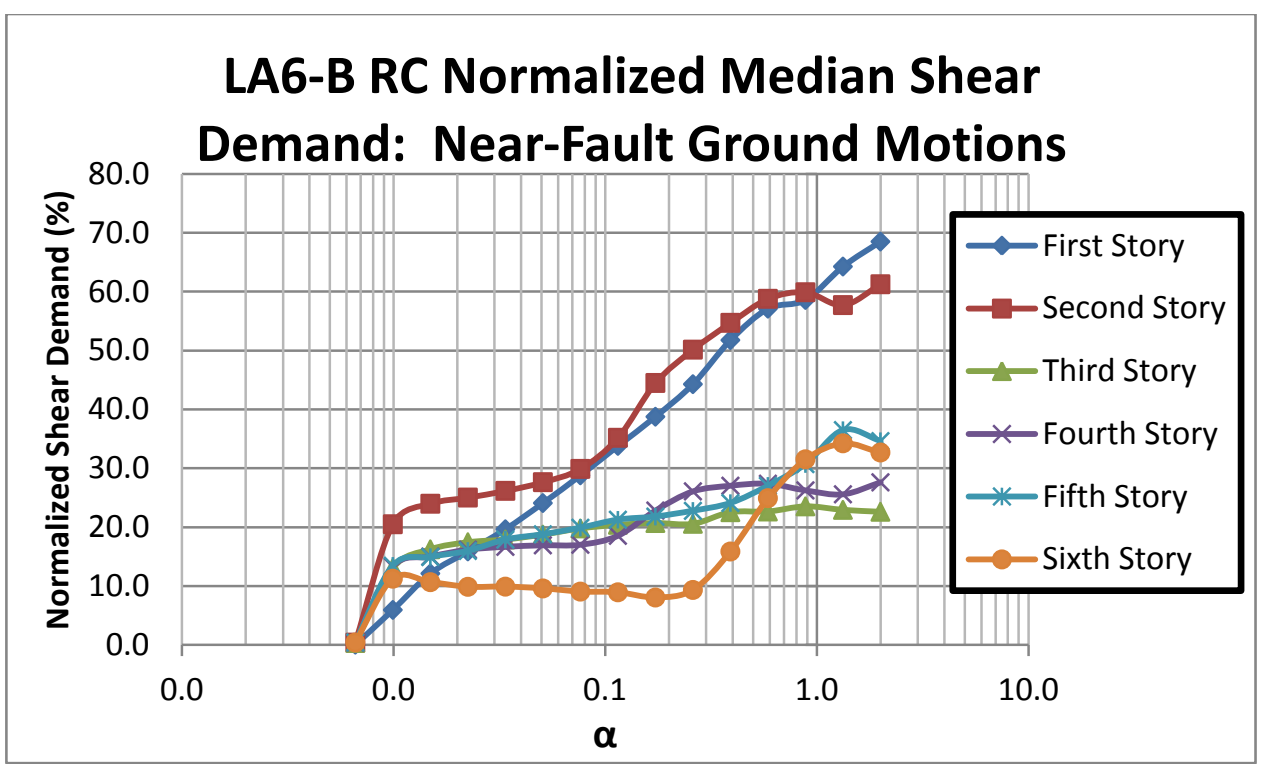

Figure 6.46: Normalized median shear demand on RC in LA6-B (Near-Fault Earthquakes)

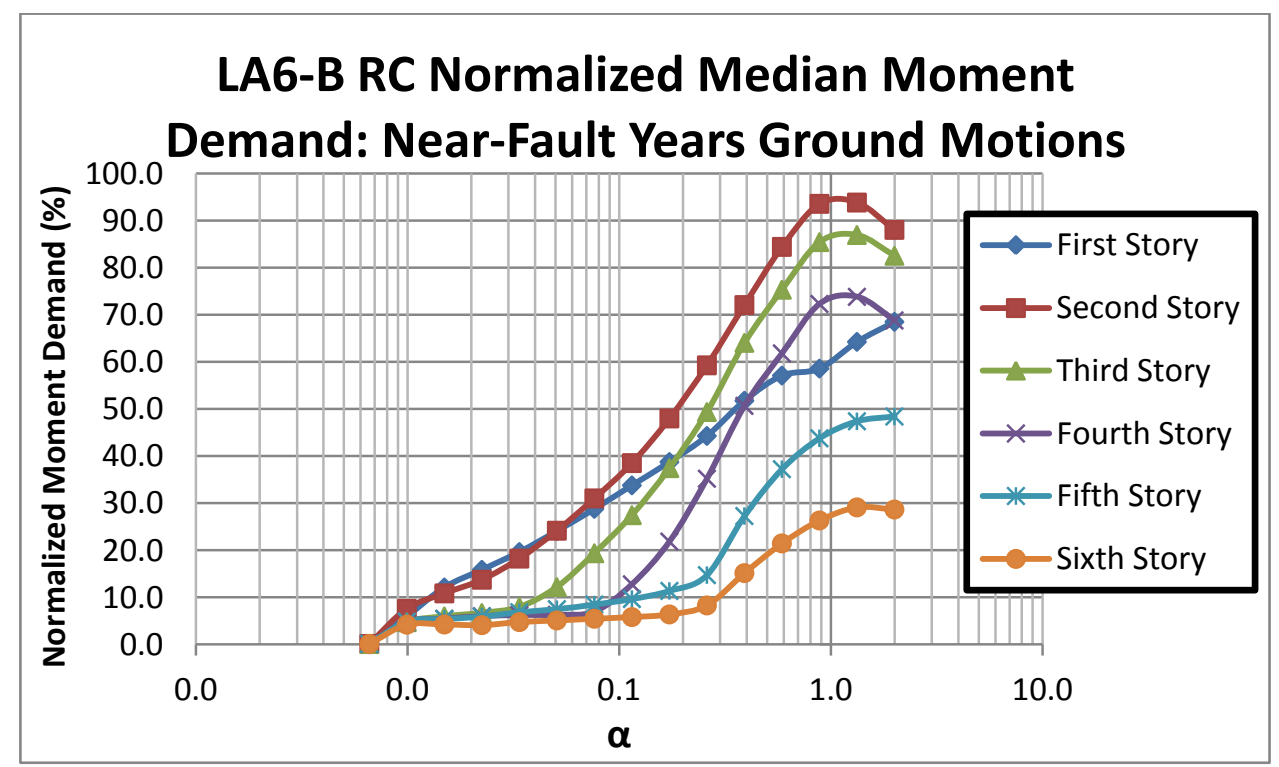

Figure 6.47: Normalized median bending moment demand on RC in LA6-B (Near-Fault Earthquakes)

The axial demand on the links from model LA6-B was also analyzed and compared to LA6-A. It was observed from Figures 6.48, 6.51 and 6.54 that the axial demand on the links are very similar to the ones obtained from LA6-A (Note: the demands are for both of the links working in parallel). This indicated that adding the links with energy 
dissipation capacity does not affect the axial demand on the links. Also, from the figures bellow it is noted that the bending moment and shear demands on the links increase very rapidly and plateau beyond a certain value of $\alpha$. This occurs because the links reach their plastic moment capacity indicating that energy is being dissipated.

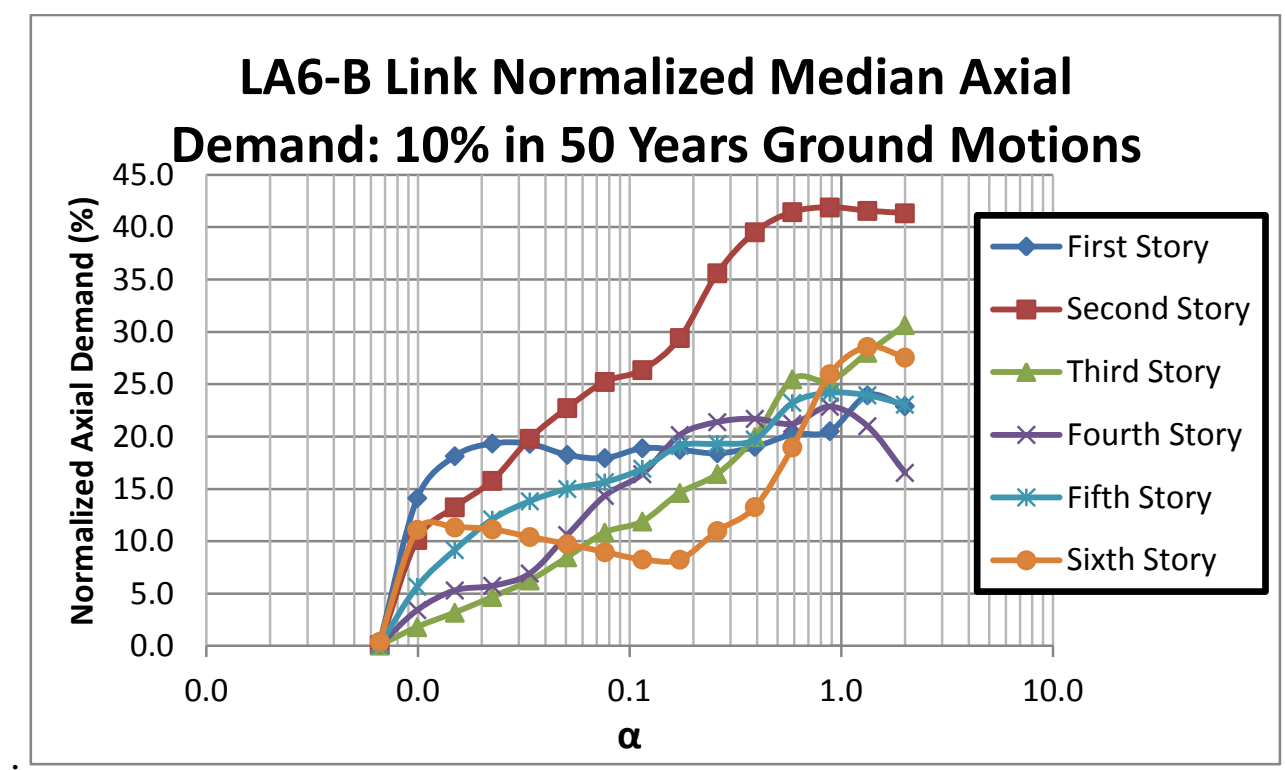

Figure 6.48: Normalized median axial demand in Links of LA6-B (Earthquakes corresponding to $10 \%$ in $\mathbf{5 0}$ years)

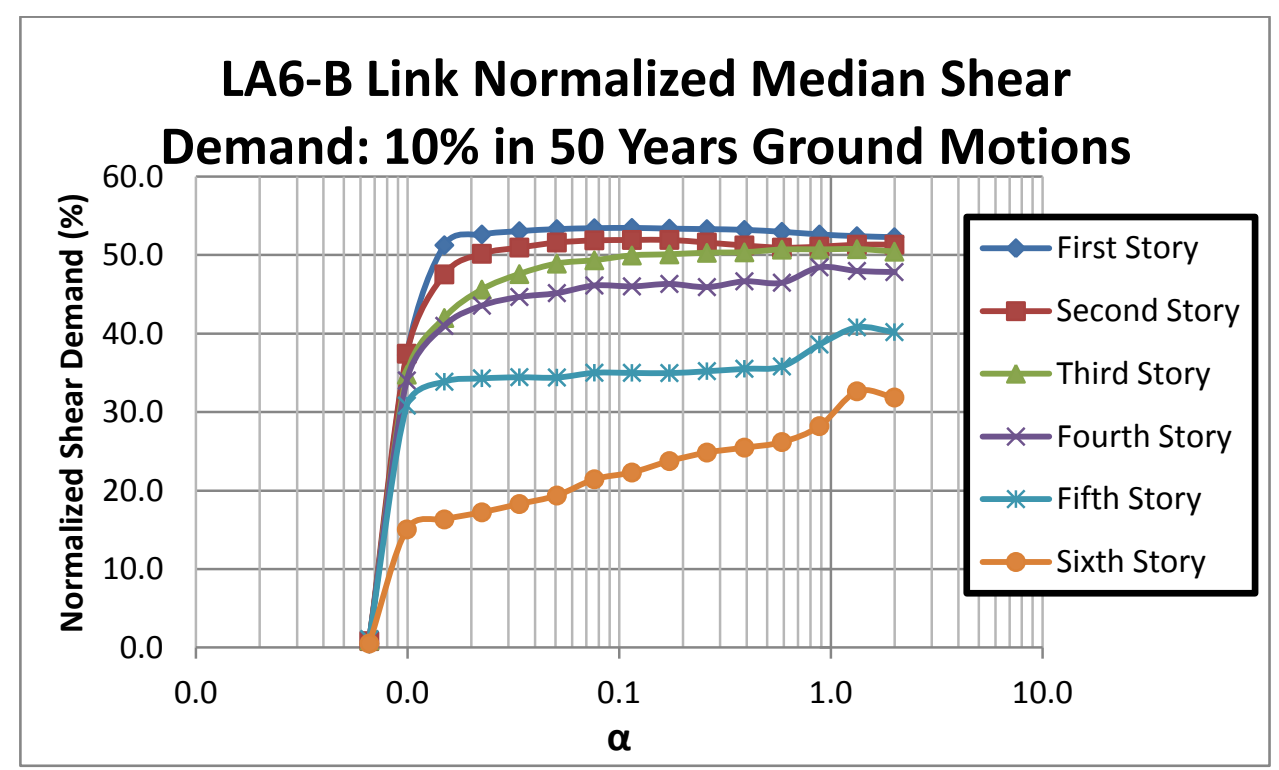

Figure 6.49: Normalized median shear demand in links of LA6-B (Earthquakes corresponding to $10 \%$ in 50 years) 


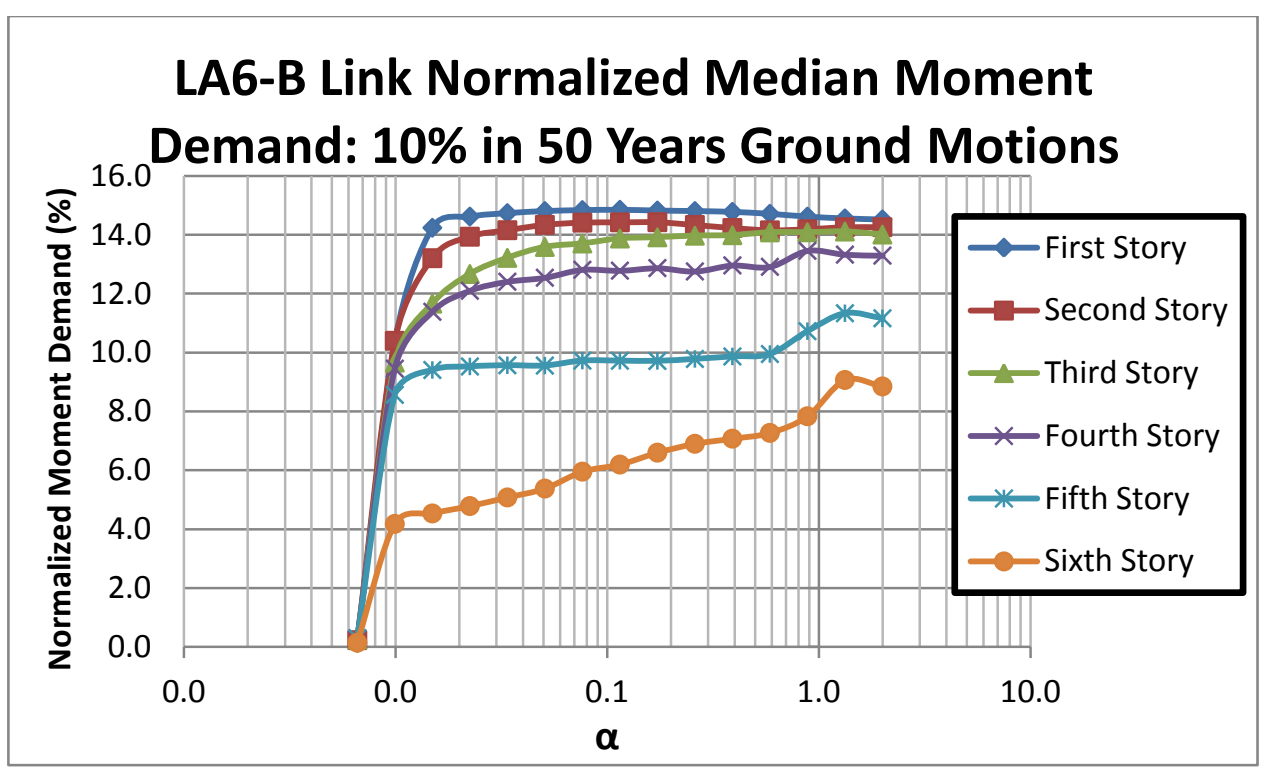

Figure 6.50: Normalized median bending moment demand in links of LA6-B (Earthquakes corresponding to $10 \%$ in 50 years)

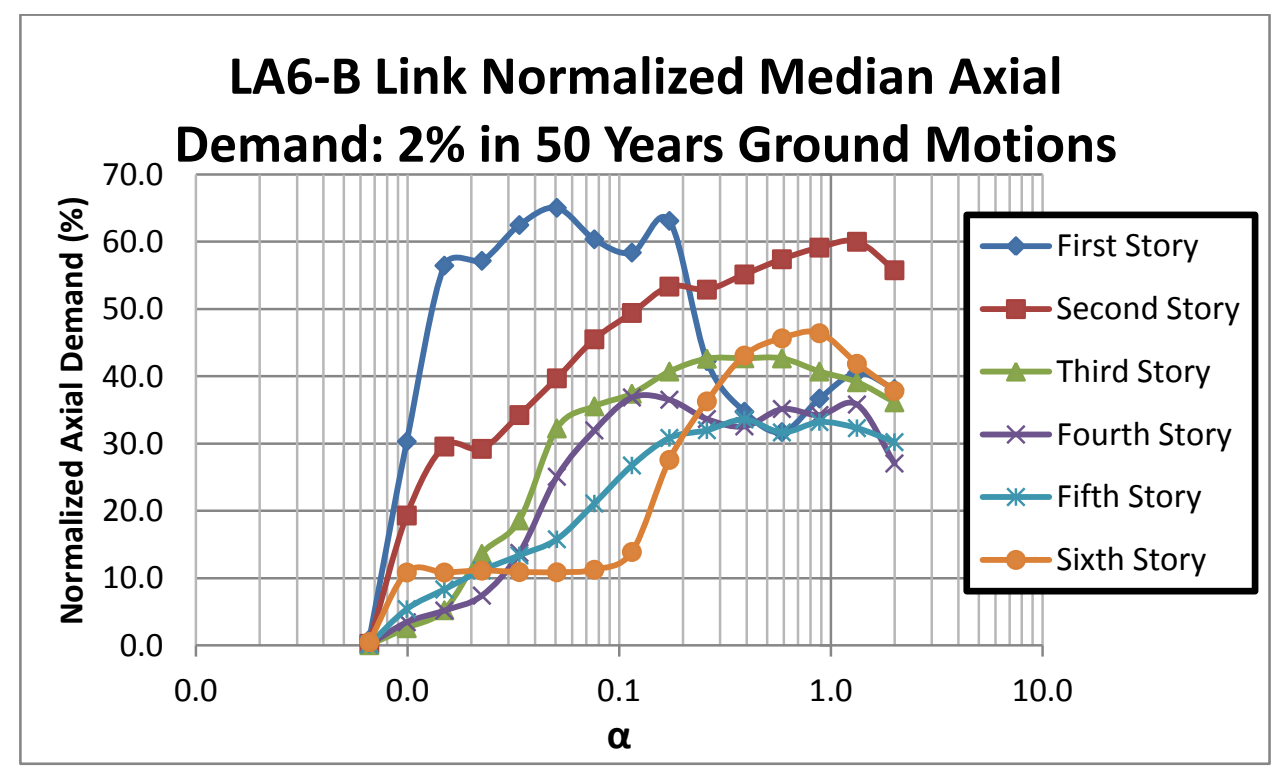

Figure 6.51: Normalized median axial demand in links of LA6-B (Earthquakes corresponding to $2 \%$ in 50 years) 


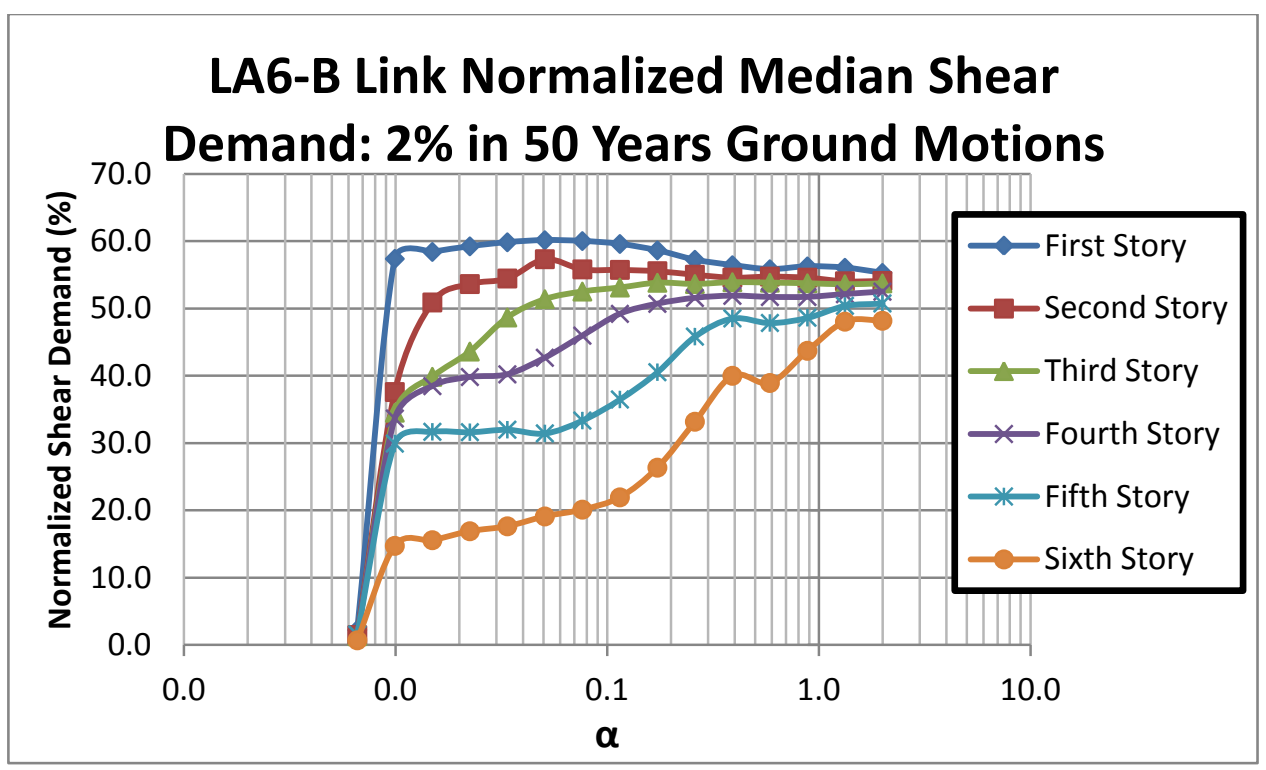

Figure 6.52: Normalized median shear demand in links of LA6-B (Earthquakes corresponding to $2 \%$ in $\mathbf{5 0}$ years)

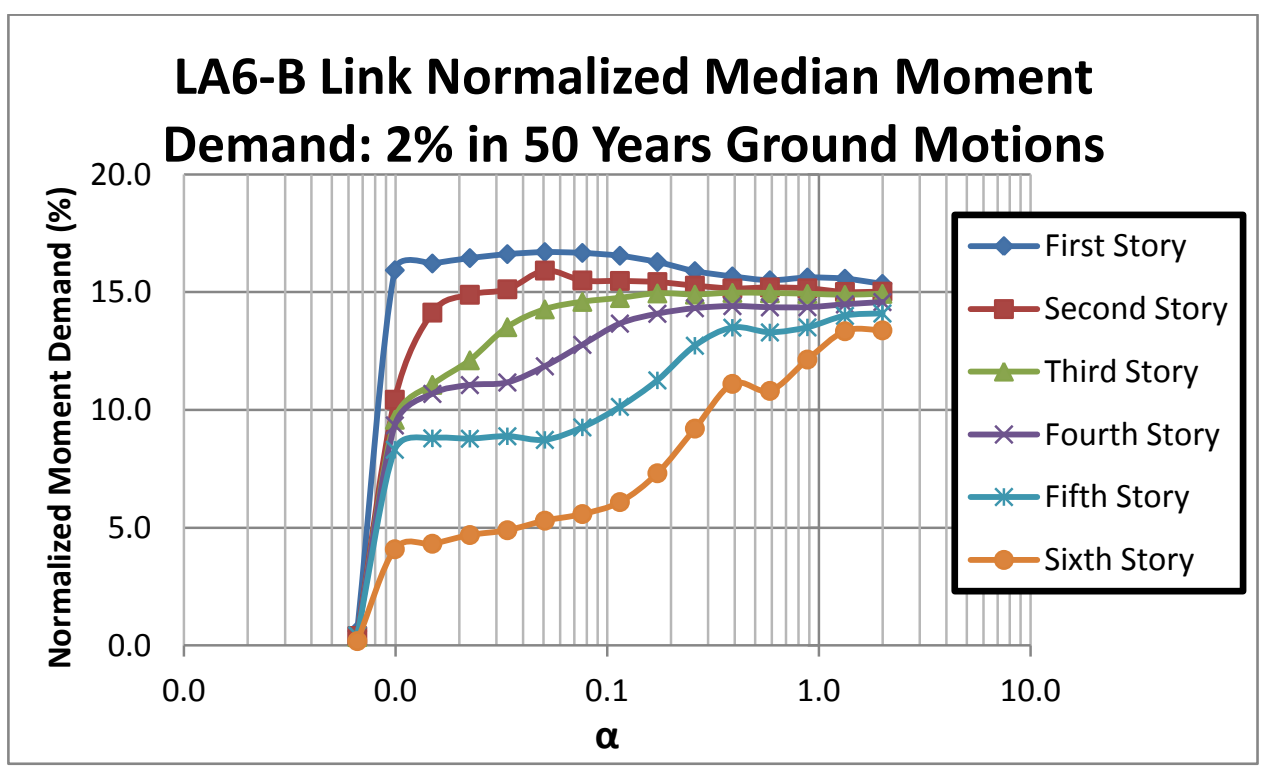

Figure 6.53: Normalized median moment demand in links of LA6-B (Earthquakes corresponding to $2 \%$ in 50 years) 


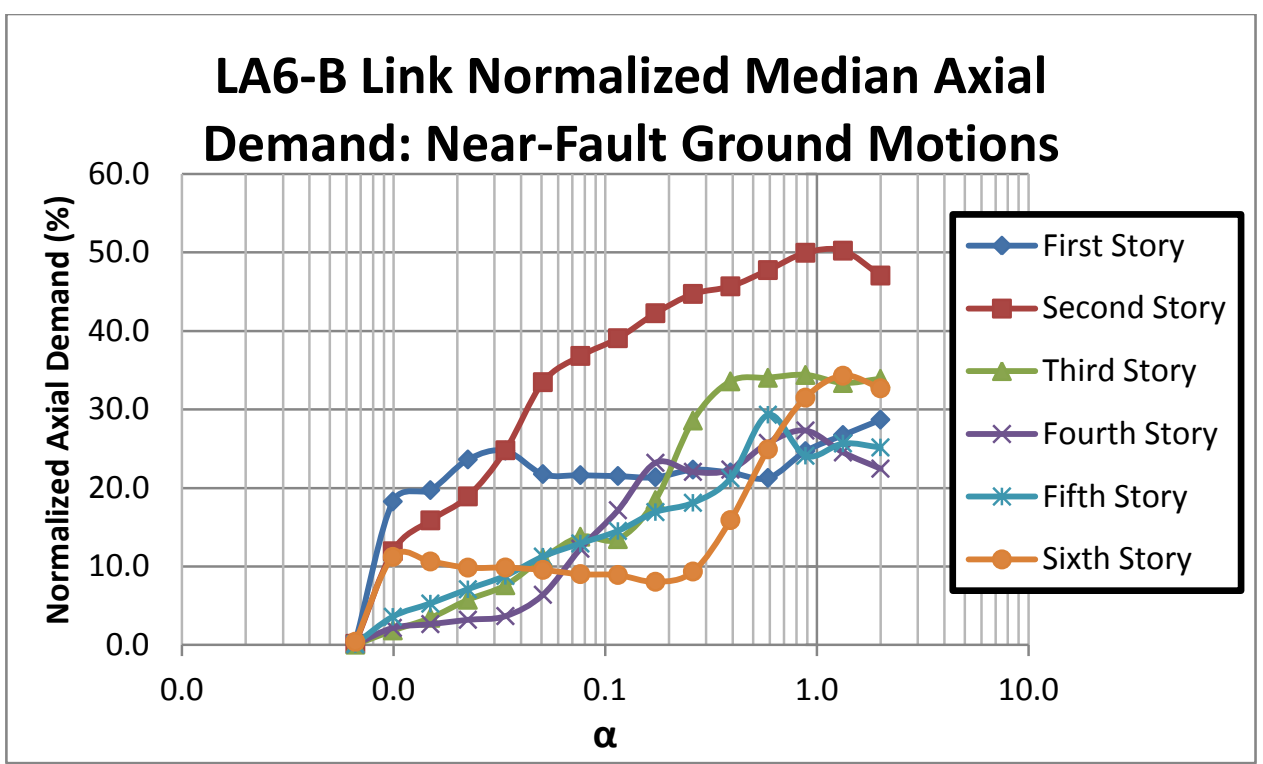

Figure 6.54: Normalized median axial demand in links of LA6-B (Near-Fault Earthquakes)

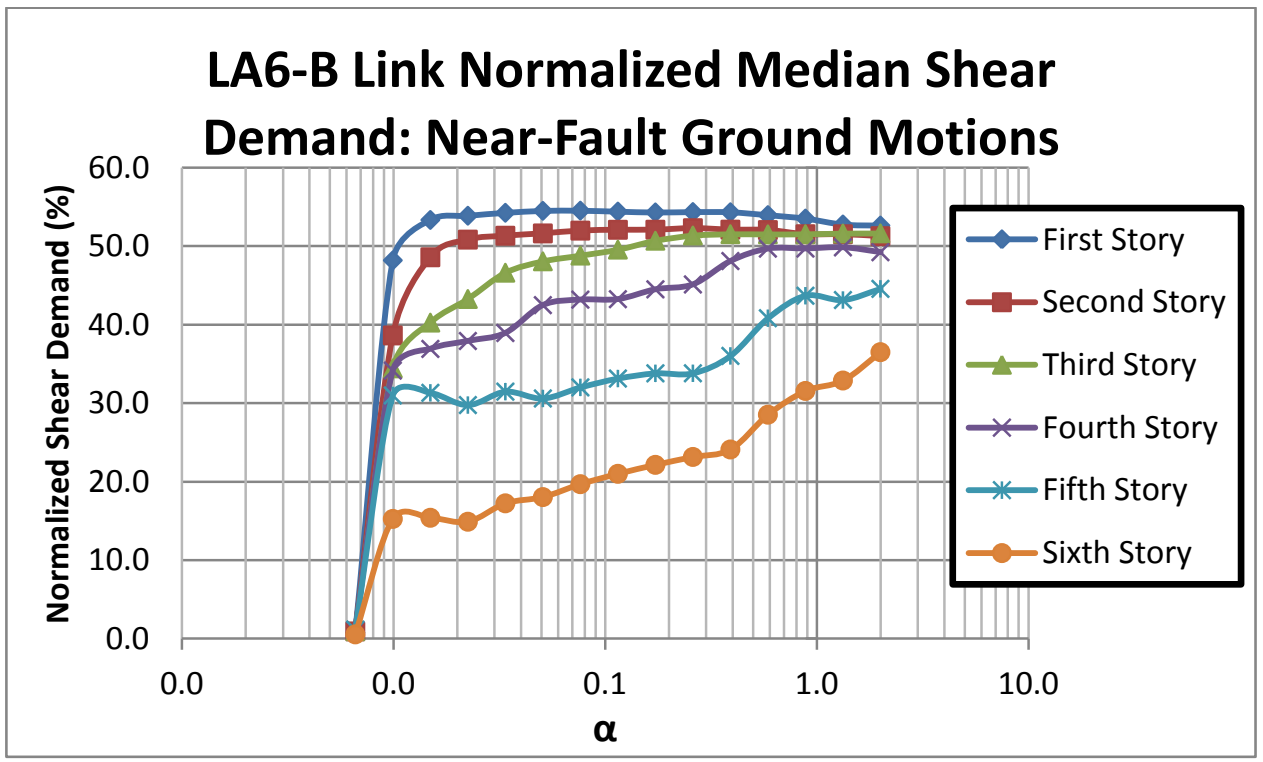

Figure 6.55: Normalized median shear demand in links of LA6-B (Near-Fault Earthquakes) 


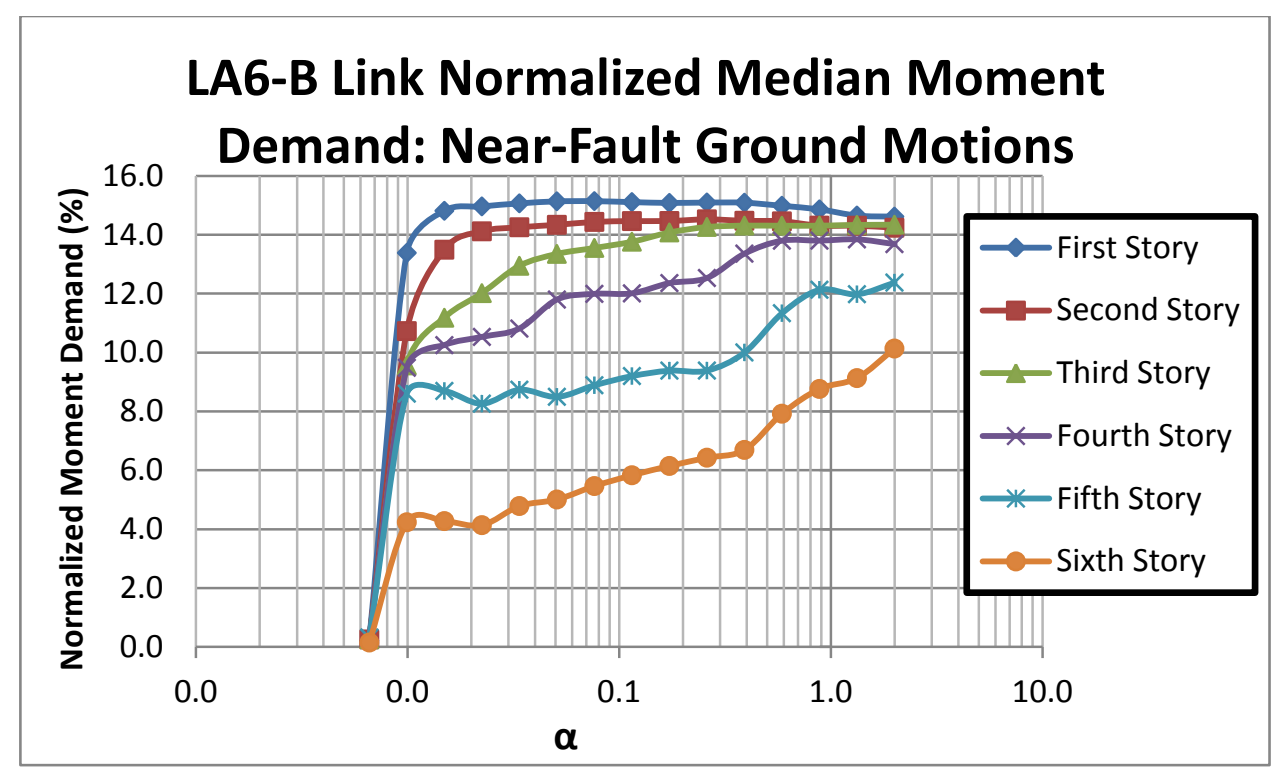

Figure 6.56: Normalized median bending moment demand in links of LA6-B (Near-Fault Earthquakes)

In summary, from the results obtained from LA6-A and LA6-B it is concluded that having the links with energy dissipation capacity allows the inter-story drift to drop below the target level at a smaller RC stiffness. For the range of $\alpha$ considered, LA6-A, under the $2 \%$ in 50 years and near-fault fault earthquakes, does not meet the FEMA356 recommendations. Having additional energy dissipation, LA6-B, helps reduce the drifts meeting the collapse prevention requirements. Under the $10 \%$ in 50 years earthquake, LA6-A was sufficient to reduce the drift to an allowable value; however, incorporating energy absorption capacity in the links (i.e., LA6-B) reduces the drift to an allowable value at a smaller RC stiffness, thus having a more economical design.

\subsection{Demonstration Retrofit using Reinforced Concrete RC}

A reinforced concrete $\mathrm{RC}$ was designed for LA6-B. The minimum $\alpha$ value at which the critical ground motions met the performance objective was 0.59 , and the median moment demand at that $\alpha$ was $105 \%$ of $\mathrm{V}_{1 \mathrm{y}}{ }^{*} \mathrm{~h}_{1}$. The reinforced concrete wall was assumed to be 
capacity protected against shear failure. Furthermore, the wall was designed to remain elastic and the material properties used were the same as in section 5.4. The following (see Figure 6.57) cross section was used. Tables 6-3 to 6-5 show the results from the system with the designed RC compared with the corresponding results from Section 6.3.

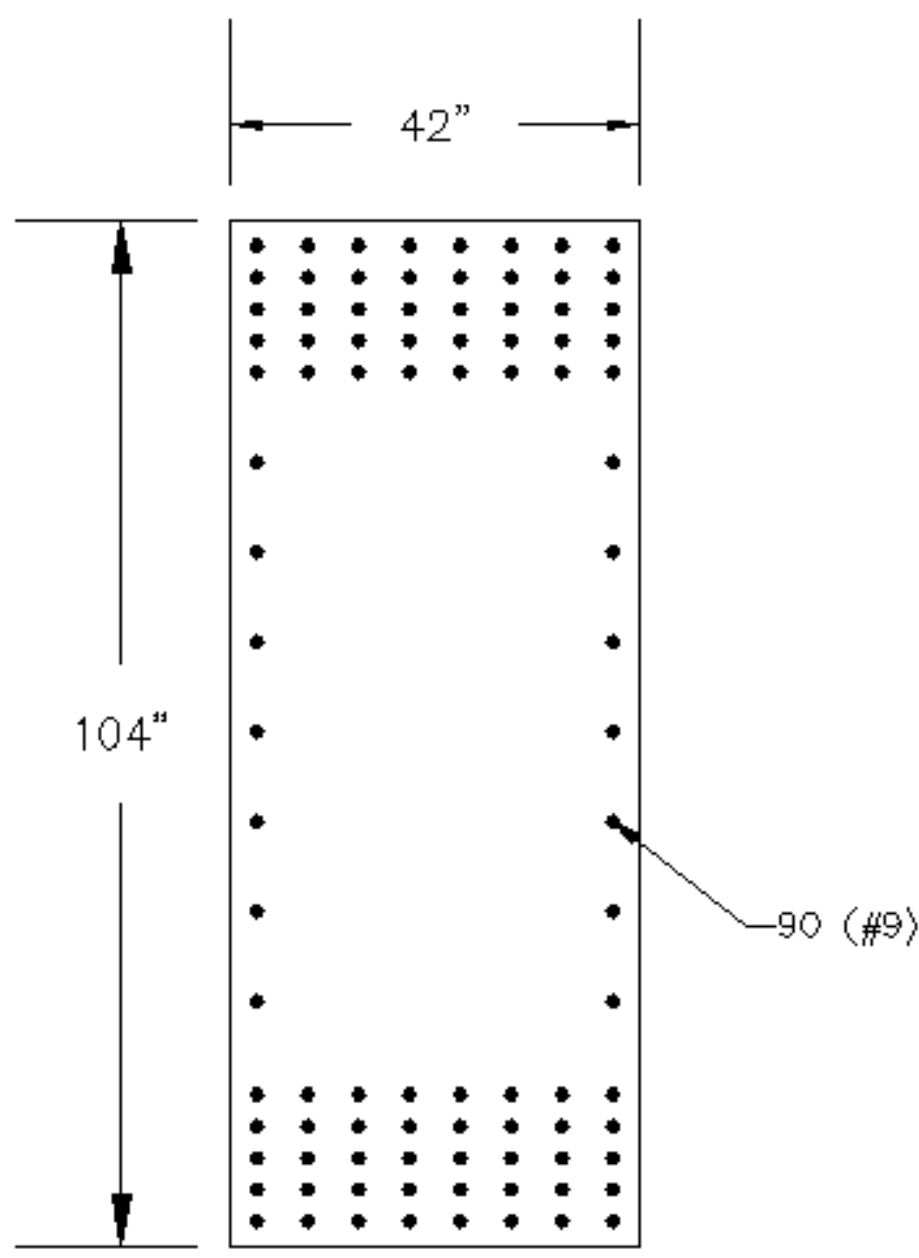

Figure 6.57: Reinforced concrete RC wall cross section for LA6-B 
Table 6-3: Comparison of elastic RC and reinforced concrete RC under 10\% in 50 years suite for LA6-B

\begin{tabular}{|c|c|c|}
\hline \multirow{2}{*}{ Response quantity of interest } & \multicolumn{2}{|c|}{$10 \%$ in 50 years Suite } \\
\cline { 2 - 3 } & Elastic RC & Reinforced Concrete RC \\
\hline Median Drift & $1.26 \%$ & $1.24 \%$ \\
\hline Median Shear Demand on RC & $40 \%$ & $40 \%$ \\
\hline Median Moment Demand on RC & $47 \%$ & $48 \%$ \\
\hline Median Axial Demand on Links & $36 \%$ & $35 \%$ \\
\hline Median Shear Demand on Links & $53 \%$ & $53 \%$ \\
\hline Median Moment Demand on links & $15 \%$ & $15 \%$ \\
\hline
\end{tabular}

Table 6-4: Comparison of elastic RC and reinforced concrete RC under $2 \%$ in 50 years suite for LA6-B

\begin{tabular}{|c|c|c|}
\hline \multirow{2}{*}{ Response quantity of interest } & \multicolumn{2}{|c|}{$2 \%$ in 50 years Suite } \\
\cline { 2 - 3 } & Elastic RC & Reinforced Concrete RC \\
\hline Median Drift & $1.75 \%$ & $1.73 \%$ \\
\hline Median Shear Demand on RC & $67 \%$ & $67 \%$ \\
\hline Median Moment Demand on RC & $82 \%$ & $83 \%$ \\
\hline Median Axial Demand on Links & $53 \%$ & $53 \%$ \\
\hline Median Shear Demand on Links & $54 \%$ & $53 \%$ \\
\hline Median Moment Demand on links & $16 \%$ & $16 \%$ \\
\hline
\end{tabular}

Table 6-5: Comparison of elastic RC and reinforced concrete RC under near-fault suite for LA6-B

\begin{tabular}{|c|c|c|}
\hline \multirow{2}{*}{ Response quantity of interest } & \multicolumn{2}{|c|}{ Near-Fault Suite } \\
\cline { 2 - 3 } & Elastic RC & Reinforced Concrete RC \\
\hline Median Drift & $1.75 \%$ & $1.74 \%$ \\
\hline Median Shear Demand on RC & $50 \%$ & $50 \%$ \\
\hline Median Moment Demand on RC & $59 \%$ & $58 \%$ \\
\hline Median Axial Demand on Links & $44 \%$ & $45 \%$ \\
\hline Median Shear Demand on Links & $54 \%$ & $55 \%$ \\
\hline Median Moment Demand on links & $15 \%$ & $15 \%$ \\
\hline
\end{tabular}




\subsection{Summary of Conclusions, and Recommendations for Future Research}

\subsection{Conclusion}

This thesis investigates the potential use of RC in low-rise and mid-rise CBF buildings that are vulnerable to soft-story mechanism under earthquake loadings. Two CBFs, which are three-and six-story buildings designed for Los Angeles based on the previous design practices, were retrofitted using the proposed RC technology and analyzed using nonlinear static pushover analysis and nonlinear dynamic analysis methods. The FE models of considered buildings are different from some previous research in the field in that 1) gusset plates were explicitly modeled, and 2) brace fracture due to low-cycle fatigue and excessive yielding were taken into account.

Through the extensive analytical work conducted in this thesis, the following conclusions may be drawn:

From nonlinear static analyses:

1. It was observed that application of RC successfully transforms the performance of both $\mathrm{CBF}$ benchmark buildings from soft-story failure to development of the more desirable sway mechanism.

2. It is found that $\mathrm{RC}$ is robust in controlling the system performance. It works as expected when the lateral force distributions are considered as random variables over a practical range and under all the three system performance objectives including (immediate occupancy, life safety, and collapse prevention).. 
From nonlinear dynamic analyses:

1. The propose system is capable of creating a more uniform inter-story drift distribution in the system through re-distributing story shears along the height of the building. With implementation of the proposed retrofit strategy, both benchmark buildings achieve the BSO defined in FEMA 356. Moreover, the proposed retrofit strategy also works as expected in both systems under near-field ground motions.

2. The RC avoids ductility concentration in the braces at the soft story, reducing the possibility of rupture failures in these braces.

3. Having the links with energy dissipation capacity allows the inter-story drifts to be reduced below target levels at a smaller value of RC stiffness, leading to a more cost effective RC.

4. Lastly, it was observe that the nonlinear static analysis may underestimate the link and RC demands due to its inability to capture brace rupture caused by low-cycle fatigue.

Based on the findings of this thesis, it was concluded that the propose system promises a reliable and realistic retrofit option. Moreover, it provides a cost effective, fast and simple retrofit, making it ideal for $\mathrm{CBF}$ buildings vulnerable to soft-story failure over the areas with high seismicity. 


\subsection{Recommendations for Future Research}

Although the results are positive, it is recommended that experimental testing should be conducted to address other issues related to implementation. Additionally, the RC was modeled as a line element neglecting the effect of the RC depth on the link rotations. It would be appropriate to consider the detailed RC geometries in the FE model when further research focuses on implementation of a specific type of RC (e.g., truss or wall). In this study, the effect of local buckling was neglected; it would be interesting to explore the effects of such phenomenon on fracture behavior of steel members. Moreover, it would be interesting to develop and validate other types of $\mathrm{RC}$ with more favorable features such as providing re-centering forces and/or extra energy dissipation capacity. 


\section{Bibliography}

AISC. (2005). "Load and Resistance Factor Design LRFD." American Institute of Steel Construction AISC, Chicago, Illinois 60601.

Alavi, B., Krawinkler, H. (2004). "Strengthening of Moment-resisting Frame Structures Against Near-fault Ground Motion Effects", Earthquake Engineering and Structural Dynamics, Vol. 33, No. 6, pp. 707-722.

Bruneau, M., Uang, C.M., Sabelli, R., (2011) Ductile Design of Steel Structures, 2nd edition McGrawHill.

FEMA 356: "Prestandard and Commentary for the Seismic Rehabilitation of Buildings" (pp. 1-35). (2000). Rehabilitation Requirements. Reston, Va.: American Society of Civil Engineers.

Gunay, S., Korolyk, D., Mar, D., Mosalam, K., Rodgers, J. (2009). "Infill Walls as a Spine to Enhance the Seismic Performance of Non-ductile Reinforced Concrete Frames", ATC and SEI Conference on Improving the Seismic Performance of Existing Buildings and Other Structures, ASCE, Dec. 2009.

Gupta, A., Krawinkler, H. (1999). "Seismic Demands For Performance Evaluation of Steel Moment Resisting Frame Structures”. (SAC task 5.4.3). Stanford, Calif.: The John A.Blume Earthquake Engineering Center.

Ji, X., Kato, M., Wang, T., Hitaka, T., Nakashima, M. (2009). "Effect of Gravity Columns on Mitigation of Drift Concentration for Braced Frames", Journal of Constructional Steel Research, Vol. 65, pp. 2148-2156.

MacRae, G., Kimura, Y., Roeder, C. (2004). "Effect of Column Stiffness on Braced Frame Seismic Behavior", Journal of Structural Engineering, ASCE, Vol. 130, No. 3, pp. 381-391.

McCormick, J., DesRoches, R., Fugazza, D., Auricchio, F. (2007). "Seismic Assessment of Concentrically Braced Steel Frames with Shape Memory Alloy Braces". Journal of Structural Engineers, 2007.133:862-870.

McKenna, F., Fenves, G. L. (2004). OpenSees command language manual, version 1.5.2, Pacific Earthquake Engineering Research Center, (http://opensees.berkeley.edu) (May 2004).

Qu, B., Guo, X., Chi, H., Pollino, M. (2012). "Probabilistic Evaluation of Effect of Column Stiffness on Seismic Performance of Steel Plate Shear Walls." Engineering Structures Journal, Vol. 43, pp. 169-179.

Sabelli, R. (2001). "Research on improving the design and analysis of earthquakeresistant steel-braced frames: The 2000 National Earthquake Hazard Reduction Program (NEHRP).” Professional Fellowship Rep., Earthquake Engineering Research Institute, Oakland, Calif.

Sacsteel.org. (2013). "Suites of Earthquake Ground Motions for Analysis of Steel Moment Frame Structures." University of California Berkeley. Berkeley CA.

Terzic, V. (2011). "Force-base Element vs. Displacement-base Element". Open System for Earthquake Engineering Simulation, (NEEScomm).

Terzic, V. (2013). "Modeling SCB frames using beam-column elements". Open System for Earthquake Engineering Simulation, (NEEScomm). 
Uriz, P., Mahin S. (2008). "Toward Earthquake-Resistant Design of Concentrically Braced Steel-Frame Structures.” Pacific Earthquake Engineering Center, University of California, Berkeley, 2008

Wada, A., Qu, Z. Ito, H., Motoyui, S., Sakata, H., Kasai, K., (2009). "Seismic Retrofit Using Rocking Walls and Steel Dampers." Conference on Improving the Seismic Performance of Existing Buildings and Other Structures, San Francisco, CA.

Williamson, C. (2012). "Seismic Performance of Symmetric Steel Moment Frames with Random Reactive Weight Distribution". California Polytechnic State University, San Luis Obispo, Thesis.

Yang, F., Mahin, S. A. (2005). Limiting Net Section Failure in Slotted HSS Braces (in preparation)." Structural Steel Education Council, Moraga, CA. 


\section{Appendix A: Response Spectra}

The following figures present the response spectra of the three ground motions suites considered in the nonlinear dynamic analyses. Also, Figure A.1 include the DBE response spectrum and Figures A.2 and A.3 shows the MCE response spectrum.

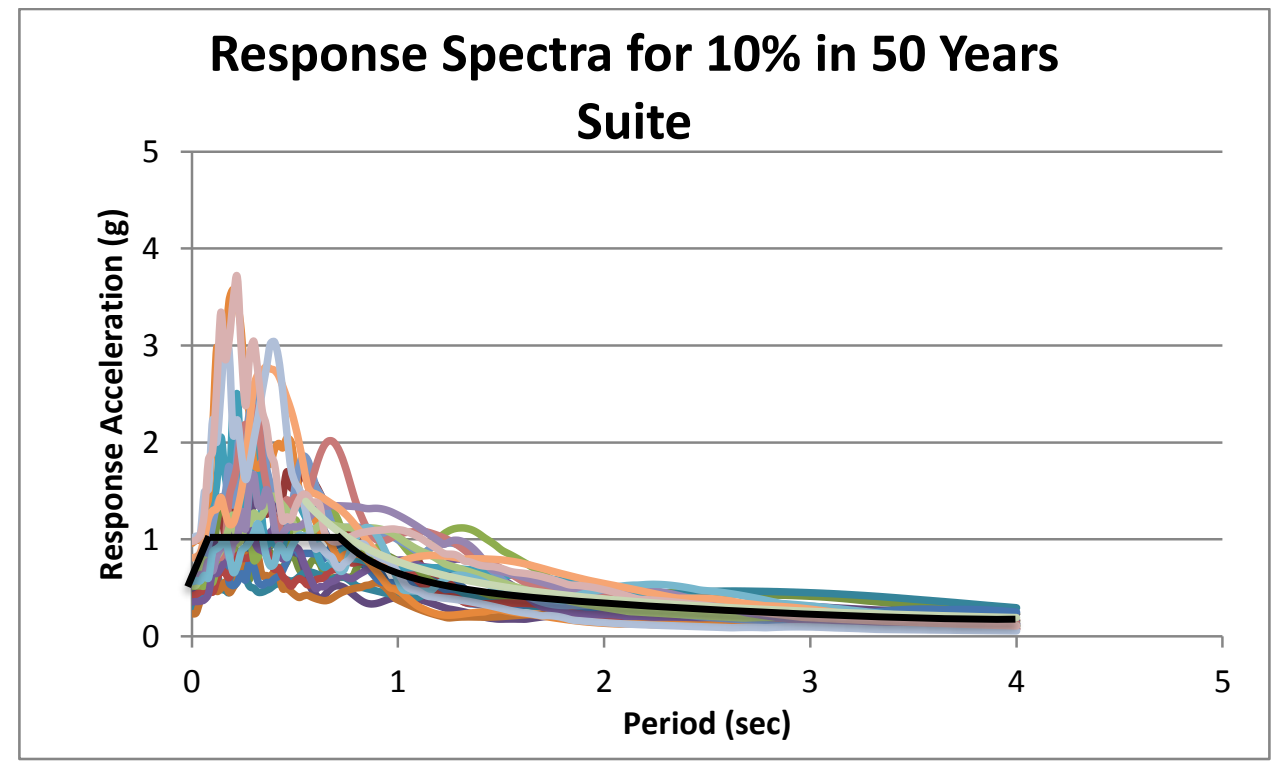

Figure A.1: Response spectra of ground motions corresponding to $\mathbf{1 0} \%$ in $\mathbf{5 0}$ years suite

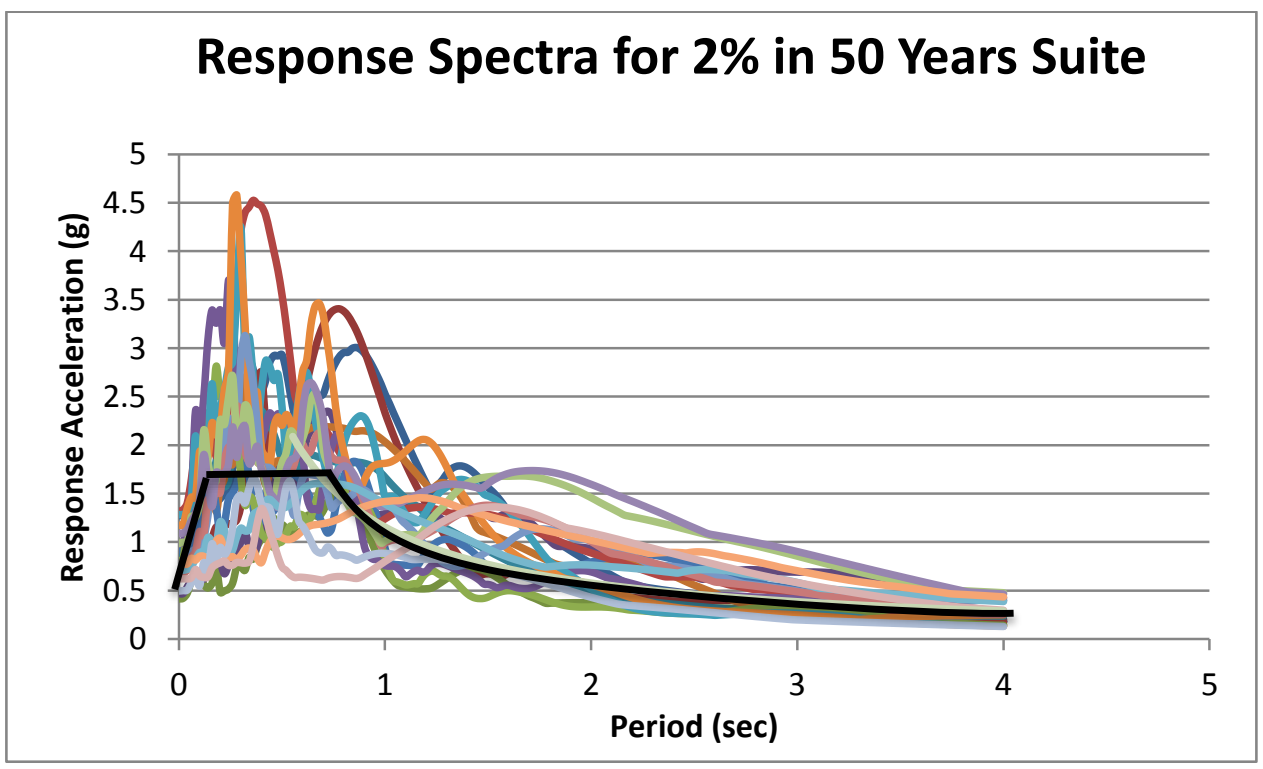

Figure A.2: Response spectra of ground motions corresponding to $2 \%$ in 50 years suite 


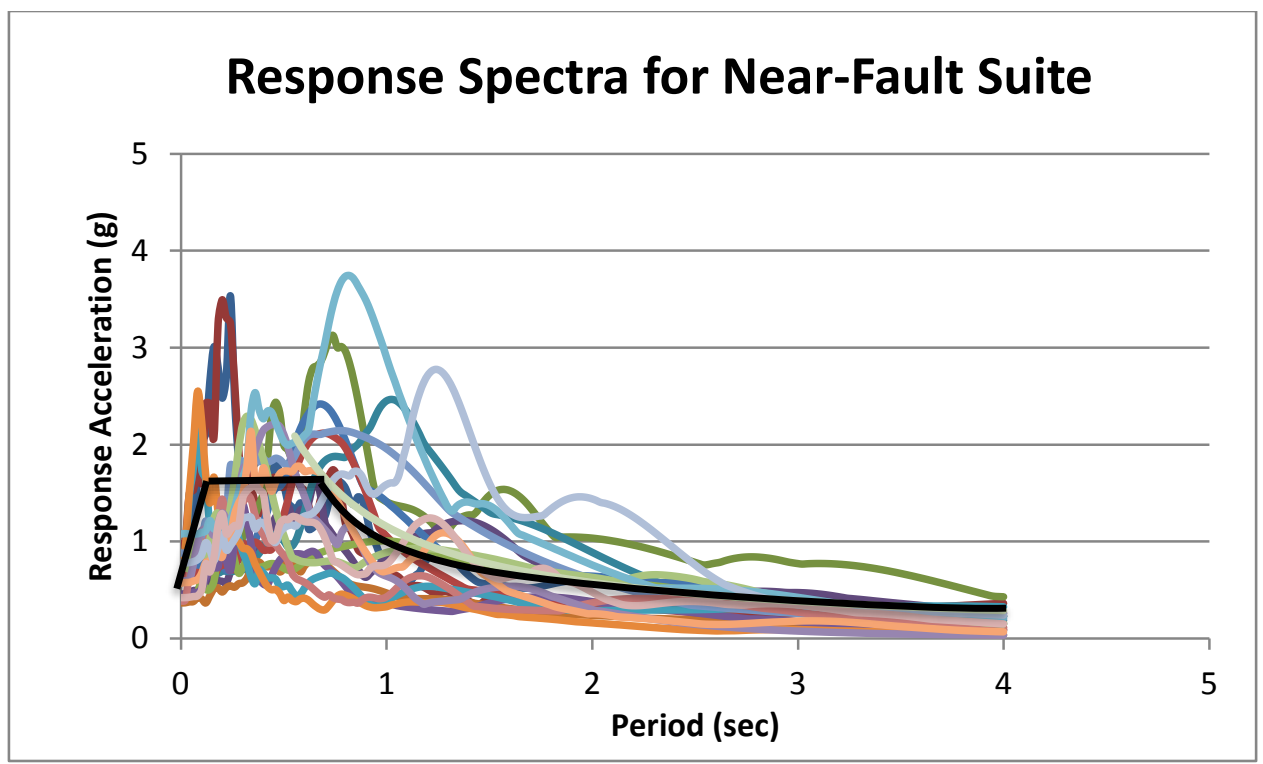

Figure A.3: Response spectra of ground motions corresponding to near-fault suite 


\section{Appendix B: Maximum Inter-Story Drift Results}

The following tables show the maximum inter-story drift corresponding to each ground motion suite and for LA3-A, LA3-B, LA6-A and LA6-B. 
Table B-1: Maximum Inter-story Drift in LA3-A under ground motions corresponding to $10 \%$ in 50 years

\begin{tabular}{|c|c|c|c|c|c|c|c|c|c|c|c|c|c|c|c|c|c|c|c|c|}
\hline \multirow{3}{*}{$\alpha$} & \multicolumn{20}{|c|}{ Maximum inter-story drift for $10 \%$ in 50 year ground motions (\%) } \\
\hline & \multicolumn{20}{|c|}{ Ground Motion } \\
\hline & LA21 & LA22 & LA23 & LA24 & LA25 & LA26 & LA27 & LA28 & LA29 & LA30 & $\begin{array}{c}\text { LA31 } \\
*\end{array}$ & LA32 & $\begin{array}{c}\text { LA33 } \\
* *\end{array}$ & $\begin{array}{c}\text { LA34 } \\
*\end{array}$ & $\begin{array}{c}\text { LA35 } \\
*\end{array}$ & LA36 & LA37 & $\begin{array}{c}\text { LA38 } \\
*\end{array}$ & $\begin{array}{c}\text { LA39 } \\
*\end{array}$ & $\begin{array}{l}\text { LA40 } \\
*\end{array}$ \\
\hline 0.007 & 0.9 & 0.9 & 0.5 & 0.9 & 0.2 & 0.3 & 0.3 & 0.5 & 0.7 & 0.6 & 2.8 & 1.3 & 2.0 & 4.9 & 1.8 & 0.6 & 0.4 & 2.4 & 2.0 & 2.0 \\
\hline 0.008 & 0.9 & 0.9 & 0.5 & 0.9 & 0.2 & 0.3 & 0.3 & 0.5 & 0.7 & 0.6 & 2.3 & 1.6 & 1.7 & 4.8 & 1.8 & 0.6 & 0.3 & 2.3 & 1.9 & 3.5 \\
\hline 0.010 & 0.9 & 0.9 & 0.5 & 0.9 & 0.2 & 0.3 & 0.3 & 0.5 & 0.7 & 0.6 & 1.8 & 1.3 & 1.7 & 3.3 & 1.7 & 0.6 & 0.3 & 2.3 & 2.1 & 1.9 \\
\hline 0.012 & 0.9 & 0.9 & 0.5 & 0.8 & 0.2 & 0.3 & 0.3 & 0.5 & 0.7 & 0.6 & 0.7 & 1.3 & 2.2 & 3.7 & 1.7 & 0.6 & 0.3 & 2.2 & 1.9 & 1.9 \\
\hline 0.014 & 0.9 & 0.8 & 0.5 & 0.8 & 0.2 & 0.3 & 0.3 & 0.5 & 0.7 & 0.6 & 2.3 & 1.3 & 1.5 & 3.7 & 1.7 & 0.6 & 0.3 & 2.1 & 2.1 & 1.8 \\
\hline 0.016 & 0.9 & 0.8 & 0.5 & 0.8 & 0.2 & 0.3 & 0.3 & 0.5 & 0.7 & 0.6 & 2.2 & 1.9 & 1.4 & 3.6 & 1.7 & 0.6 & 0.3 & 2.0 & 1.7 & 1.7 \\
\hline 0.020 & 0.9 & 0.8 & 0.5 & 0.8 & 0.2 & 0.3 & 0.3 & 0.5 & 0.7 & 0.6 & 0.7 & 2.5 & 1.3 & 3.5 & 1.6 & 0.6 & 0.3 & 1.9 & 1.7 & 1.7 \\
\hline 0.023 & 0.9 & 0.8 & 0.5 & 0.8 & 0.2 & 0.3 & 0.3 & 0.5 & 0.7 & 0.7 & 0.7 & 1.6 & 1.2 & 3.6 & 1.5 & 0.6 & 0.3 & 1.8 & 1.6 & 1.6 \\
\hline 0.028 & 0.9 & 0.7 & 0.4 & 0.7 & 0.2 & 0.3 & 0.3 & 0.5 & 0.7 & 0.7 & 0.7 & 1.5 & 1.1 & 3.4 & 1.5 & 0.6 & 0.3 & 1.6 & 1.6 & 1.5 \\
\hline 0.033 & 0.8 & 0.7 & 0.4 & 0.7 & 0.2 & 0.3 & 0.3 & 0.5 & 0.7 & 0.7 & 0.7 & 1.6 & 1.0 & 3.2 & 1.4 & 0.6 & 0.3 & 1.5 & 1.5 & 1.5 \\
\hline 0.039 & 0.8 & 0.7 & 0.4 & 0.7 & 0.2 & 0.3 & 0.3 & 0.5 & 0.7 & 0.7 & 0.7 & 1.1 & 0.9 & 2.7 & 1.6 & 0.6 & 0.3 & 1.4 & 1.4 & 1.8 \\
\hline 0.046 & 0.8 & 0.7 & 0.4 & 0.7 & 0.2 & 0.3 & 0.3 & 0.4 & 0.7 & 0.7 & 0.6 & 1.1 & 0.8 & 2.9 & 1.2 & 0.5 & 0.3 & 1.4 & 1.7 & 1.2 \\
\hline 0.077 & 0.8 & 0.8 & 0.5 & 0.6 & 0.2 & 0.3 & 0.3 & 0.4 & 0.6 & 0.7 & 0.6 & 1.2 & 0.8 & 0.9 & 1.2 & 0.5 & 0.3 & 1.7 & 1.8 & 0.9 \\
\hline 0.091 & 0.7 & 0.8 & 0.5 & 0.6 & 0.2 & 0.3 & 0.3 & 0.4 & 0.6 & 0.7 & 0.5 & 1.1 & 1.0 & 0.9 & 1.2 & 0.5 & 0.3 & 1.7 & 1.6 & 0.8 \\
\hline 0.108 & 0.7 & 0.8 & 0.5 & 0.6 & 0.2 & 0.3 & 0.3 & 0.4 & 0.6 & 0.7 & 0.5 & 1.1 & 1.2 & 0.8 & 1.3 & 0.5 & 0.3 & 1.7 & 1.2 & 0.8 \\
\hline 0.128 & 0.7 & 0.8 & 0.5 & 0.6 & 0.2 & 0.3 & 0.3 & 0.4 & 0.6 & 0.7 & 0.5 & 1.2 & 0.8 & 0.8 & 1.1 & 0.5 & 0.3 & 1.7 & 1.2 & 1.3 \\
\hline 0.152 & 0.6 & $\begin{array}{l}0.8 \\
\end{array}$ & 0.5 & 0.6 & 0.2 & 0.3 & 0.3 & 0.4 & 0.6 & 0.7 & 0.5 & 1.4 & 0.8 & 0.8 & 1.0 & 0.5 & 0.3 & 1.7 & 1.4 & 0.6 \\
\hline 0.181 & 0.6 & 0.7 & 0.4 & 0.6 & 0.2 & 0.3 & 0.3 & 0.4 & 0.6 & 0.7 & 0.5 & 1.3 & 0.8 & 0.8 & 1.0 & 0.5 & 0.3 & 1.6 & 1.3 & 0.6 \\
\hline 0.214 & 0.6 & 0.7 & 0.4 & 0.6 & 0.2 & 0.3 & 0.3 & 0.4 & 0.5 & 0.6 & 0.4 & 1.0 & 0.8 & 0.7 & 1.1 & 0.5 & 0.3 & 1.7 & 1.3 & 0.6 \\
\hline 0.254 & 0.6 & 0.7 & 0.4 & 0.6 & 0.2 & 0.3 & 0.3 & 0.4 & 0.5 & 0.6 & 0.4 & 1.1 & 0.8 & 0.7 & 1.0 & 0.5 & 0.3 & 1.5 & 1.3 & 0.6 \\
\hline 0.302 & 0.6 & 0.7 & 0.5 & 0.6 & 0.2 & 0.3 & 0.3 & 0.4 & 0.5 & 0.6 & 0.4 & 1.0 & 0.7 & 0.7 & 1.0 & 0.4 & 0.3 & 1.5 & 1.2 & 0.6 \\
\hline 0.358 & 0.5 & 0.7 & 0.5 & 0.6 & 0.2 & 0.3 & 0.3 & 0.3 & 0.5 & 0.6 & 0.4 & 1.1 & 0.7 & 0.7 & 1.0 & 0.4 & 0.3 & 1.6 & 1.2 & 0.6 \\
\hline 0.425 & 0.5 & 0.7 & 0.4 & 0.6 & 0.2 & 0.3 & 0.3 & 0.3 & 0.5 & 0.6 & 0.4 & 1.2 & 0.8 & 0.7 & 1.0 & 0.4 & 0.3 & 1.5 & 1.2 & 0.6 \\
\hline 0.504 & 0.5 & 0.7 & 0.4 & 0.6 & 0.2 & 0.3 & 0.3 & 0.3 & 0.5 & 0.6 & 0.4 & 1.1 & 0.7 & 0.7 & 1.0 & 0.4 & 0.3 & 1.5 & 1.4 & 0.6 \\
\hline 0.599 & 0.5 & 0.7 & 0.4 & 0.6 & 0.2 & 0.3 & 0.3 & 0.3 & 0.5 & 0.5 & 0.4 & 1.2 & 0.7 & 0.7 & 1.0 & 0.4 & 0.3 & 1.4 & 1.3 & 0.6 \\
\hline 0.710 & 0.4 & 0.7 & 0.4 & 0.6 & 0.2 & 0.3 & 0.3 & 0.3 & 0.5 & 0.5 & 0.4 & 1.2 & 0.6 & 0.7 & 1.0 & 0.4 & 0.3 & 1.4 & 1.1 & 0.6 \\
\hline 0.843 & 0.4 & 0.7 & 0.4 & 0.6 & 0.2 & 0.3 & 0.3 & 0.3 & 0.5 & 0.5 & 0.4 & 1.1 & 0.6 & 0.7 & 1.0 & 0.4 & 0.3 & 1.4 & 1.2 & 0.6 \\
\hline 1.000 & 0.4 & $\begin{array}{l}0.7 \\
\end{array}$ & 0.4 & 0.6 & 0.2 & 0.3 & 0.3 & 0.3 & 0.5 & 0.5 & 0.4 & 1.0 & 0.6 & 0.7 & 1.0 & 0.5 & 0.3 & 1.4 & 1.2 & 0.6 \\
\hline
\end{tabular}

* Critical earthquake records 
Table B-2: Maximum Inter-story Drift in LA3-A under ground motions corresponding to $2 \%$ in 50 years Maximum inter-story drift for $2 \%$ in 50 year ground motions (\%)

\begin{tabular}{|c|c|c|c|c|c|c|c|c|c|c|c|c|c|c|c|c|c|c|c|c|}
\hline \multirow{3}{*}{$\alpha$} & \multicolumn{20}{|c|}{ Maximum inter-story drift for $2 \%$ in 50 year ground motions $(\%)$} \\
\hline & \multicolumn{20}{|c|}{ Ground Motion } \\
\hline & $\begin{array}{c}\text { LA01 } \\
*\end{array}$ & $\begin{array}{c}\text { LA02 } \\
* *\end{array}$ & LA03 & LA04 & $\begin{array}{l}\text { LA05 } \\
*\end{array}$ & $\begin{array}{l}\text { LA06 } \\
*\end{array}$ & $\begin{array}{c}\text { LA07 } \\
*\end{array}$ & $\begin{array}{c}\text { LA08 } \\
*\end{array}$ & LA09 & $\begin{array}{c}\text { LA10 } \\
*\end{array}$ & $\begin{array}{l}\text { LA11 } \\
*\end{array}$ & $\underset{*}{\mathrm{LA} 12}$ & $\underset{*}{\mathrm{LA} 13}$ & $\begin{array}{c}\mathrm{LA} 14 \\
*\end{array}$ & $\begin{array}{c}\text { LA15 } \\
*\end{array}$ & $\begin{array}{c}\text { LA16 } \\
*\end{array}$ & $\begin{array}{c}\text { LA17 } \\
*\end{array}$ & LA18 & LA19 & LA20 \\
\hline 0.007 & 8.6 & 10.1 & 0.5 & 1.0 & 5.7 & 9.1 & 5.2 & 8.8 & 0.8 & 9.5 & 10.3 & 5.3 & 3.8 & 2.4 & 16.6 & 143 & 2.9 & 1.1 & 0.8 & 0.9 \\
\hline 0.008 & 10.8 & 6.8 & 0.5 & 0.9 & 5.2 & 10.2 & 4.6 & 8.1 & 0.8 & 1.9 & 7.2 & 7.9 & 2.9 & 2.8 & 12.6 & 13.0 & 2.8 & 2.8 & 0.8 & 0.9 \\
\hline 0.010 & 10.5 & 9.4 & 0.5 & 0.9 & 5.0 & 8.4 & 4.6 & 10.9 & 0.8 & 1.7 & 8.4 & 7.7 & 3.3 & 2.7 & 12.9 & 9.9 & 2.7 & 1.1 & 0.8 & 0.9 \\
\hline 0.012 & 11.6 & 6.6 & 0.5 & 0.9 & 4.9 & 8.2 & 4.2 & 7.3 & 0.7 & 3.9 & 7.9 & 9.4 & 2.6 & 2.4 & 14.5 & 8.8 & 2.6 & 1.1 & 0.8 & 0.9 \\
\hline 0.014 & 7.6 & 8.8 & 0.5 & 0.9 & 5.4 & 7.2 & 3.8 & 7.2 & 0.7 & 6.3 & 6.5 & 7.9 & 2.0 & 2.7 & 9.1 & 8.0 & 2.5 & 1.1 & 0.8 & 0.9 \\
\hline 0.016 & 6.6 & 7.1 & 0.5 & 0.9 & 4.4 & 8.0 & 3.4 & 6.8 & 0.7 & 3.7 & 7.5 & 6.3 & 1.7 & 2.6 & 7.3 & 7.1 & 2.4 & 1.0 & 0.8 & 0.8 \\
\hline 0.020 & 7.8 & 5.6 & 0.5 & 0.9 & 6.4 & 6.9 & 2.7 & 8.1 & 0.7 & 6.1 & 7.2 & 6.7 & 3.2 & 2.5 & 8.9 & 10.7 & 2.2 & 1.0 & 0.8 & 0.8 \\
\hline 0.023 & 11.0 & 5.3 & 0.5 & 0.9 & 7.8 & 8.0 & 2.5 & 7.3 & 0.7 & 2.8 & 6.4 & 4.3 & 3.0 & 2.4 & 98.3 & 7.0 & 2.0 & 1.0 & 0.8 & 0.8 \\
\hline 0.028 & 15.3 & 9.0 & 0.5 & 0.9 & 5.3 & 5.0 & 2.3 & 6.6 & 0.7 & 4.5 & 5.9 & 6.5 & 3.2 & 2.3 & 7.8 & 7.6 & 1.8 & 0.9 & 0.8 & 0.8 \\
\hline 0.033 & 140.7 & 83.6 & 0.5 & 0.9 & 5.3 & 6.7 & 2.1 & 5.2 & 0.7 & 1.2 & 4.9 & 6.0 & $\begin{array}{l}4.1 \\
\end{array}$ & 2.5 & 9.1 & 7.4 & 1.7 & 0.9 & 0.8 & 0.8 \\
\hline 0.039 & 92.5 & 11.6 & 0.5 & 0.9 & 3.9 & 4.5 & 1.9 & 5.1 & 0.7 & 1.3 & 5.5 & 6.0 & 3.8 & 1.6 & 12.2 & 4.5 & 1.6 & 0.9 & 0.7 & 0.8 \\
\hline 0.046 & 13.5 & 10.6 & 0.5 & 0.9 & 3.5 & 5.6 & 1.8 & 4.7 & 0.6 & 3.1 & 4.2 & 5.6 & 1.5 & 1.5 & 6.2 & 6.4 & 1.5 & 0.8 & 0.7 & 0.7 \\
\hline 0.077 & 8.1 & 5.9 & 0.4 & 0.8 & 4.1 & 4.6 & 1.5 & 4.9 & 0.6 & 1.3 & 4.0 & $\begin{array}{l}4.1 \\
\end{array}$ & 1.3 & 1.2 & 5.6 & 3.7 & 1.2 & 0.7 & 0.7 & 0.7 \\
\hline 0.091 & 6.9 & 5.6 & 0.4 & 0.8 & 3.9 & 4.1 & 1.4 & 4.2 & 0.6 & 2.7 & 3.6 & 4.2 & 2.5 & 1.2 & 5.6 & 3.5 & 1.2 & 0.7 & 0.7 & 0.7 \\
\hline 0.108 & 11.5 & 8.2 & 0.4 & 0.8 & 3.9 & 5.1 & 1.4 & 4.7 & 0.5 & 2.5 & 3.8 & 4.2 & 1.5 & 1.2 & 6.0 & 6.8 & 1.4 & 0.7 & 0.7 & 0.7 \\
\hline 0.128 & 89.4 & 8.8 & 0.4 & 0.8 & 3.7 & 5.0 & 1.3 & 4.7 & 0.5 & 1.4 & 2.6 & 4.6 & 2.6 & 1.2 & 5.7 & 8.2 & 1.2 & 0.6 & 0.7 & 0.6 \\
\hline 0.152 & 5.5 & 5.3 & 0.4 & 0.7 & 3.4 & 4.5 & 1.5 & 3.3 & 0.5 & 1.3 & 2.5 & 4.8 & 2.6 & 1.1 & 9.9 & 10.9 & 1.2 & 0.6 & 0.6 & 0.6 \\
\hline 0.181 & 83.4 & 5.9 & 0.4 & 0.7 & 2.7 & 4.9 & 1.4 & 3.5 & 0.5 & 1.2 & 2.6 & 5.8 & 2.1 & 1.1 & 5.5 & 5.5 & 1.2 & 0.6 & 0.6 & 0.6 \\
\hline 0.214 & 139.0 & 7.7 & 0.4 & 0.7 & 3.5 & 3.7 & 1.3 & 3.4 & 0.5 & 1.1 & 2.4 & 4.0 & 2.1 & 1.0 & 5.9 & 6.7 & 1.2 & 0.6 & 0.6 & 0.6 \\
\hline 0.254 & 5.7 & 8.0 & 0.4 & 0.6 & 3.0 & 4.4 & 1.3 & 3.4 & 0.6 & 2.3 & 2.3 & 6.1 & 1.5 & 1.0 & 6.7 & 6.2 & 1.1 & 0.5 & 0.6 & 0.6 \\
\hline 0.302 & 7.4 & 11.1 & 0.4 & 0.6 & 3.4 & 5.3 & 1.3 & 3.3 & 0.6 & 1.2 & 2.4 & 4.4 & 1.6 & 1.1 & 7.6 & 6.5 & 1.1 & 0.5 & 0.6 & 0.6 \\
\hline 0.358 & 86.0 & 7.0 & 0.4 & 0.6 & 3.1 & 4.6 & 1.3 & 3.2 & 0.5 & 1.2 & 4.4 & 5.4 & 2.5 & 1.0 & 4.4 & 7.0 & 1.1 & 0.5 & 0.6 & 0.5 \\
\hline 0.425 & 5.1 & 8.0 & 0.4 & 0.5 & 3.2 & 3.7 & 1.3 & 3.1 & 0.5 & 1.2 & 4.0 & 5.4 & 1.6 & 1.0 & 6.1 & 8.5 & 1.1 & 0.5 & 0.6 & 0.5 \\
\hline 0.504 & 5.4 & 8.1 & 0.4 & 0.5 & 2.7 & 4.5 & 1.2 & 4.4 & 0.5 & 1.2 & 2.6 & 4.9 & 2.5 & 1.0 & 5.2 & 8.1 & 1.1 & 0.4 & 0.6 & 0.5 \\
\hline 0.599 & 5.7 & 4.9 & 0.4 & 0.5 & 3.3 & 4.2 & 1.2 & 3.2 & 0.5 & 2.0 & 4.3 & 4.2 & 1.6 & 1.0 & 5.7 & 5.6 & 1.1 & 0.4 & 0.6 & 0.5 \\
\hline 0.710 & 7.7 & 5.0 & 0.4 & 0.5 & 2.9 & 3.1 & 1.2 & 3.1 & 0.5 & 2.6 & 3.3 & 4.3 & 2.5 & 1.0 & 6.3 & 7.6 & 1.1 & 0.4 & 0.6 & 0.5 \\
\hline 0.843 & 7.8 & 9.3 & 0.4 & 0.5 & 2.7 & 4.6 & 1.2 & 3.8 & 0.5 & 1.0 & 2.9 & 4.3 & 2.8 & 0.9 & 8.7 & 13.8 & 1.1 & 0.4 & 0.6 & 0.5 \\
\hline 1.000 & 9.3 & 8.3 & 0.4 & 0.5 & 3.2 & 4.5 & 1.2 & 4.5 & 0.5 & 1.0 & 2.8 & 4.2 & 1.9 & 0.9 & 7.7 & 8.1 & 1.1 & 0.4 & 0.6 & 0.5 \\
\hline
\end{tabular}

* Critical earthquake records 
Table B-3: Maximum Inter-story Drift in LA3-A under ground motions corresponding to near-fault earthquakes

\begin{tabular}{|c|c|c|c|c|c|c|c|c|c|c|c|c|c|c|c|c|c|c|c|c|}
\hline \multirow{3}{*}{$\alpha$} & \multicolumn{20}{|c|}{ Maximum inter-story drift for near-fault ground motions (\%) } \\
\hline & \multicolumn{20}{|c|}{ Ground Motion } \\
\hline & $\begin{array}{c}\mathrm{NF} 01 \\
*\end{array}$ & NF02 & $\begin{array}{c}\mathrm{NF} 03 \\
*\end{array}$ & NF04 & NF05 & NF06 & $\begin{array}{c}\text { NF07 } \\
*\end{array}$ & NF08 & NF09 & NF10 & NF11 & NF12 & $\begin{array}{c}\text { NF13 } \\
*\end{array}$ & NF14 & NF15 & NF16 & $\begin{array}{c}\text { NF17 } \\
*\end{array}$ & $\begin{array}{c}\mathrm{NF} 18 \\
*\end{array}$ & $\begin{array}{c}\text { NF19 } \\
*\end{array}$ & NF20 \\
\hline 0.007 & 5.3 & 1.0 & 14.5 & 0.9 & 1.8 & 0.4 & 3.4 & 1.6 & 0.3 & 0.3 & 0.3 & 0.3 & 7.6 & 0.6 & 1.4 & 0.9 & 11.3 & 3.3 & 16.8 & 1.5 \\
\hline 0.008 & 3.7 & 1.0 & 14.6 & 0.9 & 1.8 & 0.4 & 3.2 & 1.5 & 0.3 & 0.3 & 0.3 & 0.3 & 7.4 & 0.6 & 1.4 & 0.9 & 9.8 & 3.1 & 18.8 & 1.5 \\
\hline 0.010 & 4.1 & 0.9 & 9.8 & 0.9 & 1.7 & 0.4 & 2.8 & 1.5 & 0.3 & 0.3 & 0.3 & 0.3 & 6.9 & 0.6 & 1.4 & 0.9 & 9.8 & 2.8 & 308. & 1.5 \\
\hline 0.012 & 2.1 & 0.9 & 11.7 & 0.9 & 1.7 & 0.4 & 5.0 & 1.5 & 0.3 & 0.3 & 0.3 & 0.3 & 7.7 & 0.5 & 1.4 & 2.6 & 9.4 & 2.7 & 114.7 & 1.4 \\
\hline 0.014 & 3.6 & 0.9 & 9.7 & 0.8 & 1.6 & 0.4 & 3.2 & 1.5 & 0.3 & 0.3 & 0.3 & 0.3 & 6.0 & 0.5 & 1.4 & 3.2 & 7.4 & 2.4 & 12.5 & 1.4 \\
\hline 0.016 & 3.7 & 0.9 & 10.3 & 0.8 & 1.5 & 0.4 & 3.0 & 1.4 & 0.3 & 0.3 & 0.3 & 0.3 & 5.8 & 0.5 & 1.4 & 0.9 & 7.5 & 2.3 & 10.5 & 2.4 \\
\hline 0.020 & 3.1 & 0.8 & 9.0 & 0.8 & 1.5 & 0.4 & 3.0 & 1.4 & 0.3 & 0.3 & 0.3 & 0.3 & 7.3 & 0.5 & 1.4 & 0.9 & 8.2 & 2.2 & 5.7 & 1.2 \\
\hline 0.023 & 1.4 & 0.8 & 7.0 & 0.8 & 1.4 & 0.4 & 3.9 & 1.3 & 0.3 & 0.3 & 0.3 & 0.3 & 4.9 & 0.5 & 1.4 & 0.9 & 6.1 & 2.1 & 6.2 & 1.2 \\
\hline 0.028 & 2.4 & 0.8 & 8.6 & 0.8 & 1.3 & 0.4 & 2.6 & 1.3 & 0.3 & 0.3 & 0.3 & 0.4 & 4.7 & 0.5 & 1.3 & 1.0 & 5.9 & 2.1 & 4.9 & 1.1 \\
\hline 0.033 & 2.6 & 0.8 & 5.5 & 0.8 & 1.2 & 0.4 & 3.6 & 1.2 & 0.3 & 0.3 & 0.3 & 0.4 & 6.2 & 0.5 & 1.2 & 1.0 & 8.1 & 3.0 & 4.5 & 1.0 \\
\hline 0.039 & 2.3 & 0.8 & 4.5 & 0.8 & 1.2 & 0.4 & 1.7 & 1.2 & 0.3 & 0.3 & 0.3 & 0.4 & 5.3 & 0.5 & 1.2 & 2.0 & 160 & 1.5 & 1.6 & 0.9 \\
\hline 0.046 & 2.2 & 0.7 & 5.2 & 0.8 & 1.1 & 0.4 & 2.9 & 1.1 & 0.3 & 0.3 & 0.3 & 0.4 & 5.6 & 0.5 & 1.2 & 0.9 & 8.1 & 1.4 & 1.4 & 0.9 \\
\hline 0.065 & 1.3 & 0.7 & 3.9 & 0.7 & 1.6 & 0.4 & 1.3 & 1.0 & 0.3 & 0.3 & 0.3 & 0.4 & 5.3 & 0.5 & 1.2 & 1.7 & 182 & 1.2 & 1.2 & 0.8 \\
\hline 0.077 & 1.5 & 0.7 & 3.3 & 0.7 & 0.9 & 0.4 & 1.2 & 0.9 & 0.3 & 0.3 & 0.3 & 0.4 & 4.5 & 0.5 & 1.2 & 0.9 & 205 & 1.1 & 1.2 & 0.8 \\
\hline 0.091 & 1.3 & 0.7 & 3.7 & 0.7 & 0.8 & 0.4 & 1.2 & 0.8 & 0.3 & 0.3 & 0.3 & 0.4 & 3.8 & 0.5 & 1.2 & 0.9 & 5.5 & 1.6 & 1.1 & 0.7 \\
\hline 0.108 & 1.5 & 0.7 & 3.0 & 0.7 & 0.8 & 0.4 & 1.1 & 0.8 & 0.3 & 0.3 & 0.3 & 0.4 & 4.7 & 0.5 & 1.3 & 0.9 & 5.4 & 0.9 & 1.0 & 0.7 \\
\hline 0.128 & 1.6 & 0.7 & 2.6 & 0.7 & 0.7 & 0.4 & 1.9 & 0.7 & 0.3 & 0.3 & 0.3 & 0.4 & 4.0 & 0.5 & 1.3 & 0.9 & 9.3 & 0.9 & 0.8 & 0.6 \\
\hline 0.152 & 1.6 & 0.7 & 2.3 & 0.6 & 0.7 & 0.4 & 1.0 & 0.7 & 0.3 & 0.3 & 0.3 & 0.3 & 3.5 & 0.5 & 1.3 & 1.3 & 7.5 & 0.9 & 0.7 & 0.6 \\
\hline 0.181 & 1.4 & 0.7 & 2.3 & 0.6 & 0.6 & 0.3 & 1.0 & 0.7 & 0.3 & 0.3 & 0.3 & 0.3 & 4.8 & 0.4 & 1.3 & 0.9 & 5.8 & 1.8 & 0.7 & 0.6 \\
\hline 0.214 & 1.2 & 0.7 & 2.3 & 0.6 & 0.6 & 0.3 & 1.0 & 0.6 & 0.3 & 0.3 & 0.3 & 0.3 & 4.5 & 0.4 & 1.3 & 0.9 & 6.2 & 0.8 & 0.6 & 0.6 \\
\hline 0.254 & 1.3 & 0.8 & 2.3 & 0.6 & 0.6 & 0.3 & 1.0 & 0.6 & 0.3 & 0.3 & 0.3 & 0.3 & 4.4 & 0.4 & 1.2 & 1.0 & 8.0 & 0.8 & 0.6 & 0.6 \\
\hline 0.302 & 1.9 & 0.8 & 2.3 & 0.6 & 0.5 & 0.3 & 0.9 & 0.6 & 0.3 & 0.3 & 0.3 & 0.3 & 4.1 & 0.4 & 1.2 & 1.0 & 7.9 & 0.8 & 0.6 & 0.5 \\
\hline 0.358 & 1.2 & 0.7 & 2.2 & 0.5 & 0.5 & 0.3 & 1.0 & 0.5 & 0.3 & 0.3 & 0.3 & 0.3 & 3.8 & 0.4 & 1.2 & 2.1 & 9.0 & 0.8 & 0.6 & 0.5 \\
\hline 0.425 & 1.2 & 0.7 & 2.2 & 0.5 & 0.5 & 0.3 & 1.0 & 0.5 & 0.3 & 0.3 & 0.4 & 0.3 & 3.9 & 0.4 & 1.2 & 1.3 & 4.3 & 0.9 & 0.6 & 0.5 \\
\hline 0.504 & 1.4 & 0.7 & 2.2 & 0.5 & 0.5 & 0.3 & 1.0 & 0.5 & 0.3 & 0.3 & 0.4 & 0.3 & 3.9 & 0.4 & 1.2 & 1.4 & 5.1 & 0.9 & 0.5 & 0.5 \\
\hline 0.599 & 1.2 & 0.7 & 2.1 & 0.5 & 0.4 & 0.3 & 0.9 & 0.5 & 0.3 & 0.3 & 0.4 & 0.3 & 4.2 & 0.4 & 1.1 & 1.3 & 9.5 & 0.8 & 0.5 & 0.6 \\
\hline 0.710 & 1.2 & 0.7 & 2.0 & 0.5 & 0.4 & 0.3 & 0.9 & 0.4 & 0.3 & 0.3 & 0.4 & 0.3 & 4.2 & 0.4 & 1.1 & 1.0 & 63.5 & 0.8 & 0.5 & 0.6 \\
\hline 0.843 & 1.1 & 0.7 & 2.0 & 0.5 & 0.4 & 0.3 & 0.9 & 0.4 & 0.3 & 0.3 & 0.4 & 0.3 & 4.5 & 0.4 & 1.1 & 1.0 & 10.0 & 0.8 & 0.5 & 0.6 \\
\hline 1.000 & 1.1 & 0.7 & 2.0 & 0.5 & 0.4 & 0.3 & 0.9 & 0.4 & 0.3 & 0.3 & 0.3 & 0.3 & 4.1 & 0.4 & 1.1 & 1.3 & 7.7 & 0.8 & 0.5 & 0.6 \\
\hline
\end{tabular}

* Critical earthquake records 
Table B-4: Maximum Inter-story Drift in LA3-B under ground motions corresponding to $10 \%$ in 50

\begin{tabular}{|c|c|c|c|c|c|c|c|c|c|c|c|c|c|c|c|c|c|c|c|c|}
\hline \multirow{3}{*}{$\alpha$} & \multicolumn{20}{|c|}{ Maximum inter-story drift for $10 \%$ in 50 year ground motions $(\%)$} \\
\hline & \multicolumn{20}{|c|}{ Ground Motion } \\
\hline & LA21 & LA22 & LA23 & LA24 & LA25 & LA26 & LA27 & LA28 & LA29 & LA30 & $\begin{array}{c}\text { LA31 } \\
*\end{array}$ & LA32 & $\begin{array}{c}\text { LA33 } \\
*\end{array}$ & $\begin{array}{c}\text { LA34 } \\
*\end{array}$ & $\begin{array}{c}\text { LA35 } \\
*\end{array}$ & LA36 & LA37 & $\underset{*}{\mathrm{LA} 38}$ & $\underset{*}{\text { LA39 }}$ & $\begin{array}{l}\mathrm{LA} 40 \\
*\end{array}$ \\
\hline 0.007 & 0.6 & 1.0 & 0.5 & 0.8 & 0.2 & 0.3 & 0.2 & 0.5 & 0.7 & 0.6 & 0.4 & 3.0 & 2.1 & 1.1 & 1.4 & 0.6 & 0.4 & 2.6 & 2.0 & 3.3 \\
\hline 0.008 & 0.6 & 1.1 & 0.5 & 0.9 & 0.2 & 0.3 & 0.3 & 0.4 & 0.6 & 0.5 & 0.4 & 2.5 & 1.6 & 1.0 & 1.5 & 0.6 & 0.4 & 2.9 & 2.0 & 1.0 \\
\hline 0.010 & 0.6 & 1.1 & 0.5 & 0.9 & 0.2 & 0.3 & 0.2 & 0.4 & 0.5 & 0.4 & 0.4 & 2.0 & 4.0 & 1.1 & 1.2 & 0.6 & 0.4 & 2.5 & 2.0 & 1.0 \\
\hline 0.012 & 0.6 & 1.0 & 0.5 & 0.9 & 0.2 & 0.2 & 0.2 & 0.4 & 0.5 & 0.4 & 0.5 & 2.7 & 1.7 & 1.1 & 1.2 & 0.6 & 0.4 & 2.6 & 1.9 & 0.9 \\
\hline 0.014 & 0.6 & 1.0 & 0.5 & 0.9 & 0.2 & 0.2 & 0.2 & 0.4 & 0.5 & 0.4 & 0.5 & 1.9 & 1.7 & 1.1 & 1.4 & 0.6 & 0.4 & 2.7 & 2.0 & 0.9 \\
\hline 0.016 & 0.5 & 1.0 & 0.5 & 0.9 & 0.2 & 0.2 & 0.2 & 0.4 & 0.5 & 0.3 & 0.6 & 1.6 & 1.8 & 1.0 & 1.1 & 0.6 & 0.4 & 2.3 & 1.9 & 0.9 \\
\hline 0.020 & 0.5 & 0.9 & 0.5 & 0.8 & 0.2 & 0.2 & 0.2 & 0.4 & 0.5 & 0.3 & 0.6 & 1.6 & 1.7 & 3.8 & 1.1 & 0.6 & 0.4 & 2.5 & 1.9 & 0.9 \\
\hline 0.023 & 0.5 & 0.9 & 0.5 & 0.8 & 0.2 & 0.2 & 0.2 & 0.5 & 0.5 & 0.3 & 0.6 & 1.5 & 1.6 & 3.8 & 1.9 & 0.6 & 0.4 & 2.2 & 1.8 & 0.9 \\
\hline 0.028 & 0.5 & 0.9 & 0.5 & 0.8 & $\begin{array}{l}0.2 \\
\end{array}$ & 0.2 & 0.2 & 0.5 & 0.5 & 0.3 & 0.6 & 1.5 & 1.6 & 1.0 & 1.0 & 0.6 & 0.4 & 2.1 & 1.8 & 0.8 \\
\hline 0.033 & 0.5 & 0.9 & 0.5 & 0.8 & 0.2 & 0.2 & 0.2 & 0.5 & 0.5 & 0.3 & 0.7 & 1.5 & 1.6 & 0.9 & 1.0 & 0.6 & 0.4 & 2.0 & 1.9 & 0.8 \\
\hline 0.039 & 0.5 & 0.9 & 0.5 & 0.8 & 0.2 & 0.2 & 0.2 & 0.5 & 0.5 & 0.3 & 0.7 & 1.4 & 1.4 & 0.9 & 0.9 & 0.6 & 0.4 & 2.9 & 1.6 & 0.8 \\
\hline 0.046 & 0.5 & 0.8 & 0.5 & 0.8 & 0.2 & 0.2 & 0.2 & 0.5 & 0.4 & 0.3 & 1.3 & 1.8 & 1.6 & 3.0 & 0.9 & 0.6 & 0.4 & 1.8 & 1.5 & 0.8 \\
\hline 0.077 & 0.5 & 0.8 & 0.5 & 0.7 & 0.2 & 0.2 & 0.2 & 0.5 & 0.4 & 0.3 & 0.6 & 1.4 & 1.5 & 2.4 & 0.8 & 0.6 & 0.4 & 2.4 & 1.3 & 0.7 \\
\hline 0.091 & 0.5 & 0.8 & 0.5 & 0.7 & 0.2 & 0.2 & 0.2 & 0.5 & 0.4 & 0.3 & 0.6 & 1.2 & 1.3 & 1.6 & 0.8 & 0.6 & 0.4 & 2.1 & 1.2 & 0.8 \\
\hline 0.108 & 0.5 & 0.7 & 0.5 & 0.7 & 0.2 & 0.2 & 0.2 & 0.5 & 0.4 & 0.3 & 0.6 & 1.2 & 1.2 & 0.7 & 0.8 & 0.6 & 0.4 & 1.5 & 1.2 & 0.8 \\
\hline 0.128 & 0.5 & 0.7 & 0.4 & 0.6 & 0.2 & 0.2 & 0.2 & 0.5 & 0.4 & 0.3 & 0.6 & 1.4 & 1.2 & 0.7 & 0.8 & 0.6 & 0.4 & 1.4 & 1.2 & 0.8 \\
\hline 0.152 & 0.5 & 0.7 & 0.4 & 0.6 & 0.2 & 0.2 & 0.2 & 0.5 & 0.4 & 0.3 & 1.0 & 1.1 & 1.2 & 1.6 & 0.7 & 0.6 & 0.4 & 1.9 & 1.1 & 0.8 \\
\hline 0.181 & 0.5 & 0.7 & 0.4 & 0.6 & 0.2 & 0.2 & 0.2 & 0.5 & 0.4 & 0.3 & 0.6 & 1.1 & 1.1 & 1.6 & 0.7 & 0.6 & 0.4 & 1.3 & 1.1 & 0.8 \\
\hline 0.214 & 0.5 & 0.6 & 0.4 & 0.6 & 0.2 & 0.2 & 0.2 & 0.5 & 0.4 & 0.3 & 0.6 & 1.1 & 1.1 & 0.7 & 0.7 & 0.5 & 0.4 & 1.8 & 1.1 & 0.8 \\
\hline 0.254 & 0.4 & 0.6 & 0.4 & 0.6 & 0.2 & 0.2 & 0.2 & 0.5 & 0.4 & 0.3 & 0.6 & 1.0 & 1.0 & 0.6 & 0.6 & 0.5 & 0.4 & 1.6 & 1.0 & 0.8 \\
\hline 0.302 & 0.4 & 0.6 & 0.4 & 0.5 & 0.2 & 0.2 & 0.2 & 0.5 & 0.4 & 0.3 & 0.5 & 1.0 & 0.9 & 1.3 & 0.6 & 0.5 & 0.4 & 1.2 & 1.0 & 0.8 \\
\hline 0.358 & 0.4 & 0.6 & 0.4 & 0.5 & 0.2 & 0.2 & 0.2 & 0.5 & 0.4 & 0.3 & 0.5 & 1.0 & 0.9 & 0.6 & 0.6 & 0.5 & 0.4 & 1.6 & 1.0 & 0.8 \\
\hline 0.425 & 0.4 & 0.5 & 0.4 & 0.5 & 0.2 & 0.2 & 0.2 & 0.5 & 0.4 & 0.3 & 0.5 & 1.0 & 0.9 & 0.6 & 0.6 & 0.5 & 0.4 & 1.2 & 1.0 & 0.8 \\
\hline 0.504 & 0.4 & 0.5 & 0.4 & 0.5 & 0.2 & 0.2 & 0.2 & 0.4 & 0.4 & 0.3 & 0.5 & 1.0 & 0.9 & 1.6 & 0.6 & 0.5 & 0.4 & 1.2 & 1.0 & 0.7 \\
\hline 0.599 & 0.4 & 0.5 & 0.4 & 0.5 & 0.2 & 0.2 & 0.2 & 0.4 & 0.4 & 0.3 & 0.5 & 1.0 & 0.9 & 1.6 & 0.5 & 0.5 & 0.4 & 1.1 & 1.0 & 0.7 \\
\hline 0.710 & 0.4 & 0.5 & 0.4 & 0.5 & 0.2 & 0.2 & 0.2 & 0.4 & 0.4 & 0.3 & 0.5 & 1.0 & 0.9 & 0.6 & 0.5 & 0.4 & 0.4 & 1.0 & 0.9 & 0.7 \\
\hline 0.843 & 0.4 & 0.5 & 0.4 & 0.5 & 0.2 & 0.2 & 0.2 & 0.4 & 0.4 & 0.3 & 0.5 & 1.0 & 0.9 & 0.6 & 0.5 & 0.4 & 0.4 & 1.4 & 0.9 & 0.7 \\
\hline 1.000 & 0.4 & 0.5 & 0.4 & 0.5 & 0.2 & 0.2 & 0.2 & 0.4 & 0.4 & 0.3 & 0.5 & 1.0 & 1.0 & 0.6 & 0.5 & 0.4 & 0.4 & 1.1 & 0.9 & 0.7 \\
\hline
\end{tabular}

* Critical earthquake records 
Table B-5: Maximum Inter-story Drift in LA3-B under ground motions corresponding to 2\% in 50

\begin{tabular}{|c|c|c|c|c|c|c|c|c|c|c|c|c|c|c|c|c|c|c|c|c|}
\hline \multirow{3}{*}{$\alpha$} & \multicolumn{20}{|c|}{ Maximum inter-story drift for $2 \%$ in 50 year ground motions $(\%)$} \\
\hline & \multicolumn{20}{|c|}{ Ground Motion } \\
\hline & $\begin{array}{c}\mathrm{LA} 01 \\
*\end{array}$ & $\begin{array}{c}\mathrm{LA} 02 \\
*\end{array}$ & LA03 & LA04 & $\begin{array}{c}\mathrm{LA} 05 \\
*\end{array}$ & $\underset{*}{\text { LA06 }}$ & $\begin{array}{c}\mathrm{LA07} \\
*\end{array}$ & $\begin{array}{c}\mathrm{LA} 08 \\
*\end{array}$ & LA09 & $\begin{array}{c}\mathrm{LA} 10 \\
*\end{array}$ & $\underset{*}{\mathrm{LA} 11}$ & $\underset{*}{\mathrm{LA} 12}$ & $\underset{*}{\mathrm{LA} 13}$ & $\underset{*}{\mathrm{LA} 14}$ & $\underset{*}{\mathrm{LA} 15}$ & $\begin{array}{c}\mathrm{LA} 16 \\
*\end{array}$ & $\underset{*}{\mathrm{LA} 17}$ & LA18 & LA19 & LA20 \\
\hline 0.007 & 12.5 & 13.2 & 0.7 & 0.9 & 8.7 & 15.7 & 3.8 & 7.0 & 1.1 & 9.3 & 11.6 & 8.3 & 6.0 & 3.9 & 12.5 & 9.3 & 2.2 & 1.5 & 1.0 & 0.7 \\
\hline 0.008 & 7.2 & 8.8 & 0.7 & 0.9 & 5.1 & 13.8 & 3.4 & 10.0 & 1.1 & 8.2 & 7.8 & 8.2 & 10.3 & 4.5 & 17.6 & 14.6 & 2.0 & 1.5 & 1.0 & 0.7 \\
\hline 0.010 & 12.2 & 9.1 & 0.6 & 0.9 & 7.5 & 9.0 & 2.9 & 8.4 & 1.1 & 1.7 & 8.0 & 7.1 & 4.7 & 4.8 & 12.9 & 14.9 & 1.7 & 1.5 & 1.0 & 0.7 \\
\hline 0.012 & 10.5 & 14.4 & 0.6 & 0.9 & 6.6 & 9.4 & 2.7 & 8.2 & 1.1 & 8.1 & 8.6 & 9.6 & 6.8 & 3.4 & 15.2 & 11.7 & 1.7 & 1.5 & 1.0 & 0.6 \\
\hline 0.014 & 11.9 & 9.0 & 0.6 & 0.8 & 6.3 & 12.5 & 2.3 & 6.9 & 1.1 & 1.8 & 7.8 & 7.6 & 6.2 & 4.4 & 14.7 & 9.7 & 1.5 & 1.5 & 1.0 & 0.6 \\
\hline 0.016 & 10.0 & 8.4 & 0.6 & 0.8 & 6.1 & 8.2 & 1.7 & 6.8 & 1.1 & 1.8 & 7.4 & 9.2 & 4.8 & 2.9 & 12.0 & 8.3 & 1.4 & 1.4 & 1.0 & 0.6 \\
\hline 0.020 & 10.6 & 10.2 & 0.6 & 0.8 & 4.3 & 9.1 & 1.6 & 6.3 & 1.1 & 1.8 & 6.4 & 11.0 & 3.6 & 2.9 & 10.5 & 8.0 & 1.3 & 1.4 & 1.0 & 0.5 \\
\hline 0.023 & 9.5 & 7.4 & 0.6 & 0.8 & 5.2 & 6.4 & 1.5 & 5.6 & 1.1 & 4.0 & 6.1 & 9.1 & 3.2 & 2.8 & 8.7 & 5.2 & 1.2 & 1.3 & 1.0 & 0.5 \\
\hline 0.028 & 10.4 & 6.4 & 0.6 & 0.7 & 3.9 & 8.5 & 3.8 & 5.6 & 1.9 & 4.9 & 7.0 & 8.3 & 4.1 & 2.5 & 5.8 & 5.1 & 1.2 & 1.2 & 1.0 & 0.5 \\
\hline 0.033 & 9.6 & 5.5 & 0.6 & 0.7 & 4.5 & 4.3 & 4.6 & 5.5 & 1.0 & 3.2 & 4.6 & 7.2 & 2.8 & 3.2 & 5.1 & 5.8 & 1.1 & 1.2 & 1.0 & 0.4 \\
\hline 0.039 & 203.7 & 6.6 & 0.6 & 0.7 & 3.6 & 4.4 & 1.2 & 5.0 & 1.0 & 1.5 & 4.0 & 6.2 & 2.5 & 2.3 & 4.2 & 3.4 & 1.0 & 1.1 & 1.0 & 0.4 \\
\hline 0.046 & 275.0 & 15.0 & 0.6 & 0.7 & 3.5 & 3.7 & 1.1 & 4.7 & 1.0 & 1.4 & 3.2 & 7.5 & 2.5 & 1.6 & 4.9 & 4.4 & 1.0 & 1.0 & 0.9 & 0.4 \\
\hline 0.055 & 16.3 & 6.5 & 0.6 & 0.6 & 2.6 & 5.4 & 1.0 & 4.5 & 1.0 & 1.4 & 7.2 & 5.5 & 1.6 & 1.5 & 4.5 & 3.3 & 0.9 & 1.0 & 0.9 & 0.4 \\
\hline 0.077 & 86.8 & 5.7 & 0.6 & 0.6 & 2.3 & 3.9 & 0.9 & 4.0 & 0.9 & 1.3 & 3.5 & 5.6 & 2.3 & 1.3 & 3.3 & 3.5 & 0.8 & .9 & 8 & 0.4 \\
\hline 0.091 & 12.2 & 7.9 & 0.5 & 0.6 & 2.9 & 4.3 & 0.8 & 3.9 & 0.9 & 2.1 & 3.2 & 5.8 & 2.1 & 1.3 & 4.5 & 1.8 & 0.8 & 0.8 & 0.8 & 0.4 \\
\hline 0.108 & 5.8 & 9.2 & 0.5 & 0.6 & 2.6 & 5.4 & 0.8 & 3.9 & 0.8 & 3.4 & 3.1 & 5.3 & 1.2 & 1.3 & 2.9 & 1.7 & 0.8 & 0.8 & 0.8 & 0.4 \\
\hline 0.128 & 15.0 & 5.7 & 0.5 & 0.5 & 2.0 & 3.0 & 0.7 & 3.7 & 0.8 & 1.2 & 3.7 & 4.6 & 1.8 & 1.2 & 2.6 & 1.7 & 0.7 & 0.7 & 0.7 & 0.3 \\
\hline 0.152 & 199.3 & 4.8 & 0.5 & 0.5 & 2.1 & 2.8 & 0.7 & 3.5 & 0.8 & 2.7 & 1.9 & 4.7 & 1.1 & 1.2 & 2.4 & 1.6 & 0.7 & 0.7 & 0.7 & 0.3 \\
\hline 0.181 & 8.9 & 4.0 & 0.5 & 0.5 & 2.3 & 2.7 & 0.7 & 3.6 & 0.8 & 1.6 & 4.5 & 4.1 & 1.5 & 1.1 & 2.1 & 1.6 & 0.6 & 0.6 & 0.7 & 0.3 \\
\hline 0.214 & 17.6 & 4.2 & 0.5 & 0.5 & 1.8 & 2.1 & 0.6 & 3.6 & 0.7 & 1.3 & 1.8 & 4.4 & 1.1 & 1.1 & 2.1 & 1.5 & 0.6 & 0.6 & 0.7 & 0.3 \\
\hline 0.254 & 9.9 & 4.7 & 0.5 & 0.5 & 2.4 & 2.0 & 0.6 & 3.1 & 0.7 & 1.1 & 1.8 & 4.5 & 1.5 & 1.0 & 2.0 & 1.4 & 0.6 & 0.6 & 0.7 & 0.3 \\
\hline 0.302 & 96.8 & 4.0 & 0.5 & 0.5 & 1.8 & 2.3 & 0.6 & 3.5 & 0.7 & 1.1 & 1.7 & 5.9 & 1.1 & 1.0 & 2.0 & 1.4 & 0.6 & 0.6 & 0.6 & 0.3 \\
\hline 0.358 & 171.2 & 4.7 & 0.4 & 0.4 & 1.9 & 1.9 & 0.6 & 3.0 & 0.6 & 2.4 & 3.5 & 5.5 & 1.2 & 1.0 & 1.5 & 1.4 & 0.5 & 0.5 & 0.6 & 0.3 \\
\hline 0.425 & 14.7 & 4.7 & 0.4 & 0.4 & 1.9 & 1.9 & 0.5 & 2.9 & 0.6 & 1.1 & 3.5 & $\begin{array}{l}4.4 \\
\end{array}$ & 1.1 & 1.0 & 1.6 & 1.4 & 0.5 & 0.5 & 0.6 & 0.3 \\
\hline 0.504 & 144.8 & 4.3 & 0.4 & 0.4 & 1.9 & 1.8 & 0.5 & 2.8 & 0.6 & 2.6 & 1.7 & 5.6 & 1.1 & 1.0 & 1.6 & 1.5 & 0.5 & 0.5 & 0.6 & 0.3 \\
\hline 0.599 & 176.1 & 4.6 & 0.4 & 0.4 & 1.9 & 1.8 & 0.5 & 2.8 & 0.6 & 1.0 & 1.6 & 4.2 & 1.1 & 0.9 & 2.0 & 1.4 & 0.5 & 0.5 & 0.6 & 0.3 \\
\hline 0.710 & 10.4 & 4.6 & 0.4 & 0.4 & 2.1 & 2.2 & 0.5 & 2.8 & 0.6 & 1.1 & 3.1 & 4.4 & 1.1 & 0.9 & 1.8 & 1.4 & 0.5 & 0.4 & 0.6 & 0.3 \\
\hline 0.843 & 6.6 & 4.5 & 0.4 & 0.4 & 1.8 & 1.8 & 0.5 & 2.6 & 0.6 & 1.1 & 3.1 & 4.4 & 1.1 & 0.9 & 1.5 & 1.5 & 0.5 & 0.4 & 0.5 & 0.3 \\
\hline 1.000 & 114.9 & 3.8 & 0.4 & 0.4 & 2.0 & 2.4 & 0.5 & 3.1 & 0.6 & 1.0 & 2.2 & 4.5 & 1.0 & 0.9 & 1.5 & 1.5 & 0.5 & 0.4 & 0.5 & 0.3 \\
\hline
\end{tabular}

* Critical earthquake records 
Table B-6: Maximum Inter-story Drift in LA3-B under ground motions corresponding to near-fault earthquakes

\begin{tabular}{|c|c|c|c|c|c|c|c|c|c|c|c|c|c|c|c|c|c|c|c|c|}
\hline \multirow{3}{*}{$\alpha$} & \multicolumn{20}{|c|}{ Maximum inter-story drift for near-fault ground motions (\%) } \\
\hline & \multicolumn{20}{|c|}{ Ground Motion } \\
\hline & $\begin{array}{c}\mathrm{NF} 01 \\
*\end{array}$ & NF02 & $\begin{array}{c}\mathrm{NF} 03 \\
*\end{array}$ & NF04 & NF05 & NF06 & $\begin{array}{c}\mathrm{NF} 07 \\
*\end{array}$ & NF08 & NF09 & NF10 & NF11 & NF12 & $\begin{array}{c}\text { NF13 } \\
*\end{array}$ & NF14 & NF15 & NF16 & $\begin{array}{c}\text { NF17 } \\
*\end{array}$ & $\underset{*}{\mathrm{NF} 18}$ & $\begin{array}{c}\text { NF19 } \\
*\end{array}$ & NF20 \\
\hline 0.007 & 11.8 & 4.6 & 10.4 & 0.7 & 1.1 & 0.5 & 6.3 & 1.2 & 0.4 & 0.3 & 0.2 & 0.3 & 8.9 & 0.6 & 1.9 & 1.1 & 13.8 & 1.4 & 9.4 & 0.7 \\
\hline 0.008 & 10.2 & 0.9 & 5.7 & 0.6 & 0.9 & 0.5 & 2.8 & 1.1 & 0.3 & 0.3 & 0.3 & 0.4 & 7.2 & 0.6 & 3.0 & 2.8 & 15.3 & 1.2 & 10.1 & 0.8 \\
\hline 0.010 & 3.9 & 2.8 & 6.3 & 0.5 & 0.8 & 0.4 & 2.7 & 1.0 & 0.3 & 0.4 & 0.3 & 0.4 & 8.4 & 0.6 & 2.0 & 1.2 & 10.8 & 1.1 & 7.6 & 0.8 \\
\hline 0.012 & 7.0 & 0.9 & 5.6 & 0.5 & 0.7 & 0.4 & 2.5 & 0.9 & 0.3 & 0.4 & 0.3 & 0.4 & 8.4 & 0.6 & 2.0 & 3.8 & 9.6 & 0.9 & 1.7 & 0.8 \\
\hline 0.014 & 3.2 & 3.5 & 5.5 & 0.5 & 0.6 & 0.3 & 2.6 & 0.8 & 0.3 & 0.4 & 0.3 & 0.4 & 5.4 & 0.6 & 2.0 & 1.3 & 10.1 & 0.9 & 1.5 & 0.8 \\
\hline 0.016 & 1.6 & 1.0 & 8.5 & 0.5 & 0.5 & 0.3 & 2.3 & 0.8 & 0.3 & 0.4 & 0.3 & 0.4 & 6.3 & 0.5 & 2.6 & 3.0 & 8.3 & 1.0 & 1.2 & 0.8 \\
\hline 0.020 & 1.6 & 1.0 & 7.6 & 0.5 & 0.5 & 0.3 & 2.1 & 0.7 & 0.3 & 0.4 & 0.3 & 0.4 & 5.3 & 0.5 & 2.0 & 1.3 & 6.7 & 1.0 & 1.0 & 0.8 \\
\hline 0.023 & 2.2 & 3.1 & 4.5 & 0.4 & 0.4 & 0.3 & 1.7 & 0.7 & 0.3 & 0.5 & 0.3 & 0.4 & 5.9 & 0.5 & 1.9 & 2.3 & 5.9 & 1.0 & 0.9 & 0.8 \\
\hline 0.028 & 2.0 & 1.0 & 3.8 & 0.4 & 0.4 & 0.3 & 1.6 & 0.7 & 0.3 & 0.5 & 0.3 & 0.4 & 5.1 & 0.5 & 1.9 & 1.2 & 11.0 & 1.0 & 0.9 & 0.8 \\
\hline 0.033 & 1.4 & 2.5 & 2.9 & 0.4 & 0.4 & 0.3 & 1.4 & 0.6 & 0.3 & 0.5 & 0.3 & 0.4 & 3.5 & 0.5 & 1.8 & 2.6 & 16.4 & 1.0 & 0.8 & 0.8 \\
\hline 0.039 & 2.3 & 2.4 & 2.4 & 0.4 & 0.4 & 0.3 & 1.3 & 0.6 & 0.3 & 0.5 & 0.3 & 0.4 & 4.5 & 0.5 & 1.7 & 2.0 & 7.7 & 1.0 & 0.8 & 0.8 \\
\hline 0.046 & 2.0 & 2.2 & 1.9 & 0.4 & 0.4 & 0.3 & 2.4 & 0.6 & 0.3 & 0.5 & 0.3 & 0.4 & 3.5 & 0.5 & 1.6 & 1.9 & 76.4 & 1.0 & 0.8 & 0.8 \\
\hline 0.065 & 1.8 & 1.8 & 1.3 & 0.4 & 0.3 & 0.3 & 1.0 & 0.6 & 0.3 & 0.4 & 0.3 & 0.4 & 2.5 & 0.5 & 1.5 & 2.1 & 250.2 & 1.0 & 0.9 & 0.8 \\
\hline 0.077 & 1.5 & 1.7 & 1.3 & 0.4 & 0.3 & 0.3 & 0.9 & 0.6 & 0.3 & 0.4 & 0.3 & 0.4 & 3.6 & 0.5 & 2.1 & 1.0 & 87.6 & 0.9 & 0.9 & 0.8 \\
\hline 0.091 & 1.1 & 1.5 & 1.3 & 0.4 & 0.3 & 0.3 & 0.8 & 0.6 & 0.3 & 0.4 & 0.3 & 0.4 & 3.2 & 0.5 & 1.4 & 0.9 & 72.3 & 0.9 & 0.9 & 0.7 \\
\hline 0.108 & 1.0 & 0.8 & 1.2 & 0.4 & 0.3 & 0.3 & 0.7 & 0.6 & 0.3 & 0.4 & 0.3 & 0.4 & 1.9 & 0.5 & 1.3 & 1.7 & 454.5 & 0.9 & 0.9 & 0.7 \\
\hline 0.128 & 1.3 & 0.8 & 1.2 & 0.4 & 0.3 & 0.3 & 0.7 & 0.5 & 0.3 & 0.4 & 0.3 & 0.4 & 2.2 & 0.5 & 1.3 & 0.9 & 10.3 & 0.9 & 0.9 & 0.7 \\
\hline 0.152 & 1.0 & 0.7 & 1.2 & 0.4 & 0.3 & 0.3 & 0.6 & 0.5 & 0.3 & 0.4 & 0.3 & 0.4 & 1.8 & 0.5 & 1.2 & 1.5 & 149.6 & 0.8 & 0.8 & 0.7 \\
\hline 0.181 & 1.0 & 0.7 & 1.1 & 0.4 & 0.3 & 0.3 & 0.6 & 0.5 & 0.3 & 0.4 & 0.3 & 0.4 & 1.8 & 0.5 & 1.2 & 0.8 & 8.8 & 0.8 & 0.8 & 0.7 \\
\hline 0.214 & 1.0 & 0.7 & 1.1 & 0.4 & 0.3 & 0.3 & 0.5 & 0.5 & 0.3 & 0.4 & 0.3 & 0.3 & 1.8 & 0.4 & 1.1 & 0.8 & 5.7 & 0.8 & 0.8 & 0.6 \\
\hline 0.254 & 0.9 & 0.7 & 1.0 & 0.4 & 0.3 & 0.3 & 0.5 & 0.5 & 0.3 & 0.4 & 0.3 & 0.3 & 1.8 & 0.4 & 1.1 & 0.7 & 73.8 & 0.8 & 0.8 & 0.6 \\
\hline 0.302 & 0.9 & 0.7 & 1.0 & 0.4 & 0.3 & 0.3 & 0.5 & 0.5 & 0.3 & 0.4 & 0.3 & 0.3 & 1.7 & 0.4 & 1.0 & 1.2 & 13.2 & 0.7 & 0.7 & 0.6 \\
\hline 0.358 & 0.9 & 1.2 & 0.9 & 0.4 & 0.3 & 0.3 & 0.4 & 0.4 & 0.3 & 0.4 & 0.3 & 0.3 & 1.7 & 0.4 & 1.0 & 0.7 & 9.7 & 0.7 & 0.7 & 0.6 \\
\hline 0.425 & 0.8 & 0.7 & 0.9 & 0.4 & 0.3 & 0.3 & 0.4 & 0.4 & 0.3 & 0.4 & 0.3 & 0.3 & 1.4 & 0.4 & 1.0 & 0.7 & 6.8 & 0.7 & 0.7 & 0.6 \\
\hline 0.504 & 0.8 & 0.7 & 0.9 & 0.4 & 0.3 & 0.3 & 0.4 & 0.4 & 0.3 & 0.4 & 0.3 & 0.3 & 1.5 & 0.5 & 1.0 & 0.7 & 12.1 & 0.6 & 0.7 & 0.6 \\
\hline 0.599 & 0.8 & 0.7 & 0.9 & 0.4 & 0.3 & 0.3 & 0.4 & 0.4 & 0.3 & 0.4 & 0.3 & 0.3 & 1.5 & 0.4 & 1.0 & 0.6 & 211.3 & 0.6 & 0.7 & 0.5 \\
\hline 0.710 & 0.8 & 0.7 & 0.9 & 0.4 & 0.3 & 0.3 & 0.4 & 0.4 & 0.3 & \begin{tabular}{l|}
0.4 \\
\end{tabular} & 0.3 & 0.3 & 1.4 & 0.4 & 1.0 & 0.6 & 265.9 & 0.6 & 0.7 & 0.5 \\
\hline 0.843 & 0.9 & 0.7 & 0.9 & 0.4 & 0.3 & 0.2 & 0.4 & 0.4 & 0.3 & 0.4 & 0.3 & 0.3 & 1.6 & 0.4 & 1.0 & 0.9 & 207.6 & 0.6 & 0.7 & 0.5 \\
\hline 1.000 & 0.8 & 0.7 & 0.9 & 0.4 & 0.3 & 0.2 & 0.3 & 0.4 & 0.3 & 0.3 & 0.3 & 0.3 & 1.5 & 0.4 & 1.0 & 0.6 & 229.1 & 0.6 & 0.7 & 0.5 \\
\hline
\end{tabular}

* Critical earthquake records 
Table B-7: Maximum Inter-story Drift in LA6-A under ground motions corresponding to $\mathbf{1 0 \%}$ in $\mathbf{5 0}$

\begin{tabular}{|c|c|c|c|c|c|c|c|c|c|c|c|c|c|c|c|c|c|c|c|c|}
\hline \multirow{3}{*}{$\alpha$} & \multicolumn{20}{|c|}{ Maximum inter-story drift for $10 \%$ in 50 year ground motions $(\%)$} \\
\hline & \multicolumn{20}{|c|}{ Ground Motion } \\
\hline & LA21 & LA22 & LA23 & LA24 & LA25 & LA26 & LA27 & LA28 & $\begin{array}{c}\text { LA29 } \\
*\end{array}$ & LA30 & LA31 & LA32 & LA33 & $\begin{array}{c}\text { LA34 } \\
*\end{array}$ & LA35 & $\begin{array}{c}\text { LA36 } \\
*\end{array}$ & LA37 & LA38 & LA39 & $\begin{array}{c}\text { LA40 } \\
*\end{array}$ \\
\hline 0.007 & 0.84 & 1.05 & 0.51 & 0.41 & 0.41 & 0.32 & 0.83 & 0.54 & 1.94 & 0.54 & 1.01 & 1.16 & 1.43 & 1.77 & 1.38 & 3.78 & 0.84 & 1.11 & 1.17 & 1.55 \\
\hline 0.010 & 0.82 & 1.08 & 0.51 & 0.41 & 0.41 & 0.32 & 0.85 & 0.53 & 1.99 & 0.54 & 0.99 & 1.05 & 1.24 & 1.86 & 1.42 & 3.98 & 0.80 & 1.02 & 1.07 & 1.56 \\
\hline 0.015 & 0.83 & 1.09 & 0.51 & 0.41 & 0.41 & 0.32 & 0.86 & 0.51 & 2.00 & 0.55 & 0.98 & 0.95 & 1.16 & 1.88 & 1.45 & 3.77 & 0.76 & 0.92 & 0.97 & 1.56 \\
\hline 0.022 & 0.85 & 1.09 & 0.51 & 0.41 & 0.41 & 0.31 & 0.86 & 0.50 & 1.98 & 0.55 & 0.96 & 0.87 & 1.15 & 1.86 & 1.44 & 3.30 & 0.71 & 0.88 & 0.90 & 1.55 \\
\hline 0.034 & 0.86 & 1.07 & 0.51 & 0.40 & 0.42 & 0.31 & 0.85 & 0.49 & 1.93 & 0.55 & 0.94 & 0.87 & 1.19 & 1.82 & 1.42 & 3.27 & 0.67 & 0.85 & 0.88 & 1.50 \\
\hline 0.051 & 0.86 & 1.03 & 0.51 & 0.40 & 0.42 & 0.31 & 0.83 & 0.48 & 1.85 & 0.54 & 0.92 & 0.87 & 1.22 & 1.77 & 1.39 & 2.96 & 0.63 & 0.83 & 0.89 & 1.43 \\
\hline 0.076 & 0.85 & 0.98 & 0.50 & 0.40 & 0.42 & 0.30 & 0.81 & 0.47 & 1.74 & 0.52 & 0.89 & 0.88 & 1.22 & 1.74 & 1.31 & 2.66 & 0.62 & 0.81 & 0.91 & 1.36 \\
\hline 0.115 & 0.83 & 0.93 & 0.49 & 0.40 & 0.42 & 0.29 & 0.78 & 0.46 & 1.63 & 0.50 & 0.88 & 0.88 & 1.23 & 1.69 & 1.26 & 2.19 & 0.64 & 0.79 & 0.91 & 1.28 \\
\hline 0.173 & 0.80 & 0.87 & 0.49 & 0.40 & 0.41 & 0.28 & 0.75 & 0.45 & 1.51 & 0.48 & 0.85 & 0.87 & 1.26 & 1.59 & 1.21 & 2.04 & 0.66 & 0.78 & 0.90 & 1.20 \\
\hline 0.260 & 0.76 & 0.83 & 0.48 & 0.40 & 0.41 & 0.28 & 0.72 & 0.44 & 1.39 & 0.47 & 0.80 & 0.82 & 1.28 & 1.47 & 1.17 & 1.87 & 0.67 & 0.76 & 0.86 & 1.11 \\
\hline 0.391 & 0.72 & 0.76 & 0.46 & 0.38 & 0.40 & 0.27 & 0.69 & 0.44 & 1.27 & 0.46 & 0.76 & 0.77 & 1.24 & 1.34 & 1.13 & 1.68 & 0.67 & 0.81 & 0.79 & 1.03 \\
\hline 0.588 & 0.69 & 0.76 & 0.44 & 0.37 & 0.40 & 0.27 & 0.65 & 0.43 & 1.17 & 0.46 & 0.79 & 0.71 & 1.18 & 1.27 & 1.04 & 1.65 & 0.66 & 0.88 & 0.69 & 0.95 \\
\hline 0.884 & 0.67 & 0.77 & 0.45 & 0.36 & 0.40 & 0.26 & 0.62 & 0.43 & 1.08 & 0.45 & 0.72 & 0.58 & 1.10 & 1.23 & 0.95 & 1.62 & 0.65 & 0.89 & 0.59 & 0.88 \\
\hline 2.000 & 0.62 & 0.72 & 0.43 & 0.34 & 0.40 & 0.25 & 0.55 & 0.45 & 1.08 & 0.40 & 0.57 & 0.50 & 1.02 & 1.17 & 0.88 & 1.48 & 0.62 & 0.95 & 0.53 & 0.84 \\
\hline
\end{tabular}

* Critical earthquake records 
Table B-8: Maximum Inter-story Drift in LA6-A under ground motions corresponding to $2 \%$ in 50 years

\begin{tabular}{|c|c|c|c|c|c|c|c|c|c|c|c|c|c|c|c|c|c|c|c|c|}
\hline \multirow[b]{3}{*}{$\alpha$} & \multicolumn{20}{|c|}{ Maximum inter-story drift for $2 \%$ in 50 year ground motions $(\%)$} \\
\hline & \multicolumn{20}{|c|}{ Ground Motion } \\
\hline & $\begin{array}{c}\text { LA01 } \\
*\end{array}$ & $\begin{array}{c}\text { LA02 } \\
*\end{array}$ & LA03 & $\begin{array}{c}\text { LA04 } \\
*\end{array}$ & $\begin{array}{l}\text { LA05 } \\
*\end{array}$ & $\begin{array}{c}\text { LA06 } \\
*\end{array}$ & $\begin{array}{c}\mathrm{LA} 07 \\
*\end{array}$ & $\begin{array}{c}\text { LA08 } \\
\quad *\end{array}$ & LA09 & $\begin{array}{c}\text { LA10 } \\
*\end{array}$ & $\begin{array}{c}\text { LA11 } \\
*\end{array}$ & $\underset{*}{\mathrm{LA} 12}$ & $\begin{array}{c}\text { LA13 } \\
*\end{array}$ & $\begin{array}{c}\text { LA14 } \\
*\end{array}$ & $\begin{array}{c}\text { LA15 } \\
*\end{array}$ & $\underset{*}{\mathrm{LA} 16}$ & $\underset{*}{\mathrm{LA} 17}$ & $\underset{*}{\mathrm{LA} 18}$ & LA19 & LA20 \\
\hline 0.007 & 8.27 & 13.7 & 1.46 & 9.71 & 6.90 & 136.9 & 18.67 & 197.9 & 1.01 & 2.36 & 11.94 & 9.48 & 3.99 & 2.83 & 124.3 & 130.38 & 194.3 & 205.12 & 0.88 & 0.77 \\
\hline 0.010 & 6.81 & 6.93 & 1.48 & 4.96 & 5.44 & 10.90 & 7.08 & 8.09 & 1.01 & 2.25 & 5.25 & 7.50 & 3.97 & 2.73 & 14.6 & 233.40 & 14.61 & 10.64 & 0.83 & 0.75 \\
\hline 0.015 & 7.95 & 5.27 & 1.47 & 3.11 & 4.99 & 7.47 & 5.89 & 5.25 & 1.00 & 2.12 & 6.22 & 6.89 & 3.79 & 2.55 & 11.1 & 17.37 & 9.87 & 8.58 & 0.78 & 0.72 \\
\hline 0.022 & 6.15 & 4.32 & 1.45 & 2.83 & 4.53 & 7.67 & 5.05 & 5.25 & 0.99 & 2.11 & 5.31 & 6.10 & 3.48 & 2.38 & 8.92 & 8.55 & 8.28 & 6.98 & 0.73 & 0.70 \\
\hline 0.034 & 5.78 & 3.80 & 1.41 & 2.55 & 4.16 & 6.54 & 4.45 & 4.70 & 0.96 & 1.96 & 4.60 & 5.46 & 3.21 & 2.20 & 7.43 & 11.26 & 6.50 & 5.81 & 0.68 & 0.68 \\
\hline 0.051 & 5.63 & 3.29 & 1.36 & 1.62 & 3.86 & 5.48 & 3.93 & 2.53 & 0.93 & 1.70 & 3.94 & 5.07 & 2.90 & 1.95 & 6.31 & 9.03 & 5.67 & 5.17 & 0.64 & 0.65 \\
\hline 0.076 & 5.02 & 2.95 & 1.31 & 1.52 & 3.54 & 4.84 & 3.53 & 2.32 & 0.92 & 1.58 & 3.55 & 4.75 & 2.40 & 1.79 & 5.17 & 7.43 & 4.79 & 4.42 & 0.62 & 0.63 \\
\hline 0.115 & 4.34 & 2.72 & 1.24 & 1.50 & 3.02 & 4.62 & 3.25 & 2.15 & 0.93 & 1.49 & 3.09 & 4.36 & 2.20 & 1.63 & 4.42 & 5.50 & 4.15 & 3.57 & 0.64 & 0.60 \\
\hline 0.173 & 2.84 & 2.45 & 1.16 & 1.46 & 2.73 & 3.81 & 2.94 & 1.99 & 0.93 & 1.40 & 2.79 & 4.03 & 2.00 & 1.61 & 3.79 & 4.44 & 3.58 & 2.61 & 0.64 & 0.57 \\
\hline 0.260 & 3.04 & 2.07 & 1.08 & 1.37 & 2.48 & 3.42 & 2.64 & 1.80 & 0.93 & 1.29 & 2.46 & 3.69 & 1.83 & 1.58 & 3.08 & 4.23 & 3.05 & 2.24 & 0.64 & 0.54 \\
\hline 0.391 & 3.10 & 1.86 & 1.01 & 1.27 & 2.39 & 3.31 & 2.34 & 1.63 & 0.91 & 1.19 & 2.21 & 3.31 & 1.68 & 1.51 & 2.64 & 3.93 & 3.09 & 2.11 & 0.64 & 0.51 \\
\hline 0.588 & 2.86 & 2.03 & 0.98 & 1.15 & 2.37 & 3.20 & 2.10 & 1.62 & 0.87 & 1.07 & 2.38 & 3.56 & 1.45 & 1.42 & 2.43 & 3.60 & 2.52 & 2.12 & 0.66 & 0.49 \\
\hline 0.884 & 3.16 & 1.80 & 0.94 & 1.12 & 2.22 & 3.12 & 2.08 & 1.55 & 0.81 & 1.11 & 2.43 & 4.01 & 1.39 & 1.46 & 2.15 & 3.43 & 2.60 & 2.05 & 0.64 & 0.47 \\
\hline 1.330 & 3.76 & 1.81 & 0.90 & 1.07 & 2.23 & 3.07 & 2.06 & 1.40 & 0.77 & 1.14 & 2.29 & 3.78 & 1.40 & 1.38 & 1.99 & 3.40 & 2.42 & 2.02 & 0.61 & 0.46 \\
\hline 2.000 & 3.43 & 1.87 & 0.91 & 1.06 & 2.27 & 3.18 & 2.10 & 1.30 & 0.81 & 1.09 & 1.98 & 3.74 & 1.42 & 1.34 & 2.00 & 3.22 & 2.49 & 2.01 & 0.60 & 0.44 \\
\hline
\end{tabular}

* Critical earthquake records 
Table B-9: Maximum Inter-story Drift in LA6-A under ground motions corresponding to near-fault earthquakes

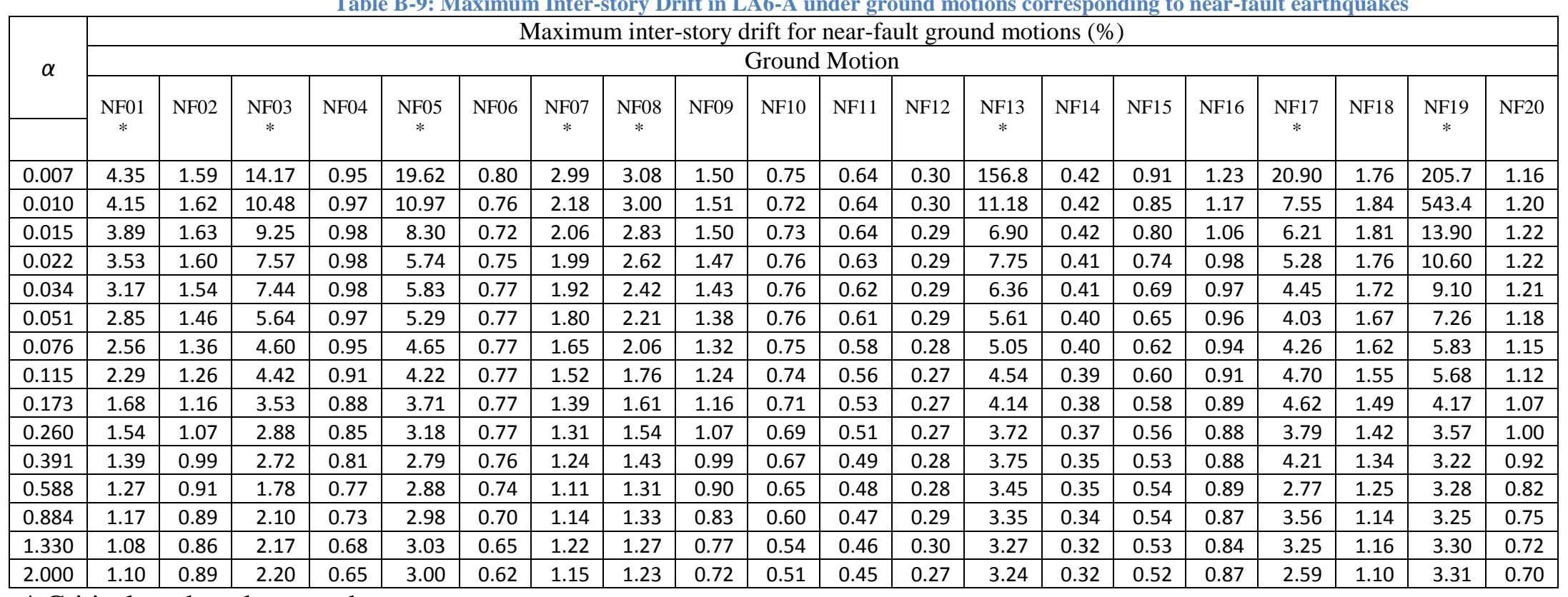

* Critical earthquake records 
Table B-10: Maximum Inter-story Drift in LA6-B under ground motions corresponding to $10 \%$ in 50

\begin{tabular}{|c|c|c|c|c|c|c|c|c|c|c|c|c|c|c|c|c|c|c|c|c|}
\hline \multirow{3}{*}{$\alpha$} & \multicolumn{20}{|c|}{ Maximum inter-story drift for $10 \%$ in 50 year ground motions $(\%)$} \\
\hline & \multicolumn{20}{|c|}{ Ground Motion } \\
\hline & LA21 & LA22 & LA23 & LA24 & LA25 & LA26 & LA27 & LA28 & $\begin{array}{c}\mathrm{LA} 29 \\
*\end{array}$ & LA30 & LA31 & LA32 & LA33 & $\begin{array}{c}\mathrm{LA} 34 \\
*\end{array}$ & LA35 & $\begin{array}{c}\mathrm{LA36} \\
*\end{array}$ & LA37 & LA38 & LA39 & $\begin{array}{c}\mathrm{LA} 40 \\
*\end{array}$ \\
\hline 0.007 & 0.84 & 1.06 & 0.51 & 0.40 & 0.41 & 0.32 & 0.83 & 0.52 & 1.98 & 0.52 & 1.01 & 1.15 & 1.41 & 1.81 & 1.38 & 4.18 & 0.84 & 1.10 & 1.17 & 1.55 \\
\hline 0.010 & 1.23 & 1.01 & 0.66 & 0.28 & 0.61 & 0.24 & 0.73 & 0.42 & 2.31 & 0.31 & 0.90 & 0.80 & 2.05 & 2.86 & 1.63 & 3.47 & 1.27 & 0.98 & 0.72 & 1.98 \\
\hline 0.015 & 1.42 & 1.07 & 0.74 & 0.29 & 0.58 & 0.23 & 0.74 & 0.31 & 2.10 & 0.39 & 0.87 & 0.71 & 2.02 & 2.68 & 1.54 & 3.06 & 1.44 & 1.08 & 0.69 & 2.13 \\
\hline 0.022 & 1.42 & 1.07 & 0.72 & 0.32 & 0.55 & 0.23 & 0.72 & 0.28 & 1.91 & 0.42 & 0.87 & 0.70 & 2.01 & 2.51 & 1.46 & 2.74 & 1.47 & 1.11 & 0.68 & 2.07 \\
\hline 0.034 & 1.40 & 1.07 & 0.68 & 0.33 & 0.53 & 0.23 & 0.70 & 0.27 & 1.74 & 0.43 & 0.84 & 0.69 & 1.88 & 2.34 & 1.39 & 2.48 & 1.44 & 1.11 & 0.66 & 1.92 \\
\hline 0.051 & 1.34 & 1.05 & 0.65 & 0.34 & 0.50 & 0.23 & 0.68 & 0.27 & 1.56 & 0.43 & 0.81 & 0.67 & 1.81 & 2.15 & 1.33 & 1.90 & 1.37 & 1.36 & 0.63 & 1.56 \\
\hline 0.076 & 1.27 & 1.02 & 0.62 & 0.34 & 0.48 & 0.23 & 0.66 & 0.27 & 1.40 & 0.43 & 0.77 & 0.65 & 1.73 & 1.98 & 1.26 & 1.76 & 1.28 & 1.10 & 0.61 & 1.47 \\
\hline 0.115 & 1.20 & 1.02 & 0.59 & 0.34 & 0.47 & 0.23 & 0.64 & 0.27 & 1.27 & 0.42 & 0.74 & 0.62 & 1.65 & 1.82 & 1.18 & 1.62 & 1.19 & 1.22 & 0.58 & 1.39 \\
\hline 0.173 & 1.14 & 1.01 & 0.57 & 0.33 & 0.45 & 0.23 & 0.62 & 0.27 & 1.17 & 0.42 & 0.72 & 0.59 & 1.55 & 1.67 & 1.11 & 1.47 & 1.09 & 1.12 & 0.55 & 1.29 \\
\hline 0.260 & 1.07 & 1.01 & 0.54 & 0.32 & 0.43 & 0.23 & 0.60 & 0.27 & 1.08 & 0.41 & 0.69 & 0.55 & 1.45 & 1.51 & 1.02 & 1.33 & 0.99 & .06 & .52 & 1.20 \\
\hline 0.391 & 1.00 & 0.99 & 0.53 & 0.31 & 0.41 & 0.23 & 0.58 & 0.27 & 0.98 & 0.41 & 0.67 & 0.54 & 1.34 & 1.34 & 0.94 & 1.20 & 0.89 & 1.03 & 0.50 & 1.10 \\
\hline 0.588 & 0.93 & 0.94 & 0.52 & 0.31 & 0.40 & 0.23 & 0.55 & 0.27 & 0.89 & 0.39 & 0.64 & 0.55 & 1.21 & 1.18 & 0.86 & 1.08 & 0.79 & 0.98 & 0.48 & 1.01 \\
\hline 0.884 & 0.85 & 0.88 & 0.49 & 0.32 & 0.38 & 0.23 & 0.51 & 0.27 & 0.81 & 0.38 & 0.60 & 0.51 & 1.09 & 1.03 & 0.78 & 0.96 & 0.70 & 0.92 & 0.46 & 0.90 \\
\hline 2.000 & 0.75 & 0.79 & 0.43 & 0.31 & 0.35 & 0.23 & 0.44 & 0.27 & 0.70 & 0.36 & 0.51 & 0.52 & 0.95 & 0.92 & 0.64 & 0.90 & 0.61 & 0.89 & 0.47 & 0.83 \\
\hline
\end{tabular}

* Critical earthquake records 
Table B-11: Maximum Inter-story Drift in LA6-B under ground motions corresponding to 2\% in 50

\begin{tabular}{|c|c|c|c|c|c|c|c|c|c|c|c|c|c|c|c|c|c|c|c|c|}
\hline \multirow{3}{*}{$\alpha$} & \multicolumn{20}{|c|}{ Maximum inter-story drift for $2 \%$ in 50 year ground motions $(\%)$} \\
\hline & \multicolumn{20}{|c|}{ Ground Motion } \\
\hline & $\underset{*}{\mathrm{LA} 01}$ & $\underset{*}{\mathrm{LA} 02}$ & LA03 & $\begin{array}{c}\text { LA04 } \\
* *\end{array}$ & $\begin{array}{c}\text { LA05 } \\
*\end{array}$ & $\begin{array}{c}\text { LA06 } \\
*\end{array}$ & $\begin{array}{l}\text { LA07 } \\
*\end{array}$ & $\begin{array}{c}\text { LA08 } \\
*\end{array}$ & LA09 & $\begin{array}{c}\text { LA10 } \\
*\end{array}$ & $\underset{*}{\mathrm{LA} 11}$ & $\underset{*}{\mathrm{LA} 12}$ & $\underset{*}{\mathrm{LA} 13}$ & $\begin{array}{c}\text { LA14 } \\
*\end{array}$ & $\underset{*}{\mathrm{LA} 15}$ & $\underset{*}{\mathrm{LA} 16}$ & $\underset{*}{\mathrm{LA} 17}$ & $\underset{*}{\mathrm{LA} 18}$ & LA19 & LA20 \\
\hline 0.007 & 14.81 & 17.00 & 1.45 & 9.62 & 6.42 & 228 & 15 & 181.2 & 1.00 & 2.39 & 11.62 & 9.62 & 3.97 & 2.93 & 477.8 & 205.0 & 876.1 & 558.9 & 0.86 & 0.76 \\
\hline 0.010 & 7.69 & 6.78 & 1.87 & 7.00 & 6.10 & 10.37 & 7.38 & 6.90 & 2.06 & 4.93 & 5.29 & 4.45 & 1.89 & 3.11 & 10.84 & 10.27 & 14.45 & 10.09 & 0.62 & 0.65 \\
\hline 0.015 & 6.35 & 4.45 & 1.61 & 3.79 & 5.48 & 8.71 & 6.33 & 2.67 & 2.07 & 4.38 & 4.77 & 5.92 & 1.71 & 2.94 & 9.75 & 14.18 & 11.76 & 7.04 & 0.68 & 0.61 \\
\hline 0.022 & 7.37 & 3.94 & 1.46 & 3.47 & 4.81 & 7.53 & 5.91 & 2.52 & 1.53 & 3.34 & 4.51 & 5.58 & 1.58 & 2.56 & 7.02 & 10.93 & 7.61 & 5.63 & 0.68 & 0.57 \\
\hline 0.034 & 7.44 & 4.21 & 1.35 & 3.12 & 4.34 & 6.29 & 6.00 & 2.40 & 1.43 & 2.90 & 4.35 & 6.36 & 1.46 & 2.32 & 5.58 & 8.60 & 5.67 & 4.58 & 0.66 & 0.54 \\
\hline 0.051 & 6.63 & 4.46 & 1.30 & 2.83 & 3.19 & 5.48 & 5.01 & 2.30 & 1.26 & 2.55 & 3.99 & 5.89 & 1.35 & 2.15 & 4.73 & 7.01 & 4.57 & 3.83 & 0.64 & 0.51 \\
\hline 0.076 & 5.22 & 3.23 & 1.25 & 2.60 & 2.91 & 4.77 & 3.45 & 1.92 & 1.11 & 2.29 & 3.36 & 5.32 & 1.25 & 2.01 & 4.09 & 5.69 & 2.59 & 3.26 & 0.63 & 0.47 \\
\hline 0.115 & 4.72 & 3.01 & 1.19 & 2.35 & 2.65 & 3.84 & 2.98 & 1.73 & 1.02 & 2.08 & 3.37 & 4.67 & 1.15 & 1.89 & 3.61 & 4.73 & 2.37 & 2.44 & 0.62 & 0.44 \\
\hline 0.173 & 4.74 & 2.74 & 1.13 & 2.05 & 2.37 & 3.64 & 2.51 & 1.58 & 0.95 & 1.81 & 3.04 & 4.28 & 1.04 & 1.75 & 3.22 & 3.78 & 2.13 & 2.11 & 0.61 & 0.41 \\
\hline 0.260 & 4.73 & 2.59 & 1.09 & 1.64 & 2.15 & 3.21 & 1.82 & 1.43 & 0.90 & 1.37 & 2.70 & 3.91 & 0.92 & 1.61 & 2.81 & 3.00 & 1.92 & 1.81 & 0.61 & 0.38 \\
\hline 0.391 & 4.54 & 2.12 & 1.04 & 1.50 & 1.94 & 2.82 & 2.11 & 1.28 & 0.87 & 1.25 & 2.27 & 3.73 & 0.82 & 1.48 & 2.38 & 2.60 & 1.70 & 1.52 & 0.60 & 0.36 \\
\hline 0.588 & 3.80 & 2.10 & 0.97 & 1.35 & 1.73 & 2.65 & 2.06 & 1.16 & 0.84 & 1.10 & 1.93 & 3.39 & 0.74 & 1.35 & 2.25 & 1.86 & 1.52 & 1.34 & 0.59 & 0.35 \\
\hline 0.884 & 3.71 & 2.14 & 0.88 & 1.20 & 1.67 & 2.63 & 1.26 & 1.03 & 0.80 & 1.03 & 1.68 & 3.25 & 0.69 & 1.23 & 2.22 & 1.87 & 1.55 & 1.27 & 0.57 & 0.33 \\
\hline 1.330 & 3.89 & 2.02 & 0.81 & 1.22 & 1.66 & 2.50 & 1.20 & 1.05 & 0.73 & 1.03 & 1.56 & 3.10 & 0.63 & 1.25 & 2.03 & 1.68 & 1.53 & 1.21 & 0.54 & 0.32 \\
\hline 2.000 & 3.86 & 2.13 & 0.76 & 1.18 & 1.64 & 2.51 & 1.16 & 1.05 & 0.66 & 0.99 & 1.54 & 3.03 & 0.60 & 1.22 & 1.94 & 1.69 & 1.45 & 1.10 & 0.51 & 0.32 \\
\hline
\end{tabular}

* Critical earthquake records 
Table B-12: Maximum Inter-story Drift in LA6-B under ground motions corresponding to near-fault earthquakes

\begin{tabular}{|c|c|c|c|c|c|c|c|c|c|c|c|c|c|c|c|c|c|c|c|c|}
\hline \multirow{3}{*}{$\alpha$} & \multicolumn{20}{|c|}{ Maximum inter-story drift for near-fault ground motions (\%) } \\
\hline & \multicolumn{20}{|c|}{ Ground Motion } \\
\hline & $\begin{array}{l}\text { NF01 } \\
*\end{array}$ & NF02 & $\begin{array}{c}\text { NF03 } \\
*\end{array}$ & NF04 & $\begin{array}{c}\text { NF05 } \\
*\end{array}$ & NF06 & $\begin{array}{c}\mathrm{NF} 07 \\
*\end{array}$ & $\begin{array}{c}\mathrm{NF} 08 \\
*\end{array}$ & NF09 & NF10 & NF11 & NF12 & $\begin{array}{c}\mathrm{NF} 13 \\
*\end{array}$ & NF14 & NF15 & NF16 & $\begin{array}{c}\mathrm{NF} 17 \\
*\end{array}$ & NF18 & $\begin{array}{c}\mathrm{NF} 19 \\
*\end{array}$ & NF20 \\
\hline 0.007 & 4.37 & 1.59 & 14.65 & 0.97 & 21.89 & 0.79 & 3.00 & 3.07 & 1.50 & 0.74 & 0.63 & 0.29 & 514.0 & 0.42 & 0.89 & 1.23 & 20.39 & 1.77 & 323.9 & 1.17 \\
\hline 0.010 & 4.62 & 1.48 & 9.97 & 1.36 & 6.78 & 0.78 & 4.19 & 2.48 & 1.19 & 0.76 & 0.38 & 0.30 & 7.99 & 0.36 & 0.60 & 1.20 & 7.76 & 1.94 & 465.7 & 1.24 \\
\hline 0.015 & 3.88 & 1.50 & 10.76 & 1.43 & 8.36 & 0.61 & 3.71 & 2.54 & 1.02 & 0.74 & 0.28 & 0.27 & 8.73 & 0.35 & 0.74 & 1.22 & 5.92 & 1.85 & 13.63 & 1.28 \\
\hline 0.022 & 3.08 & 1.48 & 6.96 & 1.38 & 7.60 & 0.52 & 3.19 & 2.35 & 0.91 & 0.69 & 0.25 & 0.26 & 7.59 & 0.36 & 0.73 & 1.21 & 6.89 & 1.74 & 10.91 & 1.23 \\
\hline 0.034 & 2.22 & 1.43 & 5.95 & 1.32 & 5.61 & 0.49 & 2.83 & 2.19 & 0.83 & 0.65 & 0.24 & 0.26 & 5.48 & 0.36 & 0.68 & 1.20 & 5.19 & 1.66 & 8.56 & 1.15 \\
\hline 0.051 & 1.52 & 1.36 & 5.29 & 1.26 & 5.46 & 0.47 & 2.55 & 2.07 & 0.77 & 0.60 & 0.25 & 0.25 & 5.17 & 0.35 & 0.63 & 1.16 & 4.89 & 1.59 & 7.37 & 1.09 \\
\hline 0.076 & 1.39 & 1.28 & 3.86 & 1.20 & 4.55 & 0.46 & 2.30 & 1.85 & 0.72 & 0.56 & 0.25 & 0.25 & 4.56 & 0.34 & 0.59 & 1.13 & 4.58 & 1.48 & 6.97 & 1.04 \\
\hline 0.115 & 1.28 & 1.20 & 3.16 & 1.13 & 4.38 & 0.44 & 2.06 & 1.54 & 0.68 & 0.53 & 0.25 & 0.25 & 4.30 & 0.33 & 0.56 & 1.10 & 5.24 & 1.38 & 5.20 & 0.99 \\
\hline 0.173 & 1.18 & 1.12 & 2.62 & 1.08 & 3.83 & 0.43 & 1.88 & 1.44 & 0.64 & 0.52 & 0.25 & 0.24 & 3.87 & 0.34 & 0.52 & 1.07 & 3.82 & 1.28 & 4.20 & 0.94 \\
\hline 0.260 & 1.08 & 1.03 & 2.18 & 1.03 & 3.26 & 0.42 & 1.55 & 1.48 & 0.59 & 0.50 & 0.25 & 0.24 & 3.04 & 0.35 & 0.50 & 1.03 & 89 & .19 & .38 & 0.88 \\
\hline 0.391 & 0.98 & 0.95 & 1.76 & 0.98 & 2.68 & 0.42 & 1.43 & 1.24 & 0.55 & 0.48 & 0.25 & 0.23 & 2.90 & 0.35 & 0.48 & 0.99 & 3.86 & 1.10 & 2.84 & 0.83 \\
\hline 0.588 & 0.84 & 0.91 & 1.61 & 0.92 & 2.36 & 0.42 & 1.29 & 1.13 & 0.51 & 0.46 & 0.25 & 0.22 & 2.79 & 0.35 & 0.46 & 0.93 & 3.66 & 1.00 & 2.48 & 0.78 \\
\hline 0.884 & 0.76 & 0.85 & 1.72 & 0.85 & 2.39 & 0.41 & 1.15 & 1.02 & 0.48 & 0.44 & 0.24 & 0.22 & 2.82 & 0.35 & 0.44 & 0.87 & 3.42 & 0.91 & 2.12 & 0.73 \\
\hline 2.000 & 0.65 & 0.73 & 1.58 & 0.78 & 2.08 & 0.39 & 1.01 & 0.89 & 0.42 & 0.40 & 0.24 & 0.24 & 2.50 & 0.34 & 0.39 & 0.77 & 3.45 & 0.75 & 1.77 & 0.64 \\
\hline
\end{tabular}

* Critical earthquake records 


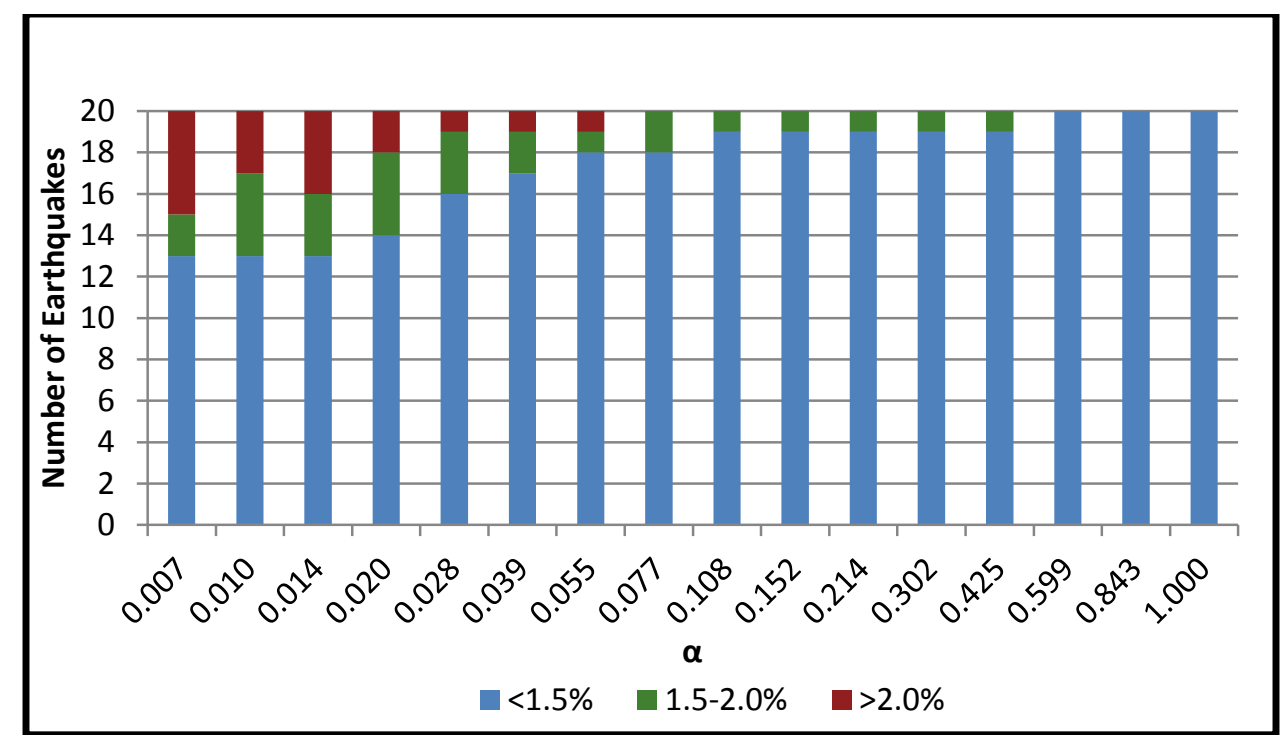

Figure B.1: Number of earthquakes under each performance objective for LA3-A (10\% in 50 years)

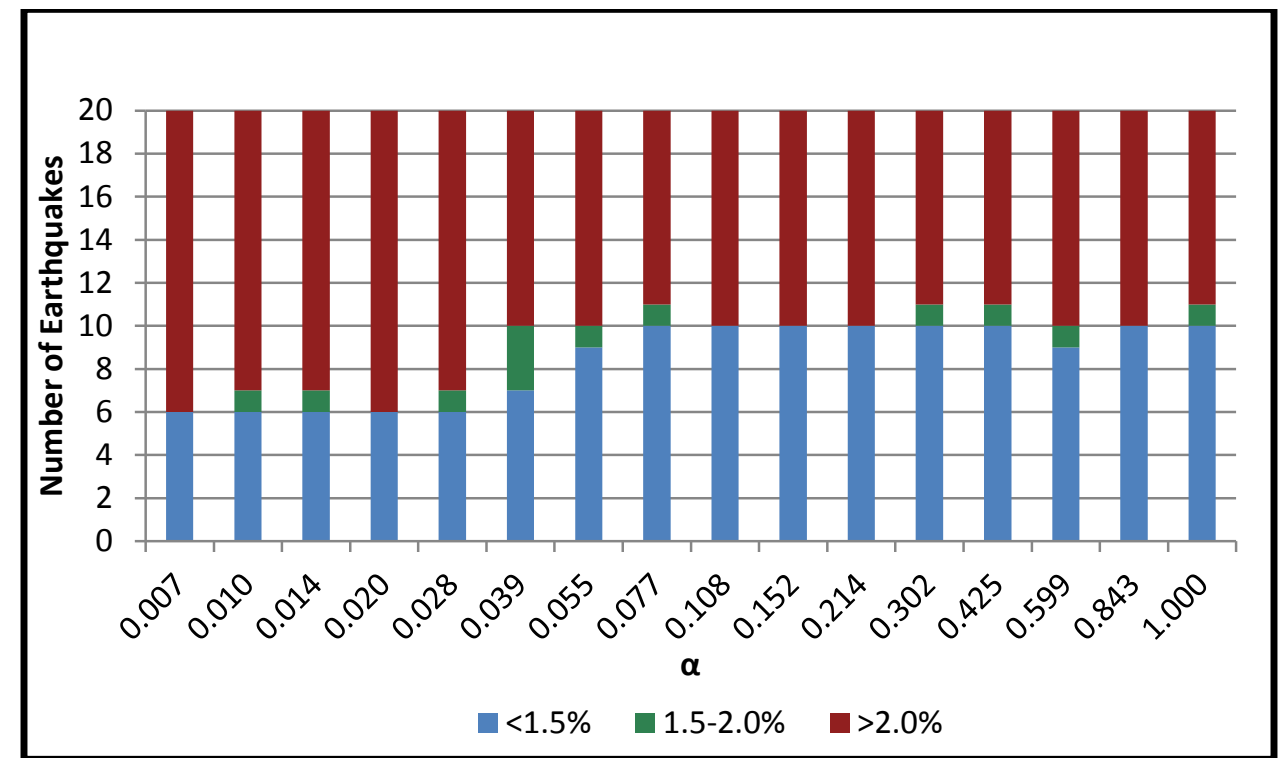

Figure B.2: Number of earthquakes under each performance objective for LA3-A (2\% in 50 years) 


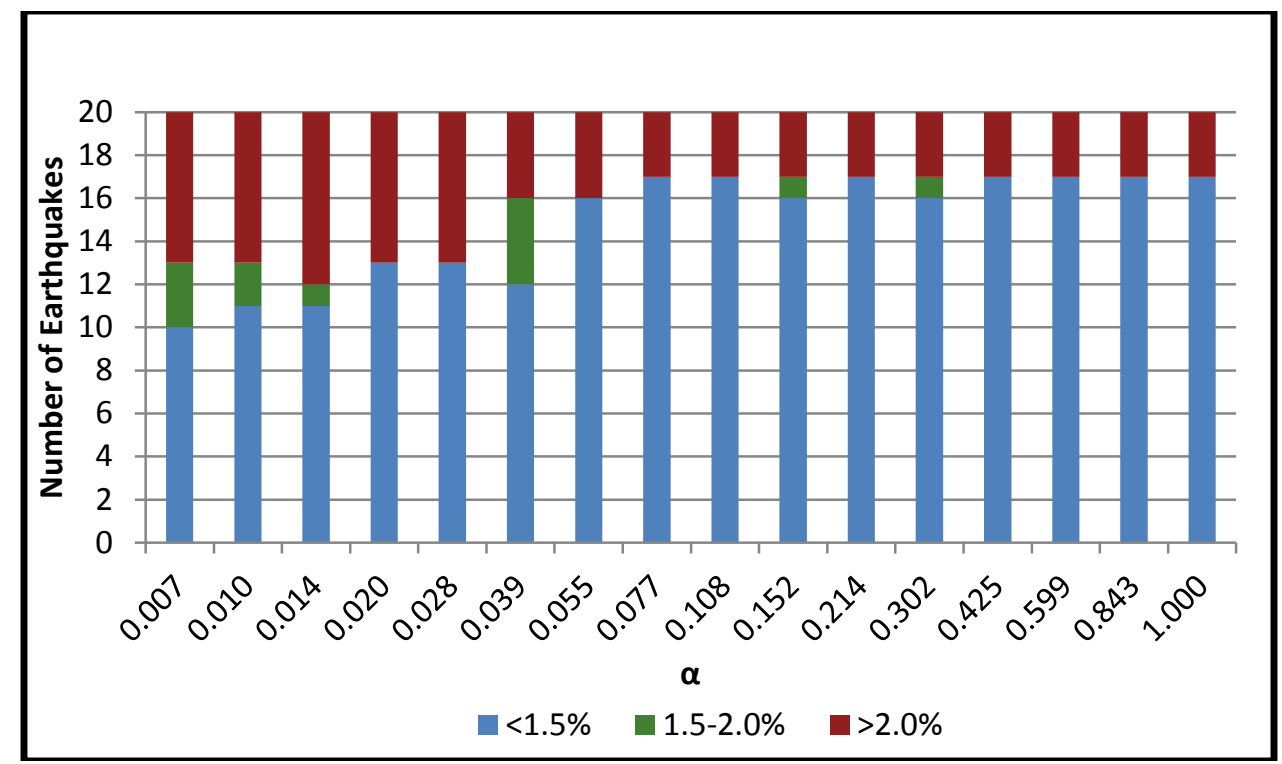

Figure B.3: Number of earthquakes under each performance objective for LA3-A (near-fault)

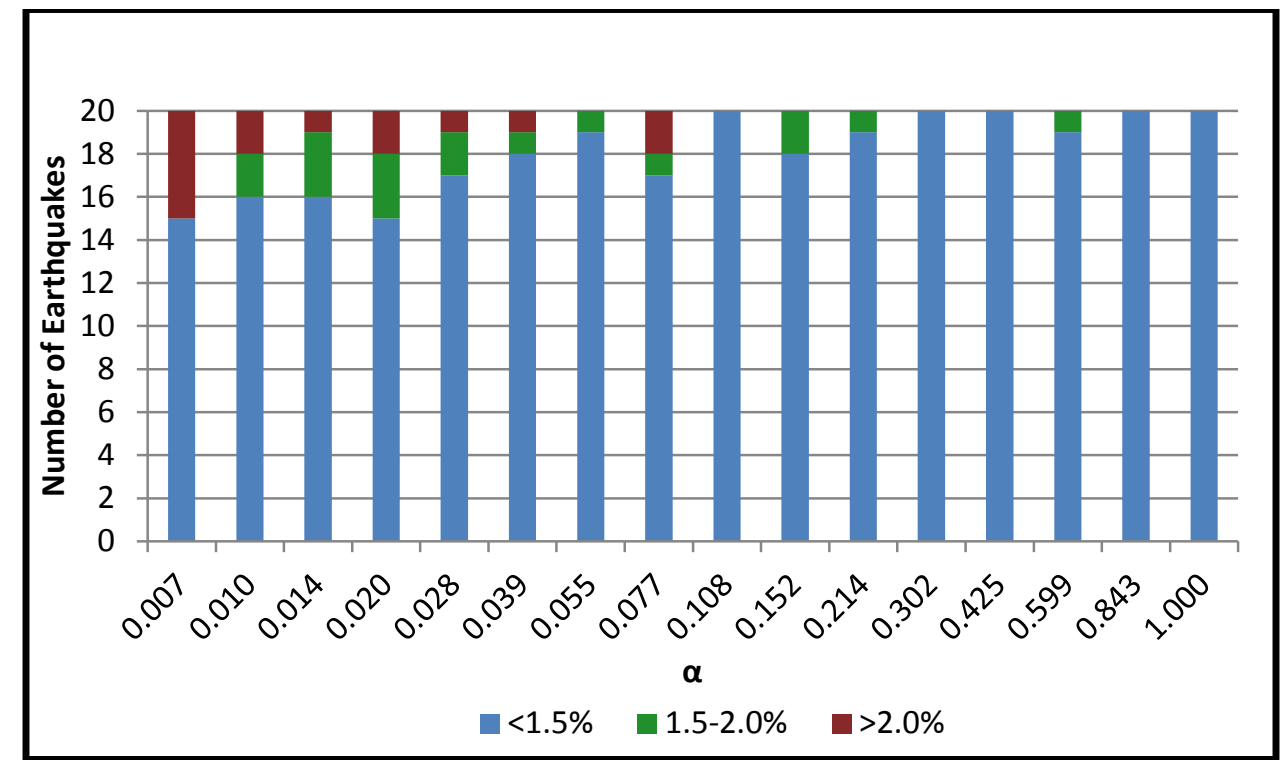

Figure B.4: Number of earthquakes under each performance objective for LA3-B (10\% in 50 years) 


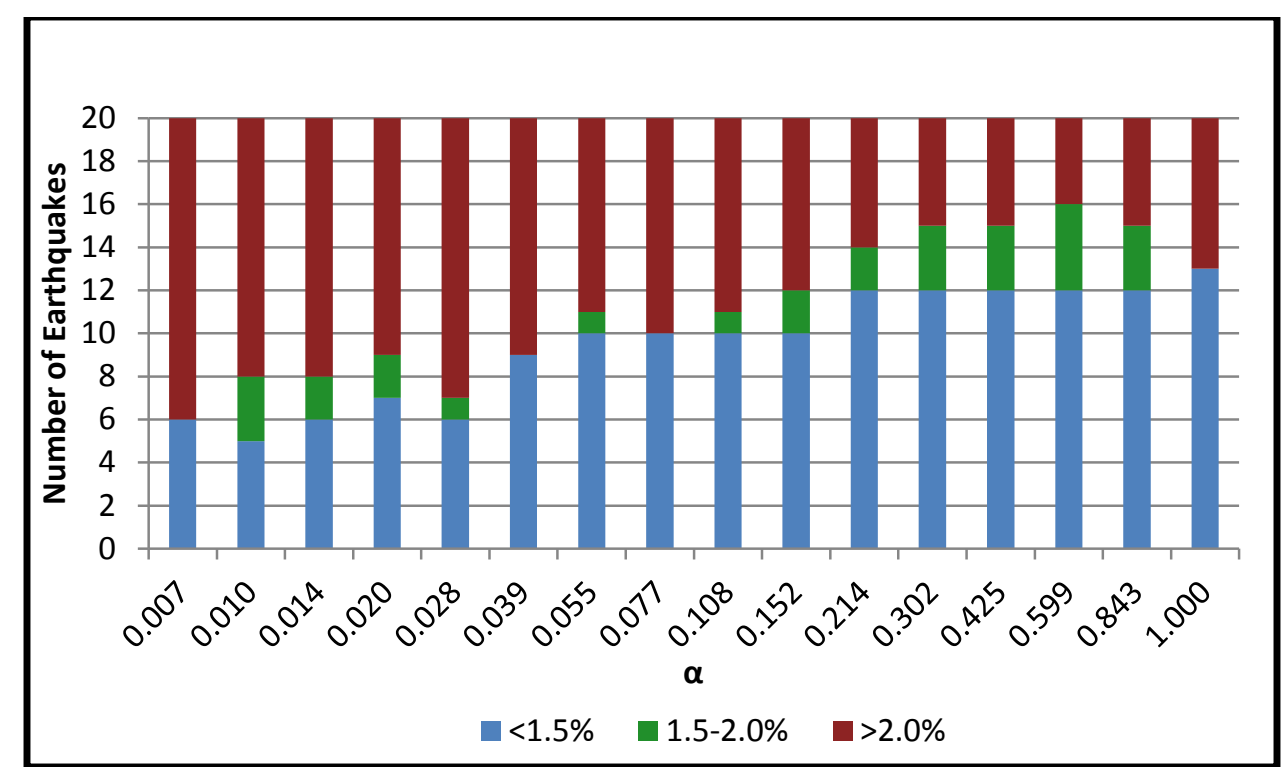

Figure B.5: Number of earthquakes under each performance objective for LA3-B (2\% in 50 years)

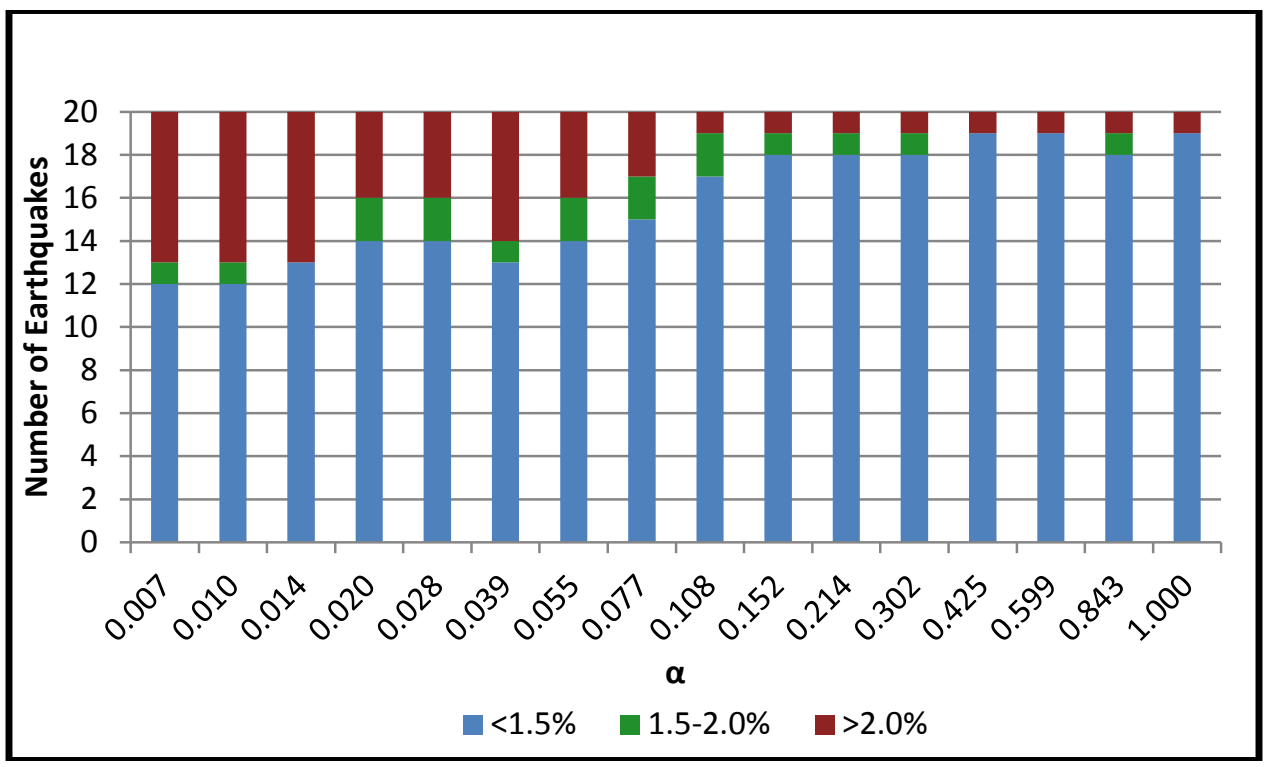

Figure B.6: Number of earthquakes under each performance objective for LA3-B (near-fault) 


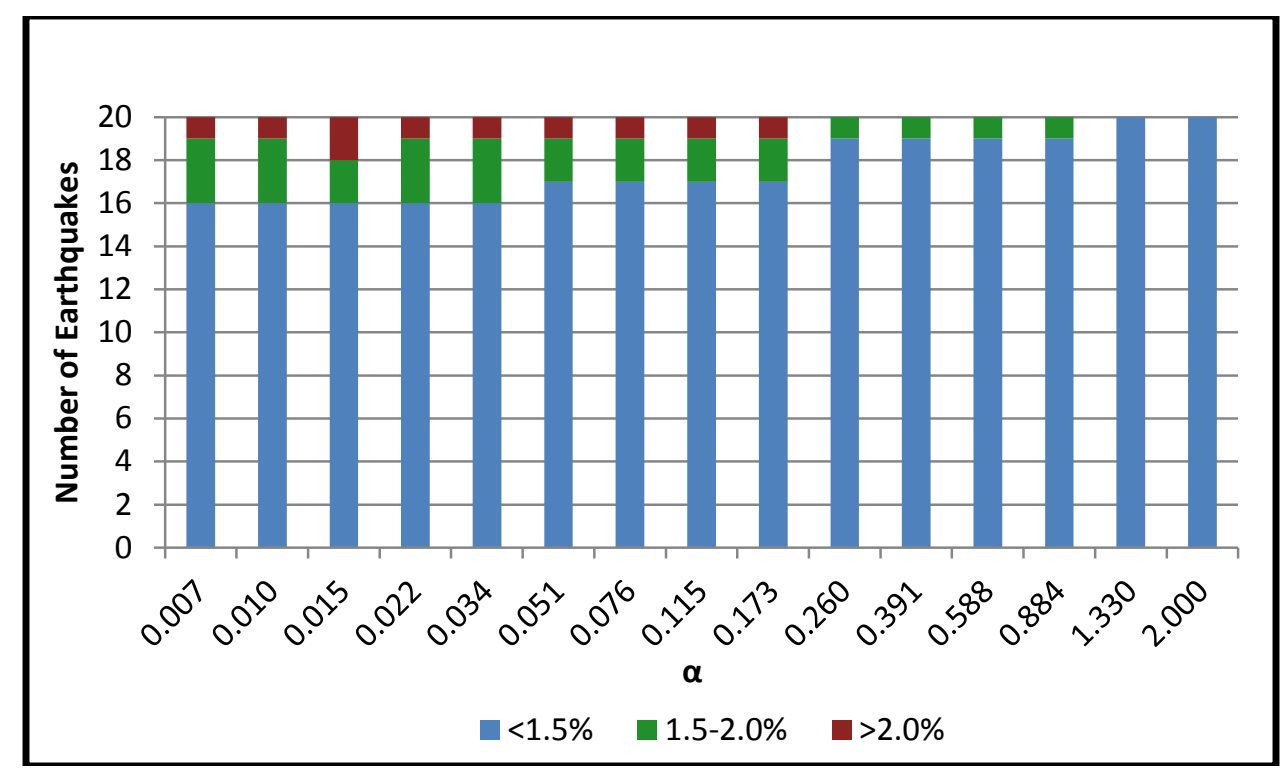

Figure B.7: Number of earthquakes under each performance objective for LA6-A (10\% in 50 years)

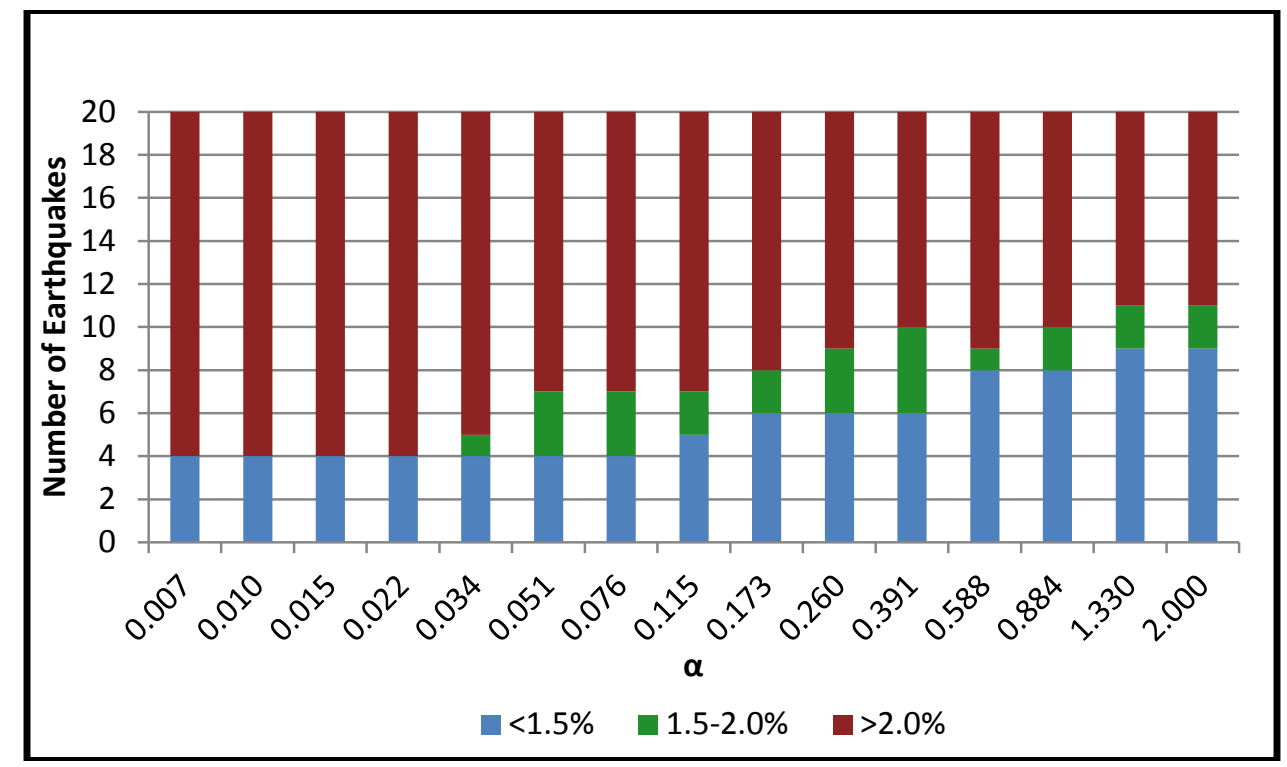

Figure B.8: Number of earthquakes under each performance objective for LA6-A (2\% in 50 years) 


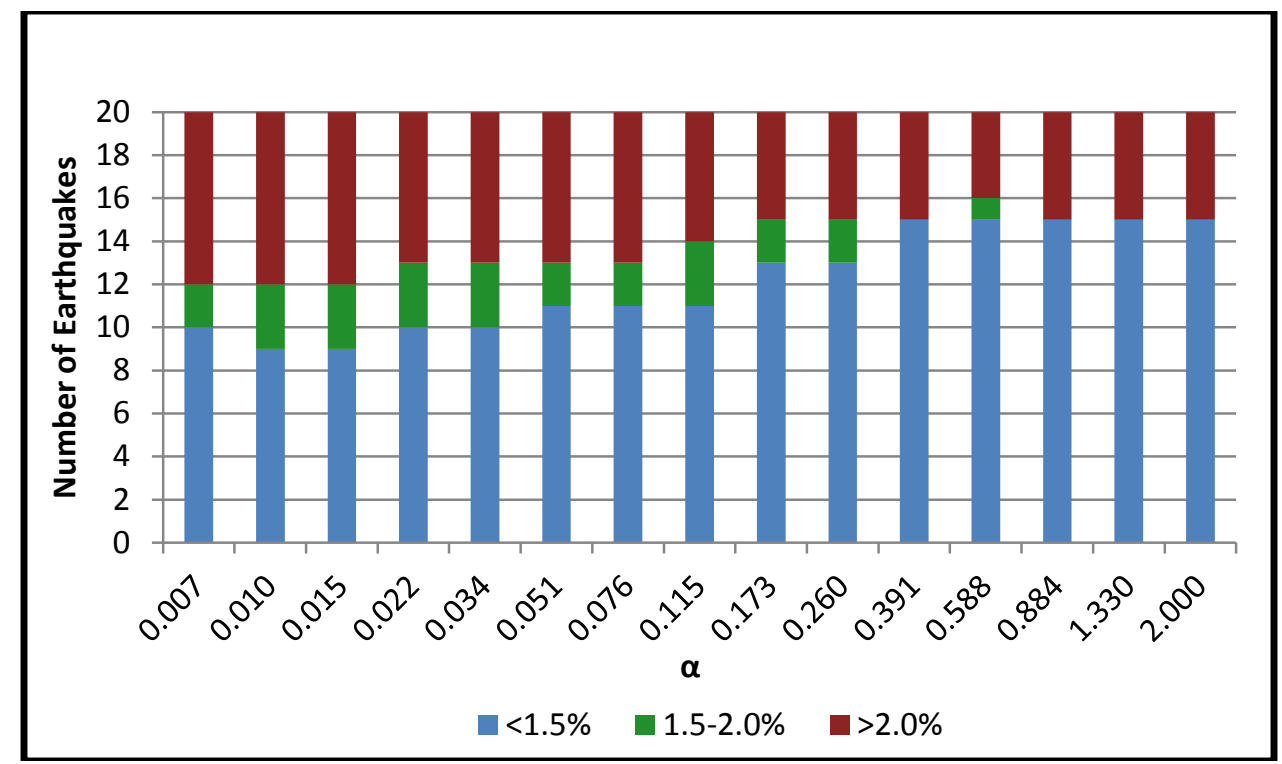

Figure B.9: Number of earthquakes under each performance objective for LA6-A (near-fault)

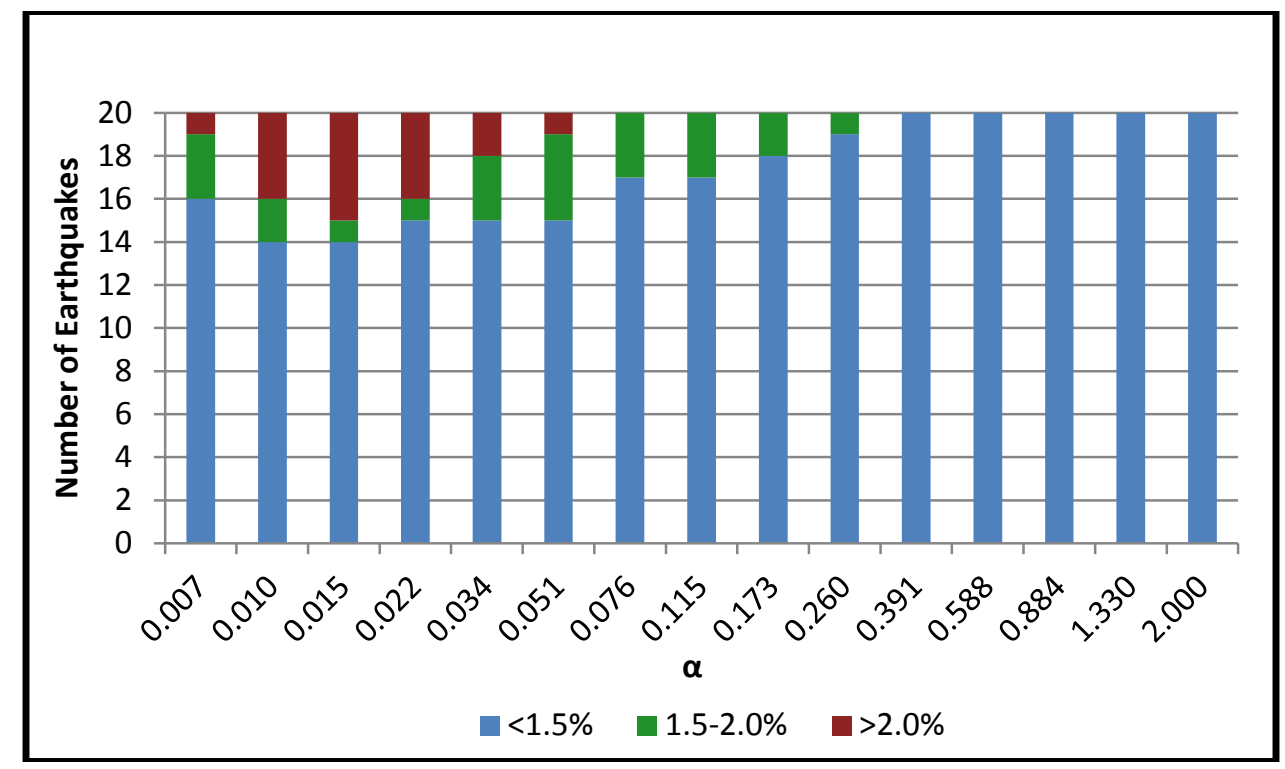

Figure B.10: Number of earthquakes under each performance objective for LA6-B (10\% in 50 years) 


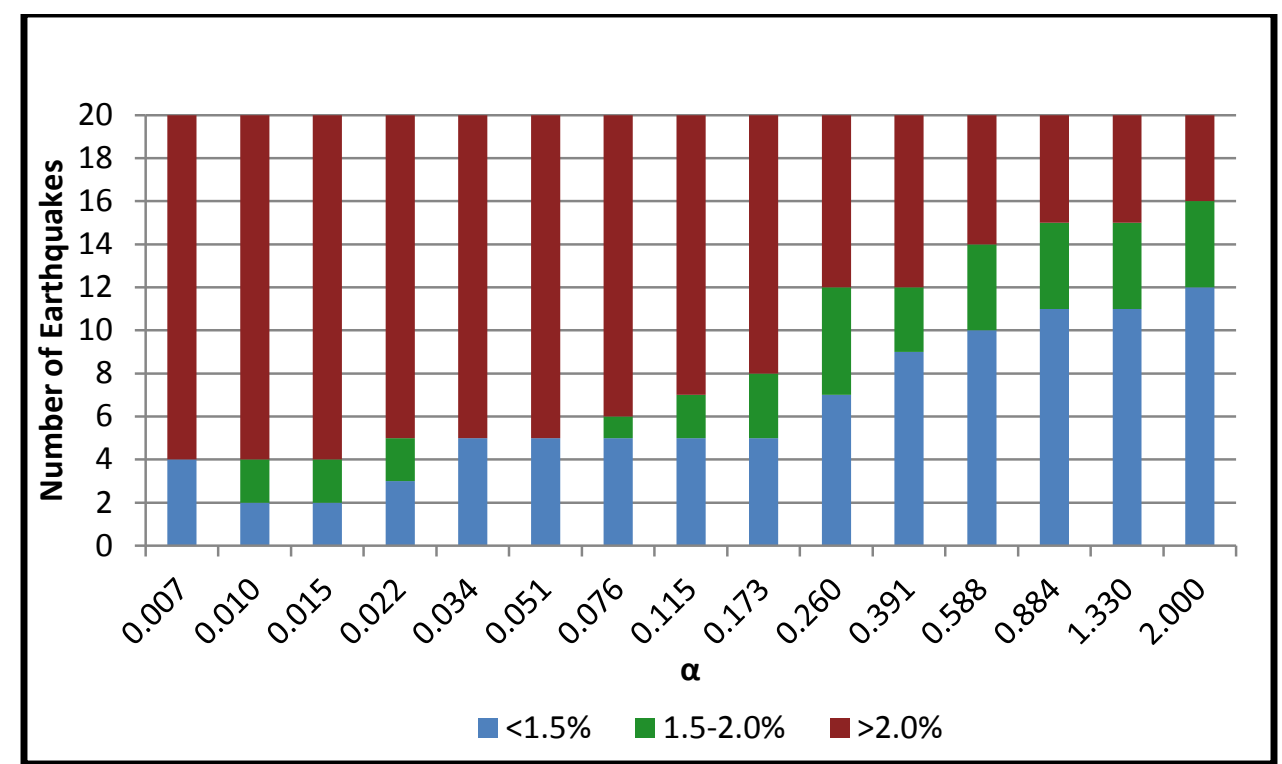

Figure B.11: Number of earthquakes under each performance objective for LA6-B (2\% in 50 years)

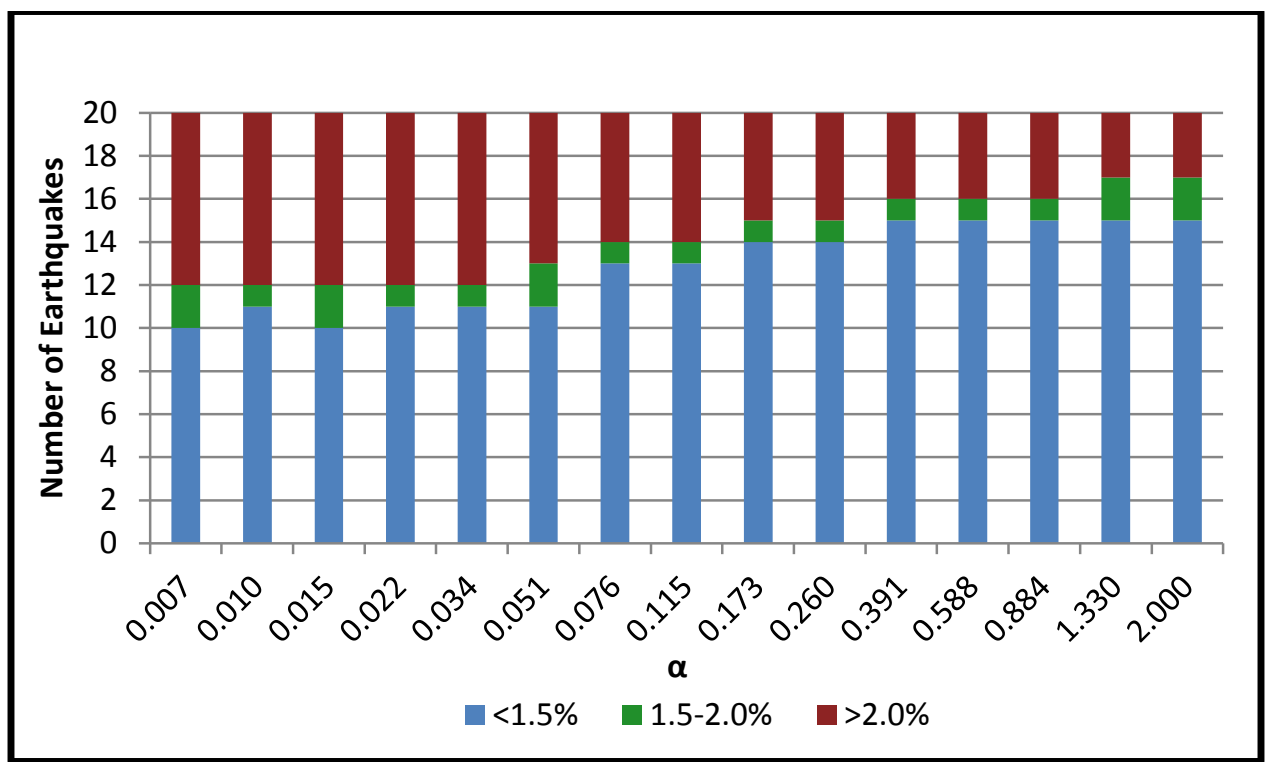

Figure B.12: Number of earthquakes under each performance objective for LA6-B (near-fault) 